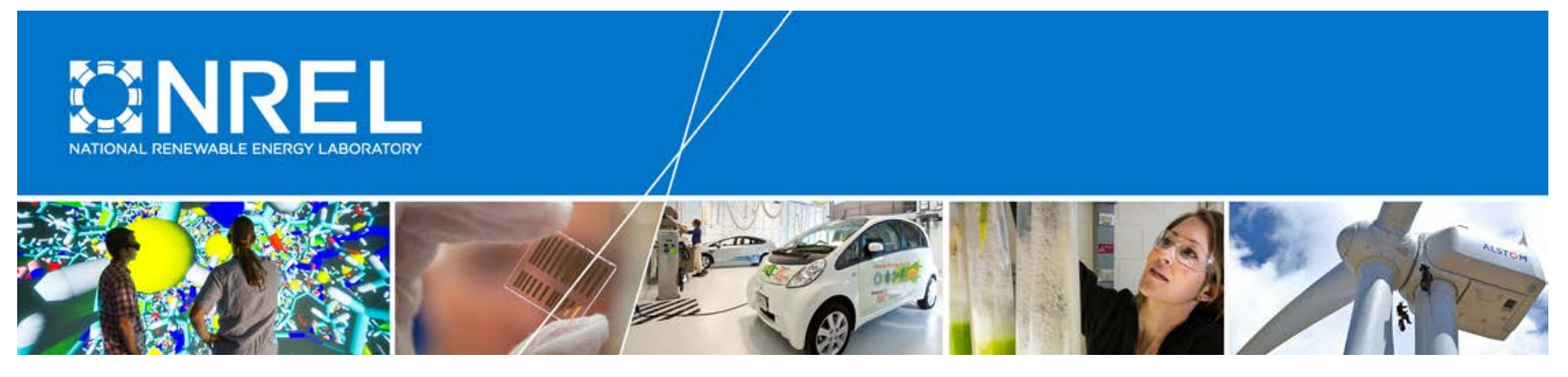

\title{
Process Design and Economics for the Production of Algal Biomass: Algal Biomass Production in Open Pond Systems and Processing Through Dewatering for Downstream Conversion
}

Ryan Davis, Jennifer Markham, Christopher Kinchin, Nicholas Grundl, and Eric C.D. Tan National Renewable Energy Laboratory

David Humbird DWH Process Consulting

NREL is a national laboratory of the U.S. Department of Energy Office of Energy Efficiency \& Renewable Energy Operated by the Alliance for Sustainable Energy, LLC

This report is available at no cost from the National Renewable Energy Laboratory (NREL) at www.nrel.gov/publications.

Technical Report

NREL/TP-5100-64772

February 2016 


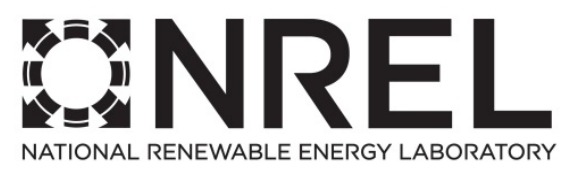

Process Design and Economics for the Production of Algal Biomass:

\section{Algal Biomass Production in Open Pond Systems and Processing Through Dewatering for Downstream Conversion}

Ryan Davis, Jennifer Markham, Christopher Kinchin, Nicholas Grundl, and Eric C.D. Tan National Renewable Energy Laboratory

David Humbird

DWH Process Consulting

Prepared under Task No. BB14.1110

NREL is a national laboratory of the U.S. Department of Energy Office of Energy Efficiency \& Renewable Energy Operated by the Alliance for Sustainable Energy, LLC

This report is available at no cost from the National Renewable Energy Laboratory (NREL) at www.nrel.gov/publications.

National Renewable Energy Laboratory 15013 Denver West Parkway Golden, CO 80401

303-275-3000 • www.nrel.gov
Technical Report

NREL/TP-5100-64772

February 2016

Contract No. DE-AC36-08G028308 


\section{NOTICE}

This report was prepared as an account of work sponsored by an agency of the United States government. Neither the United States government nor any agency thereof, nor any of their employees, makes any warranty, express or implied, or assumes any legal liability or responsibility for the accuracy, completeness, or usefulness of any information, apparatus, product, or process disclosed, or represents that its use would not infringe privately owned rights. Reference herein to any specific commercial product, process, or service by trade name, trademark, manufacturer, or otherwise does not necessarily constitute or imply its endorsement, recommendation, or favoring by the United States government or any agency thereof. The views and opinions of authors expressed herein do not necessarily state or reflect those of the United States government or any agency thereof.

This report is available at no cost from the National Renewable Energy Laboratory (NREL) at www.nrel.gov/publications.

Available electronically at SciTech Connect http:/www.osti.gov/scitech

Available for a processing fee to U.S. Department of Energy and its contractors, in paper, from:

U.S. Department of Energy

Office of Scientific and Technical Information

P.O. Box 62

Oak Ridge, TN 37831-0062

OSTI http://www.osti.gov

Phone: 865.576.8401

Fax: 865.576.5728

Email: reports@osti.gov

Available for sale to the public, in paper, from:

U.S. Department of Commerce

National Technical Information Service

5301 Shawnee Road

Alexandria, VA 22312

NTIS http://www.ntis.gov

Phone: 800.553 .6847 or 703.605 .6000

Fax: 703.605.6900

Email: orders@ntis.gov 


\section{Acknowledgements}

We gratefully acknowledge inputs and assistance from the following individuals who furnished the National Renewable Energy Laboratory (NREL) with detailed design and cost estimates for the pond system configurations considered in the present analysis:

Bill Crump - Leidos Engineering

David Hazlebeck - Global Algae Innovations

Ian Woertz, Tryg Lundquist, John Benemann - MicroBio Engineering

John Lukas, Danielle Sexton - Harris Group 


\section{Executive Summary}

The U.S. Department of Energy (DOE) promotes the production of a range of liquid fuels and fuel blendstocks from biomass feedstocks by funding fundamental and applied research that advances the state of technology in biomass production, conversion, and sustainability. As part of its involvement in this program, the National Renewable Energy Laboratory (NREL) investigates the conceptual production economics of these fuels. This includes fuel pathways from lignocellulosic (terrestrial) biomass, as well as from algal (aquatic) biomass systems.

Over the past decade, NREL conducted a campaign to quantify the economic implications associated with observed and aspirational performance for the conversion of corn stover to ethanol through techno-economic modeling. This effort served two important purposes: (1) to establish a benchmark representing the initial "state of technology" at the time and (2) to set goals for near-term R\&D and cost targets, as well as to track progress toward achieving these targets by periodically updating the models based on the latest research improvements.

Beginning in 2013, DOE began transitioning from a singular focus on ethanol to a broad slate of products and conversion pathways targeting hydrocarbon fuels, including a number of pathways from terrestrial biomass (woody/herbaceous feedstocks) and from algal biomass. To date, two reports have been published under the DOE platforms considering the economic potential for conversion of algal biomass to fuels, both based on an assumed feedstock cost for upstream biomass production and processing which was outside the scope of the analyses, but which also contributed to fuel production costs substantially more than conversion costs $[1,2]$.

This report describes in detail a set of aspirational design and process targets to better understand the realistic economic potential for the production of algal biomass for subsequent conversion to biofuels and/or coproducts, based on the use of open pond cultivation systems and a series of dewatering operations to concentrate the biomass up to $20 \mathrm{wt} \%$ solids (ash-free dry weight [AFDW] basis). The overarching process design utilizes purified $\mathrm{CO}_{2}$ sourced from power plant flue gas (the $\mathrm{CO}_{2}$ purification step is outside scope boundary limits) and commodity fertilizer nutrients to support the cultivation of algal biomass to a mid-level lipid content of $27 \mathrm{wt} \%$. This is followed by harvesting the biomass from the ponds and processing it through three dewatering steps in series consisting of gravity settling, hollow fiber membranes, and centrifugation, to concentrate the biomass from $0.5 \mathrm{~g} / \mathrm{L}(0.05 \mathrm{wt} \%$ AFDW) at harvest up to $200 \mathrm{~g} / \mathrm{L}(20 \mathrm{wt} \%)$ in the product stream. The production ponds also are coupled with an inoculum propagation system consisting of closed photobioreactors, covered ponds, and open fully-lined ponds of increasingly larger culture volumes. Ancillary areas required to support the facility operations $-\mathrm{CO}_{2}$ storage and distribution, water circulation pipelines, and product storage tanks - also are included in the design. A key attribute of this analysis is the consideration of eight separate open pond systems furnished by four separate consultants and experts in the field across three discrete pond sizes, incorporated into the integrated process model to elucidate implications on biomass production costs associated with pond sizing and resultant economy of scale impacts. Detailed material and energy balances and capital and operating costs for the process models also are documented. This case study techno-economic model provides a production cost for the thickened algal biomass product that can be used to gauge the technology potential and to quantify critical cost drivers. The analysis presented here also includes consideration of life-cycle implications by tracking environmental sustainability metrics for the modeled production facility, including greenhouse gas emissions, fossil energy demand, and consumptive water use. 
Following similar methods for design report modeling as conducted over recent years, NREL, supported by four expert contributors who furnished pond design and cost estimates (see Acknowledgements section), performed a feasibility-level analysis for a plausible commercial algal biomass production facility to understand "what it really takes" to reach a range of algal biomass costs. The modeled facility consists of 5,000 acres (approximately 2,020 hectares) of production pond cultivation area with a total facility footprint of 7,600 acres (3,075 hectares) and achieves an annual biomass product yield of $38 \mathrm{U}$.S. ton/cultivation acre/year attributed to a cultivation productivity target of $25 \mathrm{~g} / \mathrm{m}^{2} /$ day as an annual average across varying seasonal rates. Based on " $n$th -plant" design assumptions, project costs, and financing, coupled with targets projected to be demonstrated by the year 2022, the minimum biomass selling price (MBSP) is seen to distinctly follow a trend inversely proportional with individual pond size, varying from \$576-\$649/ton AFDW (average \$612/ton in 2011 dollars) of dewatered biomass for "small" 2acre pond designs, \$452-\$545/ton (average \$491/ton) for "medium" 10-acre pond designs, and $\$ 392-\$ 419 /$ ton (average \$406/ton) for "large" hypothetical 50-acre designs, although the latter scenario was primarily only considered to further quantify economy of scale trends over a larger range of pond sizes. This result suggests that although algal cultivation ponds larger than approximately 2-3 acres in size do not currently exist commercially today, moving toward larger pond sizes on the order of 10 acres is critical in enabling economically viable algal biomass production as required for subsequent conversion to commodity fuel products.

The analysis also reiterates that economics are influenced strongly by achievable cultivation productivity, with particularly dramatic penalties on MBSP if productivity was lower than the targeted $25 \mathrm{~g} / \mathrm{m}^{2} /$ day annual average. However, this tradeoff must be balanced carefully against associated nutrient requirements, given known linkages between high-nutrient (particularly nitrogen) feeding strategies and increased biomass productivity, where a sensitivity analysis found that if nutrient inputs and resultant biomass composition were to be adjusted from the nutrient-limited mid-lipid biomass baseline to nutrient-replete low-lipid (high-protein) biomass, the resulting nutrient costs increase to such a level that it would require more than a $40 \%$ improvement in productivity to ultimately lower the MBSP. Recycling nutrients fixed in the biomass back to the production ponds is critical for both controlling costs and minimizing the greenhouse gas footprint of an algal process; however, to ensure applicability of this effort's outputs to any downstream conversion processing pathway, no credit is assumed for such recycles (instead, any such credit may be applied on the downstream conversion process to reduce final fuel/product costs). If recycle credits were accounted for here instead, the cost impacts attributed to compositional variations may be less pronounced. Additionally, the work also reiterates that it is critical to avoid the use of fully lined ponds, but instead to situate the pond facilities in locations with high native clay content of the soil such that plastic liners are only required to cover small targeted areas of the ponds for erosion control (in the base case scenarios, liners only covered $2-25 \%$ of total pond area depending on specific pond design). If instead ponds were fully lined across the full 5,000 acres of cultivation area, MBSP costs would increase more than $\$ 125 /$ ton on average for the 10 -acre pond design scenarios relative to the costs indicated above. Finally, the report also includes a high-level discussion on cost tradeoffs and logistical issues between sourcing $\mathrm{CO}_{2}$ via carbon capture from power plant flue gas versus direct utilization of bulk flue gas, with concentrated $\mathrm{CO}_{2}$ costs adding significantly to MBSP; however, flue gas is challenged by substantial logistical and practicality constraints for a facility of this size. 


\section{Algal Biomass Production Process Engineering Analysis}

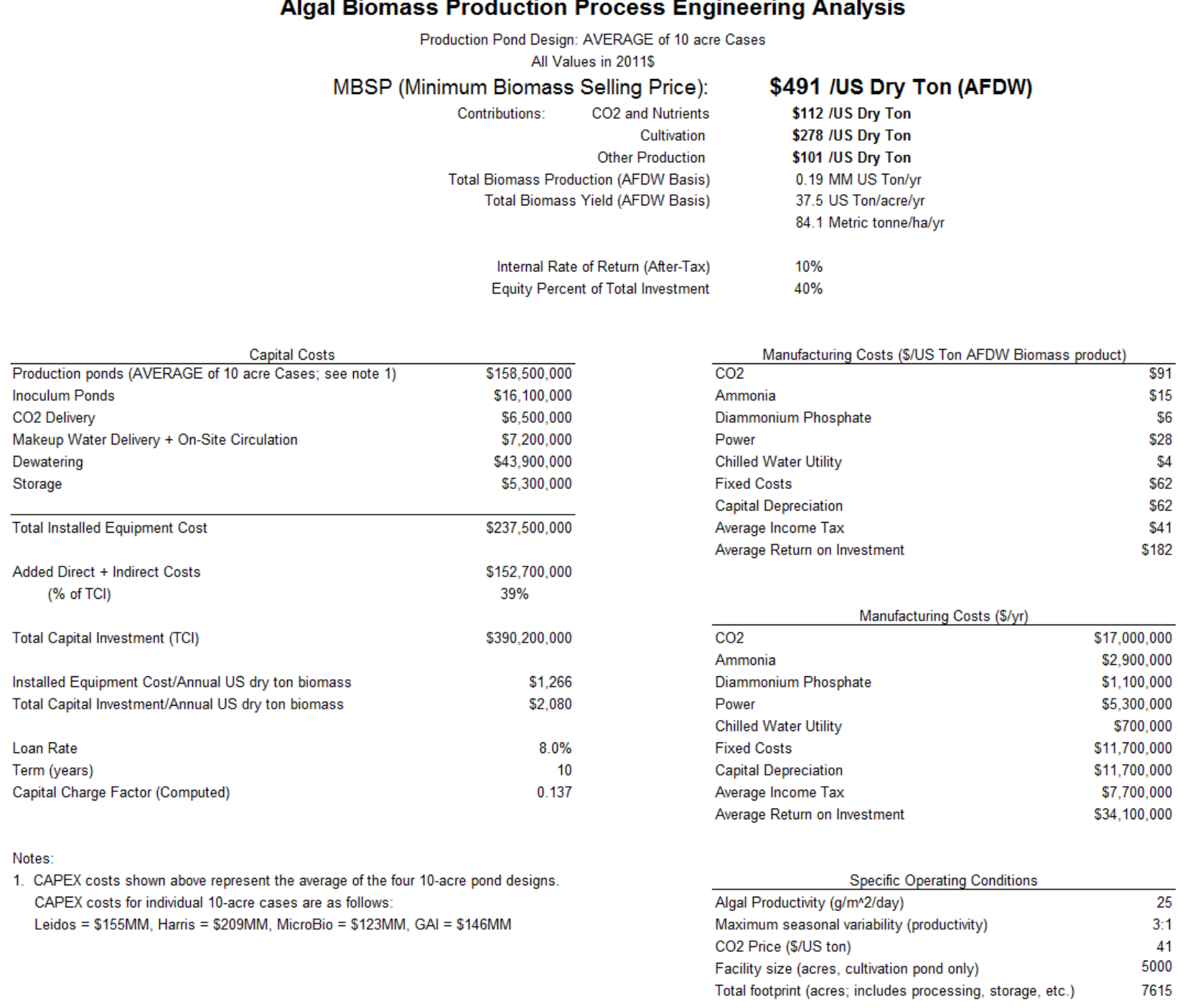

Figure ES-1. Economic summary sheet for the "base case" based on average costs of the four 10-acre pond designs. (Note: all per-ton cost and yield metrics are based on ash-free dry weight biomass.) 


\section{Table of Contents}

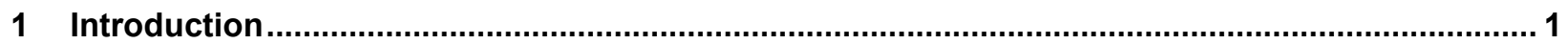

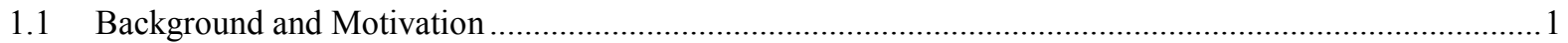

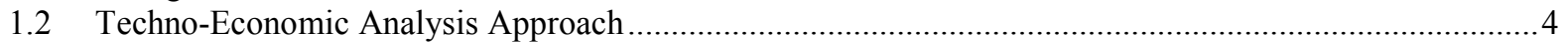

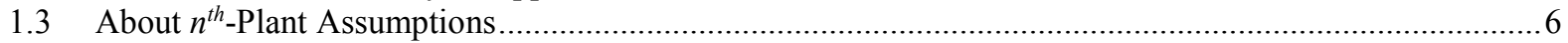

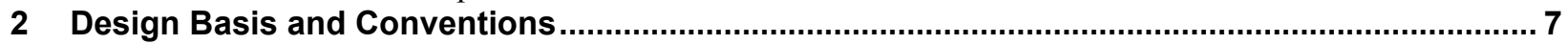

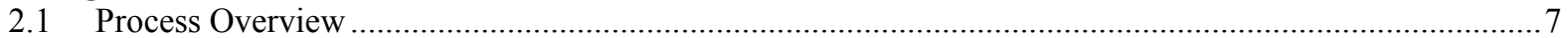

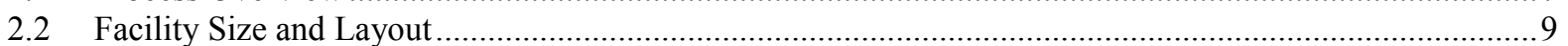

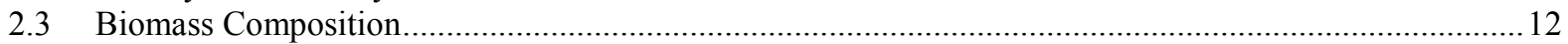

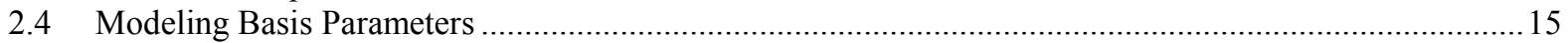

3 "Top-Down" Analysis of Cultivation Cost Demands ................................................................ 16

4 "Bottom-Up" Integrated Model: Process Design and Capital Cost Estimation Details .............. 18

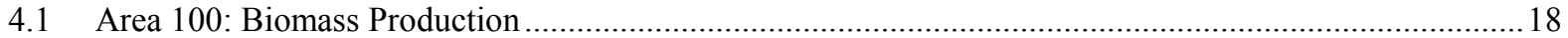

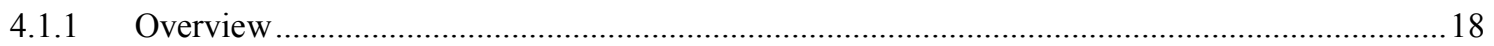

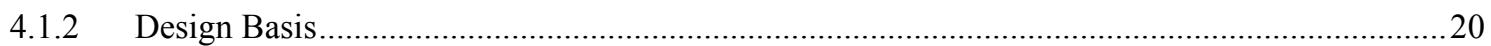

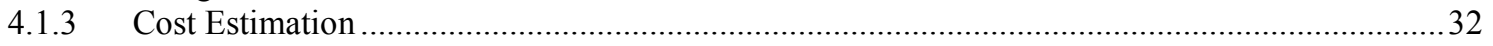

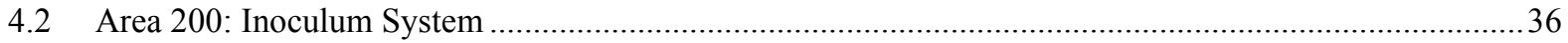

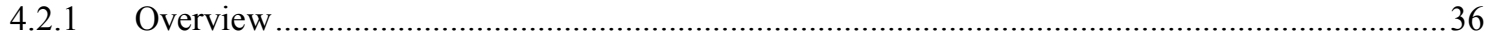

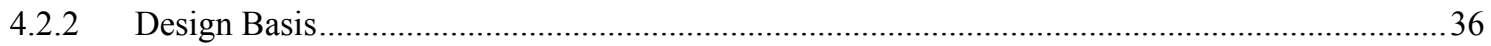

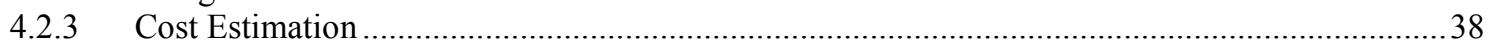

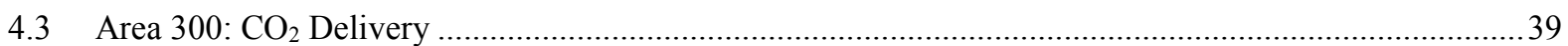

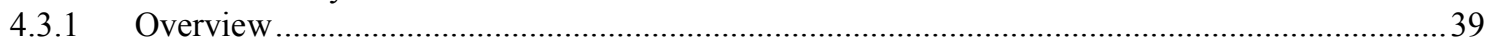

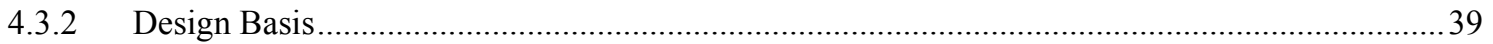

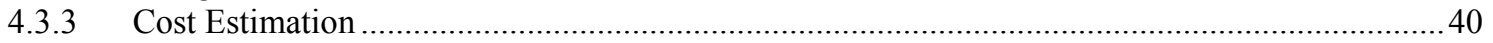

4.4 Area 400: Makeup Water Delivery + On-Site Circulation to/from Dewatering ........................................41

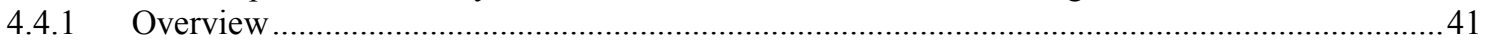

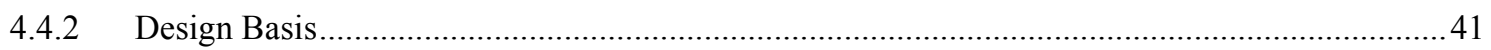

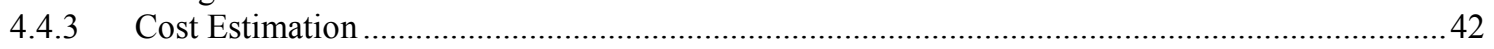

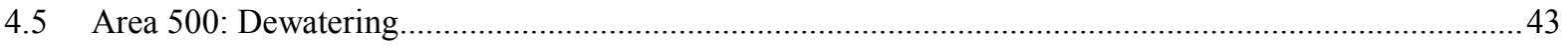

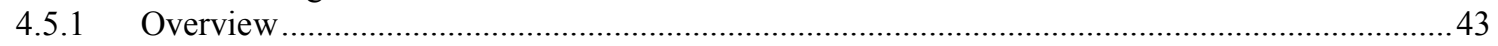

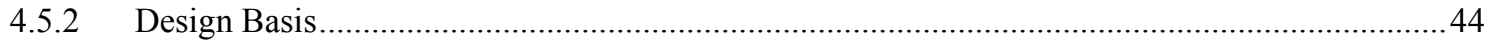

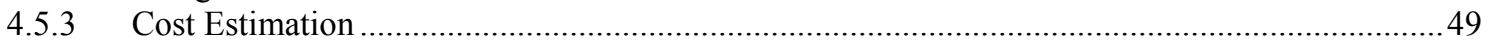

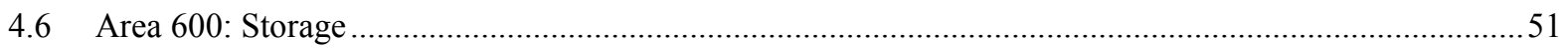

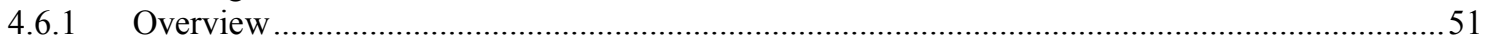

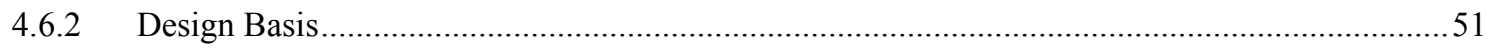

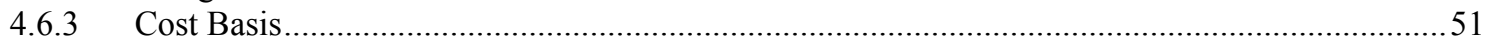

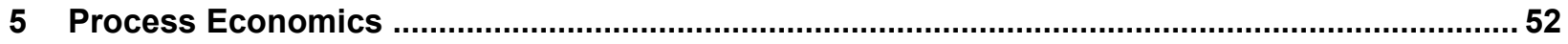

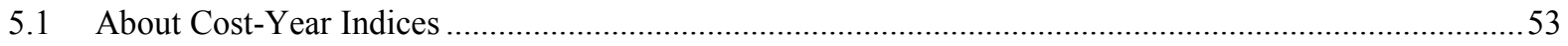

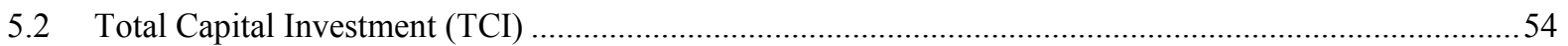

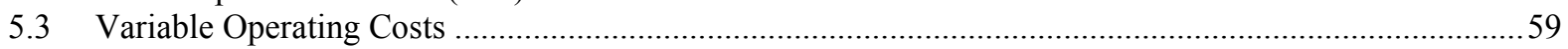

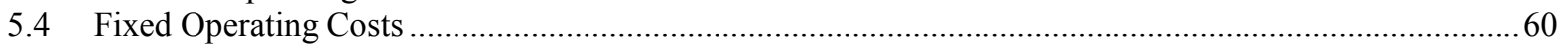

5.5 Discounted Cash Flow Analysis and the Minimum Selling Price of Biomass ..........................................62

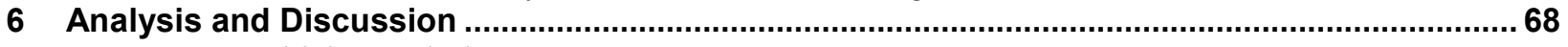

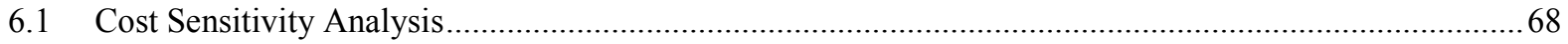

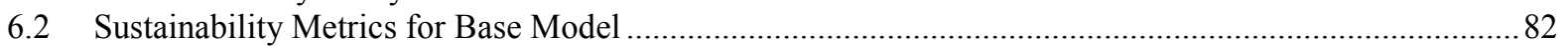

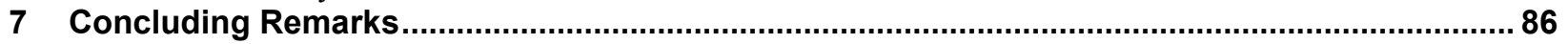

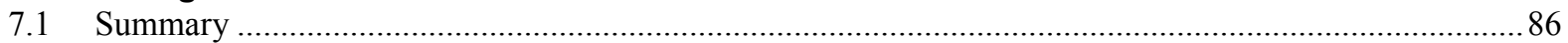

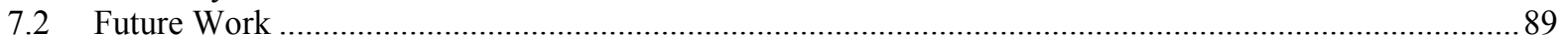

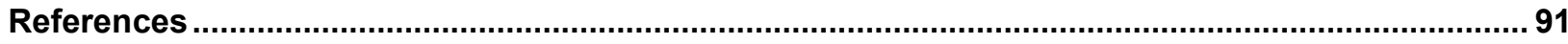

Appendix A. Individual Equipment Cost Summary ...................................................................99

Appendix B. Additional Design and Cost Details for Leidos Pond Scenarios ................................102

Appendix C. Discounted Cash Flow Rate of Return Worksheet .................................................. 103

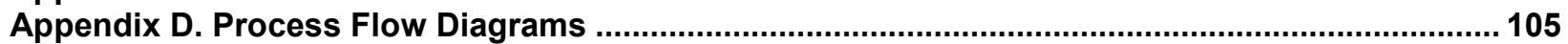

Appendix E. TEA Summary Worksheets for Individual Pond Scenarios ........................................ 112 


\section{Acronyms}

ACCE

AFDW

ALU

ANL

ASU

BETO

BGY

BLS

CAPEX

CCS

DAF

DAP

DB

DCFROR

DOE

DW

EOR

FAME

FCI

GAI

GGE

GHG

ha

HCSD

HLSD

HPSD

HDPE

HRT
Aspen capital cost estimator

ash-free dry weight

algal lipid upgrading

Argonne National Laboratory

Arizona State University

Bioenergy Technologies

Office

billion gallons per year

Bureau of Labor Statistics

capital expenditures

carbon capture and storage

technology

dissolved air flotation

diammonium phosphate

declining balance

discounted cash flow rate of

return

U.S. Department of Energy

dry weight

enhanced oil recovery

fatty acid methyl ester

fixed capital investment

Global Algae Innovations

gallon gasoline equivalent

greenhouse gas

hectare

high-carbohydrate (mid-

harvest) Scenedesmus

high-lipid (late harvest)

Scenedesmus

high-protein (early harvest)

Scenedesmus

high-density polyethylene

hydraulic retention time
HTL liquefaction

INWG

IRR

ISBL

LCA

LCI

MACRS

MBSP

MEA

MFSP

$\mathrm{MM}$

MYPP

NH3

NPV

NREL

OPEX

OSBL

PBR

PFD

PNNL

PVC

R\&D

RA

TCI

TDC

TEA

TIC hydrothermal

inches of water gauge

internal rate of return

inside battery limits (of the

plant)

life-cycle assessment

life-cycle inventory

IRS Modified Accelerated

Cost Recovery System

minimum biomass selling

price

monoethanolamine

minimum fuel selling price

million (e.g., MMBTU or

$\$$ MM)

DOE-BETO's Multi-Year

Program Plan

ammonia

net present value

National Renewable Energy

Laboratory

operating expenditures

outside battery limits

photo bioreactor

process flow diagram

Pacific Northwest National

Laboratory

polyvinyl chloride

research and development

resource assessment

total capital investment

total direct cost

techno-economic analysis

total installed cost 


\section{Introduction}

\subsection{Background and Motivation}

The U.S. Department of Energy (DOE) Bioenergy Technologies Office (BETO) promotes the production of liquid fuels and coproducts from lignocellulosic and algal feedstocks by sponsoring programs in fundamental and applied research that aim to advance the state of technology, spanning the supply chain from biomass production through processing and conversion to fuels. Within the algae platform, these programs include laboratory research to improve biological characteristics (e.g., algal cultivation productivity, biomass composition, and strain robustness) through screening and synthetic biology; engineering studies of potential systems for growth, dewatering, and conversion technologies; improvement of laboratory analytical capabilities to accurately characterize feed and product materials; and support for biomass production test-bed and processing demonstration facilities. This research is conducted by national laboratories, universities, and private industry, both individually and through multiorganization consortia partnerships.

To support the DOE program, the National Renewable Energy Laboratory (NREL) investigates the process design and economics of numerous biofuel processing pathways to develop a plant gate price projection based on process and plant design assumptions consistent with applicable best practices in engineering, construction, and operation. This plant gate price is referred to as the "minimum fuel selling price" or MFSP, when focused on the conversion stage within the supply chain from biomass-to-fuel products. The MFSP can be used by DOE to assess the costcompetitiveness and market penetration potential of a given biofuel technology in comparison with petroleum-derived fuels and established biofuel pathways such as starch- or sugar-based ethanol, vegetable oil-based biodiesel, etc. The projected MFSP for any given biofuel pathway is typically strongly dependent on the cost of producing and processing the biomass feedstock up to the point of delivery to the conversion biorefinery $[1,3,4]$, which is particularly true in the case of algal biofuels whose targeted production costs attributed to biomass production and preprocessing may reach $70 \%$ or more of overall MFSP [1,2]. As such, it is critical to also establish sound projections for biomass feedstock costs to present a clear picture for overall economic viability in a "farm-to-wheel" supply chain.

In addition to establishing absolute plant-gate prices for biomass or resultant biofuels, technoeconomic analysis (TEA) modeling also helps to direct research activities by examining sensitivities of these prices to process alternatives and research advances. Proposed research and its anticipated results can be translated into a new selling price that can be compared to established benchmark cases. Such comparison helps to quantify the economic impact of core research targets and to track progress toward meeting competitive cost goals. It also allows DOE to make more informed decisions about research proposals that claim to reduce costs.

In 2014, NREL and Pacific Northwest National Laboratory (PNNL) published design report documents projecting MFSP targets anticipated to be achievable by year 2022 for the conversion of algal biomass to fuels via algal lipid extraction and upgrading (ALU) and hydrothermal liquefaction (HTL), respectively [1,2]. Both reports documented a set of targets for yields and processing conditions that would support a modeled MFSP of roughly $\$ 4-4.5 / \mathrm{GGE}$ for the respective conversion technology pathways, dependent on an assumed biomass feedstock cost of $\$ 430 /$ ton ash-free dry weight (AFDW) following upstream dewatering to $20 \mathrm{wt} \%$ solids, based in 
turn off of BETO target projections for algal biomass production costs by 2022 [5]. Both conversion pathways also indicated strong economic sensitivities to the biomass cost, with an opportunity to reduce MFSP by nearly $\$ 1 /$ GGE at a cost of $\$ 300 /$ ton algal biomass or a similar cost penalty increasing MFSP by slightly less than $\$ 1 /$ GGE at a cost of $\$ 550 /$ ton. Such strong economic sensitivity to the cost of algal biomass as attributed to "front-end" operations (cultivation and dewatering) is well-documented elsewhere [1,6-9].

Significant progress has been made in recent years to reduce uncertainties on processing steps, yields, and resultant costs for converting algal biomass to fuels enabled by experimental data published from real-world (outdoor), commercially relevant processing conditions [2,10,11]. However, substantial uncertainties and lack of public agreement still remain with respect to demonstrated or achievable performance from front-end cultivation and dewatering operations, and resulting yields and system costs. Indeed, projected economics from public literature range from $\$ 270-\$ 2,450 /$ ton algal biomass or $\$ 2-\$ 110 /$ gal algal biofuels, with a range in algal biomass production yield spanning between 11 and 89 ton per acre per year $\left(7-60 \mathrm{~g} / \mathrm{m}^{2} /\right.$ day annual average at 330 days/year on-stream factor) [7,8,10,12-22]. Figure 1 provides an overview of some of the published estimates for cultivation and processing costs of biomass and algal oil, and shows significant variation across system yields and costs (after adjusting all original cost estimates to 2011 dollars). The figure is broken down into publications focused on projecting toward future targets based on optimistic productivities or undemonstrated technology, labeled as "future," versus existing, deployable systems and current productivity performance claims, labeled as "current," with all cases focused only on open pond cultivation methods. Even when isolated to today's current baseline performance alone, estimates range for biomass productivities between 7 and $35 \mathrm{~g} / \mathrm{m}^{2} /$ day, biomass costs between $\$ 280$ and $\$ 2,450 /$ ton, and biocrude costs between $\$ 2$ and $\$ 112 /$ gal. Future projections range for productivities between 15 and $60 \mathrm{~g} / \mathrm{m}^{2} /$ day, biomass costs between $\$ 280$ and $\$ 860 /$ ton, and bio-crude costs between $\$ 2$ and $\$ 25 /$ gal. A large contributor to such disparity in cost estimates frequently lies in several key assumptions including cultivation productivity or cultivation system design details, and it has been shown that harmonizing for such key metrics may be seen to considerably reduce cost variability [14], which is a primary point we will demonstrate in this report as well. 


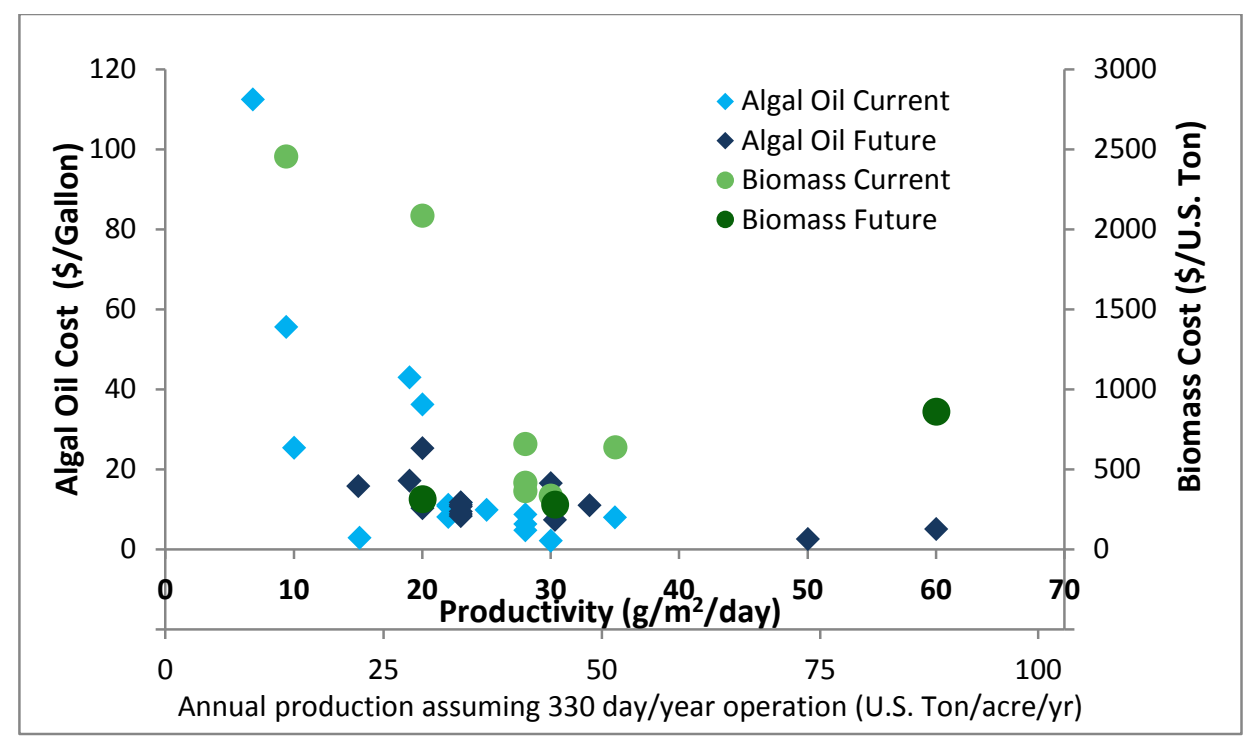

Figure 1. Literature scan demonstrating variability in estimated cost of algal biomass and bio-oil, differentiating between "current performance" versus "future projections" [7,8,10,12-22]

The first in-depth analysis undertaken by NREL and partners in estimating costs for algae production and processing was done under BETO's 2012 "Harmonization Initiative," which brought together modeling partners from NREL, Argonne National Laboratory (ANL), and PNNL to harmonize their conceptual models around TEA, life-cycle assessment (LCA), and resource assessment (RA), respectively, such that the results from each model would carry the same implications being based on consistent inputs and assumptions. This effort included a workshop to serve as a vetting process for the respective collaborators to present the details of their models to a group of expert stakeholders in industry, academia, and other national laboratories, to begin validating or improving key modeling assumptions. This ultimately resulted in the publication of a harmonization report (referred to as such hereafter) documenting model details and the resulting near-term cost, sustainability, and resource implications for production of 5 billion gallons per year (BGY) of renewable diesel at the national scale spread across a large consortium of individual unit farms [23]. While this represented an important step forward in better understanding plausible processing details and costs, including cultivation and harvesting steps, the study was limited by (1) being based on a single set of design and cost inputs, largely pulling from available public literature, which at the time remained scarce, and (2) focusing on what economics would look like "today" (in 2012) based on benchmark estimates for current productivity performance $\left(\sim 13 \mathrm{~g} / \mathrm{m}^{2} /\right.$ day) and dewatering technologies (leveraging from industrial practices for wastewater processing), but largely avoiding projections for future performance and cost targets.

The focus of this report is to document a number of modeling pathway scenarios to project plausible costs for algal biomass production and pre-processing (harvesting/dewatering nominally to $20 \mathrm{wt} \%$ solids) as targets to be achieved by 2022 . This objective is approached in two ways: first, by presenting a "top-down" analysis for what a production system "needs to cost" coupled with what the annual algal biomass productivity "needs to be" in order to achieve a given cost target for minimum biomass selling price on a dollar-per-ton basis (see Section 3 of this report). This is presented first as an objective way to address what level the system must 
perform at if it is to profitably produce dewatered algal biomass at a stipulated cost, given the uncertainties and challenges discussed previously around reaching consensus for either of these metrics, particularly for projecting what these metrics may be by 2022 . Second, we perform a "bottom-up" analysis to consider a number of discrete design configurations and associated cost estimates for cultivation systems integrated with downstream harvesting/dewatering as well as upstream delivery of $\mathrm{CO}_{2}$, makeup water, and nutrients, to determine biomass selling price estimates for each scenario attributed to a hypothetical commercial "farm" facility made up of 5,000 acres $(2,023 \mathrm{ha})$ of cultivation area dedicated to biomass production. To support this effort we have solicited assistance and inputs from a number of engineering subcontractors, consultants, and industry experts to incorporate these individual design configurations into the integrated model and to ensure consistent application of resultant cost estimates. The scope of this analysis focuses on open pond cultivation scenarios, and does not include photobioreactor (PBR) cultivation aside from its use in an inoculum system to inoculate open ponds. This decision was made to focus on pond systems, for which the most details on credible design and costing estimates are available publicly, to highlight an important conclusion: that in fact open pond costs are more consistent than current public understanding may infer, which is a critical point to establish in order to move forward in projecting future algal biomass production costs. PBR cultivation is currently envisioned to be the subject of a follow-on analysis in 2016.

Similar to caveats noted in prior NREL design reports, we stress that this design report serves to describe a limited number of feasible production and processing scenarios and to transparently document the assumptions and details that went into their designs, based either on publicly available information or information otherwise furnished to NREL with the intent to be incorporated into this public analysis. This report is not meant to provide an exhaustive survey of all process alternatives or cost-sensitivity analyses. Furthermore, it is important to reiterate that algal biomass production and processing as a technology platform is in a more nascent stage of development and understanding than other, more-established processes based on terrestrial biomass, and continue to suffer from a dearth of available public data on production and processing performance at sufficient scale. While the key inputs assumed in this analysis are leveraged from vendors, engineering companies, and other experts in the field, or otherwise supported by operational performance data at demonstration scale (e.g., for dewatering operations selected as the "base case"), further experimental work and scale-up is required to reduce model uncertainties. Moving forward, as the science and technology progresses, the process models and economic tools developed for this report may be updated in a similar fashion as prior NREL design report iterations have evolved.

\subsection{Techno-Economic Analysis Approach}

Figure 2 describes the engineering approach used for modeling the production and harvesting process for algal biomass up to the point of delivery to downstream conversion operations (outside the scope of this analysis), including process design, process modeling, and economic analysis. This approach was largely followed for this study as well, albeit under a condensed timeline and with additional extrapolations around areas with more limited supporting experimental data to date (e.g., large-scale operational data for dewatering specific to algal biomass material). As such, this report is less prescriptive in some sections than previous reports due to the early stages of development for algal biomass production, particularly regarding scaleup logistics to a large commercial facility as envisioned here. 


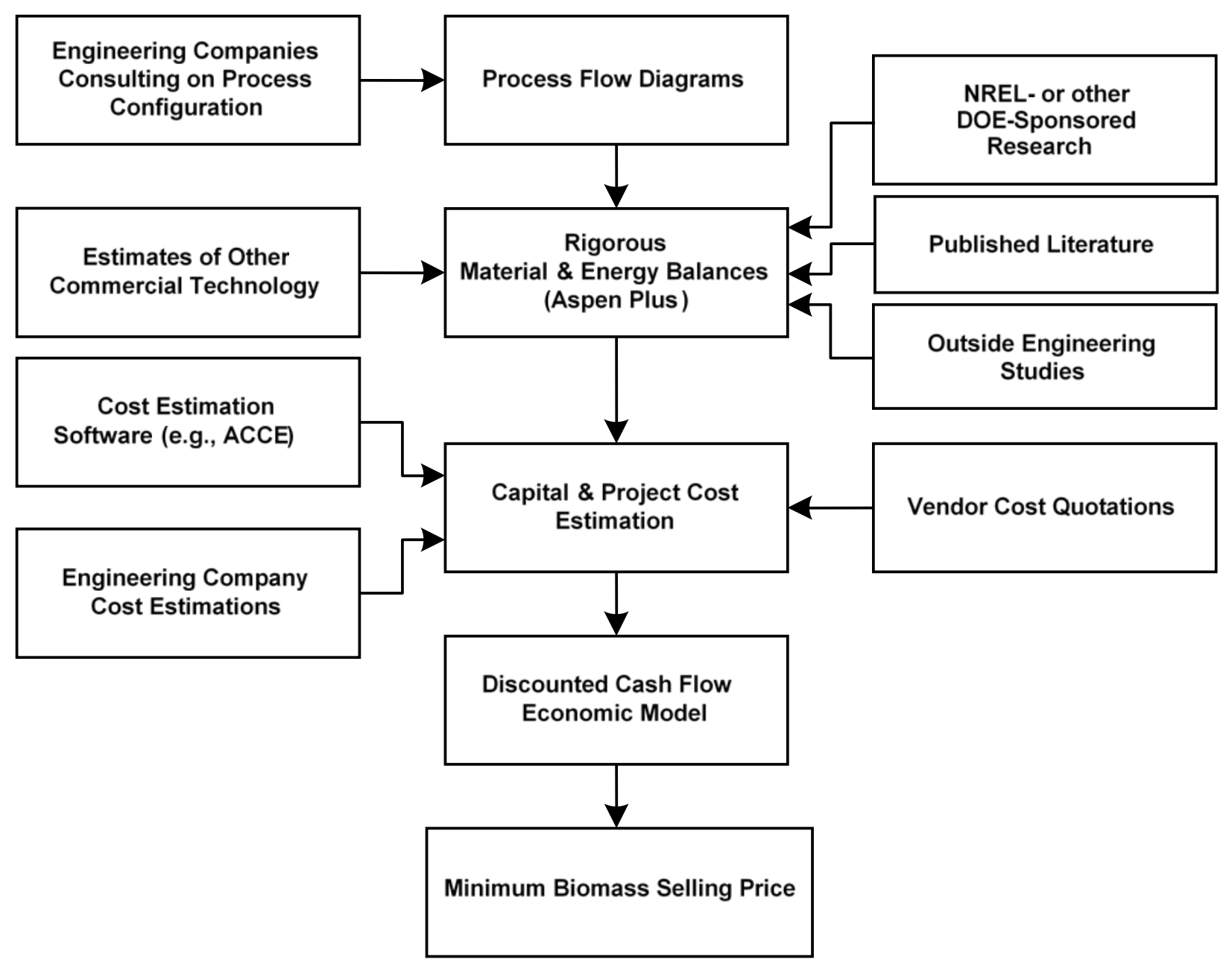

Figure 2. NREL's approach to process design and economic analysis

Starting from the general process flow diagram (PFD) shown in Figure 3 and the more detailed PFDs contained in Appendix D, a process simulation was developed using Aspen Plus software [24]. This process model computes material and energy balances for each unit operation in this conceptual integrated process. While it is recognized that the use of Aspen Plus is not as critical for this particular process schematic compared to biorefinery conversion processes, which require thermodynamic rigor in modeling separations, vapor-liquid equilibria, heat integration, and conversion reactions, Aspen modeling is still useful in tracking recycle streams, $\mathrm{CO}_{2}$ injection, and biomass elemental balances. The material and energy balance data from the Aspen simulation are next used to assist in determining the number and size of capital equipment items. As process conditions and flows change, baseline equipment costs are automatically adjusted in an Excel spreadsheet using a scaling factor (described in Section 5.2). In the case of pond systems, these baseline cost estimates were derived from detailed designs developed by others either in published literature (e.g., Lundquist et al. [17] via MicroBio Engineering [25]) or furnished to NREL by engineering subcontractors (e.g., Harris Group and Leidos) and experts in the field (e.g., Global Algae Innovations). In the case of dewatering and piping equipment, cost estimates were provided from vendor quotes typically based on AACE Class 4 estimates [26], consultation with industry experts, and internal estimates generated using Aspen Capital Cost Estimator (ACCE) [24]. Final equipment costs for this report are tabulated in Appendix A. 
Once equipment costs are determined, direct and indirect overhead cost factors (e.g., installation costs and project contingency) are applied to determine a total capital investment (TCI). The TCI, along with the plant operating expenses (also developed using flow rates from the Aspen model), are used in a discounted cash flow rate of return (DCFROR) analysis to determine a plant gate price for dewatered algal biomass feedstock, which in reality may be viewed as a "transfer price" to be delivered to downstream conversion operations co-located nearby. This plant gate price is termed here the "minimum biomass selling price" (MBSP, in \$/ton) required to obtain a net present value (NPV) of zero for a $10 \%$ internal rate of return (IRR) after taxes.

The product of the analysis described above is a techno-economic model that reasonably estimates a product price for a pre-commercial process. The resultant MBSP is unique for the set of process conditions simulated, and it should be emphasized that a certain amount of uncertainty always exists around these chosen conditions, as well as around the assumptions made for capital and raw material costs. Without a detailed understanding of the basis behind it, the absolute computed MBSP carries a risk of being taken out of context. While the MBSP can be used to assess the economic viability of a given set of inputs and conditions, it is best suited for comparing design or processing configurations against one another or for performing sensitivity analyses that indicate where economic or process performance improvements are needed.

\subsection{About $n^{\text {th }}$-Plant Assumptions}

The techno-economic analysis reported here uses what are known as " $n$th - plant" economics. The key assumption implied by $n^{\text {th }}$-plant economics is that our analysis does not describe a pioneer plant; instead, it assumes several facilities using the same technology have already been built and are operating. In other words, it reflects a mature future in which a successful industry of $n$ plants has been established. Because the techno-economic model is primarily a tool for studying new process technologies or integration schemes to comment on their comparative economic impact, $n^{\text {th }}$-plant analysis avoids artificial inflation of project costs associated with risk financing (implying higher than 10\% IRR requirements), longer start-ups, equipment overdesign, and other costs associated with first-of-a-kind or pioneer plants, lest these overshadow the real economic impact of research advances in algal biomass cultivation or process integration. At the very least, these $n^{\text {th }}$-plant economics should help to provide justification and support for early technology adopters and pioneer plants.

The $n^{\text {th }}$-plant assumptions in the present analysis apply primarily to the factored cost model used to determine the total capital investment from the purchased equipment cost and to the choices made in plant financing. The $n^{\text {th }}$-plant assumption also applies to some operating parameters, such as process uptime of $90 \%$. This factor was selected to maintain consistency with a similar 90\% uptime assumed in the above-referenced algal biofuel conversion models (HTL and ALU, respectively $[1,2]$ ), and is particularly noteworthy for the present modeling scope focused on algal cultivation under an $n^{\text {th }}$-plant scenario, which implicitly assumes the use of a robust strain resistant to crashes. This is in contrast to today's performance which lags this target given more frequent culture crashes observed under BETO's test-bed consortia sites, particularly for freshwater strains $[27,28]$. 


\section{Design Basis and Conventions}

\subsection{Process Overview}

The process described here considers open pond systems for algal biomass production (multiple pond sizes, designs, and developer/contractor costs are evaluated as discussed in Section 4.1) coupled with upstream inoculum production operations and downstream harvesting and dewatering steps to increase the biomass solids content for processing through subsequent conversion operations (outside the scope of this report). The design also includes equipment for $\mathrm{CO}_{2}$ delivery, delivery of fresh makeup water and on-site circulation, and product storage. The process is divided into six areas (see Figure 3).

- Area 100: Production Ponds. This is the primary section of the process, accounting for the majority of system costs and facility footprint. The scope of the present analysis limits the focus for the production system to the use of open pond cultivation (PBR systems will be considered in a later analysis), but considers detailed pond designs attributed to four separate sources (including consultants, developers, and industry experts) across three individual pond sizes (2-, 10-, and 50-acre ponds) to more firmly draw conclusions about pond costs and scale requirements. The base case scenarios assume the use of unlined ponds, except in specific areas of the pond where a plastic liner is required for erosion control. Areas 100 and 200 follow a continuous mode of operation.

- Area 200: Inoculum System. In this area, biomass inoculum is produced in a scale-up system to continuously inoculate a fraction of the production ponds when upsets or culture crashes occur. The inoculum system consists of closed PBRs, covered ponds, and open/lined ponds of increasingly larger volumes, sized to allow for an inoculum concentration of $0.1 \mathrm{~g} / \mathrm{L} \mathrm{AFDW}$ in the production ponds.

- Area 300: $\mathrm{CO}_{2}$ Delivery. This section accounts for delivery, on-site storage, and injection of $\mathrm{CO}_{2}$ to the inoculum and production processes. The analysis base case assumes the use of concentrated/pressurized $\mathrm{CO}_{2}$ (sourced from power plant flue gas), but considers lowpressure bulk flue gas transport and delivery as an alternative. As the scope of the present design excludes "back-end" conversion and upgrading operations, no recycle of $\mathrm{CO}_{2}$ is accounted for and all requirements for the process are met using fresh $\mathrm{CO}_{2}$ from off site.

- Area 400: Makeup Water Delivery + On-Site Circulation to/from Dewatering. Makeup water to the facility is provided by pipeline transport from a nearby local water resource in keeping with prior modeling work. Within the facility limits, water/culture circulation to and from dewatering operations is handled by a series of pipeline and aqueduct channels, leveraging the natural land slope to circulate partially dewatered culture to central dewatering over a "terraced" facility layout.

- Area 500: Dewatering. The biomass is harvested from the ponds at $0.5 \mathrm{~g} / \mathrm{L}$ AFDW density, and concentrated across three dewatering steps consisting of gravity settling, membranes, and centrifugation to a final concentration of $200 \mathrm{~g} / \mathrm{L}(20 \mathrm{wt} \%)$ AFDW. Clarified water from each step is recycled to the production ponds, less a small fraction removed as blowdown to mitigate buildup of salts and other inorganics.

- Area 600: Storage. This area provides bulk storage for the dewatered algal biomass product, as well as makeup water, fire suppression water, and nutrient inputs. 


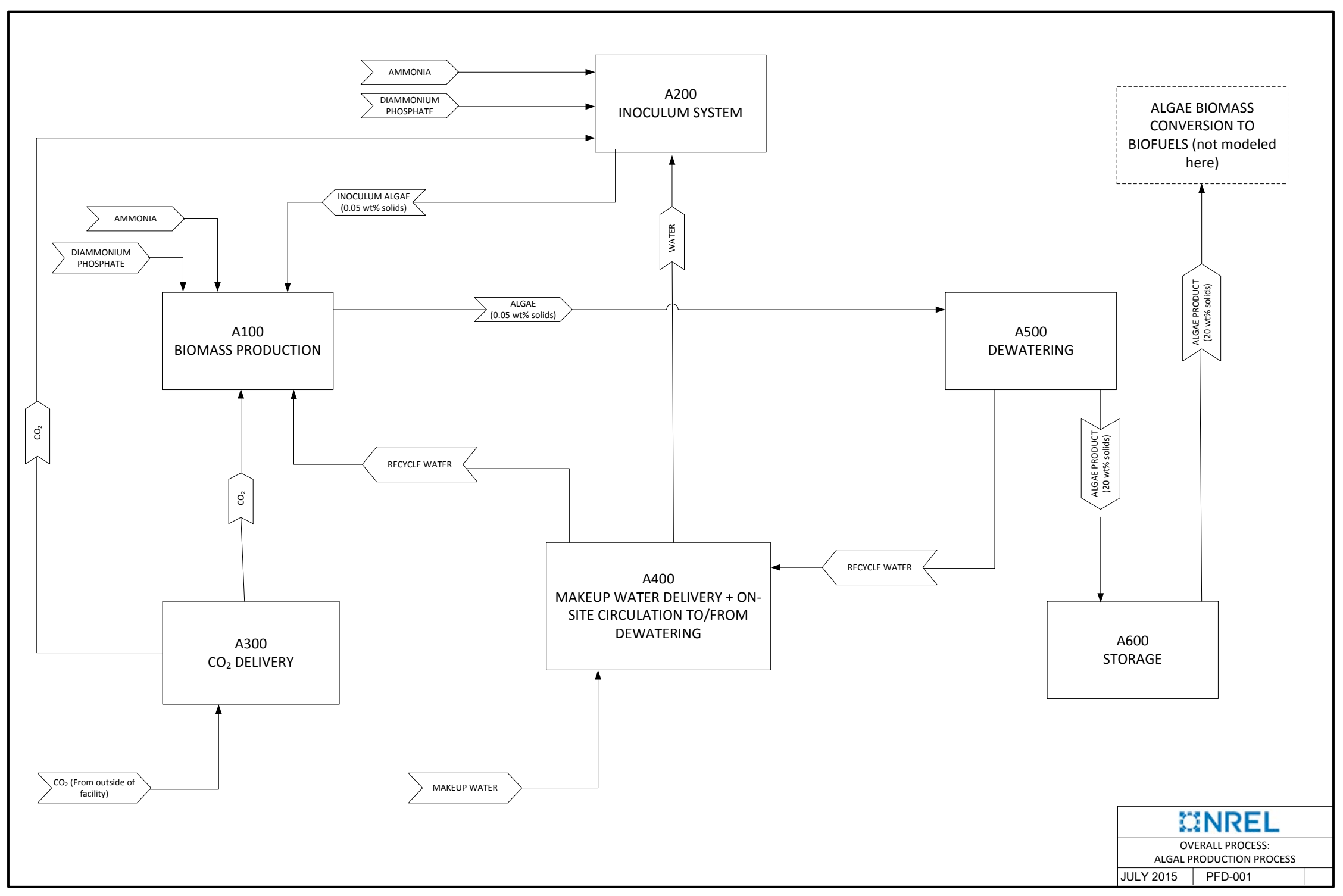

Figure 3. Simplified flow diagram of the overall process. (Key streams only; see Appendix D for more detailed diagram and PFDs.) 


\subsection{Facility Size and Layout}

The facility in the present design is sized for a total production pond cultivation area of 5,000 wetted acres (2,023 ha) excluding the inoculum system, which in the base case discussed in Section 4 enables the production of 0.19 MM U.S. dry tons per year of algal biomass based on the productivity and seasonality assumptions employed here (Section 4.1.2); as a general note, this biomass yield and all other biomass cost, yield, and concentration values discussed in this report are based on an ash-free dry weight (AFDW) basis unless otherwise noted. The 5,000-acre size is smaller than prior modeling efforts that assumed very large commercial systems (up to 10,000 acres of ponds [23]), recognizing that extremely large sizes such as 10,000 acres may present too many logistical challenges and siting constraints to be practical. However, it is still critical to maintain at least a 5,000-acre overall area of production ponds in the facility (whether a "facility" is defined as a single contiguous farm as modeled here, or as a grouping of smaller farms located in very close proximity to each other), given strong economy of scale sensitivities for downstream processing, conversion, and upgrading operations. Namely, reducing the facility size from 5,000 to 1,000 acres of production ponds would increase biomass selling price by roughly $\$ 100 /$ ton relative to the base case described below (see Section 6.1), while further reducing the size to 500 acres would add another $\$ 100 /$ ton. Extending the analysis to include downstream conversion to fuels via either the HTL or ALU pathways mentioned above (while beyond the focus of this work), the combination of higher biomass prices and lower throughputs would translate to substantial increases in fuel selling prices by roughly $\$ 2-3 /$ GGE for a 1,000acre farm basis, or by $\$ 5-6 /$ GGE for a 500 -acre farm basis [29]. Such a cost premium could impose significant challenges in achieving economic viability for algal biofuels.

While a 5,000 acre algae farm is much larger than current demonstration-scale facilities operated by private entities in the US (focused on algal fuel production), this is a similar premise to the establishment of terrestrial lignocellulosic ethanol biorefinery scales considered under BETO modeling analyses, typically 2,000 dry metric tons/day, which had been established based on tradeoffs between feedstock harvest/logistical constraints and economy of scale ramifications for the biorefinery [30]. Beyond economy of scale sensitivities noted above, additional factors also support a 5,000-acre farm basis. First, there are lower limits on operability for certain downstream conversion/upgrading equipment items, such as conversion reactors, extraction equipment, and upgrading (hydroprocessing) units, which may not be practical for outputs from smaller 500-1,000 acre algae farms (which would approach more of a "depot" concept in terms of annual biomass production). Moreover, while terrestrial crop farms vary dramatically in size, as of 2012 there were roughly 24,000 large commercial "mega-farms" of 5,000 acres or more in the US, which combined account for roughly one-third of all farmed cropland [31] thus, precedent for farms of this size is well-established in traditional agriculture. Within the commercial algae industry for food products, a 7,000-acre algae farm is in operation today in Australia [32]. Finally, a survey of industry peer reviewers of this report confirmed that there are no logistical reasons that would prevent a 5,000-acre algae facility of this nature from being viable from a practicality or operational standpoint (subject to location siting constraints). Thus, moving forward it will be important to consider this topic, e.g., through resource assessment models, to better understand implications on land availability for such farms on a national scale.

The design assumes dewatered algal biomass product is sold "at the gate" and does not take into account transportation costs to an off-site location; at $20 \mathrm{wt} \%$ solids ( $80 \%$ water content), it is 
not envisioned that the biomass would be transported off site, but rather would be sent directly to downstream operations for biomass conversion to fuels or products located on site or very nearby. Thus, the minimum biomass selling price presented here represents a "transfer price" to the downstream conversion portion of the facility. While it is not as straightforward to draw a system boundary in this way as it is for terrestrial biomass that has distinctly independent supply chain stages for biomass production and biorefinery conversion, a fully integrated algal production and conversion facility would naturally divide itself along these boundaries fairly easily anyway, as very little heating or cooling demands are incurred on the "front-end" operations considered here that would require integration with the "back-end" conversion process, nor are there substantial amounts of recycle streams between the two stages. Any recycle streams which may be provided from downstream conversion/upgrading operations (including $\mathrm{CO}_{2}$, water, or nutrient streams) are excluded from consideration in this analysis, but may instead be taken credit for on the "back-end" conversion models, e.g., by reducing estimated fuel costs or greenhouse gas profiles. Additionally, the overall land footprint and associated land cost assumed here includes allowances for integration with the downstream conversion facility.

The overall site layout assumes that ponds are grouped into unit "modules" of 100 wetted acres each. The actual module land footprint is larger than 100 acres to include allowances for pond access and piping, as well as in-ground settling ponds, which serve as first-stage dewatering prior to further dewatering that occurs in a central location serving all modules. The full facility contains 5,000 wetted acres of biomass production ponds grouped into 50 individual modules connected via a network of pipelines and roadways. The modules form a uniform grid of seven columns by eight rows. The eighth row comprises a single biomass production module as well as the dewatering facility, algae inoculum system, and support buildings, with the remaining acreage allocated for a hypothetical downstream algal conversion plant. The site is assumed to be situated on land with a continuous $1 \%$ slope (consistent with grading and civil costs estimated by the various sources for pond design discussed in Section 4.1.2); this slope is graded to be level within the individual modules where ponds and supporting equipment are located, but left ungraded everywhere else, thus forming a "terraced" layout that assists in harvesting and circulation logistics following pond cultivation and primary dewatering. The "terraced" concept has also recently been considered elsewhere in literature as a plausible design for large commercial-scale facilities [10,33]. However, although this allows for low-cost harvesting and circulation of culture to central dewatering, it considerably increases pipeline and pumping costs for returning water back uphill to the top of such a large facility, and thus may not necessarily offer substantial net cost savings compared to a more level facility layout. An alternative configuration based on a net level facility grade is evaluated as a sensitivity scenario in Section 6.1, which considers pipeline circulation and pumping both to and from the production ponds and dewatering (which may also approximate a facility with more distributed high and low areas instead of a continuous $1 \%$ slope). Figure 4 shows the layout of the modules within the overall facility footprint along with the primary pipelines and channels required for on-site circulation and transport of media.

The specific pond design within each module affects both the overall dimensions of the facility as well as the piping length requirements. An overview of the three general pond designs considered and their effect on facility footprint, as well as total lengths for overall site circulation piping, is shown below in Table 1. Pumps and pipelines internal to the 100 -acre modules (including circulation between ponds and primary dewatering, as well as clarified water return 
from primary dewatering back to ponds) are discussed later in Section 4.1. The module dimensions (A \& B) include spacing between ponds for access, piping, and electrical. Facility dimensions $(C \& D)$ include surrounding roads and fences in addition to the primary settler footprint, which is constant across all pond design choices. The physical configuration for some pond designs may have room for further optimization to slightly alter the overall module dimensions and reduce pipe distances (this is the case for the Global Algae Innovations pond designs which may allow for more compact pond spacing than that assumed here), but for simplicity a single basis for pond layout and spacing was utilized for each discrete pond size; variants for slightly more or less space-efficient layouts would impact overall biomass selling prices by less than $2 \%$. Based on the given piping diameters and lengths shown in Table 1, circulation pumps to send material back "uphill" (e.g., clarified water from second and third stage dewatering and inoculum for pond re-starts) were modeled in Aspen Plus to estimate pumping power required to overcome head and frictional losses for uphill circulation. Because these pumps and pipelines normally only carry clarified effluent from central dewatering back up the facility grade, the pumping power is not significant $(4 \%-9 \%$ of total facility power in the peak summer months), given that this amount of circulation only represents roughly onetwentieth of the amount of water circulated internally within the 100-acre modules from primary dewatering. If instead all dewatering operations occurred centrally, i.e., at the bottom of the grade, the amount of clarified water recycle would be 22 times higher, which would dramatically increase recirculation pumping power.

Table 1. Effect of Individual Pond Sizing on Facility/Module Dimensions and Pipeline Length

\begin{tabular}{|c|c|c|c|}
\hline Pond size & 2 acres & 10 acres & 50 acres \\
\hline \multicolumn{4}{|c|}{ Facility and module dimensions (see Figure 4 for "A-D" labels) } \\
\hline Module width (“A”, ft) & 5,570 & 4,588 & 2,700 \\
\hline Module length (“B”, ft) & 950 & 1,070 & 2,412 \\
\hline Facility width (“C”, ft) & 39,915 & 33,041 & 19,825 \\
\hline Facility length (“D”, ft) & 8,500 & 9,460 & 20,196 \\
\hline Facility size (Acre) & 7,789 & 7,176 & 9,192 \\
\hline \multicolumn{4}{|c|}{ Distribution pipeline requirements $(\mathrm{ft})$} \\
\hline 34" ID & 6,745 & 5,883 & 5,337 \\
\hline 26" ID & 11,390 & 9,426 & 5,650 \\
\hline 20" ID & 12,055 & 9,991 & 6,215 \\
\hline 16" ID & 8,400 & 9,360 & 20,096 \\
\hline 14" ID & 8,400 & 9,360 & 20,096 \\
\hline 12 " ID & 8,400 & 9,360 & 20,096 \\
\hline
\end{tabular}

For each pond scenario, underground distribution pipelines for water and $\mathrm{CO}_{2}$ are laid out to minimize required piping and vary based on the module dimensions. Running along the bottom edge of the facility is the primary water recirculation pipeline, which decreases in diameter as water is split off for module columns. The four vertical pipelines connecting successive terraces are identical and decrease in diameter every two terraces as water is again split off for individual modules. Changes in diameter are noted in Figure 4 and are consistent across all pond sizes. Connecting piping from the vertical distribution pipeline manifolds to the individual modules, along with clarified water recycle piping from primary settler dewatering (within the individual modules), is included in the pond cost estimates (Section 4.1) rather than overall facility 
circulation piping (Section 4.4), but is depicted for clarity in the overall facility diagram in Figure 4 as well.

Following harvesting from ponds at a concentration of $0.5 \mathrm{~g} / \mathrm{L}$ and preliminary dewatering to 10 $\mathrm{g} / \mathrm{L}$ (AFDW) via primary gravity settling within the 100 -acre modules, the partially concentrated harvest stream is routed via aqueduct channels from the modules to central dewatering at the bottom of the facility grade, following the distribution pipeline network. The channels proceed from high to low elevation along the $1 \%$ terraced sloping of the site footprint. Roads allow access to all modules. The support buildings include a laboratory, office spaces, warehouses, and nutrient storage, which are situated between the dewatering facility and inoculum ponds at the bottom edge of the facility. Placement of sensitive culture areas (PBR and lined ponds in the inoculum system) in close proximity to the laboratory allows for ease of monitoring and control.

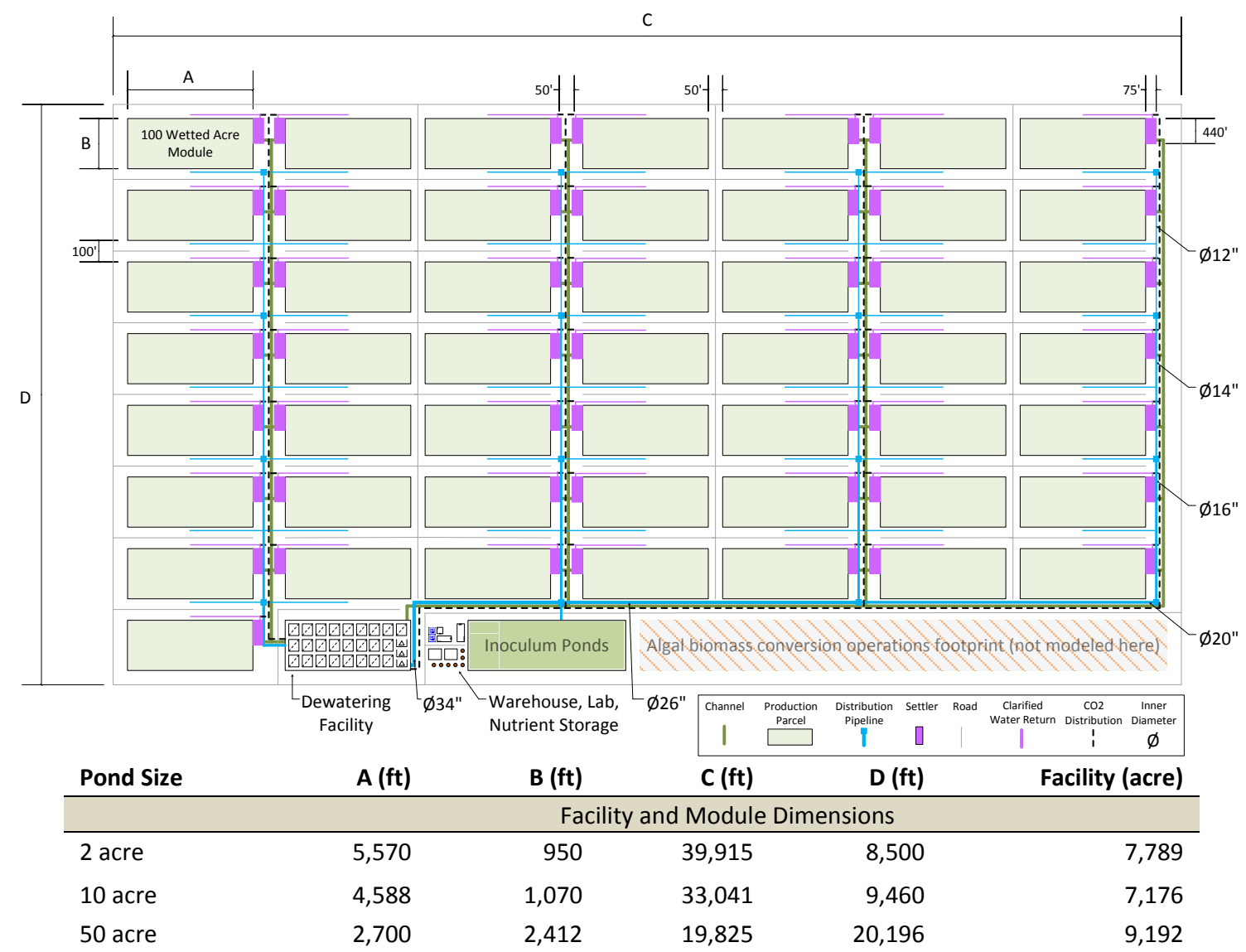

Figure 4. Schematic diagram for overall facility layout, depicting location of 100 -acre modules and connections to overall circulation networks including allowances for dewatering, inoculum, and downstream conversion operations. (Dimensions not to scale.)

\subsection{Biomass Composition}

For purposes of tracking nutrient and $\mathrm{CO}_{2}$ requirements as well as harvested biomass composition, the base case assumes the use of Scenedesmus acutus (LRB-AP 0401), a freshwater algal strain that has been well-characterized at NREL based on harvested biomass provided by Arizona State University (ASU). To generate the biomass at ASU, batch harvests were taken in early-, mid-, and late-cultivation stages, corresponding to low-, mid-, and high-nitrogen 
starvation states and also to high-protein ("HP"), high-carbohydrate ("HC"), and high-lipid ("HL") content biomass, respectively; associated cultivation batch times typically ranged from 3-5 days following nutrient depletion for mid-harvest biomass and 6-9 days for late-harvest biomass, while early-harvest biomass was obtained prior to nutrient depletion $[1,34]$. Table 2 provides the biomass compositional details for these cases, consistent with the above-referenced ALU design report and originally published by Laurens et al. [11]. For the base case, the midharvest Scenedesmus scenario titled "HCSD" in Table 2 was selected for use in the model given a reasonable $27 \%$ lipid content, which is a critical parameter to consider alongside corresponding biomass productivity (set at an annual target of $25 \mathrm{~g} / \mathrm{m}^{2} /$ day as discussed in Section 4.1) in light of known tradeoffs between achievable growth rate and lipid content [35,36]. While the earlyharvest/high-protein scenario would most easily allow for achieving high biomass productivity targets, the low lipid and carbon content of the biomass would be expected to translate to poor yields and/or product quality during downstream conversion through either the ALU or HTL conversion pathways $[1,2,37]$. Alternatively, the late-harvest/high-lipid case would allow for highest fuel yields during downstream conversion, but at $41 \%$ lipid content would place additional burdens on achievable cultivation biomass productivity. Sensitivities to these tradeoffs are explored in Section 6.1. As the experimental basis for biomass grown to the specific harvesting points described above was originally done in batch cultures at ASU, it is assumed that the same compositions may be seen for a continuous growth/harvesting regime as is modeled here, enabled by optimized production schemes, nutrient feeding strategies, and resultant growth rates.

In addition to the compositional details for Scenedesmus over the given range of harvesting regimes, Table 2 provides similar information for Chlorella vulgaris ( $L R B-A Z 1201$ ) (also a freshwater strain) and Nannochloropsis granulata (a saline strain), also provided by ASU over a similar range of harvesting time points; the latter two strains are investigated as sensitivity scenarios in Section 6.1. For all three species, there is a clear measured shift in composition of the biomass across the early, mid, and late stages of cultivation, which is typical for nutrient limited biomass, with corresponding protein, lipid, and carbohydrate values consistent with earlier reports for these species [38-40]. In both freshwater cases, the ash content is seen to reduce from $6 \%-7 \%$ to $<3 \%$ between the early and late harvest points, while measured protein content drops dramatically from $34 \%$ to $9 \%$ for Scenedesmus or from $40 \%$ to $13 \%$ for Chlorella (elemental nitrogen content closely tracks a similar trend with protein). Similar trends are also seen for Nannochloropsis, but with a higher ash content as typical for a saline strain. Further details related to the assumptions used to close component mass balances for modeling purposes (bottom portion of the table), as well as explanation of component categories in Table 2, are provided in the 2014 ALU design report [1]. One item that bears repeating is the definition of "lipid content" as shown in Table 2, which is based on fatty acid lipids as FAME (fatty acid methyl esters) produced by transesterification of the biomass lipids following NREL published methods [41]. Thus, this does not include other hydrocarbon-based lipid species such as straight and branched-chain hydrocarbons, sterols, and isoprenoid-based compounds. 
Table 2. Elemental and Component Compositions for Early-Harvest (HPSD), Mid-Harvest (HCSD), and Late-Harvest (HLSD) Algal

Biomass for Three Strains. (Top portion = raw analytical data, bottom portion $=$ adjusted values to achieve $100 \%$ mass closure for modeling $)$ $[11,34]$

\begin{tabular}{|c|c|c|c|c|c|c|c|c|c|}
\hline \multirow{2}{*}{$\begin{array}{c}\text { Measured: } \\
\text { Wt\% composition (dry basis) }\end{array}$} & \multicolumn{3}{|c|}{ Scenedesmus sp. } & \multicolumn{3}{|c|}{ Chlorella sp. } & \multicolumn{3}{|c|}{ Nannochloropsis sp. } \\
\hline & $\begin{array}{c}\text { Early } \\
\text { (HPSD) }\end{array}$ & $\begin{array}{c}\text { Mid } \\
\text { (HCSD) }\end{array}$ & $\begin{array}{l}\text { Late } \\
\text { (HLSD) }\end{array}$ & $\begin{array}{l}\text { Early } \\
\text { (HPCZ) }\end{array}$ & $\begin{array}{c}\text { Mid } \\
(\mathrm{HCCZ})\end{array}$ & $\begin{array}{c}\text { Late } \\
\text { (HLCZ) }\end{array}$ & $\begin{array}{c}\text { Early } \\
\text { (HPNC) }\end{array}$ & $\begin{array}{c}\text { Mid } \\
(\mathrm{HCNC})\end{array}$ & $\begin{array}{l}\text { Late } \\
\text { (HLNC) }\end{array}$ \\
\hline $\mathrm{C}$ & 49.3 & 52.9 & 56.3 & 48.7 & 49.8 & 54.7 & 46.6 & 48.2 & 61.6 \\
\hline $\mathrm{H}$ & 7.1 & 8.0 & 8.5 & 6.9 & 7.5 & 8.3 & 7.0 & 7.3 & 9.6 \\
\hline $\mathrm{N}$ & 8.3 & 1.8 & 1.6 & 8.8 & 2.7 & 2.2 & 6.6 & 4.5 & 2.0 \\
\hline $\mathrm{O}$ & 28.7 & 34.8 & 31.2 & 28.0 & 36.5 & 31.5 & 29.0 & 30.0 & 22.9 \\
\hline S & 0.0 & 0.2 & 0.2 & 0.6 & 0.4 & 0.4 & 0.6 & 0.5 & 0.3 \\
\hline $\mathrm{P}$ & 0.97 & 0.22 & 0.20 & 1.08 & 0.15 & 0.11 & ND & ND & ND \\
\hline Total a & 94.4 & 97.9 & 98.0 & 94.0 & 97.0 & 97.2 & 89.8 & 90.0 & 96.3 \\
\hline Ash & 6.7 & 2.3 & 2.1 & 6.1 & 3.0 & 2.8 & 14.2 & 13.6 & 5.1 \\
\hline Fermentable carbohydrates & 24.3 & 46.3 & 37.9 & 5.8 & 36.7 & 23.6 & 6.0 & 8.8 & 8.9 \\
\hline Other carbohydrates ${ }^{\mathrm{b}}$ & 3.4 & 1.6 & 1.3 & 5.9 & 5.0 & 3.5 & 2.9 & 2.4 & 2.0 \\
\hline Protein & 34.5 & 12.8 & 8.9 & 40.8 & 13.4 & 12.9 & 32.7 & 23.1 & 9.4 \\
\hline Lipids (fuel-relevant lipids as FAME) & 6.6 & 26.5 & 40.9 & 13 & 22.1 & 40.5 & 12.3 & 25.6 & 57.3 \\
\hline Non-fuel polar lipid impurities & $N^{c}$ & ND & ND & ND & ND & ND & ND & ND & ND \\
\hline Cell mass & ND & ND & ND & ND & ND & ND & ND & ND & ND \\
\hline Total & 75.5 & 89.5 & 91.1 & 71.6 & 80.2 & 83.3 & 68.1 & 73.5 & 82.7 \\
\hline Adjusted to close mass balances: & \multicolumn{3}{|c|}{ Scenedesmus sp. } & \multicolumn{3}{|c|}{ Chlorella sp. } & \multicolumn{3}{|c|}{ Nannochloropsis sp. } \\
\hline Wt\% composition (dry basis) & $\begin{array}{c}\text { Early } \\
\text { (HPSD) }\end{array}$ & $\begin{array}{c}\text { Mid } \\
\text { (HCSD) }\end{array}$ & $\begin{array}{c}\text { Late } \\
(\text { HLSD) }\end{array}$ & $\begin{array}{c}\text { Early } \\
\text { (HPCZ) }\end{array}$ & $\begin{array}{c}\text { Mid } \\
(\mathrm{HCCZ})\end{array}$ & $\begin{array}{c}\text { Late } \\
(\mathrm{HLCZ})\end{array}$ & $\begin{array}{c}\text { Early } \\
\text { (HPNC) }\end{array}$ & $\begin{array}{c}\text { Mid } \\
(\mathrm{HCNC})\end{array}$ & $\begin{array}{c}\text { Late } \\
\text { (HLNC) }\end{array}$ \\
\hline $\mathrm{C}$ & 52.2 & 54.0 & 57.4 & 51.8 & 51.3 & 56.3 & 51.4 & 53.2 & 63.8 \\
\hline $\mathrm{H}$ & 7.5 & 8.2 & 8.7 & 7.3 & 7.7 & 8.5 & 7.7 & 8.1 & 9.9 \\
\hline $\mathrm{N}$ & 8.8 & 1.8 & 1.6 & 9.3 & 2.8 & 2.2 & 7.3 & 5.0 & 2.0 \\
\hline $\mathrm{O}$ & 30.4 & 35.5 & 31.8 & 29.8 & 37.7 & 32.4 & 32.0 & 32.6 & 23.7 \\
\hline S & 0.0 & 0.2 & 0.2 & 0.6 & 0.4 & 0.4 & 0.7 & 0.5 & 0.3 \\
\hline$P$ & 1.03 & 0.22 & 0.20 & 1.15 & 0.15 & 0.11 & $0.88^{d}$ & $0.60^{d}$ & $0.24^{d}$ \\
\hline Total a & 100.0 & 100.0 & 100.0 & 100.0 & 100.0 & 100.0 & 100.0 & 100.0 & 100.0 \\
\hline Ash & 6.7 & 2.4 & 2.1 & 6.1 & 3.0 & 2.8 & 14.2 & 13.6 & 5.1 \\
\hline Fermentable carbohydrates & 26.2 & 47.8 & 38.2 & 6.8 & 39.2 & 25.2 & 8.2 & 11.0 & 9.8 \\
\hline Other carbohydrates ${ }^{\mathrm{b}}$ & 12.8 & 5.0 & 3.9 & 20.7 & 16.0 & 11.2 & 11.9 & 9.0 & 6.6 \\
\hline Protein & 43.2 & 13.2 & 9.0 & 47.8 & 14.3 & 13.8 & 44.6 & 28.9 & 10.4 \\
\hline Lipids (fuel-relevant lipids as FAME) & 8.3 & 27.4 & 41.2 & 15.2 & 23.6 & 43.3 & 16.8 & 32.0 & 63.2 \\
\hline Non-fuel polar lipid impurities & 0.8 & 2.7 & 2.1 & 1.5 & 2.4 & 2.2 & 1.7 & 3.2 & 3.2 \\
\hline Cell mass & 1.9 & 1.6 & 3.5 & 1.8 & 1.6 & 1.6 & 2.7 & 2.3 & 1.7 \\
\hline Total & 100.0 & 100.0 & 100.0 & 100.0 & 100.0 & 100.0 & 100.0 & 100.0 & 100.0 \\
\hline
\end{tabular}

a Measured element balance on dry weight basis; adjusted to AFDW basis for model (bottom portion of table).

${ }^{b}$ Non-fermentable carbohydrates.

${ }^{\mathrm{c}} \mathrm{ND}=$ not determined.

${ }^{\mathrm{d}}$ Elemental P content estimated for modeling based on assumed P:N weight ratio of 0.12:1 per separate analytical data for Nannochloropsis oceanica [42]. 
Beyond the basis of reasonable/mid-level lipid content justifying the strain/harvest selection, the choice of Scenedesmus itself as the base case strain also supports the intent to be agnostic to the downstream conversion method, i.e., ALU or HTL, while making use of a representative strain with commercial relevance (recognizing that there is not yet a "commercial" industry for algal biomass beyond Spirulina for the food market). As noted above, this particular strain has been well-characterized for both elemental and component analysis to a high degree of mass closure [11], thus reducing uncertainties regarding both nutrient/ $\mathrm{CO}_{2}$ input demands as well as harvested biomass $\mathrm{C} / \mathrm{N} / \mathrm{P}$ content and thereby potential fuel yields during downstream conversion. Such amount of detail for high mass closure is difficult to attain for most strains available in literature, particularly for presenting both the elemental composition (required for the HTL modeling basis [2]) and associated component composition (required for the ALU modeling basis [1]). Making use of the mid-harvest Scenedesmus information across both compositional data sets allows for equally usable inputs to be consistently evaluated through either conversion pathway. Additionally, Scenedesmus may be reasonably viewed as a representative strain with commercially relevant potential for fuel or coproduct opportunities, as it is closely related to Desmodesmus, a strain produced both at Cellana in partnership with the Cornell Consortium as well as at Sapphire, with favorable published results [43,33]. Sensitivities attributed to the use of a number of alternative strains (primarily impacting nutrient and $\mathrm{CO}_{2}$ inputs, with one saline scenario also considered) also are presented in Section 6.1.

\subsection{Modeling Basis Parameters}

Similar to other recently published design reports under DOE-BETO efforts $[2,23,44]$, a number of key modeling assumptions are fixed constant to allow for comparable modeling outputs. These parameters include:

1. Design and construction time: 36 months

2. Facility start-up time: 0.5 year (6 months)

3. Cost-year dollar basis: 2011 dollars (all cost results presented here will be in 2011 dollars)

4. Facility on-stream time: $90 \%$ (330 days/year or 7,920 hours/year). Note, this is intended to represent an $n^{t h}$-plant facility and may be a higher factor than what is achievable today, particularly when considering the algal cultivation step, which is dependent on strain robustness to withstand culture crashes (discussed above in Section 1.3). This on-stream factor assumes year-round operation with approximately one month per year allocated to facility shut-down, whether due to planned maintenance, pond upsets (such as culture crashes or freezes), or other downtime factors. 


\section{3 "Top-Down" Analysis of Cultivation Cost Demands}

Before considering specific pond system designs and costs as well as cultivation productivity projections, it is useful to begin with an analysis conducted from the "top down" to objectively present what both of these metrics must be in order to achieve a desired biomass selling price. To do this, the design and cost basis assumptions for all other operations aside from cultivation were first set consistently with the details documented in Sections 4.2-4.6, including the inoculum system, dewatering operations, delivery of $\mathrm{CO}_{2}$ and makeup water, on-site circulation of harvest and recycle water streams, and storage. Additionally, the same seasonal assumptions for pond evaporation rates as well as fractional variability in cultivation productivity were employed as discussed in Section 4.1.2 (i.e., productivity ratio between summer and spring, fall, or winter were set at factors of 1.2, 1.4, and 3.0, respectively). Based on these assumptions, Figure 5 presents a scan of pond costs in dollars-per-acre for all pertinent pond elements (including civil work, paddlewheel or other circulation device, concrete, lining or other leakage control methods, piping between individual ponds and central headers, and electrical) versus cultivation biomass productivity $\left(\mathrm{g} / \mathrm{m}^{2} /\right.$ day, annual average) both as independent variables, with the contour lines representing the resulting MBSP attributed to inputting these two variables into the overall model framework. The bottom bound for the selected contour lines corresponds to an optimistic goal of $\$ 300 /$ ton, followed by $\$ 430 /$ ton, which represents the current BETO 2022 target as published in recent Multi-Year Program Plan (MYPP) documents, while the top bound is closer to today's current estimated baseline costs of roughly $\$ 1,000 /$ ton or higher $[45,46]$.

As shown in Figure 5, the economics for biomass production depend strongly on both achievable productivity and the capital expenses for the cultivation system when the latter costs are high enough to represent the primary cost driver behind MBSP (i.e., the $\$ 1,000 /$ ton contour line shows a much steeper slope across the span of productivity values considered than the $\$ 300 /$ ton line). For example, at a productivity target of $30 \mathrm{~g} / \mathrm{m}^{2} /$ day, MBSP increases from $\$ 300 /$ ton at a pond system cost of $\sim \$ 1 \mathrm{k} /$ acre up to $\$ 430 /$ ton, $\$ 550 /$ ton, and then $\$ 700 /$ ton at $\$ 30 \mathrm{k} / \mathrm{acre}$, $\$ 57 \mathrm{k} /$ acre, and $\$ 90 \mathrm{k} /$ acre, respectively, and then more dramatically to $\$ 1,000 /$ ton at $\$ 157 \mathrm{k} /$ acre. We will show later that two primary requirements in driving down costs for algal pond systems are (1) making use of large ponds to capitalize on economy of scale benefits (see Sections 4.1.3 and 5.5) and (2) avoiding the use of fully lined ponds, as are typical in today's demonstration or commercial facilities (see Section 6.1). For small fully lined ponds that may be more typical for such facilities today, calculated costs would be on the order of $\$ 75-120 \mathrm{k} /$ acre.

As cultivation pond costs can be reduced to reasonable levels, ideally $<\$ 30 \mathrm{k} /$ acre (consistent with larger ponds with minimal lining as shown in Figures 8-9), other considerations start to become the dominating contributor to MBSP such that even when ponds are nearly "free," it is difficult to reduce biomass selling price below roughly $\$ 300-\$ 350 /$ ton unless productivity can be improved to aggressive target values greater than $30 \mathrm{~g} / \mathrm{m}^{2} /$ day. This is evidenced later in Section 5.5 , which shows that costs attributed to $\mathrm{CO}_{2}$ and nutrients alone make up more than $\$ 110 /$ ton of biomass based on the combination of inputs and assumptions employed in the "bottom-up" analysis of Section 4 at a $25 \mathrm{~g} / \mathrm{m}^{2} /$ day annual average productivity. In any case, this analysis supports prior conclusions that algal biomass (and therefore biofuel) economics are strongly dependent on achievable cultivation productivity, where for example biomass selling price could reduce from $\$ 1,000 /$ ton to $\$ 430 /$ ton by improving productivity from $10 \mathrm{~g} / \mathrm{m}^{2} /$ day up to 35 $\mathrm{g} / \mathrm{m}^{2} /$ day while maintaining cultivation pond cost near steady at $\$ 40-\$ 45 \mathrm{k} / \mathrm{acre}$. Although a 
productivity of $35 \mathrm{~g} / \mathrm{m}^{2} /$ day may be slightly optimistic to achieve over an annual year-round basis, pond costs may plausibly be reduced below $\$ 40 \mathrm{k} /$ acre if designed for large pond sizes to maximize economy of scale benefits; this could allow achieving costs near the $\$ 430 /$ ton goal at a lower productivity in the $25-30 \mathrm{~g} / \mathrm{m}^{2} /$ day range, which is more reasonable as a projection to achieve by 2022 . Thus, while a cost as low as $\$ 300 /$ ton remains a challenge to substantiate through TEA, this analysis validates that an MBSP target near \$430/ton (or more conservatively, at most limited to under $\$ 500 /$ ton) is in fact achievable with a number of improvements beyond today's current performance and high-cost pond configurations. This assumes that other key contributors such as $\mathrm{CO}_{2}$ or nutrient demands are not given credit for recycle possibilities that may be enabled by downstream integrated conversion processes; however, our prior analyses have instead given credit for such recycles by reducing biofuel selling prices accordingly, rather than biomass selling prices [1] (thus doing so here would double-count for such a credit). Alternatively, consideration of value-added coproduct opportunities from the algal biomass could also relax the requirement for extremely low-cost ponds and aggressive productivities, by providing a means to valorize the biomass and garner higher values relative to biomass production costs, and to supplement algal fuel production.

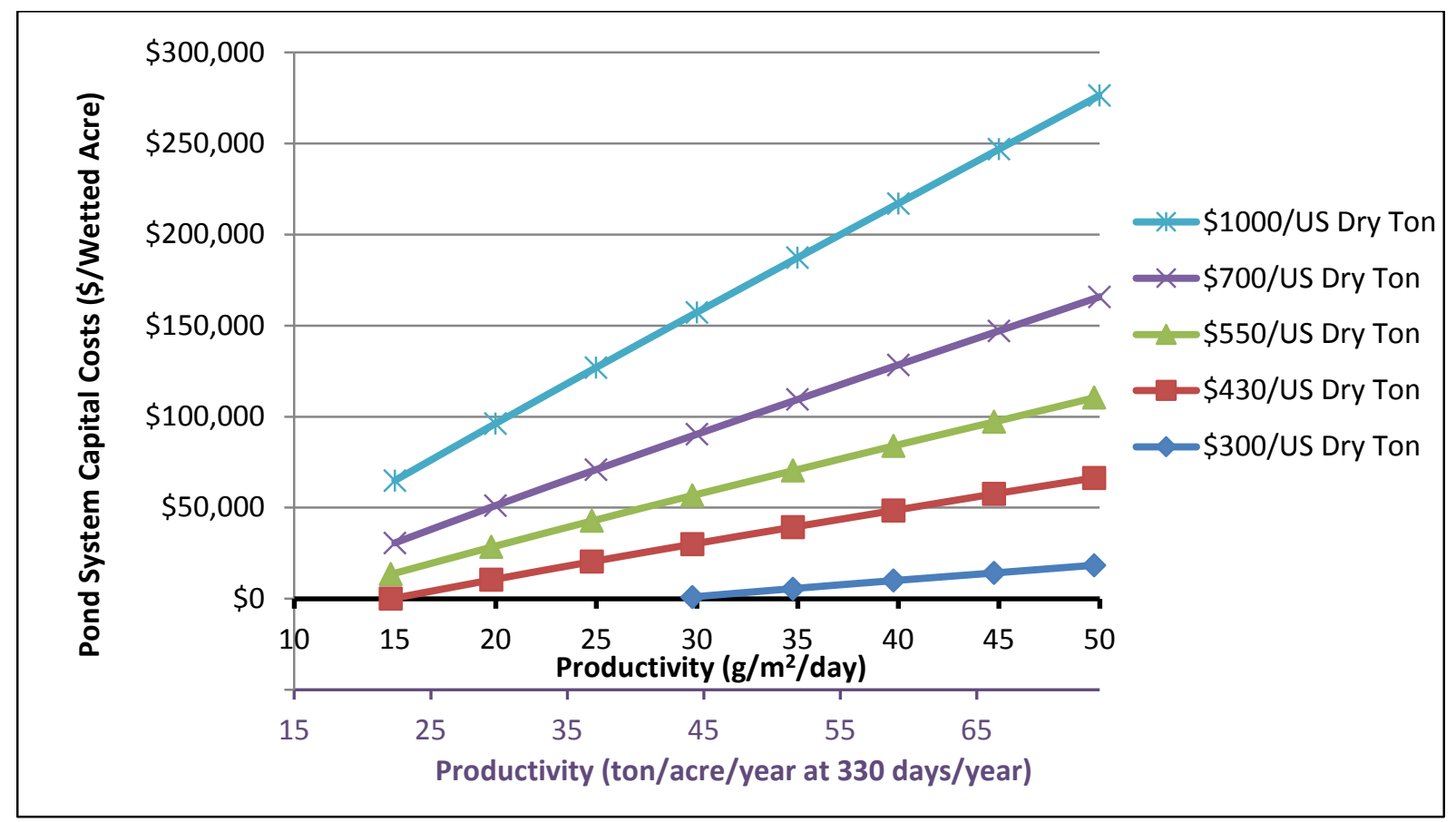

Figure 5. "Top-down" scan for minimum biomass selling price (MBSP) as a function of both cultivation pond system capital costs (agnostic of specific pond design details) and achievable annual biomass productivity. (Y-axis for "pond system costs" includes capital costs for civil work, concrete, mixing equipment and motors, lining or other leakage/erosion control costs, circulation piping, and electrical costs.) 


\section{4 “Bottom-Up" Integrated Model: Process Design and Capital Cost Estimation Details}

Moving beyond the generic cost scans presented in Section 3, the remainder of this report documents the details of a "bottom-up" analysis conducted to incorporate a number of discrete pond designs furnished to NREL into an integrated model that includes delivery and circulation of water, nutrients and $\mathrm{CO} 2$, inoculum propagation, and downstream algal biomass dewatering. Under this approach, we consider a combination of operations and conditions that represent one plausible set of targets to be achieved by 2022, but reiterate that this may not represent the most optimal possible scenario, nor a (as of yet) fully commercially demonstrated design as it represents future process goals projected onto a set of design configurations as understood today. Furthermore, the goal of this assessment is not to reach a previously prescribed MBSP target, but rather to present the implications on MBSP for a number of design and processing scenarios using a consistent modeling framework, and thereby help inform near-term research and engineering directions. This section describes the process as modeled and discusses the influence of specific R\&D goals in the decision-making process.

As the cultivation step represents the most critical and cost-intensive area of the process, a number of experts in the field were consulted in order to provide a more comprehensive survey of inputs for cultivation designs and costs, rather than relying on a single basis for this information. As discussed in Section 4.1, four independent sources were consulted to solicit detailed inputs on pond designs and costs; namely, two engineering subcontractors (Leidos and Harris Group), a commercial developer (Global Algae Innovations ["GAI"]), and a consultant group with industry expertise (MicroBio Engineering ["MicroBio"]). NREL gratefully acknowledges these sources for providing critical support to establish detailed cost projections across a range of individual pond sizes, layouts, and circulation methods for the key cost elements related to pond operations and bulk fluid handling. Beyond this step of the process, inputs and assumptions for other operations considered in the integrated model-including delivery and on-site circulation of $\mathrm{CO} 2$ and water, inoculum production, and dewatering-were based on inputs from literature, additional vendors, and engineering software (e.g., Aspen Plus and ACCE [24]). Design configurations and processing details for these additional operations beyond the production pond systems were maintained consistently across all individual pond design scenarios in the baseline model framework. While the specific cultivation and processing options evaluated here do not constitute an exhaustive survey of the published literature for all promising designs, they establish a benchmark against which additional scenarios and associated costs may be compared, as the primary objective is to set goals for both costs and performance attributed to each area of the process moving forward as the industry progresses.

\subsection{Area 100: Biomass Production}

\subsubsection{Overview}

This section describes the design and cost details for a number of pond sizes and configurations made available to NREL through subcontracts, consultations with industry stakeholders, and literature. In total, eight discrete pond scenarios are considered within the integrated technoeconomic model for their implications on resulting biomass selling price. In all cases, ponds are grouped into 100-acre modules with each module including feed and harvest pipes between individual ponds and common headers, with the harvest lines typically drawn off of pond sumps 
controlled by slide gates or valves and delivered to primary dewatering (in-ground gravity settlers, discussed in Section 4.5) located within the 100-acre module blocks. The harvested material from primary settling is routed to harvest channels for delivery to central dewatering, while the clarified effluent is routed back to pond feed header lines along with additional recycle water from central dewatering and fresh makeup water.

The individual pond scenarios span a wide range of sizes, including two 2-acre estimates (with paddlewheel mixing), which may be viewed as a standard basis for today's demonstration- or commercial-scale facilities [10,47,48]; four 10-acre estimates (three mixed by paddlewheels and one by pumping), which historically have been viewed as an upper bound for pond operability in the context of standard paddlewheel raceway designs [17,22]; and two hypothetical 50-acre estimates (both based on novel configurations without paddlewheels) primarily for illustrative purposes to demonstrate economy of scale ramifications. By considering such a large dataset beyond a single design basis, it may be demonstrated that cultivation pond costs are more strongly divided by economy of scale differences than by design details or differences of opinion in cost elements (see Figures 8 and 9), which is an important conclusion in light of commonly held beliefs that cultivation pond costs are too widely scattered to conclude with any certainty what commercial ponds would "actually" cost in an $n^{\text {th }}$-plant commercial design. Of course, more simplistic pond designs are possible with minimal agitation and therefore lower achievable productivity, but such designs are not typically envisioned for production of low-price commodity products such as algal biofuels and are not considered here. A key point to emphasize is that moving beyond currently available 2 -acre pond sizes up to 10 acres or more carries additional processing risk particularly for today's strain performance which typically may experience frequent contamination and culture crash events, which would be substantially more detrimental for a single 10 -acre pond than a single 2 -acre pond; consequently, it remains a critical research priority to develop highly robust strains that withstand culture crashes in order to enable the practical use of larger-size ponds.

High-level schematic layouts for the three different pond design configurations are shown in Figure 6. Cultivation process details were applied consistently across all pond designs considered, including seasonal biomass productivity targets, evaporation rates, and harvested biomass density. Additionally, all base case pond designs avoid the use of fully-lined ponds given significant cost premiums that pond lining incurs, but rather only utilize plastic liners sparingly on small targeted areas of the ponds for erosion control.
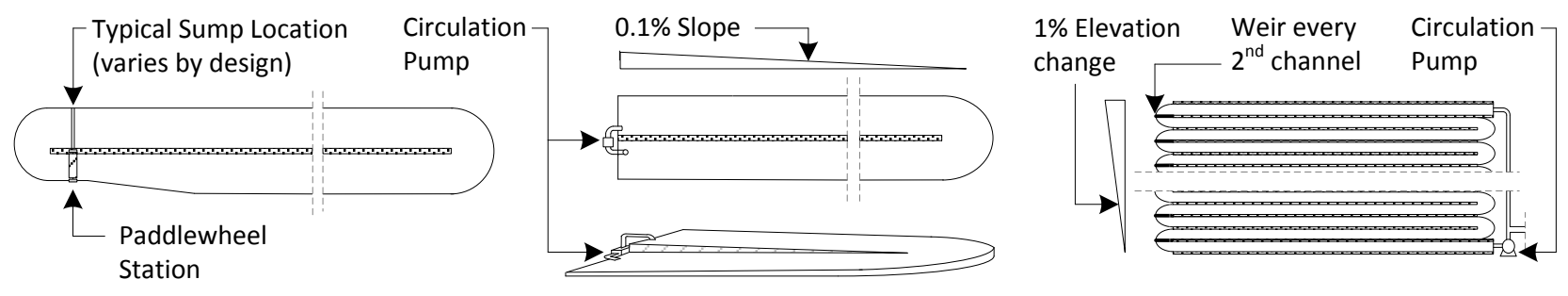

Figure 6. Schematic layouts for the three pond configurations considered over multiple size ranges. $($ Left $=$ paddlewheel raceway; center $=$ GAI pond system with pump circulation; right $=$ Leidos gravity flow serpentine pond.) 


\subsubsection{Design Basis \\ Process Assumptions}

The process begins with algal biomass grown and harvested from the production ponds under continuous steady-state conditions. For initial startup and occasional re-inoculation when necessary, the production ponds are inoculated with biomass provided from the inoculum system at a starting culture density of $0.1 \mathrm{~g} / \mathrm{L}$ (see Section 4.2). Under normal conditions, the ponds are operated under a continuous mode of harvesting to minimize fluctuations and over-design (and therefore cost) that the downstream dewatering equipment must accommodate [17]. Biomass is harvested at a fixed culture density of $0.5 \mathrm{~g} / \mathrm{L}$ AFDW for processing through primary settling.

Biomass productivity is a key parameter, with two important facets - annual average productivity $\left(\mathrm{g} / \mathrm{m}^{2} /\right.$ day) and the degree of variation by season (maximum versus minimum range). For the former parameter, the overall annual average productivity is set at $25 \mathrm{~g} / \mathrm{m}^{2} /$ day (AFDW basis) as a projection targeted to be achieved by 2022. This is slightly more conservative than prior BETO 2022 targets documented in MYPP reports at $30 \mathrm{~g} / \mathrm{m}^{2} /$ day that were implicitly attributed to 2022 fuel yield goals of 5,000 gallons per acre per year [45,46]. Furthermore, this appears to be an achievable target in light of published performance from industry at large-scale, currently demonstrated to be as high as $23 \mathrm{~g} / \mathrm{m}^{2} /$ day (coupled with a very high $40 \%$ lipid content in one publication) [43], although that was based on favorable year-round climatic conditions in Hawaii coupled with a higher use of PBR systems to supplement pond growth, and is considerably higher than other currently achieved values more typically observed at 10-15 $\mathrm{g} / \mathrm{m}^{2} /$ day based on sustained values averaged over the course of a year [49-52]. In any case, a target of at least $25 \mathrm{~g} / \mathrm{m}^{2} /$ day is critical in achieving reasonable biomass costs, as evidenced by the strong economic sensitivity to this parameter shown in Section 6.1. At this productivity coupled with the assumed steady-state biomass density of $0.5 \mathrm{~g} / \mathrm{L}$, the mean residence time for all pond scenarios is 5 days (i.e., $20 \%$ of the pond is harvested each day) on an annual average basis. Equally important is the associated lipid content and other compositional attributes that influence fuel yields during downstream conversion (particularly pertinent for ALU conversion, but also HTL), with the base case set at 27\% lipids as FAME (54 wt $\%$ C) for the Scenedesmus strain considered here, as discussed in Section 2.3. These growth rate and compositional assumptions translate to an overall biomass energy conversion efficiency (energy contained in the biomass versus total full-spectrum solar irradiance) of 3.9\%, compared to maximum limits of $\sim 14 \%$ based on the methods published in Weyer et al. and Beal et al. [53,54]. During external peer review of this report, the majority consensus among 20 expert stakeholder reviewers was that this combination of productivity and compositional targets stipulated here is (and must be) achievable by 2022 even if only demonstrable at small scales, and will likely require improved strains relative to today's wild-types.

Seasonal variability in cultivation productivity is a function of both site location and biology/strain robustness. Maintaining consistency with the harmonization modeling activities discussed previously, the same collection of site locations located along the U.S. Gulf Coast is assumed here as was identified during the 2012-2013 harmonization analyses, based on optimization to maximize productivity and minimize net water demand (i.e., net evaporation rate) $[23,42]$. The most recent harmonization assessment presented a modeled swing in productivity of roughly 5:1 between the summer and the winter as an average across these site locations, attributed to current baseline performance expected for the cultivation of a freshwater 
Chlorella strain known as DOE 1412 [42,55]. In light of the unfavorable design constraints and associated economics such a high variability incurs on downstream conversion processing [1,2], this variability is targeted to be reduced by $40 \%$ in the present analysis to a range of $3: 1$ between the summer and winter seasons (an aspirational goal to achieve by 2022). Beyond favoring site locations with low variability in seasonal temperatures and solar insolation, such a reduction may also be achieved through engineered strain improvements or by employing strain rotation strategies to make use of a strain more tolerant to cold temperatures during cold season months. Indeed, algal growth modeling work being conducted at PNNL has identified that merely by employing strain rotation to make use of (for example) Sphaeropleales during cool seasons with Chlorella 1412 used in warm seasons, preliminary unpublished estimates suggest that seasonal production variability could be reduced by more than $50 \%$ to a level near $2: 1$ relative to today's performance for Chlorella 1412 alone used year-round [56]. Furthermore, year-round cultivation data observed elsewhere suggest current swings in productivity observed lower than the 5:1 basis. For example, the $\mathrm{ATP}^{3}$ Test-Bed Consortium has observed seasonal productivity ranges typically between 2:1-3:1 for year-round cultivation of Nannochloropsis across the majority of its five test-bed sites, with a site in Florida (most closely representing the Gulf Coast region out of the $\mathrm{ATP}^{3}$ sites) limited to a range near 2:1 [49,57]. A similar range also has been observed under $\mathrm{ATP}^{3}$ for year-round cultivation of Chlorella, limited to a maximum variability of $2.4: 1$ for the same Florida site [57]. In light of the above considerations, we feel a maximum variability range in productivity of 3:1 is a reasonable projection, particularly as a target to achieve by 2022 . The resulting individual seasonal productivity values attributed to this variability range are shown in Table 3, and model sensitivity to the range of variability itself is evaluated in Section 6.1. The "shape of the curve" establishing the seasonal productivity values shown in Table 3 was developed based on: (1) limiting peak (summer) growth rate to a maximum of $35 \mathrm{~g} / \mathrm{m}^{2} /$ day; (2) setting minimum (winter) growth rate a factor of three lower $\left(11.7 \mathrm{~g} / \mathrm{m}^{2} /\right.$ day); and (3) setting spring and fall growth rates to support the annual average value of $25 \mathrm{~g} / \mathrm{m}^{2} /$ day while maintaining the same ratio of spring:fall as the most recent 2013 harmonization basis (1.15:1, translating to 28.5 and $24.9 \mathrm{~g} / \mathrm{m}^{2} /$ day respectively).

For seasonal water balance considerations, all assumptions related to water losses (primarily via pond evaporation and blowdown removal) were maintained consistently with the 2013 harmonization work [42], which presented a net water evaporation rate of $0.09 \mathrm{~cm} /$ day as an annual average across the selected Gulf Coast site locations (after accounting for precipitation), with seasonal values shown in Table 3. Net seasonal water evaporation losses shown here are based on historical weather and precipitation data gathered by PNNL and could differ significantly for other regions of the country. Both previous harmonization studies assumed the use of freshwater strains, given sufficient freshwater resources available particularly in the U.S. Gulf Coast region, to satisfy cultivation facilities totaling to 5 BGY of biofuel production capacity, coupled with environmental and logistical concerns related to the use of saltwater in land-based open ponds and large-scale salt disposal for land-locked facilities not located in close proximity to the coast $[23,58]$. Water management costs for such facilities could be considerably higher for saline species than for freshwater species; this is briefly investigated in Section 6.1 for the use of Nannochloropsis as an alternative saline strain, with costs for blowdown brine disposal adding roughly $\$ 32 /$ ton to overall biomass cost. The 2013 harmonization assessment did still include considerations for salt levels expected to be present in local freshwater resources (set here to $250 \mathrm{mg} / \mathrm{L}$ for incoming freshwater [59,56]), which required the inclusion of a small blowdown stream removed from the primary dewatering clarified effluent recycle line to 
mitigate buildup of salt and other inorganics to an acceptable level for freshwater strains (no more than $4,000 \mathrm{mg} / \mathrm{L}$ in the ponds, although the maximum observed in the current model is $2,000 \mathrm{mg} / \mathrm{L}$ ). The same assumptions for blowdown are also maintained in the present model, set as shown in Table 3. As the blowdown streams taken off from the primary settler recycle line contain very low salt levels, we do not assume any treatment or disposal costs for their inclusion.

Finally, building from previous work, nutrient requirements for the inoculum and production operations are assumed to be met using diammonium phosphate (DAP) for phosphorous requirements, and anhydrous ammonia $\left(\mathrm{NH}_{3}\right)$ for nitrogen requirements, after accounting for the amount of nitrogen available in DAP. Previous models had assumed that these nutrient components were delivered in stoichiometric amounts to meet the harvested biomass elemental composition without any additional allowances; however, such an idealized scenario may be overly-optimistic even for a future optimized commercial facility, as some level of nutrient loss may always be expected, e.g., through system losses (volatilization, percolation into soil, etc.) or uptake by competing organisms (given that the open environment does not allow for a monoculture in the pond). Thus, the model was adjusted to allow for $20 \%$ excess nutrient levels beyond stoichiometric biomass compositional demands, the majority of which remains in the recirculation loop between growth and primary dewatering (dictated by a large fraction of water/solubles being removed during primary dewatering and recirculated back to the ponds). Likewise, $\mathrm{CO}_{2}$ is also provided to the inoculum and production stages based on stoichiometric requirements plus an additional amount to account for retention/uptake efficiency losses (discussed in Section 4.3). The stoichiometric quantities are specific to the strain's elemental composition at harvest, set in the base case to $54.0 \% \mathrm{C}, 1.8 \% \mathrm{~N}$, and $0.22 \% \mathrm{P}$ by mass (AFDW basis), as shown in Table 2 . As noted earlier, to ensure applicability to any downstream biomass conversion/processing schematic, no credit is taken here for recycle of nutrients or $\mathrm{CO}_{2}$ from downstream conversion operations back to the production ponds, as doing so would require selecting a specific conversion technology and operating sequence; instead, any such recycle credits may be applied to the back-end process for example to reduce fuel costs.

Table 3. Assumptions for Seasonal Biomass Productivities, Pond Evaporation, and Blowdown Rates Used for the Base Case Models

\begin{tabular}{lccccc}
\hline Metric & Summer & Fall & Winter & Spring & $\begin{array}{c}\text { Annual } \\
\text { Average }\end{array}$ \\
\hline $\begin{array}{l}\text { Biomass Productivity } \\
\left(\mathrm{g} / \mathrm{m}^{2} / \text { day AFDW) }\right.\end{array}$ & 35.0 & 24.9 & 11.7 & 28.5 & 25 \\
$\begin{array}{l}\text { Productivity Variance } \\
\text { versus Summer Peak }\end{array}$ & $\mathrm{NA}(1: 1)$ & $1.4: 1$ & $3.0: 1$ & $1.2: 1$ & $\mathrm{NA}$ \\
$\begin{array}{l}\text { Pond Evaporation } \\
\text { (cm/day) }\end{array}$ & 0.090 & 0.035 & 0.035 & 0.189 & 0.087 \\
Blowdown (MM L/day) & 7.3 & 2.8 & 2.7 & 12.4 & 6.3 \\
\hline
\end{tabular}

\section{Pond Design Scenarios}

The pond design configurations made available to NREL for use in this analysis span three discrete sizes as defined by wetted cultivation area, namely 2-acre and 10-acre sizes to represent a range of what may be reasonable for today's most "accepted" design based on paddlewheelmixed raceway ponds, as well as a hypothetical 50 -acre size, which may be plausible for more novel configurations that do not make use of a paddlewheel. It should be noted that although all 
designs considered here fall into one of those three size categories, they are not always exactly these dimensions, as in some cases the original source based their estimate on a hectare basis (i.e., 1 ha pond $=2.47$ acres or 4 ha pond $=9.9$ acres), while other sources considered specific dimensions that translated to a cultivation acreage slightly off from the given category (i.e., 2.2 acres, 48.4 acres, etc.); these are identified accordingly in the discussion below. For all three size categories, ponds are assumed to be constructed with minimal spacing between ponds except for allowances for roads and piping as indicated in Figure 7.

Ponds are grouped into sectional modules as described in Section 2.2, where each module represents 100 acres of wetted cultivation area and is graded to be level, based on the inclusion of site preparation and grading/leveling costs provided within each respective source for the pond designs. Thus, a varying number of individual ponds are located within a single 100 -acre module based on the given pond size category, which incurs economy of scale cost penalties for the smaller pond scenarios, given the requirement for additional concrete, mixing stations, motors, electrical and piping runs to individual ponds, and valves/fittings to control harvest flows from individual ponds. In reality, electrical supply constraints may limit module size and geometry as well as equipment locations within the modules, but a detailed electrical design is beyond the scope of this analysis and is not assumed to preclude the placement of ponds and other equipment as described here. A schematic of the individual pond layouts within a given 100-acre module is shown below in Figure 7 (including piping hookups to common headers for overall facility culture circulation discussed in Section 2.2), followed by a discussion of the designs furnished by the various sources.

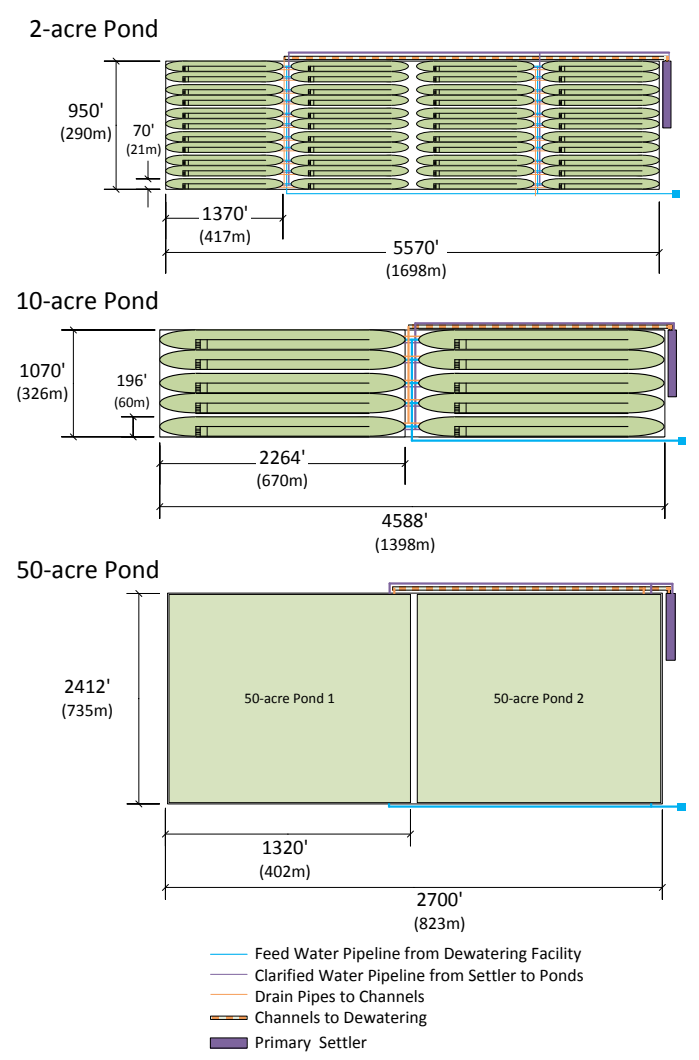

Figure 7. Schematic of pond layout within 100-acre modules. (See Figure 4 for overall facility layout). 


\section{Leidos Pond Designs}

Leidos Engineering is an engineering firm with expertise in the design and construction of algal cultivation ponds. Through a subcontract placed between Leidos and NREL, Leidos provided design and cost estimates for three pond configurations all based on optimal (but still realistic) cost structures for procurement and construction. These configurations included paddlewheel raceway systems of 2.2 and 10 acres in size, intended to represent realistic scenarios that are either built and operational today (2-acre systems) or may be readily constructed and verified to be operable in the near future (10-acre systems), as well as gravity-driven serpentine ponds 48.4 acres in size based on total wetted cultivation area (intended strictly for illustrative purposes to demonstrate one possible means of achieving additional economy of scale benefits for larger ponds exceeding the 10 -acre threshold).

All Leidos pond scenarios included considerations for a number of different leakage control options, with the lowest-cost option selected for the base case as in-situ clay with minimal plastic lining only on specific areas of the pond, as required for erosion control (pond turns in this case), rather than fully lining the pond with plastic liners or other alternatives for leakage control. A similar approach dictating the use of minimally lined ponds is maintained for all other pond scenarios as well (i.e., MicroBio, Harris, and GAI ponds), with complete pond liners evaluated as sensitivity scenarios in Section 6.1 . As will be seen from these sensitivity cases and has been shown in prior work $[23,17,12]$, the requirement to fully line algae ponds with standard high-density polyethylene (HDPE) or similarly priced plastic liners adds substantially to capital costs and resulting biomass selling price, and would pose significant challenges in achieving cost viability for commodity fuel products produced from algal biomass. In reality, the requirement for pond liners will depend on factors including soil characteristics and governing regulatory policies. On this point, it is noteworthy to mention that one of the largest algal pond systems constructed to date at roughly 3.1 acres, located in Christchurch, New Zealand, was constructed with $5 \mathrm{~mm}$ liners only covering the pond berms but without lining the pond base, and has successfully demonstrated soil self-sealing without any noted operability problems due to the lack of full pond liners; moreover, this is for an algal pond treating wastewater [47]. This has also been demonstrated in use by other algal wastewater treatment systems of varying sizes for several decades. Additional long-term production trials and soil studies are required to further support this stipulation and to substantiate mechanisms for soil self-sealing and unlined pond operation. Furthermore, future work should consider assessing locations with sufficient soil characteristics to support unlined ponds, e.g., as part of screening criteria considered in Resource Assessment modeling. Such future studies would be particularly pertinent as focus turns to saline cultures or engineered organisms.

The Leidos 2-acre design (nominally 2.2 acres in wetted cultivation area) was based on an actual developer design already constructed, extrapolated to optimal low-cost construction quotations that would be reasonable today under $n^{\text {th }}$-plant conditions. The given 100 -acre module plots each contain 44 ponds with 100 acres of total cultivation area, shown in Figure 7. Each raceway pond is $417 \mathrm{~m}$ long with channels that are $10.7 \mathrm{~m}$ wide. Within the 100 -acre facility there are four columns of 11 ponds. It is assumed that the site of the facility contains native in-situ clay and has a natural $1 \%$ slope, which is level graded within the 100 -acre modules. Additional land in the 100 -acre module includes roads between every other column of ponds, as well as piping and channel footprints. The module has 100 wetted acres of cultivation but actually takes up 121 acres of land. The land is prepared by removing surface vegetation and top soil not suitable for 
compaction. In total, $15 \mathrm{~cm}$ (6 in) of overburden is removed. The land is then scarified to $30 \mathrm{~cm}$ (1 ft) deep. Soil from clearing, grubbing, and overburden removal is stock-piled on site and used for berm creation. Berms and ponds are created and compacted. The berm walls are $61 \mathrm{~cm}(24$ in) high, while the separation walls within the raceways are $41 \mathrm{~cm}$ (16 in) high. Under the "marginally lined" base case noted above, geo-membrane liners are only present on the pond turns to control erosion and weeds. For all Leidos pond cases (2-acre raceway, 10-acre raceway, and 50-acre serpentine), the geo-membrane liner costs $\$ 7.11 / \mathrm{m}^{2}$. The total liner footprint per pond is $233 \mathrm{~m}^{2}$, which includes allowances for liner overlap and trimming of the liner; this translates to $2.5 \%$ liner coverage for the Leidos 2 -acre design. The normal pond water depth is $23 \mathrm{~cm}$ (9 in). Turning vanes are not included, based on Leidos' experience that they offer little benefit to justify their added expense (though a cost-benefit analysis should be done on a case by case basis to consider actual observed productivity or operational tradeoffs versus the use of turning vanes). Formed concrete is used to create paddlewheel support structures and a concrete sump. For each 100-acre module, $477 \mathrm{~m}^{3}$ of formed concrete is required, of which $20 \mathrm{~m}^{3}$ is used for the sump while the remainder is for the paddlewheel support structure. An additional $752 \mathrm{~m}^{3}$ of non-formed concrete is used to create piping stays for the underground piping within the 100acre modules.

The 2-acre raceway ponds use paddlewheels to circulate the culture. Each paddlewheel is coupled to a $5.6 \mathrm{~kW}(7.5 \mathrm{hp})$ motor, but the actual power consumed is $2.8 \mathrm{~kW}$ per paddlewheel (operating as such 24 hours/day); this equates to a $10 \%$ paddlewheel efficiency at a channel velocity of $20 \mathrm{~cm} / \mathrm{s}$, which Leidos validated with a developer based on operational data for ponds of this size. Electrical runs to the paddlewheels are included, with 10 gauge- 3 conductor wire routed to each pond, resulting in a total of 5,486 $\mathrm{m}$ of wire run for each 100 -acre module (including a 5\% additional contingency). Although Leidos considers water piping for the whole facility, this design report estimates the cost of piping outside the 100-acre modules separately (i.e., circulation piping and aqueducts to and from central dewatering as discussed in Section 4.4, applied consistently across all eight pond scenarios). Thus, only the circulation piping originally quoted by Leidos that would be located within the 100-acre module is included within the "pond cost" category here, i.e., piping required to bring water to and from the individual ponds and a central point (in this case, primary harvesting settlers on the pond outlet header and tie-ins to facility circulation manifolds on the pond inlet side, respectively). The pertinent piping includes an 18-inch diameter, 800 -foot (244 m) PVC pipe that takes the water from the main line to within the 100-acre module. The 18-inch pipe feeds into a 16-inch PVC sub-header pipe that is used to fill the individual ponds. Each 16 -inch pipe feeds two columns of ponds. Therefore, two 16-inch pipes are required to fill all the ponds in a 100-acre module. One 16-inch pipe runs between pond columns 1 and 2 , and the other runs between columns 3 and 4 . The total length of the feed 16-inch pipe for a 100-acre module is $2,170 \mathrm{~m}$. The harvest takeoff from a given pond is controlled with a slide gate, which is opened and the algae medium enters an 8-inch PVC pipe. The 8-inch pipe runs $12 \mathrm{~m}$ from each pond to the main header, totaling $585 \mathrm{~m}$ in a 100 -acre module. Similar to the 16-inch feed header, the drain header has a total of two pipes running inbetween pond columns 1 and 2 and pond columns 3 and 4 . The 16-inch drain header totals $670 \mathrm{~m}$ and feeds into a drain channel. As the costs provided from Leidos did not originally include harvest/external circulation pump costs (as was also the case with most other design scenarios as well), additional pumps to move the water between the harvest manifolds and the primary settling units were added to this and all other pond designs, based on cost estimates generated 
from ACCE. Finally, the design also includes $\mathrm{CO}_{2}$ diffusers located in the pond sumps to allow for $\mathrm{CO}_{2}$ sparging.

The Leidos 10 -acre pond design is similar to the 2 -acre basis, with the most notable exception being a reduction in channel size and increase in pond depth around the paddlewheel to control costs for very large paddlewheels and supports (which also may bring an added benefit of increased paddlewheel efficiency). The 10 -acre ponds are $670 \mathrm{~m}$ long with $30 \mathrm{~m}$ channels. The channels narrow from $30 \mathrm{~m}$ to $20 \mathrm{~m}$ wide at the paddlewheels. When the channels narrow they also deepen to maintain a consistent velocity throughout the ponds; this also more fully submerges the paddlewheel and increases the efficiency of the paddles to move water. However, higher head and resistance from additional paddlewheel supports for the larger 10-acre design would be expected to at least somewhat offset this efficiency gain, thus for lack of operational data to validate actual paddlewheel efficiencies for a design this large, Leidos maintained the assumption of $10 \%$ efficiency consistent with the 2 -acre basis. The resulting power consumption for paddlewheel circulation is $11.8 \mathrm{~kW}$ for every 10 -acre pond, maintaining channel velocity at $20 \mathrm{~cm} / \mathrm{s}$.

Relative to the 2-acre basis, economy of scale benefits are incurred for the larger 10-acre design in that the amount of civil work, liners, paddlewheel equipment, electrical, and piping are all reduced per 100-acre module footprint. As seen in Figure 7, in a 100-acre module there are two columns of ponds with five 10-acre ponds per column, totaling 10 ponds. Additional land is used for roads, piping, and channels, translating to a total footprint of 112 acres for a given 100-acre module. Civil grading and overburden removal costs were based on consistent assumptions as employed in the 2-acre design, including grading from a 1\% starting slope, $15 \mathrm{~cm}$ (6 in) of surface vegetation and overburden removal, and land scarifying to $30 \mathrm{~cm}(1 \mathrm{ft})$ deep. Because the ponds are larger than their 2-acre counterparts, the berms and center dividers have a smaller total footprint in the 100-acre module. The smaller footprint of berms reduces the amount of cut and fill and total compaction for the facility. The height of the berm walls and the separation walls are the same as the 2 -acre case, at $61 \mathrm{~cm}(24 \mathrm{in})$ and $41 \mathrm{~cm}(16 \mathrm{in})$, respectively. The normal water depth for the 10-acre ponds is $25 \mathrm{~cm}$ (10 in). Paddlewheel supports and sump stations are again formed with concrete, with additional non-formed concrete used for underground piping stays. The ponds are lined in the same fashion as the Leidos 2 -acre pond case, namely, lining the pond turns but not pond bottoms. In addition, for the 10 -acre case the berm wall is also lined when the channels narrow from $30 \mathrm{~m}$ to $20 \mathrm{~m}$ and when the channels expand from $20 \mathrm{~m}$ to $30 \mathrm{~m}$ (for further erosion protection). The berm liner total footprint is $40 \mathrm{~m}^{2}$ per pond, with another $584 \mathrm{~m}^{2}$ per pond allotted for pond turns. In all, $1.5 \%$ of each Leidos 10 -acre pond is lined. Similar to the Leidos 2 -acre ponds, the 10 -acre ponds do not have turning vanes. For this and all pond designs, storm surge capacity has not been considered as a factor in setting berm heights or overall module configurations, and would be an important issue to investigate in the future (although this would also be highly location-specific depending on frequency and severity of storms).

For a 100-acre module there are also fewer paddlewheels needed in the Leidos 10-acre case compared to the 2-acre basis. For the 2-acre case, 44 paddlewheels are needed with 5,490 m of electrical wiring, whereas for the 10 -acre case, only 10 paddlewheels are needed with $2,888 \mathrm{~m}$ (including an extra 5\%) of 10 gauge-3 conductor wire. The paddlewheels are larger and therefore more expensive per unit for the 10 -acre case, but the lower total number of paddlewheels 
outweighs this effect and results in a lower net cost for paddlewheels in a 100-acre module. Piping layout inclusions are similar to the 2-acre case, where the ponds are fed from the main facility circulation manifold via a $712 \mathrm{~m}(2,335 \mathrm{ft}) 18$-inch pipe running in between the two columns. The ponds are again harvested by opening a slide gate and entering an 8 -inch pipe that runs $12 \mathrm{~m}$ to the main drain header. The drain header is 18 inches wide and $350 \mathrm{~m}$ long and runs to a drain channel, ultimately routed to primary settling. Harvest pumps are again added externally based on estimates generated from ACCE.

In addition to the two raceway pond designs described above, Leidos also considered an aspirational serpentine pond design. This design was more hypothetical in nature without supporting operational details from any currently constructed system to validate pond operability for this configuration (particularly at the assumed size), thus it is stressed that this design is primarily intended to serve as an illustrative scenario to further demonstrate economy of scale benefits that may be gained by moving beyond 10 -acre ponds, which would require moving away from a paddlewheel-based system (unless multiple paddlewheel stations were employed in a single pond which would mitigate economy of scale benefits for larger ponds). Each serpentine pond is 48.6 acres and two ponds cover a 100-acre module (illustrated in Figure 7). Each serpentine pond has 134 channels which are $3.7 \mathrm{~m}$ wide and $418 \mathrm{~m}$ long, with spacing included for access to each set of channels, additional berms, and precise grading. Serpentine ponds exploit the natural land slope to promote gravity circulation (maintaining the previous Leidos scenario assumptions of a $1 \%$ slope), with the channels designed to provide a 78 -hour residence time from the top to the bottom of the ponds at a $20 \mathrm{~cm} / \mathrm{s}$ velocity. Such a long single-pass residence time could pose a danger of becoming carbon or nutrient limited, and could require multiple points of $\mathrm{CO}_{2}$ and nutrient injection along the channel length (this was not considered here). Again, in this scenario, in-situ clay soil is specified with the use of partial plastic liners, in this case installed at the ends of each channel and on earthen weirs to control erosion. To ensure proper coverage an additional $0.6 \mathrm{~m}(2 \mathrm{ft})$ of liner extends beyond the weir and $15 \mathrm{~cm}(6 \mathrm{in})$ of liner is buried at the channel's bottom. Within a given 100-acre module, a total of $9,897 \mathrm{~m}^{2}$ of liner is used for the Leidos serpentine design, which is less than the 2-acre case at $10,252 \mathrm{~m}^{2}$ but greater than the 10 -acre case at $6,244 \mathrm{~m}^{2}$. Liner coverage for the Leidos serpentine design represents $2.4 \%$ of total pond area. The civil work includes removing $15 \mathrm{~cm}(6$ in) of overburden, scarifying down $30 \mathrm{~cm}$ (1 ft), compacting, cut and fill, and fine grading. Access roads and a piping footprint are included in the 100-acre modules, which translates to a total module footprint of 149 acres.

To maintain a specific velocity the serpentine ponds not only require a graded layout, but also make use of earthen weirs to control the medium height from one set of channels to the other. Every two channels make a set, and an earthen weir is placed in between two sets of channels. If variations exist in the grade of the pond then the weir heights can be varied to maintain desired culture depths. Additionally, weir heights could also be varied to optimize circulation and the water column to maximize light capture as cultures get denser. The medium flows from the highest elevation channel to the next channel, until it reaches the bottom channel at which point a portion of the flow is harvested and routed to primary settling (set by the seasonal productivity while maintaining the fixed $0.5 \mathrm{~g} / \mathrm{L}$ harvest density as stipulated above for the raceway pond scenarios). The medium that is not sent to settling is re-circulated back to the top channel by flowing into one of two water return pipes. With only two ponds to service per every 100 -acre module, the piping for a given module only requires two 12-inch PVC pipes each running 1,067 
$\mathrm{m}$. These pipelines also connect to the recirculation manifold from central dewatering. The 12inch pipes include a $7.3 \mathrm{~m}(24 \mathrm{ft})$ elevation gain from the bottom channel to the top with an additional $10 \%$ head loss included for fittings. As pumps were not included in the Leidos work scope, positive displacement pumps on the recirculation pipes were modeled separately in Aspen based on providing this required head, resulting in a circulation pumping power of $0.8 \mathrm{~kW} / \mathrm{acre}$ over a 24-hour day (when translated to a cultivation acre basis for consistency with other scenarios' circulation power estimates). The pond harvested fraction is assumed to feed directly into a drain channel, without requiring additional harvest pipes. Harvest pump costs were maintained consistently with the other pond scenarios, based on estimates generated from ACCE. The recycle pumps and pipelines were also based on estimates from ACCE, routing the fraction of the culture which is not harvested back to the top of the serpentine pond.

Relative to Leidos' 2 -acre and 10-acre raceway pond cases, the 50-acre serpentine pond design requires a larger footprint of channel separation walls. This translates into a larger cut and fill requirement, as well as compaction to create the channel walls. However, the penalty in civil work cost for this design is made up for in economies of scale given such a large area for a single pond, and the associated benefits in reduced equipment, electrical, and piping requirements. Namely, paddlewheels are not required, which also greatly reduces electrical and concrete demands (neither paddlewheel supports nor sumps are included in this design). Concrete is still used for underground piping stays, however with smaller total pipe distances in the 100-acre module, fewer stays are required. Compared to the $133 \mathrm{~m}$ of 12 -inch pipe included for the serpentine ponds, the Leidos 10 -acre pond design uses a total of 2,495 $\mathrm{m}$ of pipe. The lower total pipe distance for the serpentine case is attributed to the lower number of ponds and associated individual feed/harvest lines. Additionally, the 10-acre ponds have a total of $121 \mathrm{~m}$ of pipe leading to the drain channels whereas the two 50-acre serpentine ponds do not. Consequently, while this 50 -acre serpentine design is more speculative and raises questions as to the operability of such a large system, it does demonstrate economy of scale benefits that may be gained beyond even large paddlewheel systems attributed to low costs for circulation equipment, electrical, concrete, and piping, which outweigh additional liner and civil costs that this design incurs.

\section{MicroBio Pond Designs}

The comprehensive literature report published in 2010 by Lundquist et al. [17] considers the economics of a 100-hectare raceway pond system with 4-hectare (9.9-acre) individual ponds. The analysis, conducted by several co-authors who now make up the consulting company MicroBio Engineering, presented a thorough cost model for a number of algal production scenarios based on aggressive cost minimization measures justified by taking an approach to system design and costing more consistent with simplistic low-cost agricultural engineering practices than higher-cost industrial engineering approaches commonly assumed for most other algal processing analyses. This literature basis formed the baseline for the 2012 Algae Harmonization Model described previously [23]. For the present analysis, the coauthors of the Lundquist report were contacted to solicit additional details related to the original 4-ha (9.9 acre) pond system described in that report, as well as to provide a second cost estimate for a smaller design similar in size to the Leidos 2 -acre pond system, both of which were furnished to NREL in support of this report as the basis for the MicroBio scenarios.

The MicroBio 4-ha ("10-acre") pond design will not be discussed in detail in the present report as all design and cost details for this case are consistent with the information as originally 
presented in depth in the above-cited Lundquist report [17], but will be briefly summarized here. In short, the ponds are designed as a standard single-loop system with channel dimensions $30 \mathrm{~m}$ wide by $690 \mathrm{~m}$ long and $30 \mathrm{~cm}$ deep. Each pond has a paddlewheel mixer, sump with baffle, and gas diffuser. The paddlewheel mixer includes a motor and gearbox, and concrete is used for the sump station and paddlewheel support. At the point of paddlewheel mixing the pond channels are reduced from $30 \mathrm{~m}$ to $20 \mathrm{~m}$ (similar to the Leidos 10-acre pond design discussed above). The mixing velocity is $20-25 \mathrm{~cm} / \mathrm{s}$, and $2.0 \mathrm{~kW}$ of power per hectare of cultivation area is consumed by the paddlewheel as an average over the course of a 24-hour day (higher during daylight hours, and lower at night). This paddlewheel power was calculated from standard engineering equations to optimize for daytime versus nighttime mixing and channel velocity requirements, based on a paddlewheel motor and drive system efficiency of $40 \%$.

The MicroBio base case 10-acre design again stipulates minimally lined ponds, with a partial liner used this time only on the pond berms (a similar concept to the Leidos design although based on lining the berms of the straight channel sections rather than the pond turns as in the Leidos design). The liner cost for both of the MicroBio pond designs is $\$ 4.49 / \mathrm{m}^{2}$. For the 2 -acre pond, $25 \%$ of the pond is lined, which reduces to $24 \%$ for the 10 -acre pond. A fully lined pond was also estimated by MicroBio, which is considered as a sensitivity in Section 6.1. The land is assumed to contain in-situ clay such that again the pond bottom is left unlined aside from native soil compaction. For building the ponds, civil work includes excavation, trenching, compaction, and fine grading to build the berms $0.9 \mathrm{~m}$ high. Water piping to and from the ponds and a central point (dewatering) is included for a 100-hectare footprint in the original published report. We assume the same cost per acre for the water piping for each 100-acre module in the present design as was originally presented for a larger 247-acre (100-ha) facility. Costs for electrical runs and instrumentation were also presented in the original Lundquist report, which were further broken down to the portion allocated strictly to ponds for the present design, based on further discussions with the MicroBio engineers [25].

Beyond the published 10-acre design basis, MicroBio furnished an additional design scenario to NREL focused on smaller ponds closer to the 2-acre size considered by Leidos, specifically 1-ha (2.5-acre) ponds [25]. As in the Leidos case, the MicroBio "2-acre" ponds are similar in design to the larger 10-acre versions, based on paddlewheel-driven raceway ponds with sloped berms, concrete sumps and paddlewheel support stations, and plastic lining covering only the sloped berms (in-situ clay otherwise forming the pond bottoms). The 2-acre pond scenario was developed based on the same overall cultivation footprint for a 100-ha integrated facility as had been assumed in the published base case for 10-acre ponds, thus still includes considerations for feed/harvest and circulation piping as well as electrical requirements for a grouping of individual 2-acre ponds. Consistent with the MicroBio 10-acre case, we assume the resulting rolled-up dollar-per-acre costs furnished by MicroBio for all elements (ponds, civil, lining, piping, and electrical) remain the same between the 247 acre (100-ha) facility basis from MicroBio to the 100 -acre modules assumed in the present work.

Relative to the 10-acre design, the MicroBio 2-acre design maintains the same cost per acre for grading, but fourfold higher for excavation and trenching (i.e., this cost element linearly increases as pond size decreases). The smaller 2 -acre ponds require roughly $6 \%$ more plastic lining for pond berms, given the higher ratio of berm area to wetted cultivation area for smaller ponds. Electrical costs per acre increase by roughly threefold (similar to Leidos), while piping 
costs increase by roughly $20 \%$ (given the use of more piping runs to individual ponds, which are partially offset by smaller diameter pipes). The number of paddlewheels and motors increases linearly for the smaller ponds, but costs $60 \%$ less each, thus translating to roughly $60 \%$ higher cost per acre for these elements. Finally, concrete requirements increase substantially at roughly 4.3 times more total concrete required on a per-acre basis compared to the larger 10-acre ponds, dictated by a similar total concrete requirement between the two pond sizes. Paddlewheel circulation power demand is roughly $30 \%$ higher for the smaller ponds per unit cultivation area, at $2.6 \mathrm{~kW}$ per hectare over a 24 -hour day.

\section{Harris Pond Design}

Harris Group ("Harris") is another engineering firm with expertise in algal pond design, whose assistance was also solicited through a subcontract to provide design and cost estimates for raceway pond systems and other downstream processing equipment. Harris was instructed to provide independent cost estimates, based on their own vendors, for a paddlewheel raceway pond identical in dimensions and overall layout/design as the MicroBio 10-acre (4-ha) case discussed above and presented in Lundquist et al. [17]. As such, the Harris design assumes a base case with native in-situ clay and pond liners again limited to covering the straight channel berms, as well as concrete used for paddlewheel support and sump stations. The liner costs $\$ 4.49 / \mathrm{m}^{2}$ and covers $14 \%$ of the pond. A civil contractor provided Harris with the required civil work and associated costs including pond excavation, compaction, and grading; in this case, grading costs were low as the contractor assumed nearly flat land to start with. A second vendor provided Harris with estimates for concrete requirements/costs for the paddlewheel and sump stations, as well as water circulation piping. The water circulation piping was originally based on a level 10,000-acre (4,050-ha) overall facility; however, the large majority of the piping was attributed to pond feed/harvest and circulation lines, thus the present design maintains the same piping estimate on a dollar/acre basis to be applied strictly to the level 100-acre modules (with external circulation piping to and from central dewatering considered separately as consistent with the other pond scenarios and discussed in Section 4.4). Harris estimated the paddlewheel circulation power demand for the 10 -acre pond design at $2.4 \mathrm{~kW} /$ ha over a 24 -hour day, which falls between the estimates from MicroBio and Leidos for paddlewheel ponds of the same size.

One small deviation in the Harris design relative to the other pond scenarios described above is the inclusion of turning vanes at the ends of the ponds for the Harris case. However, because turning vanes are not included in the other raceway pond designs as they either are not expected to represent a significant cost (input from MicroBio) or otherwise are not anticipated to offer enough benefit to warrant their inclusion (input from Leidos), the turning vanes originally included in the Harris pond design were removed for this analysis to maintain consistency in projecting costs for similar pond designs. The turning vanes would add an additional $\$ 4,100 /$ acre to the cost of the Harris ponds, which would translate to $\$ 23 /$ ton in terms of resulting MBSP impacts. The Harris estimate did not include the cost for electrical equipment. Thus, electrical equipment for the Harris 10-acre ponds is added based on the Leidos 10 acre system design.

\section{Global Algae Innovations Pond Designs}

Global Algae Innovations Inc. (GAI) is a commercial developer and operator of an algal production and processing facility located in Kauai, Hawaii [60]. GAI takes a focused approach to process design based on engineering optimization, with a number of unique features including 
pond configuration, dewatering system, and $\mathrm{CO}_{2}$ injection. The GAI facility consists of open ponds of varying sizes up to a maximum of 3.2 acres, configured as a "hybrid" between raceway ponds (each pond consists of two channels separated by a center divider) and serpentine gravityflow ponds (the channels are continuously sloped to induce circulation by gravity). Starting at one end of the pond, channels are continuously sloped over a gradual grade of roughly $0.1 \%$, turning back at the far end and continuing down over a similar graded slope in the second channel. Culture movement is imparted by gravity flow following the graded channel slope. Rather than paddlewheel stations on one end of the pond, circulation is provided by pumping from the lower to the upper channel. GAI provided NREL with design and cost details for this pond configuration over a range of sizes, ranging from a minimum of 10 acres for envisioned commercial-scale operation up to a maximum of 200 acres which GAI views as still being plausible given the gravity-assisted design, where larger pond sizes of 50 acres or more would likely include a circulation pump on both ends of the pond to assist in circulation over large distances [61]. For purposes of consideration in the present analysis, we selected the 10-acre and 50 -acre designs for incorporation into the TEA models.

In addition to typical economy of scale benefits enabled by larger pond sizes of 10 acres or more (i.e., lower costs for piping, electrical runs, and circulation equipment needed on each individual pond as documented above for the Leidos and MicroBio paddlewheel designs), the GAI pond design brings a number of additional benefits beyond standard paddlewheel-driven raceway ponds. This includes replacing low-efficiency paddlewheels with pumps, including associated concrete supports, as well as avoiding the use of concrete sumps as are typically included in most pond designs (including all paddlewheel scenarios described above). In contrast to flat paddlewheel ponds, which typically include sumps both to provide a low point in the pond for harvesting and to allow for $\mathrm{CO}_{2}$ gas sparging, the GAI design already includes a "low point" at the lowest elevation near the circulation pump (to which harvesting pipelines also may be connected), and avoids $\mathrm{CO}_{2}$ delivery to individual ponds by instead injecting $\mathrm{CO}_{2}$ into closed carbonation stations located on water circulation manifolds. For the GAI pond designs considered here, $\mathrm{CO}_{2}$ was similarly assumed to be injected into the pumped recirculation pipeline between the bottom and top channels of the pond. Culture circulation is accomplished at GAI with the use of aqueducts, which have the potential to reduce circulation costs relative to pipelines; but at a quoted price of $\$ 5,000$ /acre representing costs for both harvest and feed circulation lines [61], the resulting costs for circulation aqueducts within a given 100-acre module are similar for the GAI 10-acre scenario as standard pipeline costs quoted by the other pond scenario sources discussed previously.

Circulation pumping power demand for the GAI pond design is on average approximately 0.75 $\mathrm{kW} /$ acre $(1.9 \mathrm{~kW} / \mathrm{ha})$, estimated to be equally applicable to both the 10 - and 50-acre sizes; this is comparable to the low range of paddlewheel power consumption estimates discussed above (for example the MicroBio 10-acre pond at $2.0 \mathrm{~kW} / \mathrm{ha}$ ). Pumping is done using low-shear axial flow pumps. The GAI facility shuts circulation down at night (which would result in considerable energy savings compared to other pond scenarios, at $9 \mathrm{kWh} /$ acre over a 24 -hour day or 22 $\mathrm{kWh} / \mathrm{ha} /$ day) and indicated that this protocol does not detrimentally impact culture stability or productivity; however, for incorporation into the present TEA model framework which assumes continuous 24-hour harvesting as noted previously, the original basis of $0.75 \mathrm{~kW} /$ acre was maintained over a 24-hour day. The currently operating GAI ponds are fully lined, and GAI indicated that in the near term they continue to plan for fully lined ponds. However, there is no 
fundamental reason why the ponds must be lined (assuming that suitable soil with in-situ clay is present); thus, to enable consistent comparison against all other pond scenarios that stipulate minimal liners only where necessary to control erosion, for the present assessment the GAIfurnished pond liner costs were reduced by assuming the same fraction for partial versus full liner areal coverage as provided by Leidos for their 10-acre pond design. Thus, both the 10- and 50-acre GAI pond scenarios assume the presence of in-situ clay soil with minimal use of plastic liners (with dollar-per-acre partial liner costs applying equally to 10 - or 50-acre ponds), while fully lined ponds are considered in the sensitivity analysis shown in Section 6.1. The liner cost for the 10 - and 50 -acre cases is $\$ 7.11 / \mathrm{m}^{2}$, with liners covering $1.5 \%$ of total pond area for both cases. Finally, civil costs were provided by GAI, in this case estimated to scale linearly by pond size, and corresponded to similar values furnished for other pond scenarios. Remaining pond equipment costs were also provided, which primarily include circulation pumps and electrical costs rolled together; these costs were estimated as roughly twofold higher per individual pond for the 50 -acre pond design relative to the 10-acre basis. A smaller per-acre pumping cost for the 50 -acre design is a function of the fact that the primary points for head loss and therefore pumping demands occur at pond turns, which become a smaller fraction of overall pond volume as ponds get larger.

\subsubsection{Cost Estimation}

Table 4 shows the capital costs attributed to a 100-acre module for each of the eight pond designs, as furnished by Leidos, MicroBio, Harris, and GAI. Based on inputs from each of these sources, the module costs are broken down into five categories wherever possible: civil work, liner costs, piping, electrical, and other pond costs. The civil category incorporates all costs associated with land preparation and grading, such as overburden removal, scarifying, compaction, etc. The liner category represents the cost of a partial plastic liner either on the pond berm or pond turns (specific to the given design). Piping includes pond harvest, feed, and circulation piping located within the 100 -acre module as well as harvest pumps (costed in ACCE and applied consistently to all scenarios) to move the medium from pond harvest headers to primary in-ground settling. The electrical category accounts for the electrical runs to individual ponds and associated instrumentation. Finally, "other pond costs" account for remaining pond equipment and other cost elements, primarily paddlewheels or circulation pumps (in the case of GAI and Leidos serpentine ponds), motors, and concrete (for paddlewheel supports and sumps where applicable). In some cases, cost breakouts into the respective categories are imperfect as some or all of the cost for a given element is accounted for elsewhere, thus the primary value of note is the total summation of all cost elements. All costs presented here are indexed to 2011 dollars, as discussed in Section 5.1. Beyond capital equipment costs, other costs including labor, variable expenses, and land, are discussed later in Sections 5.2-5.4. Additional design and cost details for the Leidos pond cases (which were provided to NREL in the highest level of detail and thus warrant presenting this additional detail here) may be seen in Appendix B. 
Table 4. Pond Cost Details for all Designs Considered in TEA Model, Attributed to a Single 100Acre Module

\begin{tabular}{|c|c|c|c|c|c|c|c|c|}
\hline \multirow[b]{2}{*}{$\begin{array}{c}\text { Pond } \\
\text { Design a }\end{array}$} & \multirow{2}{*}{$\begin{array}{l}\text { Pond } \\
\text { Size } \\
\text { (acres) }\end{array}$} & \multirow{2}{*}{$\begin{array}{c}\text { Circulation } \\
\text { Power } \\
\text { (kWh/ } \\
\text { ha/day) }\end{array}$} & \multicolumn{6}{|c|}{ Installed Capital Cost, $\$ / 100$-acre module (2011\$) } \\
\hline & & & Civil & $\begin{array}{l}\text { Other Pond } \\
\text { Costs }\end{array}$ & Liner & Piping & Electrical & Total \\
\hline Leidos $R$ & 2.2 & 75.5 & $\$ 1,170,000$ & $\$ 2,490,000$ & $\$ 70,000$ & $\$ 1,430,000$ & $\$ 430,000$ & $\$ 5,590,000$ \\
\hline MicroBio & 2.5 & 63.0 & $\$ 420,000$ & $\$ 1,640,000$ & $\$ 450,000$ & $\$ 890,000$ & $\$ 870,000$ & $\$ 4,270,000$ \\
\hline Leidos $R$ & 10 & 70.0 & $\$ 1,110,000$ & $\$ 980,000$ & $\$ 40,000$ & $\$ 830,000$ & $\$ 140,000$ & $\$ 3,100,000$ \\
\hline MicroBio & 9.9 & 48.0 & $\$ 220,000$ & $\$ 720,000$ & $\$ 430,000$ & $\$ 820,000$ & $\$ 290,000$ & $\$ 2,480,000$ \\
\hline Harris & 9.9 & 58.2 & $\$ 800,000$ & $\$ 1,980,000$ & $\$ 250,000$ & $\$ 1,000,000$ & $\$ 140,000^{d}$ & $\$ 4,170,000$ \\
\hline GAI & 10 & 44.0 & $\$ 910,000$ & $\$ 1,160,000^{b}$ & $\$ 40,000^{c}$ & $\$ 800,000$ & $\mathrm{INCL}^{\mathrm{b}}$ & $\$ 2,910,000$ \\
\hline Leidos $S$ & 48.6 & 41.5 & $\$ 1,310,000$ & $\$ 140,000$ & $\$ 70,000$ & $\$ 700,000$ & Negligible & $\$ 2,220,000$ \\
\hline GAI & 50 & 44.0 & $\$ 910,000$ & $\$ 470,000^{b}$ & $\$ 40,000^{c}$ & $\$ 330,000$ & $\mathrm{INCL}^{\mathrm{b}}$ & $\$ 1,720,000$ \\
\hline
\end{tabular}

a Letter designations for Leidos designs: $R$ = raceway, $S$ = serpentine.

b Electrical included with "other pond costs" for GAI system.

c Original GAl costs were for full pond liners; adjusted here for in-situ clay with partial liners based on the ratio for partial versus full liner coverage for Leidos 10 -acre ponds.

${ }^{d}$ Based on Leidos electrical cost for a 10-acre pond (Harris electrical costs were outside design scope).

A number of clarifying details are warranted with respect to the values presented in Table 4. First, although self-explanatory, the costs are shown here for a grouping of the given number of ponds and supporting equipment that make up an individual 100-acre module considered in the integrated facility process, rather than costs for a single pond. This is presented this way given the inclusion of piping and electrical, whose costs are more appropriate to present for the full 100 -acre module than attributed to a single pond of varying size. Additionally, of all scenarios shown in Table 4 the only one published previously is for the MicroBio 10-acre pond design; however, costs shown here, even when divided by 10 for a single 10-acre (4-ha) pond, do not match up exactly with the published values for this scenario [17]. This is due both to cost indexing from 2009 to 2011 dollars, as well as removal of roughly $12 \%$ of the originally published MicroBio pond cost, which was confirmed with the co-authors to represent inclusion of inoculum system costs, which are considered separately in the present analysis (see Section 4.2). Similarly, the circulation piping and electrical costs shown in Table 4 are lower on a peracre basis than the originally published values for the MicroBio 10-acre pond, as they represent strictly the portion of those elements attributed to cultivation ponds rather than the overall processing facility. Next, the Harris 10-acre pond design did not originally include considerations for electrical, which were excluded from the subcontract design scope. Thus, to include an allowance for electrical costs in the Harris case, the same cost was applied as the Leidos 10-acre pond design. Finally, as noted previously, GAI supplied costs for only a fully lined pond; therefore to maintain consistency, the fully lined cost was adjusted by scaling by the ratio of partial versus full pond liner coverage as estimated by Leidos for the 10-acre pond design. Also as noted previously, the GAI "piping" costs primarily consist of aqueducts and channels for circulation within the 100 -acre modules.

As can be seen from Table 4 there are two ranges of liner costs: (1) $\$ 40,000-\$ 70,000 / 100$ acres and (2) $\$ 250,000-\$ 450,000 / 100$ acres. The distinction between these ranges is attributable to the assumption of where on the pond plastic liner coverage is required. The lower cost range is associated with the Leidos and GAI designs (when scaling GAI full liner costs to a partial liner scenario) only stipulating lining pond turns, which are a substantially smaller fraction of the 
pond area than the straight channel berms as assumed for the MicroBio and Harris designs (roughly $2 \%$ of total pond area for designs that line pond turns versus up to $25 \%$ for lining straight channel berms). In addition to the categorized pond cost, Table 4 also shows the circulation power demand for each scenario. For the paddlewheel ponds, the MicroBio designs tend toward lower circulation power while Leidos power estimates are on the high side for a given pond size; a key contributor to these differences is likely the paddlewheel efficiency, at $40 \%$ for the MicroBio designs and 10\% for the Leidos designs. Paddlewheel power demand tends to decrease per cultivation area as pond size increases (between 2 and 10 acres); however, it could be argued that the 10-acre cases are more speculative as a pond of this size has not been constructed to validate optimal circulation demands, whereas the 2-acre cases are consistent with currently operating ponds of this size. Moving beyond paddlewheel designs, circulation power demands further decrease for systems that make use of pumps instead of paddlewheels, including both the GAI and Leidos serpentine design. However, while the GAI circulation pumping power demand is consistent with real-world operating data for a 3-acre pond, the larger 10- and 50-acre GAI ponds, as well as the Leidos 50-acre serpentine pond, are more speculative and will depend strongly on onsite grading conditions and circulation rates.

The cost breakouts from Table 4 are shown graphically in Figure 8, translated to a per-wettedacre basis for ease of comparison against Figure 5 (Section 3). To further demonstrate cost alignment based on pond size, two additional data points were added to Figure 8 based on literature for currently operating "small" ponds slightly larger than 2 acres; these include a 2.5acre pond published by Beal et al. [10] and a 3.1-acre pond published by Craggs et al. [47] (again indexed here to 2011 dollars for consistency with the other cases). Although these additional sources also represent realistic cost projections, they were not considered in the present TEA model for implications on MBSP. While the Craggs design is based on marginally lined raceway ponds consistent with the other scenarios described above, the Beal design as published was for a fully lined pond. To estimate the cost for a similar pond with only minimal lining, the original Beal cost was scaled according to partially lined versus fully lined pond costs based on the Leidos 2-acre pond case, with the resulting allocated costs for liners and "other pond costs" combined together. As noted previously, the GAI pond cost allocations combine electrical and "other pond costs" together as well. For the majority of pond cases shown in Figure 8, the combination of civil and "other pond costs" (typically circulation device, motor, and concrete) represent the largest contributors ( $>50 \%$ of total cost) with the exception of the Beal 2.5 -acre case (37\% contribution), and the MicroBio 10-acre case (38\% contribution). For these two cases, piping represents the largest cost driver, which is still a significant contributor for the other cases as well. Liner and electrical costs are the least significant cost drivers for all ponds, specific to the use of minimally lined ponds (fully lined pond costs are explored in Section 6.1).

While the allocated pond cost details are insightful, the primary point to emphasize is that ponds are, in fact, seen to cluster reasonably well as a function of pond size when categorized into small (2-acre), medium (10-acre), or large (50-acre) ponds, consistently demonstrating economy of scale benefits for moving toward increasingly large ponds. This point is delineated more clearly in Figure 9, which presents the rolled-up overall pond costs per wetted cultivation acre, categorized into the three size classifications. Total installed costs range from $\$ 43 \mathrm{k}-\$ 56 \mathrm{k} /$ acre (\$48k/acre average) for small 2- to 3-acre pond designs, from $\$ 25 k-\$ 42 k /$ acre $(\$ 32 k /$ acre average) for medium 10 -acre designs, and from $\$ 17 k-\$ 22 k / a c r e(\$ 19 k / a c r e$ average) for large 50-acre designs. 


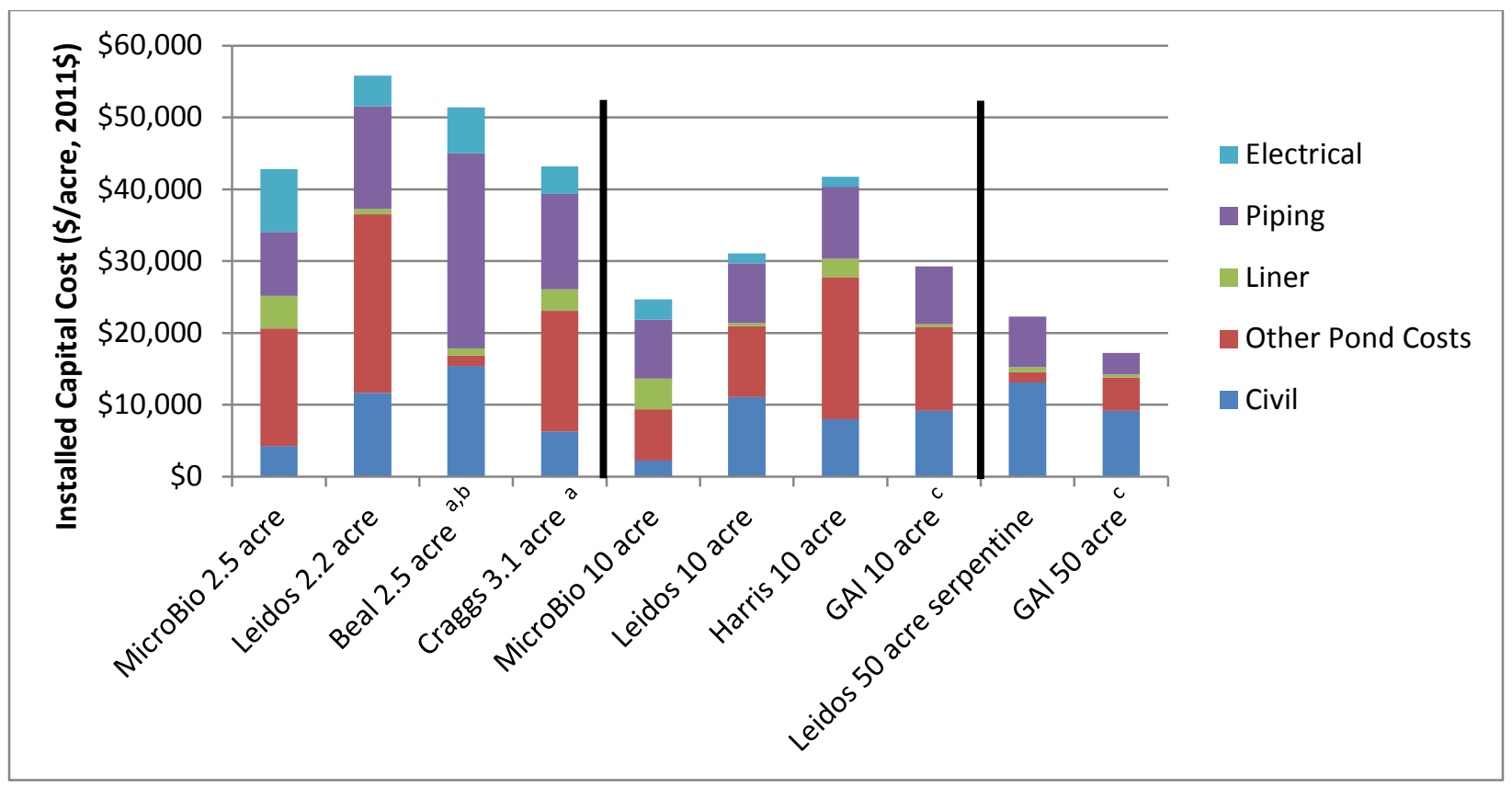

Figure 8. Capital cost details for all eight pond design scenarios considered in TEA model, plus two additional values from literature for comparison

a Additional data points were not modeled in the present design report but were added to this plot to further demonstrate cost alignment by pond size.

$\mathrm{b}$ The installed cost shown here for the Beal design estimates the cost for a minimally lined pond scenario compared to the original cost for this case which assumed a fully lined pond [10]. If a fully lined pond were used for the Beal case, total installed cost would be $\$ 114,000 / a c r e$.

" GAl cases include electrical costs under "other pond costs".

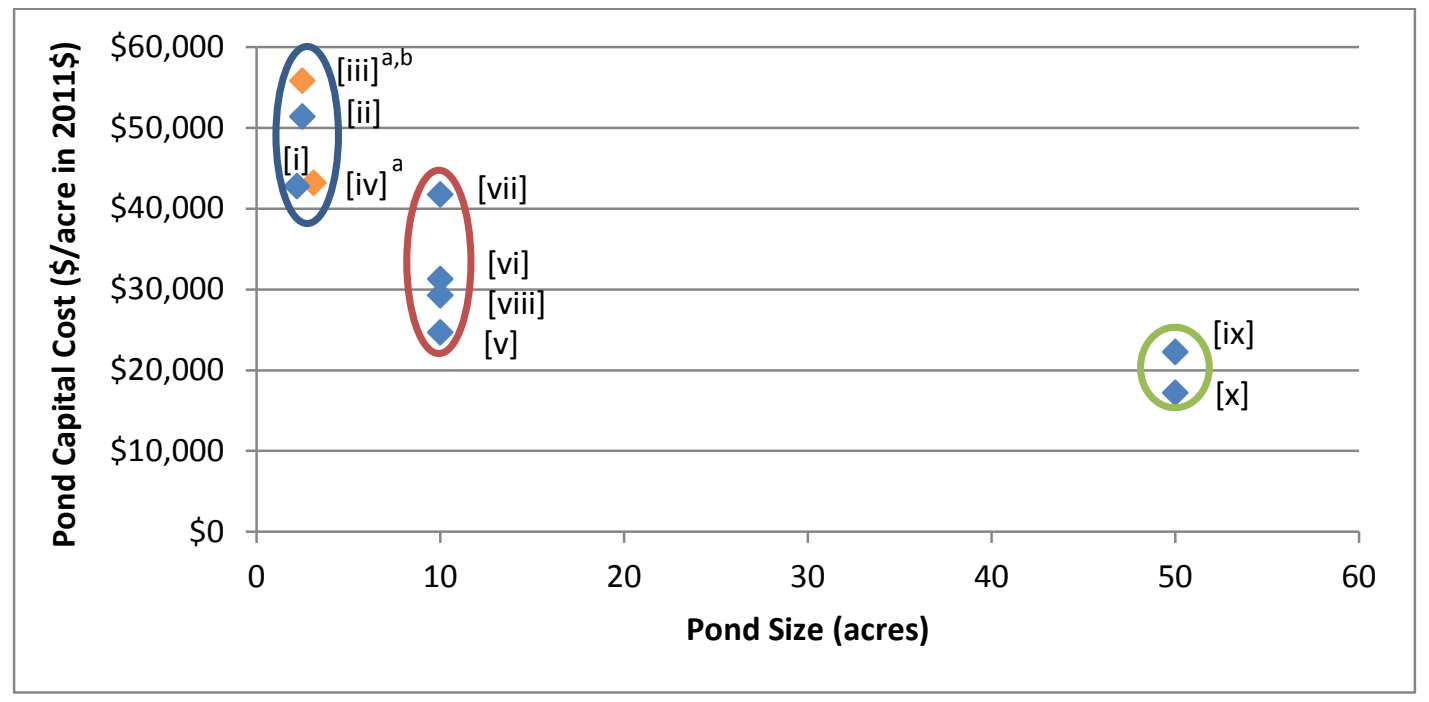

Figure 9. Overall installed pond system capital costs categorized by size groupings

a Additional data points were not modeled in the present design report but were added to this plot to further demonstrate cost alignment by pond size (shown in orange).

b The installed cost shown here for the Beal design estimates the cost for a minimally lined pond scenario compared to the original cost for this case which assumed a fully lined pond [10].

c Legend for numerals: [i] MicroBio 2.5-acre pond, [ii] Leidos 2.2-acre pond, [iii] Beal et al. 2.5-acre pond [10], [iv] Craggs 3.1-acre pond [47], [v] MicroBio 10-acre pond, [vi] Leidos 10-acre pond, [vii] Harris 10-acre pond, [viii] GAI 10-acre pond, ${ }^{[i x]}$ Leidos 50 -acre pond, and ${ }^{[x]}$ GAI 50 -acre pond. 


\subsection{Area 200: Inoculum System}

\subsubsection{Overview}

The inoculum system produces algae starter cultures used to re-inoculate the production ponds. Production ponds can require re-inoculation after scheduled pond downtime, culture crashes, and other events that require the pond to be drained and restarted with new culture, although under normal facility operation, ponds are envisioned to operate continuously, thus negating the need for large inoculum systems designed for continuous re-inoculation, e.g., daily or weekly. Culture crashes can be caused by a variety of weather and pest/predator/pathogen-related events, such as freezing in the winter or incursion by invasive species. Similar to other envisioned commercial designs, inoculum propagation occurs over a series of increasingly larger cultivation steps beginning in closed photobioreactors and moving to small ponds $[17,43]$. Following the concepts proposed by Lundquist et al. and Huntley et al., a closed PBR is used as the first stage of inoculum grow-out, followed by covered (enclosed) ponds of a significantly larger cultivation footprint than the PBRs, and then lined open ponds with a larger footprint than the covered pond stage $[17,43]$. Figure 10 provides a simplified schematic of the inoculum system.

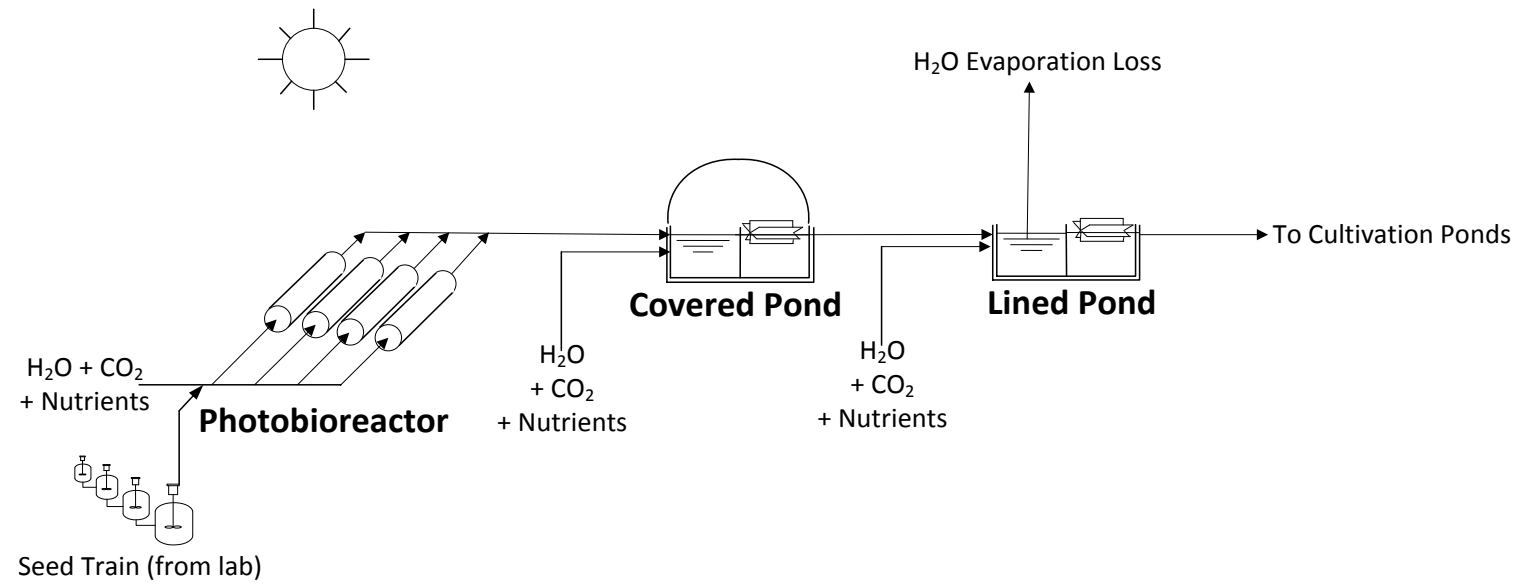

Figure 10. Simplified schematic diagram of the inoculum production system

\subsubsection{Design Basis}

The on-site inoculation system covers a separate area beyond the 5,000 wetted acres dedicated to the main production ponds. Area 200 is sized by assuming that any given cultivation pond must be re-inoculated on average every 20 days during peak summertime production, meaning that $5 \%$ of the cultivation ponds in the facility are re-inoculated any one day (primarily to recover from contamination events). Based on this frequency, the inoculum system is sized to target an initial algae concentration of $0.1 \mathrm{~g} / \mathrm{L} \mathrm{AFDW}$ in the main cultivation ponds. Table 5 provides a summary of the key assumptions used to set the design for each stage of the inoculum system. As shown in Table 5, the areal productivity of the PBRs, covered ponds, and lined ponds are set to match the seasonal productivity of the main cultivation ponds shown in Table 3 of Section 4.1.2. 
Table 5. Design Parameters for Each Stage of the Inoculum System

\begin{tabular}{|c|c|c|c|c|c|}
\hline Parameter & Units & PBR & $\begin{array}{l}\text { Covered } \\
\text { Pond }\end{array}$ & $\begin{array}{l}\text { Lined } \\
\text { Pond }\end{array}$ & Total \\
\hline Annual Average Productivity & $\mathrm{g} / \mathrm{m}^{2} /$ day & 25 & 25 & 25 & - \\
\hline Initial Concentration & $\mathrm{g} / \mathrm{L}$ & 0.1 & 0.1 & 0.1 & - \\
\hline Harvest Concentration & $g / L$ & 1.5 & 0.5 & 0.5 & - \\
\hline Areal Footprint Coverage & acres & $8.7^{a}$ & 23 & 116 & 147.7 \\
\hline $\begin{array}{l}\text { Area Coverage Percent of Total } \\
\text { Biomass Cultivation Area }\end{array}$ & $\%$ & $0.2 \%$ & $0.5 \%$ & $2.3 \%$ & $3.0 \%$ \\
\hline Work for Blowers and Mixing & kW/acre & $3.9^{b}$ & $1.3^{c}$ & $1.3^{c}$ & - \\
\hline Heat Removed by Chillers & GJ/day & 83.4 & 333.7 & - & 417.1 \\
\hline
\end{tabular}

The design of the PBR is based on the PBR system described in detail by Beal et al. and Huntley et al. $[10,43]$. This PBR design has been developed for commercial application and is of the horizontal tubular variety with airlift driven mixing [43]. It has a higher volume-to-area ratio than other typical tubular PBR systems due to its large diameter $(0.38 \mathrm{~m})[7,43,62,63]$. The design has $250 \mathrm{~m}^{2}$ of lit area and a total areal footprint of $371 \mathrm{~m}^{2}$ for every $50 \mathrm{~m}^{3}$ cultivation volume. The PBR design from Beal was originally based on a $50 \%$ harvest, whereas this process assumes a much smaller daily harvest of 5\%. Although Beal et al. set forth a baseline productivity of $24 \mathrm{~g} / \mathrm{m}^{2} /$ day for the PBR system based on commercial performance achieved in Hawaii, the PBR here is instead sized based off of this design report's summer productivity target of $35 \mathrm{~g} / \mathrm{m}^{2} /$ day (Table 3). Accordingly, the volumetric productivity of the PBR for this design report is $0.2 \mathrm{~g} / \mathrm{L} /$ day in the summer (based on cultivation area).

Both the covered and lined ponds are designed based off of the Leidos 2-acre pond design described previously. Briefly, the pond design includes civil work, paddlewheel equipment, electrical and instrumentation equipment, concrete, and water piping. $\mathrm{CO}_{2}$ piping was determined separately, and it is accounted for in the total $\mathrm{CO}_{2}$ distribution cost for the facility. Additionally, both the covered ponds and the open lined ponds are fully lined with a 40-mil geomembrane. One fully lined 2 -acre pond requires $44,266 \mathrm{~m}^{2}$ of the liner. The covered pond also is enclosed by a plastic hoop air-supported greenhouse [17].

Because of the enclosed design of the PBRs and covered ponds, it is assumed that no $\mathrm{CO}_{2}$ is lost to outgassing in either of these stages. Ten percent of the $\mathrm{CO}_{2}$ pumped into the open lined ponds is assumed lost due to outgassing. Additionally, water evaporation only occurs in the open lined ponds, matching the seasonal pan evaporation rate for the main production ponds shown previously in Table 3. With no water evaporation to help regulate the temperature of the two enclosed systems, a chiller is used to remove heat accumulated in these systems. The amount of solar irradiation absorbed as heat is calculated based on the information provided by Bosma et al. and Bechet et al. $[63,64]$, assuming that these closed systems will absorb similar irradiation on an areal basis as the tubular PBR described by Bosma. It is assumed that the PBR and closed pond absorb $14.4 \mathrm{GJ} /$ acre/day of heat with total footprint coverage of 29 acres (lit cultivation area). Table 5 shows the assumed heat absorbed by the PBRs and covered ponds, which must then be removed using the chiller system. In total, $417 \mathrm{GJ} /$ day of heat is removed for the entire system. This translates to $0.08 \mathrm{GJ} /$ acre/day for the 5,000 acre cultivation area, and is a minimal cost of 
less than $1 \%$ of the total facility. Cooling demands may be reduced or eliminated depending on the specific species and the location of the facility. Nutrients are supplied to each step of the inoculum system assuming the same demands for $120 \%$ of stoichiometric minima based on biomass elemental composition as described previously for the main production ponds.

Paddlewheel mixing occurs both in the covered pond and the lined pond. Based on the Leidos 2acre pond design, the paddlewheel power demand is assumed at $31.2 \mathrm{kWh} /$ acre/day for both the covered and open lined ponds. The PBR uses an airlift system for mixing with a power demand of $93.6 \mathrm{kWh} /$ acre/day [10]. Table 5 shows the power demand for each inoculum stage.

\subsubsection{Cost Estimation}

As with the design of the PBR, the cost of the PBR system is also based on Beal et al. at $\$ 18.22 / \mathrm{m}^{2}$ for the Gulf Coast [10]. The costs for both the covered and open lined ponds are based on the 2-acre pond design quoted by Leidos. Leidos' quote includes civil work (i.e., clear and grub, strip and stockpile the overburden, scarify, compaction, cut and fill, and fine grade), the paddlewheel, electrical instrumentation, concrete, and water piping. However, in this case, the "marginally lined" designs providing only berm liner coverage were not assumed as were stipulated for the main production ponds, as both inoculum pond stages are fully lined. The installed cost for the inoculum pond stages, excluding lining and pond coverings is $\$ 53,656$ /acre of cultivation area. The installed cost for lining adds an additional $\$ 30,626$ / acre of cultivation area, based on the Leidos estimate for a fully lined 2-acre pond. For the covered pond stage, an air-supported plastic hoop greenhouse was assumed based on cost estimations from Lundquist et al., at $\$ 142,115 /$ acre of cultivation area [17]. Table 6 provides the inoculum areal coverage, installed cost per acre of wetted cultivation area, and the total installed cost for the present design model. Finally, as noted above there is a small utility requirement for chiller cooling on the PBR and covered pond stages. Recognizing that in reality this "front-end" portion of the facility would likely be integrated with "back-end" conversion operations on site (which typically have inclusions for utility cooling and heating systems), as well as the fact that the chiller duty requirement is marginal given such a small inoculum footprint relative to the total facility, the required chilled water is costed here as a material operating cost rather than constructing a chiller system; the associated utility price for chilled water was set at $\$ 5 / \mathrm{GJ}[65]$.

Table 6. Inoculum System Capital Costs and Areal Coverage

\begin{tabular}{lccc}
\hline \multicolumn{1}{c}{ Stage of Inoculum } & $\begin{array}{c}\text { Areal Coverage for } \\
\text { Inoculum Stage (acres) }\end{array}$ & $\begin{array}{c}\text { Installed Cost } \\
(\$ / \text { acre of cultivation area) }\end{array}$ & $\begin{array}{c}\text { Installed Cost } \\
(\$ M M ; 2011 \$)\end{array}$ \\
\hline 1 - Photobioreactor & 5.8 & $\$ 109,000$ & $\$ 0.65$ \\
2 - Covered Pond & 23 & $\$ 233,000$ & $\$ 5.41$ \\
$3-$ Open Lined Pond & 116 & $\$ 87,000$ & $\$ 10.06$ \\
\hline Total & 144.8 & NA (varies by stage) & $\$ 16.12$ \\
\hline
\end{tabular}




\subsection{Area 300: $\mathrm{CO}_{2}$ Delivery}

\subsubsection{Overview}

This section describes the assumptions related to $\mathrm{CO} 2$ delivery to the site, storage, and injection to the culture media. It is well established that in order to promote high biomass growth rates required to achieve economical production of commodity fuel products, supplemental $\mathrm{CO} 2$ must be delivered to the cultivation system beyond merely relying on $\mathrm{CO} 2$ transfer from ambient air $[66,67]$. The two primary means of providing $\mathrm{CO} 2$ to algal systems are either via bulk flue gas transported and sparged into ponds at low pressure, or concentrated $\mathrm{CO} 2$ captured and purified out of flue gas, and transported and delivered to the facility under high pressure. In either case, the flue gas is primarily envisioned to be sourced from a coal- or natural gas-fired power plant, though other opportunities exist for co-location with ethanol plants, ammonia plants, or other (non-fossil) CO2 sources. While prior harmonization modeling activities focused on transport and delivery of bulk flue gas via low-pressure pipeline transport [23,42], this option requires a significant number of assumptions related to specific facility siting, layout, proximity to the power plant, flue gas rate and composition, etc., which tend to introduce subjectivity and a higher degree of uncertainty in the expected cost of delivered $\mathrm{CO} 2$. Instead, for the base case considered in this report, we focus on purified $\mathrm{CO} 2$ from flue gas carbon capture (i.e. amine scrubbing, membrane purification, etc. which may be expected to provide $\mathrm{CO} 2$ at $>99 \%$ purity), which reduces uncertainty by treating $\mathrm{CO} 2$ as a material operating expense with substantial literature documentation for appropriate pricing. The alternative of low-pressure flue gas transport and delivery is considered as an alternative sensitivity scenario in Section 6.1. Under the purified $\mathrm{CO} 2$ base case scenario, $\mathrm{CO} 2$ is delivered to the facility under high pressure, stored in spherical storage tanks, and distributed and sparged into individual ponds during daylight hours.

\subsubsection{Design Basis}

Similar to nutrient requirements discussed previously, the $\mathrm{CO}_{2}$ demand for the facility is determined by the algal biomass carbon content at harvest, set to $54 \mathrm{wt} \% \mathrm{C}$ for the base case strain on an AFDW basis as shown in Table 2. The $\mathrm{CO}_{2}$ demand is further weighted by a $90 \%$ culture utilization factor, which accounts for a $10 \%$ outgassing loss consistent with observed losses of pure $\mathrm{CO}_{2}$ in sparged sumps [22,68]. In contrast, $\mathrm{CO}_{2}$ outgassing losses are typically higher at $15 \%-25 \%$ for sparging low-pressure bulk flue gas (with significant levels of nitrogen) directly into pond sumps $[69,70]$, which is one of several logistical challenges attributed to a low-pressure flue gas scenario, in addition to another major challenge being the use of very large ductwork networks routed to numerous locations spread over such a large facility footprint. As $\mathrm{CO}_{2}$ is only delivered to the culture during the daylight, the $\mathrm{CO}_{2}$ storage and pond distribution systems are designed to deliver the total daily demand (based on peak summertime daily biomass productivity) in 12 hours, assuming a consistent $\mathrm{CO}_{2}$ uptake efficiency.

In the base case design, pure $\mathrm{CO}_{2}$ enters the plant via pipeline and is stored in a pressurized storage sphere. Typical pipeline $\mathrm{CO}_{2}$ conditions for purified $\mathrm{CO}_{2}$ from carbon capture operations are supercritical at $130 \mathrm{bar}$ and $40^{\circ} \mathrm{C}$, thus this is the assumed condition for $\mathrm{CO}_{2}$ entering the facility; $\mathrm{CO}_{2}$ pipeline transport does not necessarily have to be under supercritical conditions, but could also be lower pressure as long as the $\mathrm{CO}_{2}$ is high purity. The incoming $\mathrm{CO}_{2}$ is throttled to $50 \mathrm{psig}$ (4.4 bar) for storage as a liquid. Electric immersion heaters in the sphere slowly vaporize the liquid $\mathrm{CO}_{2}$ to maintain pressure in the tank. $\mathrm{CO}_{2}$ for the facility is then taken from the vapor 
space and distributed under moderate pressure. The storage sphere is sized with a $45-\mathrm{ft}$ diameter, enough to hold one day (12 hours) of $\mathrm{CO}_{2}$ demand for the entire facility. The sphere is constructed from carbon steel that has been Charpy impact-tested for cold performance.

The on-site $\mathrm{CO}_{2}$ piping network consists of a 20 inch trunk line from the sphere to the opposite end of the facility. The trunk line supplies 12 inch branch lines running down the aisles between 100 -acre module plots (see Figure 4), which reduce to 8 inch midway. Within each module, a network of 3 inch piping delivers the $\mathrm{CO}_{2}$ to the sumps in individual ponds. All piping was designed as HDPE to reduce capital costs. With sufficient thickness, HDPE pipe can have pressure ratings up to several hundred psig; the current design pressure is 75 psig. HDPE is suitable for carrying gaseous $\mathrm{CO}_{2}$ though it should be noted that liquid $\mathrm{CO}_{2}$ must be transported in steel for safety reasons. If liquid $\mathrm{CO}_{2}$ is exposed to atmospheric conditions, it will form dry ice at $-79^{\circ} \mathrm{C}$, which is lower than the minimum allowable temperature for $\operatorname{HDPE}\left(-50^{\circ} \mathrm{C}\right)$.

\subsubsection{Cost Estimation}

The existing $\mathrm{CO}_{2}$ commodity market supplies gaseous $\mathrm{CO}_{2}$ in large amounts for use in enhanced oil recovery (EOR). The majority of currently available $\mathrm{CO}_{2}$ for industrial use is sourced from naturally occurring $\mathrm{CO}_{2}$ reservoirs, ammonia production plants, and ethanol production plants. The availability of $\mathrm{CO}_{2}$ and ease of transportation is heavily dependent on locality; multiple pipelines serve the Permian basin and Gulf Coast in response to the extensive EOR operations in those areas, and proximity to the ethanol industry provides an abundant $\mathrm{CO}_{2}$ source to the Midwest region [71]. Although the production facility assumed here (which is not tied to a specific single location but is modeled based on leveraging work from prior harmonization efforts that focused on the Gulf Coast region) may have an opportunity to tap into existing $\mathrm{CO}_{2}$ pipeline infrastructure, e.g., dedicated EOR operations, many such algal facilities likely would not be able to rely on existing $\mathrm{CO}_{2}$ resources, and more importantly making use of EOR $\mathrm{CO}_{2}$ from underground reservoirs would ultimately constitute a fossil $\mathrm{CO}_{2}$ emissions pathway once combusted as fuel (in contrast to $\mathrm{CO}_{2}$ from power plant flue gas emissions which represents $\mathrm{CO}_{2}$ recycling and does not release new $\mathrm{CO}_{2}$ to the atmosphere, see Section 6.2). Thus, the current design case assumes that $\mathrm{CO}_{2}$ is purchased as a product from a power plant point source implementing carbon capture and storage technology (CCS). This approach for $\mathrm{CO}_{2}$ sourcing was taken given the relatively large and continuous $\mathrm{CO}_{2}$ requirement for the facility at the given productivity rates (Table 3 ) and biomass carbon content (Table 2). The average $\mathrm{CO}_{2}$ demand for the facility is 1,148 tonne/day, which can be supported by a single power plant that may be expected to emit over 11,000 tonne/day $\mathrm{CO}_{2}$ for a typical $500 \mathrm{MW}$ coal-fired power plant (see Section 6.1).

For the base case, the cost of $\mathrm{CO}_{2}$ including purification, compression, and transportation via pipeline is set at $\$ 45 /$ metric tonne $\mathrm{CO}_{2}(\sim 41 / \mathrm{U}$.S. ton), which includes all parasitic energy demands placed on the power plant CCS system; thus, power demand for the CCS operations is considered outside the current model scope and is not explicitly included in the facility power balance, but rather is rolled up in the delivered $\mathrm{CO}_{2}$ price for the algae facility. In other words, the algae facility takes on the cost burden for implementing a CCS system into a power plant including integration of the CCS heat and power requirements with power plant operations, resulting in an amortized cost of the captured $\mathrm{CO}_{2}$ at $\$ 45 /$ metric tonne, which accounts for diverting this required heat and power from the power plant to the CCS system. This parasitic energy demand for CCS is estimated explicitly in Section 6.2 for purposes of evaluating 
sustainability metrics, based on CCS literature. Recognizing this design case is specific to a 2022 target timeframe, the $\$ 45 /$ tonne $\mathrm{CO}_{2}$ cost represents an average future projected price estimate for feasible carbon capture cost from power plant flue gas sources based on three separate technologies and studies: ammonia post-combustion capture in a pulverized coal plant, physical solvent pre-combustion capture in an integrated gasification combined cycle (IGCC) plant, and a membrane process for a supercritical pulverized coal plant; pipeline transport up to a distance of $80 \mathrm{~km}$ was also included in the cost for one of the studies [72-74]. This price also is consistent though slightly more conservative compared with DOE's targets for carbon capture via secondgeneration technologies, at a goal of \$40/metric tonne $\mathrm{CO}_{2}$ in the 2020-2025 timeframe [75]. Industry estimates place the current cost of existing pipelined $\mathrm{CO}_{2}$ supplies at $\$ 0.75$ per thousand cubic feet ( $\$ 15 /$ metric tonne) with forecasts up to $\$ 4.00$ per thousand cubic feet $(\$ 80 / \mathrm{metric}$ tonne) by 2030, further supporting the assumed basis for dedicated CCS sourcing to supply the algal facility considered here [71]. Sensitivity to $\mathrm{CO}_{2}$ price is presented in Section 6.1. Capital costs for the HDPE piping network and storage sphere/immersion heaters were developed in ACCE, costing roughly $\$ 5 \mathrm{MM}$ and $\$ 2 \mathrm{MM}$ installed, respectively.

\subsection{Area 400: Makeup Water Delivery + On-Site Circulation to/from Dewatering}

\subsubsection{Overview}

Area 400 represents the transfer circulation pipelines between the 100 -acre modules and the central dewatering facility, as well as makeup water pipelines bringing in fresh water from outside the facility boundaries. Although in other design reports focused on biorefinery conversion operations such piping would typically be costed based on indirect capital cost factors $[44,76]$, in this case the piping is more critical as it covers a large land footprint and the details related to piping dimensions, frictional losses, and elevation change have a large bearing on other modeled parameters such as pumping power demand, thus this overall facility circulation piping is considered explicitly as its own process area section here. As Area 400 is an integral part of the overall facility design and layout, Section 2.2 is referenced often in the following paragraphs. In each 100-acre module the harvested material from the ponds is drained to channels, which flow to the settler ponds, assisted by harvest pumps. The partially thickened stream exiting primary settling is drained to aqueduct channels sent to central dewatering, which represents the boundary where Area 400 begins (at the take-off point from the settler outlet). Water removed during the second and third dewatering stages in central dewatering is sent back uphill to the 100-acre modules via a pipeline system. In addition to water circulation, Area 400 also brings in makeup water from a nearby groundwater resource outside the facility.

\subsubsection{Design Basis}

Figure 4 in Section 2.2 shows the aqueduct channels in green and the distribution pipelines in blue. The distance that the aqueducts and pipelines travel is specific to the pond size considered in the 100 -acre modules. Table 1 shows the size variations for the circulation pipeline segments as well as the distances that the pipelines travel for each pond size scenario. There are four aqueduct channels, and the algae medium at the highest point of each channel flows, on average, $4,907 \mathrm{~m}, 4,328 \mathrm{~m}$, and 4,267 $\mathrm{m}$ for the 2 -acre, 10 -acre, and 50 -acre cases, respectively. The total channel distance in the facility is $10.9 \mathrm{~km}(6.8 \mathrm{miles})$ for the 2-acre pond designs, $9.8 \mathrm{~km}(6.1$ miles) for the 10 -acre pond designs, and $9.7 \mathrm{~km}$ ( 6.0 miles $)$ for the 50 -acre pond designs. The aqueduct channel design and cost assumed here was provided by an estimate furnished by GAI 
who make use of aqueducts for circulation of their cultivation systems [61]. Only 5\% of the water entering the primary settling ponds is contained in the thickened slurry that enters the aqueducts. During the summer, the water flow rate leaving a single 100-acre module is 1,044 $\mathrm{L} / \mathrm{min}$ (276 gal $/ \mathrm{min})$, which translates to $13,105 \mathrm{~L} / \mathrm{min}(3,462 \mathrm{gal} / \mathrm{min})$ in each of the four aqueduct trunks. After consulting with GAI, it was determined that this does not constitute a very large flow and could be handled simply with a dug and compacted trough, particularly given the $1 \%$ slope assumed for this facility, which would prevent settling through the aqueducts [61].

The clarified water from the central dewatering facility is routed back to the 100 -acre modules via the pipeline shown in Figure 4 in Section 2.2. Table 1 in Section 2.2 shows the pipeline dimensions and lengths for each of the pond size scenarios. The main pipeline header is 34 inches in diameter when the water first enters. As water is split to each of the vertical columns it reduces from 34 inches to 26 inches and then to 20 inches. When the pipeline turns against the elevation grade to move uphill it is 16 inches wide in each of the four pipelines, and then further decreases in size as it rises in elevation until it reaches 12 inches in diameter at the top. All pipelines estimated in ACCE are buried $4 \mathrm{ft}$ underground. The horizontal feed line into each of the 100-acre modules is estimated in Area 100 and is specific to the pond design. Based on the modeled flow rates and pipe dimensions, Aspen calculates the circulation pumping power demand to move the clarified water recycle through the pipeline network and up the facility grade, based on maintaining positive pressure at all points in the pipeline. The pump efficiency for the facility pipeline is set at $67 \%$ (combined pump and motor efficiency). For the 2 -acre pond facilities, the pump outlet pressure leading into the pipeline from central dewatering is $5.3 \mathrm{~atm}$. Similarly, for the 10 -acre facility the outlet pressure is $5.4 \mathrm{~atm}$. The 50 -acre pond facilities require a pumping outlet pressure of $8.3 \mathrm{~atm}$ to overcome the larger elevation change. This translates to an annual average of 390,400 , and $650 \mathrm{~kW}$ of pumping power for the three pond size scenarios, respectively, for the overall facility (i.e. not per single module). Only a single pipeline network as described here is included in the facility design for normal water circulation, i.e., a second pipeline system is not included to accommodate events such as pond crashes and drainage/disposal; instead, it is assumed that the contaminated pond would be isolated with proper valving on feed and harvest lines, and the pond would be drained and disposed by truck.

The assumptions for makeup water pipeline delivery from off site were maintained based on the previously described harmonization models, the most recent of which (2013) considered transporting fresh water from local groundwater resources. Pipeline distance from source to facility gate varied by individual site, with an average distance of 1,287 meters ( 0.8 miles) and 108 meters of total pumping head based on inputs from PNNL's Biomass Assessment Tool model as reasonable average values for the consortium of sites considered along the U.S. Gulf Coast [58]. Costs were included for the off-site makeup water pipeline and pumps, but at a 0.8mile pipeline distance these costs are small compared to costs for on-site pipeline circulation, which is spread over a much larger total distance (10.1 miles total recirculation pipeline distance for the 10 acre pond scenarios). Pump efficiency for the off-site makeup water pipeline also was maintained at $67 \%$.

\subsubsection{Cost Estimation}

Based on the given harvested/partially concentrated stream flow rate to central dewatering coupled with the assistance of the $1 \%$ land slope, GAI estimated the costs for the aqueduct 
channels to central dewatering as approximately $\$ 100 /$ wetted cultivation acre for a large facility of this size [61]; this includes marginal pumping costs to assist in moving the material down the elevation grade and across the level terraces. This is an estimation that is specific to this facility design and layout, and could increase significantly for either a less (downhill) sloped grade or higher volumetric flow rates, as might be seen if primary dewatering were also to be done centrally at the bottom of the facility grade (i.e., increasing total harvested flow rates by a factor of 22). The uphill circulation piping costs for this portion of the facility pipelines were determined from ACCE based on the use of HDPE pipes at the designated pipe diameters in Table 1 of Section 2.2 [24]. The costs for the makeup water pipeline and pumps were maintained based on the previously-discussed harmonization report (ultimately also costed using ACCE [23]). Additional piping and pump costs within the 100 acre module boundaries are considered separately and are not included in Area 400.

\subsection{Area 500: Dewatering}

\subsubsection{Overview}

Harvesting and dewatering algal biomass is challenging due to the small size of algal cells, density similar to water, and dilute initial concentration (typically around $0.5 \mathrm{~g} / \mathrm{L}$ from open pond systems). As a result, for some dewatering options the energy input required to harvest algal biomass can approach or exceed the energy content of the biomass [77], and can account for $20 \%$ to $30 \%$ of the overall cost of renewable fuel production [78] when considering standard approaches taken today, such as centrifugation by itself. Many harvesting and dewatering strategies have been investigated and are currently under development, including settling and gravity sedimentation, screen filtration, membrane filtration, flocculation, centrifugation, dissolved air flotation, filter presses, electrocoagulation, magnetic separation, and ultrasonic separation. A full review of all harvesting and dewatering options and associated advantages and challenges is beyond the scope of this report, but has been well-documented elsewhere (for example, [78,79]). This report describes the dewatering operations included in the Aspen Plus model, either in forming the base case or evaluated as alternative sensitivity scenarios. The terms "harvesting" and "dewatering" are sometimes used interchangeably, although typically harvesting refers to removing the algal biomass from the pond, and sometimes also to primary (first-stage) concentration, where dewatering then refers to secondary concentration steps. In this section, all unit operations that concentrate algal biomass are referred to as dewatering.

Recognizing that a large number of dewatering technologies are currently under investigation and development, for this modeling effort a comprehensive literature review was conducted and a number of vendors, technology developers, and consultants were contacted to discuss and ultimately select a series of promising and cost-effective methods (based on considerations including capital and operating cost, power consumption, technology readiness level, proven experience based on processing algae, and effect on product and coproduct options downstream). The operations selected to form the base case are in-ground gravity settlers, followed by hollow fiber membranes, and then centrifugation to ultimately concentrate the harvested biomass from $0.5 \mathrm{~g} / \mathrm{L}(0.05 \mathrm{wt} \%)$ to $200 \mathrm{~g} / \mathrm{L}(20 \mathrm{wt} \%)$ AFDW basis (see Figure 11). However, it should be emphasized that algal biomass dewatering is still a relatively new and broadly varied research area spanning numerous existing and novel concepts, and it is premature to dictate what "the best" strategy will be. Thus, for purposes of projecting future 2022 cost targets, the dewatering steps selected here are most appropriately viewed as goals for both dewatering performance (i.e., 
retention efficiencies, power demand) and cost (capital and operating expenses) that any technology option may aspire to. Another important factor that influenced the decision to select these three operations was to maintain downstream flexibility as much as possible, in terms of being agnostic to biomass conversion pathways or fuel/product purity limitations that may become challenged with the introduction of foreign chemicals such as flocculants or metal ions, which are not introduced for any of the steps selected for the base case. Beyond the baseline dewatering configuration, three alternative dewatering strategies were also evaluated with cost implications on MBSP presented in the sensitivity analysis (Section 6.1). These alternative scenarios include: (1) replacing membranes with a dissolved air flotation (DAF) system employing chitosan flocculant, (2) replacing the membranes with electrocoagulation technology, and (3) replacing the membranes and centrifuges with a belt filter press.

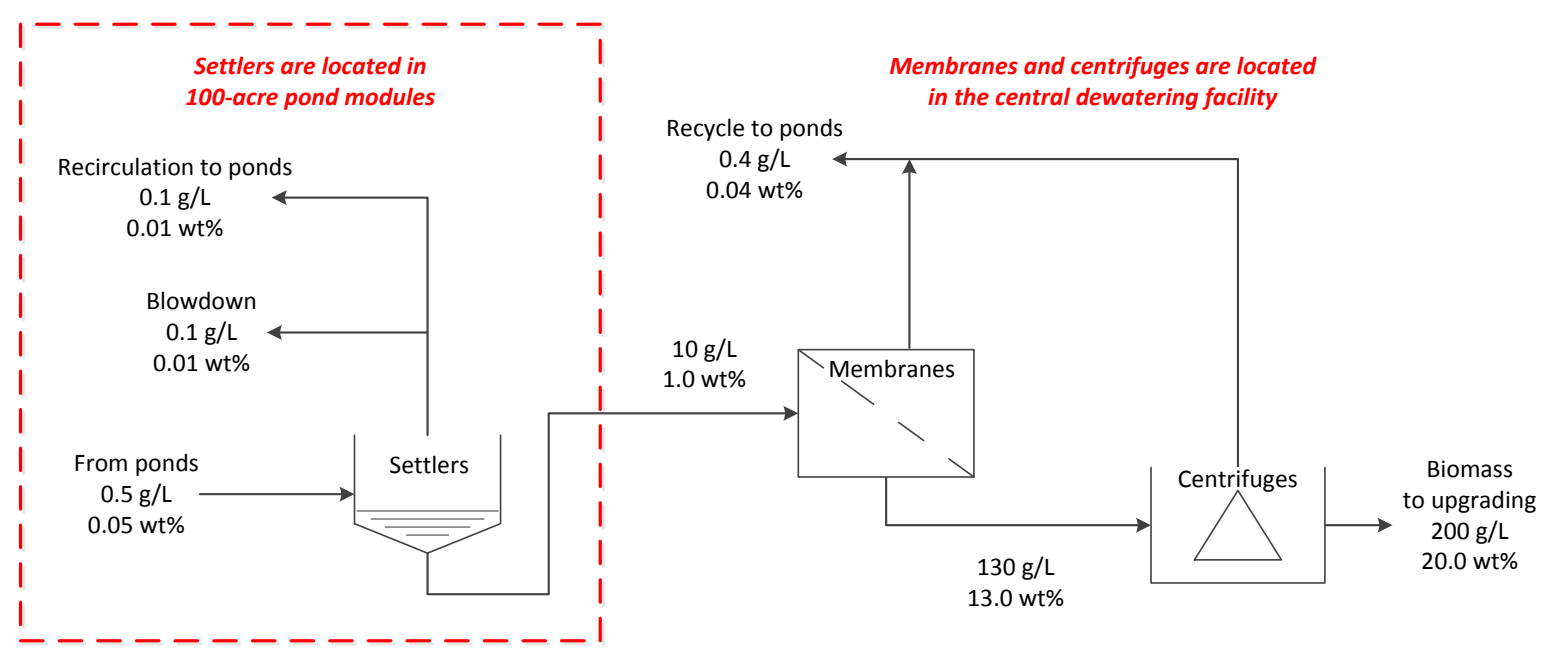

Figure 11. Block flow diagram of dewatering strategy considered for the base case. All g/L concentration values are based on AFDW biomass.

\subsubsection{Design Basis}

\section{Base Case}

The dewatering process begins with primary settling ponds, placed at one end of each 100-acre plot. Settling units are characterized by low energy demand, as power is required only for pumps and in some designs scraping equipment. Settling performance can be improved if flocculants and lamina separators are employed, although both add cost, and lamina separators are advantageous for applications where space (equipment footprint) is a constraining factor, which is not applicable here. The high water content of the material harvested from ponds $(99 \%-$ 99.5\%) translates to tremendous volumetric flow rates that must be processed through first-stage dewatering on the order of $9 \mathrm{MM}$ gal/day during peak summer flows in a single 100-acre module, or $445 \mathrm{MM}$ gal/day for the full facility (based on 24-hour pond harvesting to minimize harvest flows as much as possible). Consequently, it is critical to target the simplest and lowestcost option possible for this first-stage operation in order to both control costs for primary dewatering, as well as to reduce subsequent throughputs and therefore costs for further dewatering requirements. On the latter point, gravity settlers can be used to increase algal biomass concentration by a factor of 20-40, which even for a twentyfold concentration reduces the operating capacity of expensive secondary dewatering equipment by $95 \%$. However, gravity settlers have only been demonstrated to achieve outlet biomass concentrations up to $1.5 \%-2 \%$ in 
the most optimistic scenarios found in literature [43], therefore one or more subsequent steps are necessary to reach $20 \mathrm{wt} \%$ to $25 \mathrm{wt} \%$ as typically targeted for downstream conversion processes $[1,2]$. In any case, although spontaneous gravity settling (also termed bioflocculation) requires further supporting data to demonstrate consistent performance at commercial scales, this operation (or an alternative equivalent in cost) is a prerequisite to achieving cost viability for algal biomass and biofuel production, thus it is maintained here consistent with prior efforts [23]. A limited number of large-scale operations have recently been shown to support the efficacy of bioflocculation, including commercial operations at Cellana as published by Huntley et al. [43], as well as algal settling ponds installed and operating at a wastewater treatment facility located in Delhi, California, that utilizes algal biomass for treating wastewater [25]. Bioflocculation efficacy is highly strain-specific, and is known to work well for Scenedesmus (another supporting factor in selecting this strain for the base case), but may not be as effective for other strains such as Chlorella or Nannochloropsis.

The primary settlers concentrate the algal biomass from 0.5 to $10 \mathrm{~g} / \mathrm{L}(0.05$ to $1.0 \mathrm{wt} \% \mathrm{AFDW})$, reducing the volume of water flowing to the central dewatering facility by a factor of 20 . Economic sensitivity to the initial harvest density exiting the ponds and processed through primary settling is considered in Section 6.1. Following consultation with MicroBio Engineering [25] based on a similar design published in Lundquist et al. [17], the primary settlers were designed as simple in-ground settling ponds based on low-cost agricultural engineering practices, rather than higher-cost above-ground steel tanks as typically utilized for industrial wastewater processing (sludge thickening). The in-ground design consists of long trenches with sufficient volume to provide four hours of residence time serving the entire 100-acre module at steady state flow. The targeted concentration and residence time are in line with other known data for largescale bioflocculation operations, including $>1 \%$ concentration through a two-stage settling sequence (the first being done in the ponds themselves after suspending circulation) over a period of "several hours" [43], as well as $1.5 \%-2 \%$ concentration achieved with a $4-6$ hour residence time [25,17]. Open settling ponds may lead to accumulation of ash in the concentrated product stream, which could increase total throughputs (and therefore costs) for further downstream dewatering operations, as well as cleaning/maintenance for the membrane units. This is not considered here, but would not likely impact economics to any significant degree given the relatively low overall costs for the second and third dewatering steps.

The settler trenches are 440 feet in length, and trapezoidal in profile: 75 feet wide at the top, 3 feet wide at the bottom, and 15 feet deep. The bottom of the trench is concrete and the sides are lined with geosynthetic membrane. A continuous raking system moves along the bottom of the trench to push the settled biomass into six evenly-spaced collection sumps. The biomass is removed from these sumps by positive-displacement pumps. The clarified water is recirculated back to the production ponds through a 22-inch pipeline and return pump (costed here as part of the dewatering section, but included in the Figure 7 overall module piping depiction as the clarified water pipeline from settlers to ponds), less blowdown necessary to mitigate buildup of salts and other inorganics. The blowdown rates vary by season and were set consistent with prior harmonization models as presented in Table 3 to ensure salt accumulation remains below 4,000 $\mathrm{mg} / \mathrm{L}$ [42]. Being based on a freshwater system, the blowdown rates are relatively low and translate to a maximum loss of algae of $0.1 \%$. The dewatering efficiency of the settling step is targeted at $90 \%$, meaning $10 \%$ of the biomass remains in the clarified water stream recirculated to the ponds. However, given the low blowdown loss, $99.9 \%$ of algal biomass produced during 
cultivation ultimately is recovered in the dewatered product available for downstream conversion (given that the clarified water streams from second- and third-stage dewatering are also fully recycled to the ponds). As noted previously, the choice to locate the primary settling unit distributed on each 100-acre module rather than centrally with the secondary and tertiary dewatering steps was made in order to minimize pumping and circulation costs to move large volumes of water up the overall facility grade. Similar to caveats raised in prior modeling efforts, one potential challenge with recovering and recycling nearly all of the unrecovered algal biomass present in the clarified effluent from dewatering is that it could enrich the culture for variants that do not readily settle; a potential mitigation measure for this issue may be to place a trickle bed filter or other mechanism on the recycle line to reduce the amount of recycled biomass or, alternatively, to increase the blowdown rate to remove more of the recirculated biomass.

After primary settling, the partially concentrated material is sent to central dewatering for further concentration. The second concentration step takes place using hollow fiber membrane technology, which was selected primarily in light of favorable performance and cost results attributed to a commercial-scale membrane system currently installed and operating at the GAI facility [61]. Beyond favorable operational data furnished to NREL by GAI, in general, membrane technology offers several advantages over competing dewatering strategies, including high reliability, direct scalability, and simple thermal, mechanical, and chemical management demands [80]. Additionally, membrane technology produces a filtrate product suitable for recycle, and does not add chemicals to the algal biomass that must be removed later or may negatively impact the value of coproducts [80]. Historical arguments against the use of membrane systems for algal dewatering primarily have been based on fouling and maintenance/reliability issues that have been observed for other membrane types [77]; however, GAI indicated that maintenance and fouling are not typically problematic or costly issues for their process, based on a daily cleaning protocol for the membrane modules. Still, such issues could be both strain- and location/media-dependent and could pose challenges depending on factors such as membrane material, organic (biological) contaminants growing on the membrane surface, or inorganic (silica/ash) contaminants depositing on the surface and blocking pores [77].

The performance and cost inputs assumed in the integrated model for the membrane system were based on guidance from GAI associated with details made available for their process. Namely, the operation employs hollow fiber membrane units that receive algae at $1 \%(10 \mathrm{~g} / \mathrm{L})$ from the settling ponds and concentrate the biomass to $13 \%(130 \mathrm{~g} / \mathrm{L})$; the system as operated at GAI processes a lower inlet biomass concentration than the $1 \%$ value modeled here, but can accommodate $1 \%$ or higher incoming solids content levels, and can also achieve higher outlet concentration levels as well. Dewatering efficiency is very high at near-100\% biomass retention (modeled here at 99.5\%) with low turbidity in the clarified filtrate. The overall power consumption for the membrane system is $0.04 \mathrm{kWh} / \mathrm{m}^{3}$ based on feed rate to the unit. Approximately 4\% additional installed capacity is added to allow for daily maintenance of membrane modules, performed on a rotating hourly basis. Due to the proprietary nature of the membrane system, the membrane material and operating techniques were not disclosed to NREL and are not reported here. The membrane dewatering performance furnished by GAI and incorporated in the base case, specifically power demand, is significantly better than values found elsewhere in peer-reviewed literature, as in Bilad et al. [77], which presents power consumption values roughly an order of magnitude higher than the basis utilized here. However, GAI has subsequently improved even more on the $0.04 \mathrm{kWh} / \mathrm{m}^{3}$ basis to further reduce this value 
and validate that the basis applied here is in fact reasonable. The filtrate (clarified water) from the membranes is combined with clarified water from the centrifuge and is fully recycled to the production ponds.

Following secondary dewatering via membranes, centrifugation is used as the final dewatering step due primarily to its ability to achieve high biomass concentration (20 wt $\%$ or greater [81]) and high technology readiness level with widespread commercial use across many industries. Centrifuges have been used to concentrate algae for years at laboratories and small scales, and centrifuges represent a mature technology that has been used commercially for decades.

Although costly if implemented as the sole dewatering technology or otherwise processing more dilute biomass feed streams, as a tertiary dewatering step centrifugation is not a significant cost driver or power consumer. Performance and cost estimates for a bowl centrifuge design were provided by subcontractor Harris Group, based on a vendor quotation. The centrifuge concentrates algae from $13 \%$ to $20 \%(200 \mathrm{~g} / \mathrm{L})$, with a dewatering efficiency of $97 \%(3 \%$ of algal biomass is removed with the clarified water), although again $100 \%$ of the clarified water from this step is recycled back to the ponds. Power consumption for the centrifuge is estimated at $1.35 \mathrm{kWh} / \mathrm{m}^{3}$ based on feed to the centrifuge step. At a final dewatered concentration of $20 \%$ AFDW, the slurry will be considerably more viscous than the material harvested from the ponds; however, NREL's experience working with Scenedesmus at $20 \%$ solids in small pilot trials is that the material still behaves as a flowable slurry and thus does not likely require conveyors for transfer to product storage. The performance of the dewatering steps selected for the base design case is summarized in Table 7.

Table 7. Summary of Base Case Dewatering Steps

\begin{tabular}{lcccc}
\hline & $\begin{array}{c}\text { Inlet Flowrate, } \\
\mathbf{m}^{\mathbf{3}} / \text { day a }^{\mathbf{a}}\end{array}$ & $\begin{array}{c}\text { Outlet Concentration, } \\
\text { wt\% AFDW }\end{array}$ & $\begin{array}{c}\text { Separation } \\
\text { Efficiency }\end{array}$ & $\begin{array}{c}\text { Energy Demand, } \\
\mathbf{k W h} / \mathbf{m}^{\mathbf{3}}\end{array}$ \\
\hline Settling Ponds & $1,685,000$ & 1 & $90 \%$ & Negligible $^{\mathrm{b}}$ \\
Membranes & 76,000 & 13 & $99.5 \%$ & 0.04 \\
Centrifuges & 6,000 & 20 & $97 \%$ & 1.35 \\
\hline Overall & & 20 & $86.9 \%^{\mathrm{c}}$ & $0.006^{\mathrm{d}}$ \\
\hline
\end{tabular}

${ }^{a}$ Flowrates shown are for peak summer season, which sets the design basis for equipment capacity.

${ }^{b}$ Primary power demand for settlers is for inlet/outlet pumping, but this is not reflected here for operational power of the settler pond itself. A small power demand for a raking mechanism is expected, but is anticipated to be marginal.

${ }^{c}$ Overall separation efficiency = mass flowrate of algae leaving final dewatering step (centrifuges) divided by mass flowrate of algae into first dewatering step (settlers); $>99 \%$ of algae "lost" to clarified effluent streams is recycled back to ponds and ultimately recovered in final product, less a small fraction removed as blowdown.

d Total dewatering power divided by total volumetric flow into the primary settling ponds.

\section{Alternative Scenarios}

A number of alternative dewatering scenarios were also considered beyond the selected base case sequence, which are briefly described here but whose resulting implications on MBSP are presented in the sensitivity analysis (Section 6.1). One alternative strategy is to replace the membranes with a DAF system employing a flocculant. This option was considered as an alternative design because DAF systems have been used extensively in wastewater treatment applications for sludge thickening and algae removal, and therefore have a high technology readiness level. DAF was also previously considered in the base case during prior harmonization modeling activities given its longer history being researched for algal dewatering [7,23]. 
However, the power requirements for generating air bubbles (dissolved air) can be substantial. Also, flocculants can significantly increase operating costs and introduce foreign materials, such as metals, that can negatively impact the value of products or coproducts [82] or interfere with conversion processing equipment. Flocculants work by blocking the negative surface charge surrounding the algal cell, allowing the cells to adhere to each other [82]. Dissolved air flotation aids in flocculation by creating small air bubbles that attach to algal cells, causing them to float to the surface where they can be collected with a mechanical skimming device. Chitosan was selected as the flocculant for consideration here (consistent with prior harmonization modeling approaches) due to its organic, non-toxic properties and ability to break down in downstream operations such as anaerobic digestion. The design and cost basis for the DAF system was provided by Harris Group. The DAF system receives algae from the settling ponds at $1 \%$ and concentrates to $6 \%$, with a separation efficiency of $95 \%$. Power consumption for the DAF, including air compression, is maintained consistent with prior harmonization modeling assumptions, which in turn were based on standard processing conditions for wastewater sludge thickening, estimated at $0.133 \mathrm{kWh} / \mathrm{kg}$ of algae removed. The chitosan loading rate is targeted at $40 \mathrm{mg} / \mathrm{L}$ based on Heasman et al. [83]. Optimal chitosan loading can vary from 2 to $200 \mathrm{mg} / \mathrm{L}$ depending on the algal species [84], therefore chitosan loading and cost are further explored in the sensitivity analysis (Section 6.1).

The second alternative dewatering scenario explored is replacing the membranes with electrocoagulation technology. In electrocoagulation, the surface charge of the algae cell is altered by generating an electric field between two electrodes. Coagulation of the algal cells is enhanced by the release of metal ions from the reactive metal electrode into the water through electrolysis. In effect, the metal ions act as chemical flocculants [78]. Compared to chemical flocculation employed in the DAF process, electrocoagulation reduces raw material costs by eliminating chemical treatment, although metal electrodes are continuously consumed and therefore must be continuously replaced. Power demand for electrocoagulation systems is generally greater than other dewatering techniques [78]. Performance and cost estimates for the electrocoagulation design were provided by an equipment vendor. The electrocoagulation units receive algae directly from the settling ponds at $1 \mathrm{wt} \%$ and concentrate the material up to $6 \mathrm{wt} \%$, with $95 \%$ separation efficiency. The power demand is set at $0.7 \mathrm{kWh} / \mathrm{m}^{3}$ of feed to the electrocoagulation units, based on vendor input; however, performance and power demand for this operation may vary significantly depending on fresh versus saline media (e.g., water salinity and thus conductivity) [85].

The third alternative scenario replaces the membranes and centrifuge with a belt filter press. The belt filter press was considered as another viable alternative dewatering option based on accompanying publications by Huntley et al. and Beal et al. $[10,43]$, who showed that gravity settling followed by a belt filter press compared favorably against other dewatering routes (including DAF followed by centrifugation) based on models extrapolated from literature. Belt filter presses may allow for dewatering algae to higher concentrations of $25 \mathrm{wt} \%$ to $30 \mathrm{wt} \%$. A belt filter press works by applying mechanical pressure to the algae slurry between two tensioned belts that pass through a serpentine series of rollers of decreasing size. The algal biomass is effectively sandwiched between the belts, which are porous enough to allow water to pass through, but retain algal biomass as a cake that builds up. The belt filter press modeled for this alternative scenario is based on the design described in the Supplemental Information of Beal et al. [10]. The filter press receives algae directly from the settling ponds at $1 \mathrm{wt} \%$, and 
concentrates the material to $20 \mathrm{wt} \%$, with $98 \%$ separation efficiency. The power demand for the filter press is $0.3 \mathrm{kWh} / \mathrm{m}^{3}$ of algal slurry into the filter press [10], which was confirmed with the equipment manufacturer.

\subsubsection{Cost Estimation}

\section{Base Case}

Excavation and grading costs for the primary settler and material costs for the concrete bottom and lined sides were taken from the Leidos cost details for these elements (which originally were developed for shallower raceway ponds, but apply equally to this in-ground settler operation if the volume of earthwork and concrete are known). Estimated costs for the sumps and raking mechanism were obtained from discussions with MicroBio [25]. For purposes of model scaling, the overall capital costs were normalized by settler volume, which translates to $\$ 34,300$ per $1,000 \mathrm{~m}^{3}$ in $2014 \$$ (comparable to costs developed separately by MicroBio at $\$ 36,700 / 1000 \mathrm{~m}^{3}$ in 2009\$ as published in Lundquist et al. [17]). The diameter of the settler return pipeline is a constant 22 inches as the total liquid volume does not change with pond design. The pipeline length varies per pond size with $1,852 \mathrm{~m}(6,078 \mathrm{ft})$ required for the each module in the 2-acre case, $1,025 \mathrm{~m}(3,364 \mathrm{ft})$ for the 10 -acre case, and $411 \mathrm{~m}(1,350 \mathrm{ft})$ for the 50 -acre case. This results in a cost variation of $\$ 20 \mathrm{MM}, \$ 11 \mathrm{MM}$, and $\$ 5 \mathrm{MM}$ for the 2-, 10-, and 50-acre cases, respectively, based on extrapolating from a similar 22-inch PVC pipeline cost quoted for the 2acre case by Leidos and scaled by pipe length required for each design. Corresponding settler water return pumps on this pipeline were costed in ACCE.

Capital and operating costs for the membrane system were provided by GAI based on their installed commercial process [61]. Costs for the membranes alone constitute roughly $40 \%$ of the total installed cost for the unit (scaling linearly with feed rate based on a fixed membrane flux), while the remaining $60 \%$ of the installed cost is associated with other supporting items such as membrane housing, pumps, and piping (scaling with a 0.6 factor given economy of scale accommodations for varying flow rates associated with this portion of the membrane system). Operating costs for this system are primarily driven by power demands (discussed previously) and maintenance costs, which were set at 3\% annually of Area 500 installed capital expenses.

Capital costs and power requirements for the centrifuge were provided by Harris Group. The purchased capital cost was scaled from an original quote for a bowl centrifuge capable of processing a throughput of $154 \mathrm{~m}^{3} / \mathrm{hr}$ at a cost of $\$ 747,500$ in $2013 \$$. Operating cost for the centrifuge is primarily power demand, discussed previously.

\section{Alternative Scenarios}

Capital costs for the DAF system were also provided by Harris Group. The purchased capital cost was scaled from an original quote for a DAF unit capable of processing $1,531 \mathrm{~m}^{3} / \mathrm{hr}$ at a cost of $\$ 560,000$ in 2013\$ (total cost including DAF tank and mechanism), which translates to $\$ 366 / \mathrm{m}^{3} / \mathrm{hr}$ of capacity. The chitosan cost is estimated to be $\$ 18 / \mathrm{kg}$ based on information from industrial grade chitosan suppliers [86]. At the chitosan loading of $40 \mathrm{~g} / \mathrm{L}$ assumed for the DAF scenario, the chitosan costs constitute a significant operating cost; furthermore, given limited availability of chitosan at large industrial scales (particularly to support numerous commercial algal production facilities), this may not ultimately be the best choice for flocculant but was maintained here given the data availability for flocculant use in algal dewatering. 
Capital and operating costs for electrocoagulation are based on quotes from discussions with a vendor. The purchased capital cost for electrocoagulation equipment was set at $\$ 16,667 / \mathrm{m}^{3} / \mathrm{hr}$ of operating capacity. This value is based on a pilot-scale unit, and electrocoagulation is not a mature technology, therefore it is reasonable to anticipate capital costs will decrease with further development and scale-up toward commercialization. Power requirements and operating costs were obtained from personal quotes and vendor product literature, set at $0.7 \mathrm{kWh} / \mathrm{m}^{3}$ of feed into the electrocoagulation unit [87]. Operating costs not including power are primarily attributed to electrode replacement costs, which are estimated at roughly \$24 per MM gal of feed to the unit. This figure is significantly less than the standard 3\% of installed capital cost assumed for A500 maintenance expenses, therefore the electrode replacement costs (except power demand) are not considered as a separate operating expense, but rather are assumed to be accounted for in the maintenance cost allowance.

The capital and operating cost for the filter press dewatering operation are based on results presented in Beal et al. [10]. The purchased capital cost for the filter press was quoted to NREL at $\$ 5,300 / \mathrm{m}^{3} / \mathrm{hr}$ of operating capacity based on information provided by a filter press manufacturer.

The installed capital costs of all baseline and alternative dewatering technologies are summarized in Table 8, scaled to a per-volume-feed rate basis to the given unit operation for summer season flowrates. However, it is important to note that installed capital costs represent only a portion of the cost impact attributed to each dewatering technology. For example, the capital costs for the DAF scenario are relatively low, but flocculant (chitosan) operating costs are significant, and power demand may also be significant as well (potentially higher than the basis currently considered based on industry feedback). Also, different outlet concentrations achievable for each dewatering technology confound making direct comparisons. DAF and electrocoagulation concentrate to $6 \%$ solids, leaving more concentration requirements (and therefore costs) for the centrifuge step to achieve the final concentration of $20 \%$. Membranes are assumed to concentrate to $13 \%$, while filter presses are assumed to concentrate all the way to $20 \%$, allowing elimination of the centrifuge step altogether. Another cost consideration not reflected here is the potential impact of coagulant and metal ion contaminants on product and co-product values, resulting from DAF and electrocoagulation operations. The installed capital costs presented in Table 8 are based on the peak summer season capacities modeled for the process scenarios. Capital cost scaling exponents and installation factors are different for each dewatering technology, therefore the scaled, installed costs shown here apply only to the base case.

Table 8. Installed Capital Costs for Dewatering Technology Options, Per Volume Feed Rate to Unit

\begin{tabular}{lc}
\hline & $\begin{array}{c}\text { Installed Capital Cost, } \\
\$ /\left(\mathbf{m}^{3} / \text { day }\right)\end{array}$ \\
\hline Base Case: & $\$ 5.80$ \\
Settling Ponds & $\$ 178$ \\
Membranes & $\$ 478$ \\
Centrifuges & \\
\hline Alternatives: & $\$ 29$ \\
DAF & $\$ 157$ \\
Electrocoagulation & $\$ 70$ \\
Filter Press & \\
\hline
\end{tabular}




\subsection{Area 600: Storage}

\subsubsection{Overview}

Bulk storage for process chemicals and the dewatered biomass product is provided in this area of the plant. Specific tanks that are costed include the algae product tank, makeup water, and water for fire suppression. Additional tankage for chemicals (primarily nutrients) is included as a balance of plant factor. All assumptions for storage costs and logistics are set consistently with other recent design report practices. It also should be noted that storage for $\mathrm{CO}_{2}$ is included separately in Area 300, to provide more clarity on costs attributed to $\mathrm{CO}_{2}$ delivery, storage, and injection for the base case focused on captured/purified $\mathrm{CO}_{2}$, and for sake of comparison against the alternative scenario considering bulk flue gas considered in the sensitivity analysis.

\subsubsection{Design Basis}

The three primary storage tanks include storage for the algae product, makeup water, and fire suppression water (summarized in Table 9). The algae product tanks are sized to have at least 24 hours of storage (varies seasonally), whereas the makeup water tanks were scaled to have at least 6 hours of storage. The fire water storage tank was scaled from NREL's 2013 design report according to the dry algae product rate (summer capacity case). While fire suppression may not be a concern for the majority of the facility footprint made up of numerous algae ponds, it still may be required for other uses e.g. land or structure fires. Storage of the dewatered algal biomass material at $80 \%$ moisture content in standard storage tanks without refrigeration may pose a risk of product degradation losses (such as fermentation and degassing) if not processed quickly. As the facility is envisioned to be integrated with downstream conversion operations, the biomass product should be sent immediately to the conversion facility and it is not anticipated that the product would be stored for more than a few hours under normal operation; still, a $1 \%$ degradation loss of the stored product was added to the model to account for marginal biomass yield losses during storage.

Table 9. Storage Requirements for Major Tanks

\begin{tabular}{ll}
\hline Material & \multicolumn{1}{c}{ Size } \\
\hline Algae product & Sufficient to contain >24 hours of production: 2 carbon steel tanks @ 600,000 gal \\
Makeup water & Sufficient to contain >6 hours of production: 4 carbon steel tanks @ 500,000 gal \\
Fire water & 4 hours of fire suppression @ 2,500 gpm: 1 glass-lined carbon steel tank @ \\
& 600,000 gal (scaled on dry algae product flow rate) \\
\hline
\end{tabular}

Other supplemental tanks and pumps were not considered explicitly here, but were costed based on a $20 \%$ balance of plant factor relative to the total cost of the major tanks listed above, based on the same methodology detailed in NREL's 2014 ALU design report [1].

\subsubsection{Cost Basis}

The costs for the A600 storage section were based on prior NREL design reports $[44,4]$ with costs scaled according to the new material flows to estimate new prices of the tanks. 


\section{Process Economics}

The ultimate purpose for developing the process designs, simulation models, and cost estimates described above is to determine the economics of algal biomass production and processing for delivery to downstream conversion/upgrading operations. This information is used either as an absolute cost to assess the implications on cost drivers for an integrated algal biorefinery or to provide a means for "valorizing" the biomass based on converting constituent components into higher-value products, or as a relative cost that can be used to guide research by examining the change in production cost associated with a process modification or other core research activity.

The total capital investment (TCI) is first computed from the total equipment cost. Next, variable and fixed operating costs are determined. With these costs, we use a discounted cash flow analysis to determine the minimum biomass selling price (MBSP) required to obtain a zero net present value (NPV) with a finite internal rate of return (IRR) (for the given IRR target, NPV is zero after the end of the 30-year facility lifetime). Even though the resulting MBSP is most appropriately viewed as a "transfer price" for delivery to downstream conversion operations, which are likely to be co-located and integrated with the production facility (at a dewatered biomass moisture content of $80 \mathrm{wt} \%$ which precludes it from being transported over substantial distances to a remote conversion facility), approaching the financial analysis in this way would ultimately yield the same minimum fuel selling price (MFSP) for a downstream conversion facility applying the MBSP projected here for its biomass feedstock cost as if a single integrated facility were modeled, including both the biomass production and biomass conversion operations together. The following section summarizes the assumptions made in completing the discounted cash flow analysis, with more details and supporting description available in previous NREL design reports for assumptions that remain unchanged $[1,44,76]$.

Our analysis does not take into account any policy factors such as subsidies, mandates, or carbon credits, because these would be purely speculative. The purpose of this analysis is to demonstrate the process requirements needed to achieve specific cost projections, and to demonstrate how the technology pathway described here is able to achieve such costs on its own merits (through bottom-up TEA modeling) and, if it cannot otherwise achieve a prescribed cost goal, to give stakeholders a sense of the magnitude of incentive required to make it so.

Finally, while the MBSP cost results for all eight pond design scenarios considered in the TEA model (described in Section 4.1) are presented individually here in Section 5.5, for ease of discussion in Sections 5.2-5.4 related to capital and operating costs as applied to cash flow calculations, it is appropriate at this point to establish a single "base case" representing system costs and concomitant MBSP goals for a 2022 target projection. As equipment designs and costs for all other process areas excluding production ponds (Areas 200-600) are essentially identical for any pond design configuration, the primary variables between the pond scenarios are capital costs and power demand for Area 100. For purposes of selecting a base case, we demonstrate below and in Section 4.1.3 that 2-acre ponds, while serving as "today's standard" commercially available design, are too costly to enable favorable biomass production costs given economy of scale challenges, while 50-acre ponds although more economical than 2- or 10-acre ponds are currently too large to justify selecting such a design as the base case without operational data to validate their practicality. Thus, the 10 -acre size is selected as the most reasonable design for a 2022 target base case. As all four 10-acre pond cases are based either on detailed engineering 
designs or currently constructed systems furnished by experts in the field, rather than selecting a single "winner," we take the average of the capital costs and (circulation) power demands attributed to the four designs to represent a single "base case" for projecting an aspirational system to be demonstrated by 2022. These average costs are used as the basis for discussing cash flow calculations, total capital investment, etc. in the following sections, but all individual pond scenarios were also run through the same methodology independently to arrive at MBSP estimates for each case as presented in Section 5.5.

\subsection{About Cost-Year Indices}

The cost-year of 2011 was chosen for this analysis to provide more updated and relevant cost output information relative to the 2007-year basis, which had been utilized for a number of years in prior analyses. This new basis is being applied consistently across all DOE-BETO platforms for which similar "design case target" reports are being established during 2013-2015 efforts, and it is expected that performance goals and TEA outputs will remain in 2011 dollars through 2017 to permit comparison of future feedstocks, conversion technologies, and other alternative scenarios. However, the present equipment costs were originally provided in cost-years ranging between 2009 (primarily for the MicroBio pond costs as published in Lundquist et al. [17]) and 2015 (for the most recent pond estimates furnished by Leidos and GAI, as well as a number of vendor costs for dewatering operation scenarios). Cost-years for chemicals range from 2003 to 2014.

The methods used for determining MBSP in another year's dollar value and for scaling capital, operating, and labor cost estimates to a desired target year remain similar to those described in prior design reports. Thus, the details will not be repeated here, but will be summarized briefly. Capital costs provided in a year other than 2011 dollars were adjusted using the Plant Cost Index from Chemical Engineering Magazine [88] to a common basis year of 2011. The final cost index for a given year is generally not made available until the spring of the following year. Therefore, for the small number of equipment items that were quoted in 2015 dollars, we assumed the same Plant Cost Index value from 2014 (all cost quotes that fall in this category were provided in the first half of 2015). Consistent with methods utilized for all other recent design reports, costs are not inflated over the 30-year facility lifetime (i.e., inflation is kept constant over the modeled facility lifetime). Employee salaries were scaled using the labor indices provided by the U.S. Department of Labor Bureau of Labor Statistics [89]. Finally, for chemical costs we also maintain a similar approach for cost-indexing as in prior design reports [1], including the use of the Industrial Inorganic Chemical Index formerly published by SRI Consulting up through 2011 [90]. For new chemical cost values between 2012-2014, following a change in the SRI (now IHS) Chemical Index methodology, we make use of the Producer Price Index industry data for chemical manufacturing published by the Bureau of Labor Statistics [91], which tracked the SRI/IHS Chemical Index values through 2011. The general formula for converting nominal values to real values and for adjusting dollars to a common basis is:

$$
2011 \text { Cost }=(\text { Base Cost })\left(\frac{2011 \text { Cost Index }}{\text { Base Year Index }}\right)
$$




\subsection{Total Capital Investment (TCl)}

Section 4 of this report describes the details of the conceptual "bottom-up" process design model and how the purchased cost of the equipment was determined. The next step is to determine the installed cost of that equipment where applicable, although a number of process areas such as the production pond systems (Area 100) are already largely given as installed costs. The installation cost can be determined by performing a detailed study of everything required to install the necessary equipment and make it operational (e.g., foundation, piping, and wiring). This type of detail is not warranted at this level of analysis, and a factored approach in which multipliers are applied to the purchased equipment cost is considered satisfactory. The methodology and rationale for applying unit-level installation costs remains the same as described in prior design reports $[1,44,76]$, and again further detail can be found there which will not be repeated here. In summary, each type of equipment utilizes a different installation factor to scale the given direct equipment purchased cost to a final installed cost, with these factors generally varying between 1.3 and 2.0. A complete listing of the equipment is provided in Appendix A, along with equipment purchased and installed costs. Similar to prior design reports, a number of equipment items such as dewatering operations were quoted as a package which includes all supporting equipment. The installation factor for such packages can be relatively low because most of the engineering is already included in the price. Additionally, equipment designed as a pre-fabricated skid generally has a lower construction cost. Equipment costed in ACCE (primarily pipelines, pumps, and tanks) also includes estimates for both purchased and installed costs, thus separate installation factors are unnecessary for this equipment.

The cost for a given component reflects a baseline equipment size. As changes are made to the process, the required equipment size may be different than what was originally designed. Instead of re-costing in detail, an exponential scaling expression was used:

$$
\text { New Cost }=(\text { Base Cost })\left(\frac{\text { New Size }}{\text { Base Size }}\right)^{n}
$$

In this equation, the scaling exponent $n$ varies depending on the type of equipment to reflect economy of scale dependencies. The basis for scaling is typically some characteristic of the equipment related to production capacity, such as flow or heat duty. Some equipment does not follow such a scaling-factor approach, namely when the capacity for a given operation is exceeded and requires multiple units in parallel (thus losing economy of scale benefits, which are captured in the exponential expression above). More detail on reasonable scaling values for different types of equipment is provided in NREL's 2011 ethanol report [76], which describes this approach, but for a different biomass feedstock. In summary for the present case, ponds and inoculum equipment scale linearly for a given pond size (i.e. many individual production and inoculum ponds are employed in the facility), and primary settling units also scale linearly based on a given dollar-per-volume basis applied here (see Section 4.5.3). Costs scale exponentially for downstream dewatering equipment (membranes and centrifuges) which may vary in capacity for a given unit as throughput changes. Cost and scaling details for all processing equipment are provided in Appendix A.

Once the total equipment cost has been determined in the year of interest, several direct and indirect costs are added to determine the total capital investment (TCI). First, direct cost factors 
are applied relative to the installed costs to determine the total direct cost (TDC) and include warehouse allowances, site development, and additional yard piping (i.e., piping for downstream operations beyond the piping explicitly considered in Areas 100 and 400). Indirect cost factors including project contingency, field expenses, home-office engineering and construction activities, and other construction-related costs are then computed relative to TDC and summed to yield the fixed capital investment (FCI). Finally, the FCI is combined with working capital and land costs to give the TCI. In prior NREL design reports, application of direct and indirect cost factors was relatively straightforward and followed a standard methodology applicable to most biorefinery systems focused on the conversion of biomass into fuels and coproducts $[1,44,76]$. For the current design, while the cost factor categories remain the same, the methodology for estimating these factors has been modified to reflect significant differences in the present process (comprised largely of "farming" operations and pipeline networks spanning thousands of acres) relative to standard biorefineries (comprised of conversion and upgrading units similar to ethanol or petrochemical facilities constrained to $\sim 100$ acres of land footprint). In prior biorefinery design cases, direct and indirect factors were handled based on separating out costs attributed to process areas falling inside battery limits (ISBL) and outside battery limits (OSBL) of the facility. For the current effort, installed costs and associated cost factor estimates were divided into three categories: cultivation (Areas 100 and 200), dewatering (Area 500), and OSBL (Areas 300,400 , and 600). Table 10 presents a summary of the direct and indirect factor cost allowances as applied to each of the three facility categories, followed by a discussion on the rationale for the assumptions employed to select the given cost factor values. 
Table 10. Additional Costs for Determining Total Capital Investment (TCI)

\begin{tabular}{|c|c|c|c|c|}
\hline Item & Description & Dewatering & Cultivation & OSBL \\
\hline \multicolumn{5}{|c|}{ Additional direct costs } \\
\hline Warehouse & $\begin{array}{l}\text { Includes on-site storage of equipment and } \\
\text { supplies. }\end{array}$ & $\begin{array}{l}4 \% \text { of } A 500 \\
\text { installed cost }\end{array}$ & $\begin{array}{l}1.2 \% \text { of } A 100 \\
\text { and } A 200 \\
\text { installed cost }\end{array}$ & $0 \%$ \\
\hline Site development & $\begin{array}{l}\text { Includes fencing, curbing, parking lot, roads, well } \\
\text { drainage, rail system, soil borings, and general } \\
\text { paving. This factor allows for minimum site } \\
\text { development assuming a clear site with no } \\
\text { unusual problems such as right-of-way, difficult } \\
\text { land clearing, or unusual environmental problems. }\end{array}$ & $\begin{array}{l}9 \% \text { of } A 500 \\
\text { installed cost }\end{array}$ & $\begin{array}{l}\text { Included in } \\
\text { pond cost } \\
\text { estimate }\end{array}$ & $\begin{array}{l}\$ 1,534 / \text { acre } \\
\text { (roads and } \\
\text { fences) }\end{array}$ \\
\hline Additional piping & $\begin{array}{l}\text { To connect ISBL equipment to storage and } \\
\text { utilities outside the battery limits. }\end{array}$ & $\begin{array}{l}4.5 \% \text { of } \mathrm{A} 500 \\
\text { installed cost }\end{array}$ & $\begin{array}{l}\text { Included in } \\
\text { pond cost } \\
\text { estimate }\end{array}$ & $0 \%$ \\
\hline & Indirect costs & $\begin{array}{l}\% \text { of A500 } \\
\text { Total Direct } \\
\text { Cost (TDC) }\end{array}$ & $\begin{array}{l}\% \text { of } A 100 \text { and } \\
\text { A200 TDC }\end{array}$ & $\begin{array}{l}\% \text { of OSBL } \\
\text { TDC }\end{array}$ \\
\hline $\begin{array}{l}\text { Prorateable } \\
\text { expenses }\end{array}$ & $\begin{array}{l}\text { Includes fringe benefits, burdens, and insurance } \\
\text { of the construction contractor. }\end{array}$ & $10 \%$ of TDC & $4 \%$ of TDC & $1 \%$ of TDC \\
\hline Field expenses & $\begin{array}{l}\text { Consumables, small tool and equipment rental, } \\
\text { field services, temporary construction facilities, } \\
\text { and field construction supervision. }\end{array}$ & $10 \%$ of TDC & $4.5 \%$ of TDC & $1 \%$ of TDC \\
\hline $\begin{array}{l}\text { Home office and } \\
\text { construction }\end{array}$ & $\begin{array}{l}\text { Engineering plus incidentals, purchasing, and } \\
\text { construction. }\end{array}$ & $20 \%$ of TDC & $10.3 \%$ of TDC & $1 \%$ of TDC \\
\hline $\begin{array}{l}\text { Project } \\
\text { contingency }\end{array}$ & $\begin{array}{l}\text { Extra cash on hand for unforeseen issues during } \\
\text { construction. }\end{array}$ & $10 \%$ of TDC & $10 \%$ of TDC & $10 \%$ of TDC \\
\hline Other costs & $\begin{array}{l}\text { Start-up and commissioning costs; land, rights-of- } \\
\text { way, permits, surveys, and fees; piling, soil } \\
\text { compaction/dewatering, and unusual foundations; } \\
\text { sales, use, and other taxes; freight, insurance in } \\
\text { transit and import duties on equipment, piping, } \\
\text { steel, and instrumentation; overtime pay during } \\
\text { construction; field insurance; project team; and } \\
\text { transportation equipment, bulk shipping } \\
\text { containers and plant vehicles. }\end{array}$ & $10 \%$ of TDC & $2.6 \%$ of TDC & $1 \%$ of TDC \\
\hline
\end{tabular}

As presented in Table 10, for the dewatering section (Area 500), percentage allocations for direct and indirect cost allowances were set equal to those typically utilized in prior biorefinery design cases [1] as this process area shares similarities with equipment utilized in biorefinery processes, e.g., the use of equipment for solids handling and separations that must be engineered, fabricated, and shipped to the facility for installation, which requires warehousing for storage of spare parts, etc. The OSBL process areas including $\mathrm{CO}_{2}$ delivery (whose equipment consists of storage tanks, pipelines, and valves), facility circulation pipelines and aqueducts, and tankage, are simplistic and are not envisioned to require substantial allowances for additional indirect factors to escalate their expenses dramatically beyond the installed costs primarily quoted in ACCE, thus all indirect factors for the OSBL equipment were set at $1 \%$ with the exception of contingency allowances which were maintained at the standard 10\% (see Table 10). Direct cost factors for both warehouse and additional piping were excluded, as warehouse costs are not anticipated to be necessary for this equipment and essentially all piping in this portion of the facility is costed explicitly. However, an allowance for "site development" is included in the 
OSBL category, costed at approximately $\$ 1,530$ /acre representing the cost for roads and fences [17].

The final category with a separate set of cost factor allocations is cultivation (Areas 100 and 200). Both site development (representing a large fraction of pond civil work) and piping costs were included in the pond construction cost estimates obtained for all eight pond scenarios considered, with inoculum system costs primarily extrapolated from pond costs plus additional elements such as full pond liners, hoop houses for covered ponds, and PBR "system" costs (see Section 4.2). Therefore, only the warehouse line item applies for additional direct cost inclusions within the cultivation process areas. To help estimate warehouse direct cost allowances as well as the various indirect cost factors as pertinent to algal cultivation systems, three detailed capital cost breakdowns reported in literature $[10,17,92]$ were analyzed and cost factors were calculated relative to the cultivation capital cost in each case. When available, the average of all three sources was selected for use here, with the exception of contingency, which was fixed at the standard $10 \%$ value, and field expenses, which were set at $4.5 \%$ of cultivation TDC. Table 11 shows the cultivation factors back-calculated from literature as well as those selected for use in this report, along with standard factors typically used in biorefinery design models as well as the wastewater industry for comparison. Relative to standard biorefinery processes, the selected warehouse direct factor is smaller for the cultivation areas reflecting the smaller and standardized parts inventory required to maintain raceway ponds compared to refinery units (i.e., spare paddlewheels and motors). The home office and construction factor is also lower owing to pond modularity and lack of detailed engineering/procurement necessary for raceway pond development for many repeating pond units. Similarly, prorateable expenses and field expenses are smaller due to lower requirements for scaffolding, cranes, and other temporary on-site items. The "other costs" category is also considerably smaller due to the inclusion of surveys, pilings, soil compaction/dewatering, and foundations already accounted for in the pond cost estimates, thus leaving fewer remaining items such as transportation and permit costs alone.

Finally, land costs at $\$ 3,000$ /acre were applied to the total facility footprint (see Section 2.2), consistent with prior algae TEA efforts [7,23]. This cost is lower than typical land costs applied for biorefinery conversion facility design reports (for example $\$ 14,000 /$ acre as presented in the the 2014 ALU design report [1]); however, it is appropriate for use here, given the emphasis on the use of low-value land not otherwise suitable or intended for crop production or other industrial uses. A land price of $\$ 3,000$ /acre is a conservative estimate for such land, applicable to both the Gulf Coast as well as the Southwestern United States (both attractive regions for algal production), based on performing a statistical analysis of land prices in Louisiana and Arizona [93]. Based on the details described above, Table 12 shows the application of all applicable cost factors to obtain the TCI for the base case (where the "base case" is taken here based on averaging the installed capital costs for all four 10-acre pond designs as discussed previously). Applying the cost factor assumptions discussed above and summarized in Table 10 for all three process categories, the resulting ratio for FCI to installed costs is 1.3 for cultivation (Areas 100 and 200), 1.9 for dewatering (Area 500), and 1.8 for OSBL (Areas 300, 400, and 600), resulting in an overall total FCI to total installed cost ratio of 1.5. As expected for reasons discussed above, this is slightly lower than ratios typically seen for biorefinery design models at 1.7-1.8 $[1,44]$. 
Table 11. Cost Factors Pertinent to Algal Cultivation Systems Deduced from Literature [10,17,92], and Selected for Use Here. (Standard factors for typical biorefinery designs and wastewater processing are also provided for comparison.)

\begin{tabular}{|c|c|c|c|c|c|c|}
\hline Cost Factor & Selected & $\begin{array}{l}\text { Beal } \\
\text { et al. }\end{array}$ & $\begin{array}{c}\text { Lundquist } \\
\text { et al. }\end{array}$ & $\begin{array}{l}\text { Alabi } \\
\text { et al. }\end{array}$ & Wastewater & $\begin{array}{l}\text { Biorefinery } \\
\text { "Standard" }\end{array}$ \\
\hline & \multicolumn{4}{|c|}{$\%$ of Cultivation Cost } & \multicolumn{2}{|c|}{$\%$ of Total Direct Cost } \\
\hline Warehouse & $1.2 \%$ & $1.3 \%$ & $2.0 \%$ & $0.3 \%$ & - & $4 \%$ \\
\hline Prorateable Expenses & $4.0 \%$ & $0.03 \%$ & $8.4 \%$ & - & $4 \%$ & $10 \%$ \\
\hline Field Expenses & $4.5 \%$ & $4.5 \%$ & $25.1 \%$ & - & $12 \%$ & $10 \%$ \\
\hline Home Office \& Construction & $10.3 \%$ & $8.4 \%$ & $10.4 \%$ & $12.2 \%$ & $5 \%$ & $20 \%$ \\
\hline Other Costs (Start-Up, Permits, etc.) & $2.6 \%$ & $1.4 \%$ & $5.2 \%$ & $1.4 \%$ & $2 \%$ & $10 \%$ \\
\hline
\end{tabular}

Table 12. Project Cost Worksheet Including Total Direct Costs and Total Capital Investment (base case for 10-acre average pond costs a; all costs in 2011 dollars)

\begin{tabular}{|c|c|c|c|c|c|}
\hline \multirow[b]{2}{*}{ Process Area } & \multirow{2}{*}{$\begin{array}{l}\text { Purchased } \\
\text { Cost }^{\mathrm{b}}\end{array}$} & \multicolumn{3}{|c|}{ Installed Cost ${ }^{b}$} & \multirow{2}{*}{$\begin{array}{l}\text { Total Installed } \\
\text { Cost }^{\mathrm{b}}\end{array}$} \\
\hline & & \multirow{2}{*}{$\begin{array}{c}\text { Cultivation } \\
\$ 158,500,000\end{array}$} & Dewatering & OSBL & \\
\hline $\begin{array}{l}\text { Area 100: Production Ponds } \\
\quad \text { (average of } 10 \text {-acre cases } \\
\end{array}$ & $\$ 158,500,000$ & & $\$$ & $\$$ & $\$ 158,500,000$ \\
\hline Area 200: Inoculum Ponds & $\$ 16,100,000$ & $\$ 16,100,000$ & $\$$ & $\$$ & $\$ 16,100,000$ \\
\hline Area 300: $\mathrm{CO}_{2}$ Delivery & $\$ 6,100,000$ & $\$ \quad-$ & $\$$ & $\$ 6,500,000$ & $\$ 6,500,000$ \\
\hline $\begin{array}{l}\text { Area 400: Makeup Water } \\
\quad \text { Delivery + On-Site Circulation }\end{array}$ & $\$ 5,400,000$ & $\$$ & $\$$ & $\$ 7,200,000$ & $\$ 7,200,000$ \\
\hline Area 500: Dewatering & $\$ 41,700,000$ & $\$$ & $\$ 43,900,000$ & $\$$ & $\$ 43,900,000$ \\
\hline Area 600: Storage & $\$ 4,000,000$ & $\$ \quad-$ & $\$ \quad-$ & $\$ 5,300,000$ & $\$ 5,300,000$ \\
\hline Totals & $\$ 231,900,000$ & $\$ 174,600,000$ & $\$ 43,900,000$ & $\$ 19,000,000$ & $\$ 237,500,000$ \\
\hline Warehouse & & $\$ 2,100,000$ & $\$ 1,800,000$ & NA & $\$ 3,900,000$ \\
\hline Site Development & & NA & $\$ 3,900,000$ & $\$ 11,700,000$ & $\$ 15,600,000$ \\
\hline Additional Piping & & NA & $\$ 2,000,000$ & NA & $\$ 2,000,000$ \\
\hline Total Direct Costs (TDC) & & $\$ 176,800,000$ & $\$ 51,500,000$ & $\$ 30,700,000$ & $\$ 259,000,000$ \\
\hline Prorateable Expenses & & $\$ 7,100,000$ & $\$ 5,200,000$ & $\$ 300,000$ & $\$ 12,500,000$ \\
\hline Field Expenses & & $\$ 7,900,000$ & $\$ 5,200,000$ & $\$ 300,000$ & $\$ 13,300,000$ \\
\hline Home Office \& Construction Fee & & $\$ 18,300,000$ & $\$ 10,300,000$ & $\$ 300,000$ & $\$ 28,900,000$ \\
\hline Project Contingency & & $\$ 17,700,000$ & $\$ 5,200,000$ & $\$ 3,100,000$ & $\$ 25,900,000$ \\
\hline Other Costs (Start-Up, Permits, & & $\$ 4,700,000$ & $\$ 5,200,000$ & $\$ 300,000$ & $\$ 10,100,000$ \\
\hline Total Indirect Costs & & $\$ 55,600,000$ & $\$ 30,900,000$ & $\$ 4,300,000$ & $\$ 90,800,000$ \\
\hline Fixed Capital Investment (FCl) & & $\$ 232,300,000$ & $\$ 82,500,000$ & $\$ 35,000,000$ & $\$ 349,800,000$ \\
\hline Land & & & & & $\$ 22,800,000$ \\
\hline Working Capital & & & & & $\$ 17,500,000$ \\
\hline Total Capital Investment (TCI) & & & & & $\$ 390,200,000$ \\
\hline Lang Factor (TCI/Purchased Equip & nent Cost) & & & & 1.5 \\
\hline $\mathrm{TCl}$ per Annual Ton & & & & & $80 /$ Ton (AFDW) \\
\hline $\begin{array}{l}\text { a Total facility size for } 10 \text { acre "bas } \\
\text { acre modules each consisting of } \\
\text { b Capital costs are based on peak } \\
\text { c Pond capital costs shown are the } \\
\text { individual } 10 \text {-acre case is } \$ 208,9 \\
\$ 123,500,000 \text { for MicroBio. }\end{array}$ & $\begin{array}{l}\text { case" is } 7,600 \\
10 \text { acre ponds } \\
\text { ummer producti } \\
\text { average of all fol } \\
0,000 \text { for Harris, }\end{array}$ & $\begin{array}{l}\text { cres }(5,000 \text { acr } \\
\text { n capacity. } \\
\text { r 10-acre pond } \\
\$ 146,400,000 \mathrm{f}\end{array}$ & $\begin{array}{l}\text { sign cases. T } \\
\text { GAI, } \$ 155,30\end{array}$ & $\begin{array}{l}\text { installed ca } \\
00 \text { for Leido }\end{array}$ & $\begin{array}{l}\text { ed into 100- } \\
\text { I cost for each } \\
\text { nd }\end{array}$ \\
\hline
\end{tabular}




\subsection{Variable Operating Costs}

Variable operating costs, which include $\mathrm{CO}_{2}$, other raw materials, and power demand, are incurred only when the process is operating. For the algal processing facility modeled here, variable operating costs by definition also vary as seasonal biomass productivities and associated harvest rates and equipment throughputs fluctuate, in contrast to fixed operating costs (and equipment capital costs), which do not. Variable costs for nutrient inputs $\left(\mathrm{CO}_{2}, \mathrm{NH}_{3}\right.$, and DAP) scale proportionately with seasonal biomass productivity rate, but power demand is less strongly tied to this metric, given a large fraction of facility power consumption attributed to pond mixing which remains fixed across the year for a given pond design. Quantities of raw materials used were determined using the Aspen material balance, based on running individual Aspen models for each season and then taking the average of all four seasons in setting the net annual operating expenses, power demand, and product yields. Table 13 documents the costs and sources of chemicals used in the process and Table 14 summarizes the variable input flow rates on a perseason basis, as well as the resulting variable costs on a per-year and per-ton-of-biomass basis.

Material costs for the present model consist of $\mathrm{CO}_{2}$, ammonia and DAP nutrients, and utilities. The base case model assumes the use of purified $\mathrm{CO}_{2}$ produced from flue gas carbon capture sourced from a nearby power plant, with a cost set at \$45/metric tonne representing 2022 technology goals as discussed in more detail in Section 4.3. As noted previously, this was done both to reduce uncertainty and subjectivity in $\mathrm{CO}_{2}$ cost contributions relative to more speculative modeling scenarios for bulk flue gas transport and distribution, as well as the fact that the latter approach based on flue gas poses significant logistical challenges and raises questions as to its practicality for a facility of this size (these issues, as well as cost implications associated with a flue gas scenario, are presented in Section 6.1). Ammonia and DAP prices were updated in this report relative to assumptions employed in previous work, to make use of market fertilizer pricing published by the USDA as the most appropriate basis for large-scale use of fertilizers for biomass production [94]. Given significant fluctuations in the prices for both fertilizers over recent years, average prices were taken for years 2011-2014 (the most recent year currently available). The resulting prices for ammonia and DAP are $\$ 772 /$ ton and $\$ 630 /$ ton, respectively, after indexing to 2011 dollars. As discussed previously, ammonia and DAP nutrient demands are set in the model based on nitrogen and phosphorous elemental content of the biomass at harvest (Table 2) plus an additional 20\% excess allowance present in the circulated culture. While the biomass composition has also been measured to contain a small level of elemental sulfur, a cost for "sulfur delivery" is not included in the base case model. This is because sulfur is likely to be present in more than sufficient quantities in bulk flue gas delivered to the ponds, and even potentially in the captured $\mathrm{CO}_{2}$ basis scenario depending on affinity of the carbon capture technology for sulfur species (e.g., $\mathrm{SO}_{2}$ ). Even if sulfur were not present in sufficient amounts with the delivered $\mathrm{CO}_{2}$, if it were to be costed as an external nutrient $\left(\mathrm{SO}_{2}\right)$ it would add a negligible amount to MBSP on the order of $\$ 1 /$ ton.

Utility costs include power and marginal chilled water demands. The electricity price was set at $6.8 \phi / \mathrm{kWh}$, based on the EIA 2011 average industrial retail price [95]. As discussed previously, given that chilled water demand is relatively low in this design (required for seasonal cooling in the PBR and covered pond inoculum operations) coupled with the fact that this facility is likely to be integrated with downstream biorefinery conversion operations (which typically include utility systems for chilled water, cooling water, and steam), chilled water demands were costed 
in this design based on a utility operating expense rather than constructing a dedicated chiller system on site, which would likely be duplicative with the downstream conversion facility. A chilled water utility "transfer price" was thus utilized, at a value of $\$ 5 / \mathrm{GJ}$ [65]. Consistent with prior harmonization models $[23,42]$, makeup process water to primarily make up for evaporation and blowdown losses was not costed as an operating expense, but rather was costed based on pipeline, pumping, and power demands attributed to bringing water to the facility from a nearby local groundwater resource located 1,287 meters $(0.8$ miles $)$ from the facility boundary, including 108 meters of pumping head (see Section 4.4). The resultant total facility operating costs translate to $\$ 5,400 /$ cultivation acre for the base case (10-acre average scenario), which agrees closely with $\$ 5,000 /$ cultivation acre described in Beal et al. and Huntley et al. $[10,43]$.

Table 13. Chemical/ Utility Costs and Sources

\begin{tabular}{lll}
\hline Component & Cost (2011\$) & Source \\
\hline Inputs & $\$ 0.0204 / \mathrm{lb}$ & {$[72-74]$ (\$45/metric tonne) } \\
$\mathrm{CO}_{2}$ & $\$ 0.3862 / \mathrm{b}$ & {$[94]$ (average of 2011-2014) } \\
Ammonia & $\$ 0.3150 / \mathrm{lb}$ & {$[94]$ (average of 2011-2014) } \\
Diammonium phosphate & $\$ 0.0682 / \mathrm{kWh}$ & {$[95]$} \\
Power & $\$ 5.00 / \mathrm{GJ}$ & {$[65]$} \\
Chilled water utility price & Water is sourced from a nearby local water resource; costs \\
& $\mathrm{NA}$ & are accounted for via pipelines, pumps, and pumping power \\
Process water & & to bring makeup water on site. \\
\hline
\end{tabular}

Table 14. Variable Operating Costs (includes seasonal flow rates and resulting annual costs) a

\begin{tabular}{|c|c|c|c|c|c|c|c|c|}
\hline $\begin{array}{l}\text { Process } \\
\text { Area }\end{array}$ & Stream Description & $\begin{array}{c}\text { Summer } \\
\text { Usage } \\
(\mathrm{kg} / \mathrm{h})\end{array}$ & $\begin{array}{c}\begin{array}{c}\text { Fall } \\
\text { Usage } \\
(\mathrm{kg} / \mathrm{h})\end{array} \\
\end{array}$ & $\begin{array}{l}\text { Winter } \\
\text { Usage } \\
(\mathrm{kg} / \mathrm{h})\end{array}$ & $\begin{array}{c}\text { Spring } \\
\text { Usage } \\
\text { (kg/h) }\end{array}$ & $\begin{array}{c}\text { Annual } \\
\text { Average } \\
(\mathrm{kg} / \mathrm{h})\end{array}$ & $\begin{array}{l}M M \$ / y r \\
(2011 \$)\end{array}$ & $\begin{array}{c}/ \text { Ton AFDW } \\
\text { Algae } \\
(2011 \$) \\
\end{array}$ \\
\hline \multicolumn{9}{|c|}{ Raw materials } \\
\hline$\overline{\mathrm{A} 100}$ & $\mathrm{CO}_{2}$ & 66,908 & 47,600 & 22,366 & 54,482 & 47,839 & 17.05 & 90.90 \\
\hline and & Ammonia & 603 & 428 & 201 & 491 & 431 & 2.91 & 15.49 \\
\hline A200 & Diammonium Phosphate & 292 & 208 & 98 & 238 & 209 & 1.15 & 6.13 \\
\hline \multirow[t]{3}{*}{ A600 } & Electricity $(\mathrm{kW})^{\mathrm{b}}$ & 11,620 & 9,581 & 7,130 & 10,683 & 9,753 & 5.27 & 28.09 \\
\hline & Chilled Water Utility (GJ/h) & 17 & 17 & 17 & 17 & 17 & 0.69 & 3.66 \\
\hline & Process Water & $1,222,975$ & 520,358 & 460,576 & $2,261,033$ & $1,116,236$ & NA & NA \\
\hline \multicolumn{2}{|c|}{ Total variable operating costs } & & & & & & 27.06 & 144.27 \\
\hline
\end{tabular}

${ }^{a}$ All costs shown are for the base case average of the 10-acre designs. Values for Harris 10-acre, Leidos 10-acre, GAI 10-acre, and MicoBio 10-acre ponds match the values provided, excepting electricity.

b The Harris 10-acre case, Leidos 10-acre case, GAl 10-acre case, MicroBio 10-acre case, and overall average 10acre case have variable electricity demands because of different paddlewheel or circulation pump requirements. The average 10-acre case electricity usage is shown in the table. The annual average power demand for the individual 10-acre design cases is 10,000 kW for Harris, $11,000 \mathrm{~kW}$ for Leidos, 8,850 kW for GAl, and 9,150 kW for MicroBio.

\subsection{Fixed Operating Costs}

Fixed operating costs are generally incurred in full whether or not the plant is producing at full capacity. These costs include labor and various overhead items. Again as with indirect cost factors discussed above, staffing requirements and resulting labor costs were modified for this effort relative to standard assumptions employed in recent biorefinery conversion pathway design reports $[1,44]$. A number of labor cost assumptions were maintained with these prior analyses where appropriate, including the plant manager, lab manager, maintenance supervisor, shift supervisors, and clerks/secretaries. Additionally, maintenance and lab technicians and associated salaries were also maintained, but the required number of each employee type was 
adjusted to vary depending on pond size and thus number of total ponds in the facility that must be monitored and maintained (shown in Table 15 for each of the three pond size scenarios). As pond size decreases and thus total number of individual ponds increases, the number of each of these technicians required to service the ponds increases. A similar modification was made for production pond operators, which represent the most costly labor category based on the large number of pond operators required for such a large facility (between 33 for the large 50 -acre pond designs up to 73 for the 2-acre pond designs). Pond operator salaries were set based on data from the Bureau of Labor Statistics (BLS) for an "agricultural equipment operator" [96]. Likewise, operators for the inoculum system (fixed at eight total operators regardless of production pond scenario) and the dewatering section (fixed at nine total operators) were also adjusted using BLS data, in this case matching employee categories for "water and wastewater treatment plant operators" and "separating, filtering, clarifying ... and still machine operators" [97]. Finally, engineering labor costs were also increased, based on assuming two each of civil and environmental engineers also based on BLS salary data [98,99].

The resulting employee requirements and associated labor costs are shown in Table 15, with the 10 -acre base case selected for presenting the annual labor expenses. The estimated labor costs are in line with other published TEA studies for algal biomass production after adjusting for facility size $[10,17,92]$. These estimates suggest a considerable difference in total labor costs depending on individual pond size considered for the facility, further adding to economy of scale benefits for moving toward larger pond size designs. For the 2-acre pond case, the total burdened labor cost is estimated at $\$ 8.4 \mathrm{MM} / \mathrm{yr}$, which decreases to $\$ 7.0 \mathrm{MM} / \mathrm{yr}$ and $\$ 5.5 \mathrm{MM} / \mathrm{yr}$ for the 10 - and 50-acre pond cases, respectively.

Table 15. Fixed Operating Costs

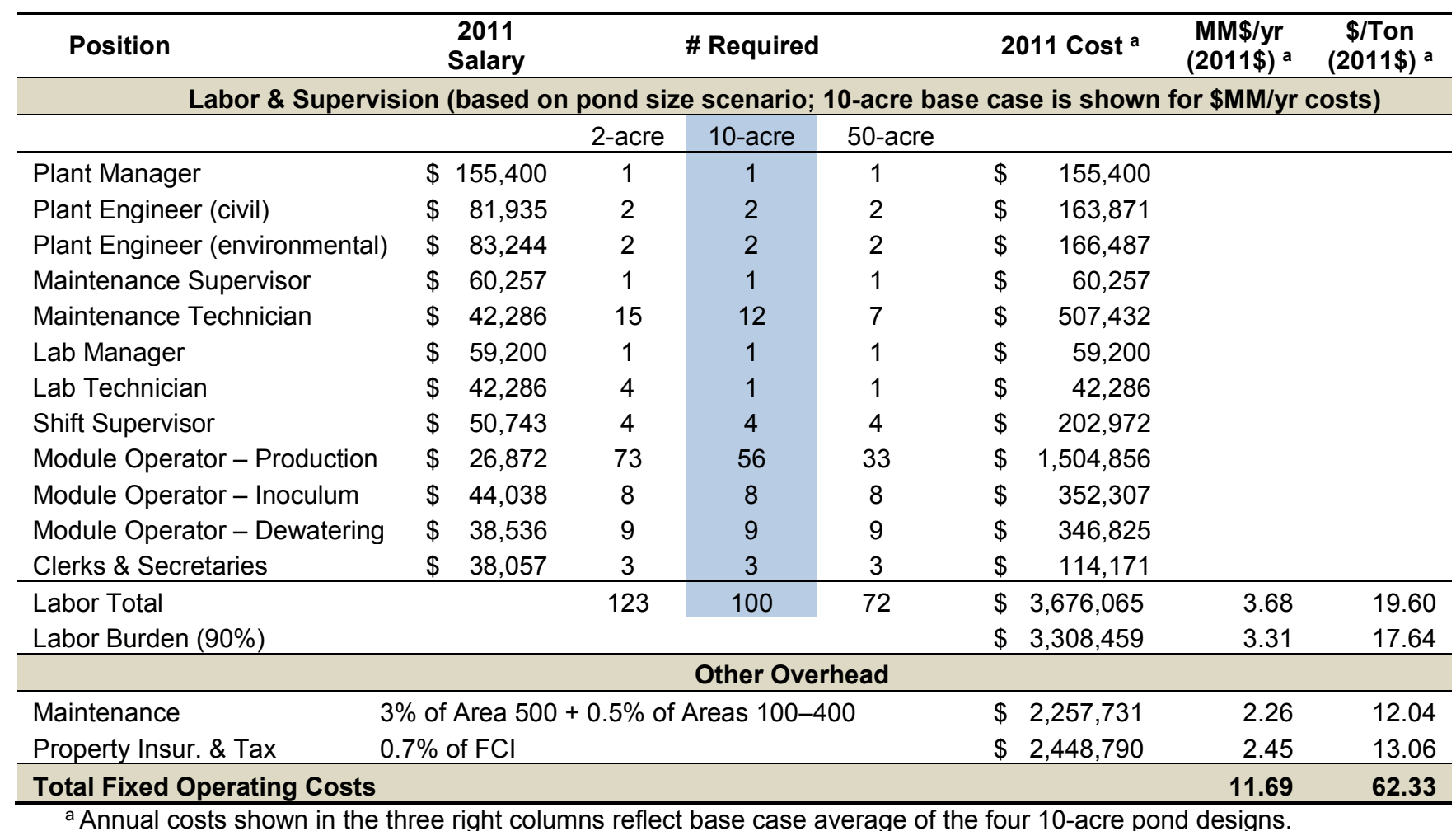


A $90 \%$ labor burden is applied to the salary total and covers items such as safety, general engineering, general plant maintenance, payroll overhead (including benefits), plant security, janitorial and similar services, phone, light, heat, and plant communications. The $90 \%$ estimate is the median of the general overhead range suggested in the 2008 PEP Yearbook produced by SRI Consulting (now IHS) [90]. Annual maintenance costs were estimated as $3 \%$ of the installed cost for the dewatering section plus $0.5 \%$ of the installed costs for Areas 100, 200, 300, and 400, which consist of cultivation ponds and supporting equipment or circulation piping and tankage, which are expected to incur much lower maintenance requirements than "standard" biorefinery type equipment and machinery. Property insurance and local property tax were estimated at $0.7 \%$ of the fixed capital investment, based on the 1994 Chem Systems report described in NREL's 2011 ethanol report [76].

\subsection{Discounted Cash Flow Analysis and the Minimum Selling Price of Biomass \\ Discount Rate}

For this analysis, the discount rate (which is also the internal rate of return [IRR] in this analysis) was set to $10 \%$ and the plant lifetime was set to 30 years. This discount rate is standard for all BETO design reports, and was based on the recommendation in Short et al. [100] on how to perform economic evaluations of renewable energy technologies for DOE. His view was that, "In the absence of statistical data on discount rates used by industrial, transportation and commercial investors for investments with risks similar to those of conservation and renewable energy investments, it is recommended that an after tax discount rate of $10 \%$...be used."

\section{Equity Financing}

For this analysis, it was assumed that the plant would be $40 \%$ equity financed. The terms of the loan were taken to be $8 \%$ interest for 10 years. The principal is taken out in stages over the 3year construction period. Interest on the loan is paid during this period, but principal is not paid back (this is another $n^{\text {th }}$-plant assumption, which says that this cash flow comes from the parent company until the plant starts up). This is all consistent with the assumptions used in recent NREL design reports since 2011. Figure 12 illustrates the sensitivity of minimum biomass selling price to the percentage of equity financing and the after-tax discount rate (the IRR), associated with the above-discussed "base case" average for the four 10-acre pond designs. 


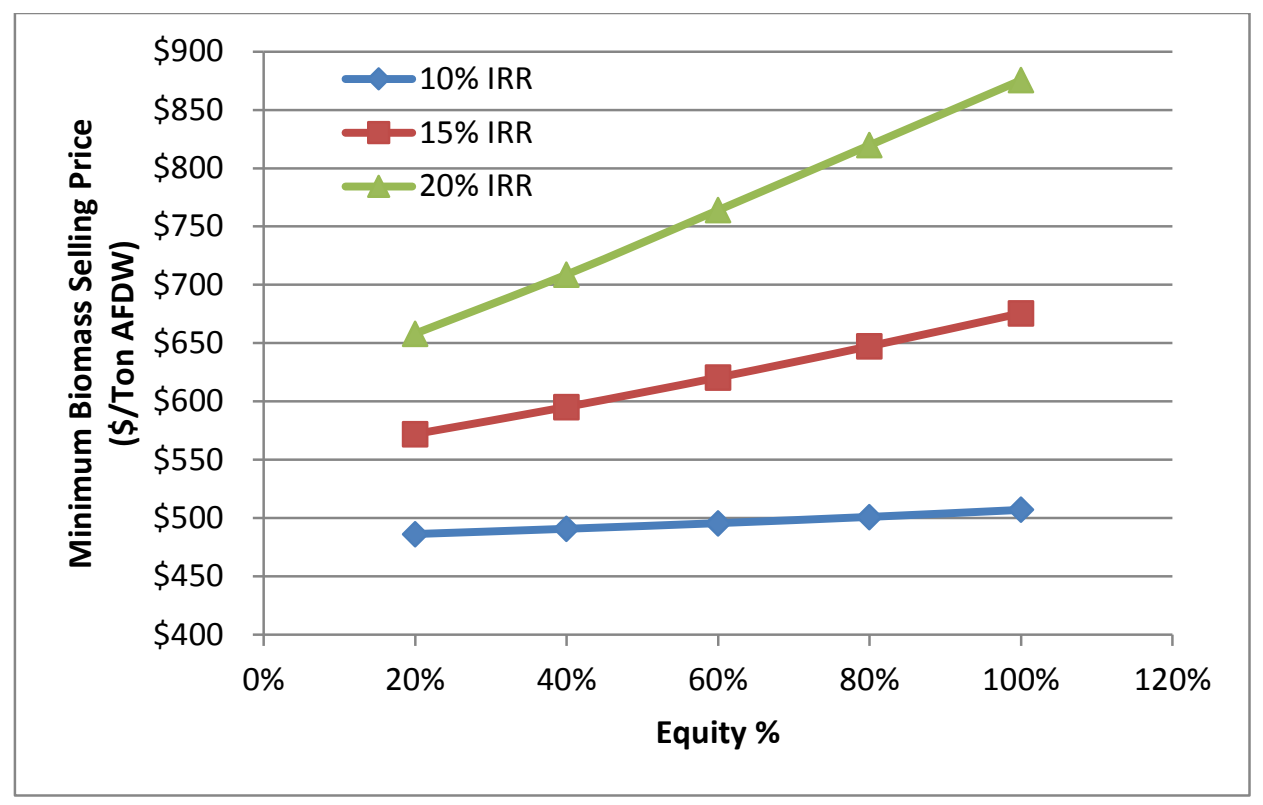

Figure 12. Sensitivity of MBSP to IRR and \% equity (8\% interest on a 10-year loan)

\section{Depreciation}

To determine the capital depreciation amount for the calculation of federal taxes to be paid we used the IRS Modified Accelerated Cost Recovery System (MACRS). Within the MACRS system is the General Depreciation System (GDS), which allows both the $200 \%$ and $150 \%$ declining balance (DB) methods of depreciation. This offers the shortest recovery period and the largest tax deductions. According to IRS publication 946 [101], a biorefinery plant would fall under Asset Class 49.5, "Waste Reduction and Resource Recovery Plants." This class uses a 7year recovery period, not including any power plant (i.e., gas or steam turbine) equipment. Again, all assumptions employed here are maintained consistently with prior design reports.

\section{Taxes}

The federal corporate tax rate used in our analysis is $35 \%$. Income tax is averaged over the plant life and that average is calculated on a per-ton-biomass basis. The amount of income tax to be paid by a potential biomass (or fuel) producer varies annually due to changes in the volume of product produced and the allowable depreciation deduction. In fact, no income tax is paid in the first eight years of operation because the depreciation and loan interest deductions are greater than the net income. State taxes are not considered, primarily because the location of the plant is not specified (to a state level) and tax rates vary from state to state (from $0 \%$ to $12 \%$ ); this is consistent with previous design report practice standards and is applied consistently here as well. As noted previously, applying factors such as income taxes and IRR to both the models for biomass production and biomass conversion to fuels will ultimately yield the same minimum fuel selling price as a single integrated facility model.

\section{Construction Time}

The construction time is important to the cash flow analysis because no income is earned during construction but large sums of money are being expended. Construction time assumptions were left unchanged from other recent design reports. Perry and Green [102] indicate that small 
projects (less than $\$ 10$ million investment) can be constructed in fewer than 18 months and that larger projects can take up to 42 months. An overview of petroleum refining economics indicates that large refineries (on the order of a $\$ 1.5$ billion investment) can be constructed in 24 months [103]. Certainly this algal biomass facility is less costly than such a petroleum refinery, so using a construction time of 24 months fits within these references, although the present facility is significantly different in terms of land footprint size and type of equipment being installed. In any case, the present design consists largely of many modular pond systems of identical configuration, which are envisioned to allow for relative ease and speed of construction. Table 16 summarizes the schedule for construction and the cash flow during that time. Twelve months are added before construction for planning and engineering.

Table 16. Construction Activities and Cash Flow

\begin{tabular}{|c|c|c|c|}
\hline $\begin{array}{l}\text { Project } \\
\text { Start } \\
\text { Month }\end{array}$ & $\begin{array}{l}\text { Project } \\
\text { End } \\
\text { Month }\end{array}$ & Activity Description & $\begin{array}{l}\% \text { of } \\
\text { Project } \\
\text { Cost }\end{array}$ \\
\hline 0 & 12 & $\begin{array}{l}\text { Project plan and schedule established; conceptual and basic } \\
\text { design engineering and permitting completed; major equipment } \\
\text { bid packages issued, engineering started on selected sub- } \\
\text { packages, P\&IDs complete, and preliminary plant and equipment } \\
\text { arrangements complete. }\end{array}$ & $8 \%$ \\
\hline 12 & 24 & $\begin{array}{l}\text { All detailed engineering including foundations, structure, piping, } \\
\text { electrical, and site complete; all equipment and instrument } \\
\text { components purchased and delivered; all site grading, drainage, } \\
\text { sewers, rail, fire pond, foundation, and major structural } \\
\text { installation complete; } 80 \% \text { of all major process equipment set (all } \\
\text { except longest-lead items); all field-fabricated tanks built; and the } \\
\text { majority of piping and electrical materials procured. }\end{array}$ & $60 \%$ \\
\hline \multirow[t]{2}{*}{24} & 36 & $\begin{array}{l}\text { Complete process equipment setting, piping, and instrumentation } \\
\text { installation complete; all electrical wiring complete; all building } \\
\text { finishing and plumbing complete; all landscaping complete; pre- } \\
\text { commissioning complete; and commissioning, start-up, and initial } \\
\text { performance test complete. }\end{array}$ & $32 \%$ \\
\hline & & TOTAL & $100 \%$ \\
\hline
\end{tabular}

\section{Start-Up Time}

Perry and Green [102] indicate that for a moderately complex plant, start-up should be about $25 \%$ of the construction time, or 6 months in this case. The start-up period is not completely wasted, however. We expect that an average of $50 \%$ production could be achieved during that period while incurring $75 \%$ of variable expenses and $100 \%$ of fixed expenses.

\section{Working Capital}

Peters and Timmerhaus [104] define working capital as money available to cover (1) raw materials and supplies in inventory, (2) finished product in storage, (3) accounts receivable, (4) cash on hand for monthly payments such as wages and maintenance supplies, (5) accounts payable, and (6) taxes payable. The present analysis applies the same basis for working capital as was used in prior work, namely $5 \%$ of fixed capital investment. 
Table 17 summarizes the parameters used in the discounted cash flow analysis. Using these parameters, plus the cost information in Table 12, Table 14, and Table 15, the resulting minimum biomass selling price for the base case (average of the four 10-acre pond designs) is $\$ 491 /$ ton (2011 dollars, AFDW basis). It is worthwhile to distinguish this MBSP result, based on $10 \%$ IRR and other economic inputs noted above, from the cost of production (i.e., breakeven cost to cover capital and operating expenses at $0 \%$ IRR), as these terms are often incorrectly used interchangeably; the associated cost of production for this case is estimated at $\$ 309 /$ ton. Table 18 summarizes the yields and processing costs for the base case model. According to the methodology of Cran [105], the expected accuracy of the TCI analysis is $+/-25 \%$. If we apply this uncertainty to the TCI, the impact on the MBSP is $+/-\$ 73 /$ ton. The complete discounted cash flow summary worksheet is shown in Appendix C. The contributions to the base case MBSP are broken down into major cost drivers as shown in Figure 13, along with individual MBSP results for each of the eight discrete pond designs.

Table 17. Discounted Cash Flow Analysis Parameters

\begin{tabular}{ll}
\hline Plant life & 30 years \\
Discount rate & $10 \%$ \\
General plant depreciation & $200 \%$ declining balance (DB) \\
General plant recovery period & 7 years \\
Federal tax rate & $35 \%$ \\
Financing & $40 \%$ equity \\
Loan terms & 10 -year loan at $8 \%$ APR \\
Construction period & 3 years \\
First 12 months' expenditures & $8 \%$ \\
Next 12 months' expenditures & $60 \%$ \\
Last 12 months' expenditures & $32 \%$ \\
Working capital & $5 \%$ of fixed capital investment \\
Start-up time & 6 months \\
Revenues during start-up & $50 \%$ \\
Variable costs incurred during start-up & $75 \%$ \\
Fixed costs incurred during start-up & $100 \%$ \\
\hline
\end{tabular}

Table 18. Summary of Yields, Rates, and Processing Costs (base case 10-acre average)

\begin{tabular}{ll}
\hline Facility size & 5,000 acres $(2,023 \mathrm{ha})$ wetted cultivation area \\
$\mathrm{CO}_{2}$ demand & $417,700 \mathrm{ton} / \mathrm{yr}$ \\
On-line time & $7,920 \mathrm{~h} / \mathrm{yr}(330$ days/yr, i.e., $90 \%$ on-line factor) \\
Biomass production rate & $0.19 \mathrm{MM}$ ton/yr (AFDW) \\
Biomass yield & 37.5 ton/acre/yr $(84.1$ tonne/ha/yr AFDW) \\
Total installed equipment cost & $\$ 238 \mathrm{MM}$ \\
Total capital investment $(\mathrm{TCl})$ & $\$ 390 \mathrm{MM}$ \\
TCl per annual ton biomass & $\$ 2,080$ \\
Minimum Biomass Selling Price & $\$ 491 /$ ton AFDW \\
$\quad$ Contribution from cultivation system & $\$ 278 /$ ton \\
Contribution from $\mathrm{CO}_{2}+$ nutrients & $\$ 112 /$ ton \\
Contribution from remainder & $\$ 101 /$ ton \\
\hline
\end{tabular}




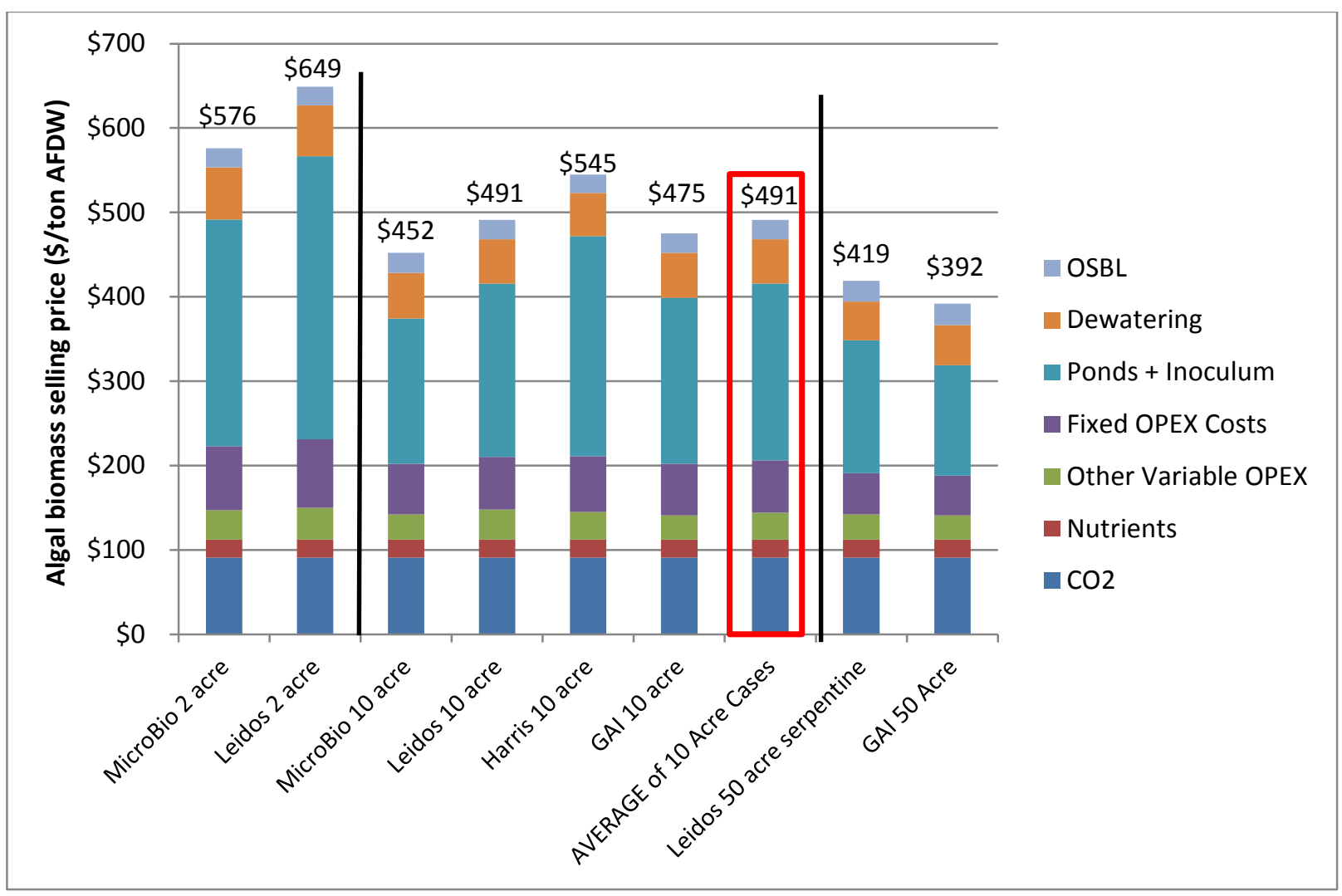

Figure 13. MBSP results for each pond scenario broken out by major contributions. (Figure also shows "base case" selected for presentation of cost details shown in Sections 5.2-5.4, attributed to average of the four 10-acre pond designs representing 2022 design and cost targets.)

Figure 13 reiterates the primary conclusion presented in prior analyses [23] that the cost of algal biomass (which in turn dominates the cost of algal biofuels) is driven most strongly by the cost for cultivation systems, even for both a reasonably high targeted annual productivity at 25 $\mathrm{g} / \mathrm{m}^{2} /$ day combined with low-cost pond systems with only marginal inclusions for plastic liners in small targeted areas of the pond for erosion control. As either productivity decreases or pond costs increase, system costs and biomass selling price increase (see Figure 5) driven primarily by pond costs becoming an even larger fraction of overall selling price. Within the pond cost category itself, more specific cost drivers are presented in Figure 8. Inoculum costs account for $\$ 25 /$ ton across all pond designs (between $9-19 \%$ of total pond costs). Beyond this, although major cost drivers vary by pond design, generally for the 10-acre cases the largest contributors to pond costs are the "other" category (e.g. paddlewheels, motors, and concrete), followed by civil work and then piping. Given otherwise consistent assumptions for algal biomass productivity and composition, harvest density, dewatering performance and costs, and overall facility layout, all cost contributions to MBSP are nearly identical across the eight pond system designs considered, except of course for the costs attributed to ponds (including partial pond liners) and inoculation system equipment, which vary inversely proportional with individual pond size as presented in Figure 9. While intuitively this is to be expected, given economy of scale benefits discussed previously (attributed to fewer individual feed and harvest pipelines, pipe fittings/control valves, electrical runs, and circulation equipment required for fewer ponds of 
larger size), the results presented in Figure 13 provide quantitative implications on MBSP for this important attribute.

The 2-acre pond cases, while based on today's standard commercially available designs and demonstrated operability, are too costly to support cost viability for algal biomass production (particularly when focused on conversion of the biomass to commodity fuel products), at an average MBSP cost of $\$ 122 /$ ton higher than the average cost for the 10 -acre designs.

Alternatively, the large 50-acre pond designs enable even lower MBSP costs than the 10-acre designs considered, at an average of $\$ 85 /$ ton lower than the 10 -acre averages. However, the improvements become limited by diminishing returns, at an average $17 \%$ cost reduction associated with a fivefold pond size increase. Given the fact that such a large size for a single pond drastically exceeds the largest ponds currently constructed and operating today, the 50-acre pond designs are viewed more as example scenarios to further quantify economy of scale trends than to conclude that such a design is "the best" or most optimum configuration to target without supporting operational data. Consequently, the 10 -acre pond designs are projected here to be the most optimum practical size to target for construction and demonstration by 2022, with an average MBSP of $\$ 491 /$ ton algal biomass across the four given 10 -acre pond configurations. As noted previously, the practicality of ponds as large as 10 acres is contingent on the development of highly robust algal strains resistant to contamination and culture crash events, which would be much more detrimental on system yields and costs in a single 10 acre pond than a 2 acre pond (i.e. five-fold higher loss in biomass present in a given pond).

Beyond cultivation system cost allocations to MBSP, varying between $\$ 172-\$ 261 /$ ton for the 10 acre pond designs, the next largest cost drivers are $\mathrm{CO}_{2}(\$ 91 /$ ton), fixed operating costs $(\$ 60$ $66 /$ ton) driven primarily by labor costs, which also somewhat follow economy of scale trends based on the total number of individual ponds that must be operated and serviced in the facility, and dewatering at $\$ 53 /$ ton. Sensitivities to all three of these parameters are investigated in the next section. 


\section{Analysis and Discussion}

\subsection{Cost Sensitivity Analysis}

\section{Single-Point Sensitivity Analysis}

A single-point sensitivity analysis was performed using the variables and limits shown in Table 19. The baseline for all variables used in the design case is described previously in this report. Reasonable minima and maxima for each variable were chosen to understand and quantify the resulting cost impact on overall MBSP, using the "base case" pond design projection based on the average capital costs and power demand attributed to the four 10-acre pond scenarios. Each variable was changed to its maximum and minimum value with all other factors held constant. The results of the sensitivity analysis are displayed as a tornado plot in Figure 14.

Table 19. Assumptions Varied in the Sensitivity Analysis (baseline = base case 10-acre average)

\begin{tabular}{|c|c|c|c|c|}
\hline Area & Assumption & Min & Baseline & Max \\
\hline \multirow[t]{9}{*}{ Biomass Production } & Annual average evaporation rate, $\mathrm{cm} /$ day & 0.06 & 0.09 & 0.12 \\
\hline & Paddlewheel work, kWh/ha/day & 48 & 55 & 75 \\
\hline & Cultivation area, acres & 1,000 & 5,000 & 10,000 \\
\hline & Biomass composition & - & HCSD & HPSD \\
\hline & Leakage control & - & In-situ clay & Fully lined \\
\hline & Seasonal variability (summer:winter) & 1 & 3 & 5 \\
\hline & Recirculation method & - & $\begin{array}{l}\text { Gravity flow } \\
\text { one direction }\end{array}$ & $\begin{array}{l}\text { Pumping both } \\
\text { directions }\end{array}$ \\
\hline & Average productivity, $\mathrm{g} / \mathrm{m}^{2} /$ day & 15 & 25 & 40 \\
\hline & Composition + productivity, $\mathrm{g} / \mathrm{m}^{2} /$ day & HLSD@15 & HCSD@ 25 & HPSD@ 35 \\
\hline Inoculum & $\begin{array}{l}\text { Inoculum system design basis, summer days } \\
\text { between inoculation }\end{array}$ & 10 & 20 & 40 \\
\hline \multirow[t]{2}{*}{$\mathrm{CO}_{2}$ Delivery } & $\mathrm{CO}_{2}$ utilization efficiency & $85 \%$ & $90 \%$ & $95 \%$ \\
\hline & Co-located flue gas versus purchased $\mathrm{CO}_{2}$ & Flue gas & $\mathrm{CO}_{2}$ & - \\
\hline \multirow[t]{3}{*}{ Dewatering } & Centrifuge power, $\mathrm{kWh} / \mathrm{m}^{3}$ & 0.7 & 1.45 & 2.0 \\
\hline & Membrane power, $\mathrm{kWh} / \mathrm{m}^{3}$ & 0.02 & 0.04 & 0.4 \\
\hline & Overall (combined) dewatering efficiency "net" & $90.0 \%$ & $99.9 \%$ & - \\
\hline \multirow[t]{6}{*}{ Operating Costs } & Sulfur "nutrient" cost, $\$ / \mathrm{lb}$ & - & $\$ 0$ & $\$ 0.14$ \\
\hline & Phosphorus recycle ${ }^{a}$ & - & $0 \%$ & $50 \%$ \\
\hline & Nitrogen recycle ${ }^{a}$ & - & $0 \%$ & $90 \%$ \\
\hline & $\mathrm{CO}_{2}$ recycle $^{\mathrm{a}}$ & - & $0 \%$ & $30 \%$ \\
\hline & $\mathrm{CO}_{2}$ price, $\$$ /tonne & $\$ 0$ & $\$ 45$ & $\$ 100$ \\
\hline & Power cost, $\$ / k W h$ & - & $\$ 0.068$ & $\$ 0.100$ \\
\hline \multirow[t]{5}{*}{ Financial/Other } & Labor costs & $-50 \%$ & $0 \%$ & $+50 \%$ \\
\hline & Dewatering CAPEX & $-50 \%$ & $0 \%$ & $+50 \%$ \\
\hline & On-stream factor, days/year & 300 & 330 & 365 \\
\hline & Pond CAPEX, million dollars & \$124MM & \$159MM & \$197MM \\
\hline & Total capital investment (TCl) & $-25 \%$ & $0 \%$ & $+25 \%$ \\
\hline
\end{tabular}

${ }^{a}$ Recycle of $\mathrm{N}, \mathrm{P}$, and $\mathrm{CO}_{2}$ is not considered in the model base case as it is intended to be given credit on the downstream processing side for biomass conversion. Parameters are included here in sensitivity analysis strictly for purposes of demonstrating economic benefit for conversion pathways that allow for nutrient $/ \mathrm{CO}_{2}$ recovery.

As shown in Figure 14, cultivation productivity exhibits the strongest cost driver on MBSP of all parameters considered, particularly if achievable productivity were lower than $25 \mathrm{~g} / \mathrm{m}^{2} /$ day (annual average). Both the strong sensitivity to productivity in general and the trend for diminishing economic returns between 15 and $25-30 \mathrm{~g} / \mathrm{m}^{2} /$ day versus $25-30$ and $40-45 \mathrm{~g} / \mathrm{m}^{2} /$ day 
are consistent with trends shown in prior harmonization efforts $[23,42]$ and reiterated here in Figure 16; namely that costs reduce dramatically between an initial benchmark productivity near $15 \mathrm{~g} / \mathrm{m}^{2} /$ day (representing today's estimated "state of technology" performance) to roughly 25$30 \mathrm{~g} / \mathrm{m}^{2} /$ day, at which point further cost reductions begin reaching asymptotic limits between 30$50 \mathrm{~g} / \mathrm{m}^{2} /$ day. In this case, if productivity could be further increased from an annual average of 25 to $35 \mathrm{~g} / \mathrm{m}^{2} /$ day (40\% improvement), MBSP could be further reduced by roughly $\$ 90 /$ ton. Although such an improvement is still significant relative to most other sensitivity parameters, it is much less dramatic than a $\$ 220 /$ ton MBSP penalty incurred for a $40 \%$ reduction in productivity to $15 \mathrm{~g} / \mathrm{m}^{2} /$ day, dictated by the fact that ponds are costed on a dollar-per-acre basis and do not scale with biomass productivity; thus, particularly when productivity is low, the "capital utilization efficiency" of the ponds is poor. Thus, it is critical when projecting future targets that annual average productivity increase to at least $25-30 \mathrm{~g} / \mathrm{m}^{2} /$ day, both from an economic standpoint as well as in reaching a more "stable"/less sensitive (uncertain) portion of the curve in setting TEA cost estimates.

The second line in Figure 14 attempts to investigate the combination of both productivity and biomass composition at harvest. As discussed in Section 2.3 and shown in Table 2, relative to the mid-harvest Scenedesmus (HCSD) strain selected for use in the base case model, the biomass N and $\mathrm{P}$ demands are higher for early-harvest biomass (HPSD), as required to keep the biomass nutrient-replete in the active growth phase. If such a higher nutrient supply for HPSD biomass hypothetically enabled a $40 \%$ productivity improvement to $35 \mathrm{~g} / \mathrm{m}^{2} /$ day relative to the HCSD base case at $25 \mathrm{~g} / \mathrm{m}^{2} /$ day, any MBSP reductions would be offset by an associated 4.8 -fold increase in nutrient costs resulting in an MBSP nearly equivalent to the base case. If instead lateharvest/high-lipid biomass (HLSD) were desired but required a $40 \%$ reduction in productivity to $15 \mathrm{~g} / \mathrm{m}^{2} /$ day, MBSP would increase by a similar $\$ 220 /$ ton magnitude as for the original 15 $\mathrm{g} / \mathrm{m}^{2} /$ day sensitivity parameter investigated by itself (noted above), given that $\mathrm{N}$ and $\mathrm{P}$ content differences are much smaller between mid- and late-harvest biomass and thus do not play a significant role like they do for the difference between early- and mid-harvest biomass. These results are based on hypothetical differences in productivity attributed to each biomass composition/harvest point and require experimental data to quantify actual tradeoffs between nutrient loading and achievable productivity. However, if they were to follow similar variances in productivity as assumed here, this is an interesting result which suggests that it may not be "worth" strictly targeting the highest productivity possible if it requires significant nitrogen loading at substantial cost, relative to later-harvest biomass under mildly nutrient-deplete conditions (particularly given downstream dependencies on conversion yields to fuels which may be significantly improved, e.g., for high-carbohydrate/mid-lipid [HCSD] biomass relative to high-protein/low-lipid [HPSD] biomass). Additionally, it is imperative to stress that these results are drawn based on meeting $100 \%$ of nutrient demands with fresh makeup fertilizers, without any credit given for downstream recycling (which is intended to be taken on the "back end" conversion models to reduce final product costs). In reality, for fuel-based processes it is critical to achieve high rates of nitrogen and phosphorus recycle for both economic and sustainability reasons [23], and indeed a number of conversion pathways have been posited which may reasonably achieve $\geq 50 \% \mathrm{P}$ recycle and $\geq 80 \% \mathrm{~N}$ recycle $[1,2]$. In such scenarios with high nutrient recycling, the economic effects of one biomass compositional profile (namely C:N:P ratio) compared to another would be significantly diminished, either for a single strain over multiple harvest points or for different strains altogether. For example, Figure 14 demonstrates a 
credit of roughly $\$ 14 /$ ton for $90 \% \mathrm{~N}$ recycle, if it were to be credited here on the front end to biomass costs instead of to fuel costs on the back end.

Similar arguments apply as discussed above for the "productivity + composition" parameter as for the "biomass composition" parameter alone in Figure 14 ( $7^{\text {th }}$ line from the top of the plot), which shows a nearly \$80/ton increase in MBSP in going from the HCSD basis to the highnutrient HPSD biomass, when considering economic implications for biomass compositional changes in isolation without considerations for productivity tradeoffs. The MBSP for HLSD biomass is similar (actually marginally higher) than for the HCSD case, again when isolating the focus only to compositional changes and associated nutrient costs, because $\mathrm{N}$ and $\mathrm{P}$ levels remain similar to HCSD, but carbon content is further increased (due to the higher lipid content) and thus $\mathrm{CO}_{2}$ costs are higher for the HLSD case. However again, the same caveat applies that the magnitude of the impacts would be considerably diminished for fully integrated processes which enable high $\mathrm{N}$ and $\mathrm{P}$ nutrient recycling. More details on compositional impacts to MBSP, for both the base case Scenedesmus strain and for two alternative strains, are provided in the following section.

Beyond productivity considerations, the strongest sensitivity attributed to system costs is the method employed for pond leakage control. As discussed above, the basic assumptions for all eight pond scenarios stipulate the use of in-situ clay soil to mitigate percolation issues, with the use of plastic pond liners only on small portions of the ponds (typically either channel berms or pond turns, depending on the individual pond design) as required for erosion control. If instead ponds were fully lined across the full 5,000 acres of cultivation, the MBSP would increase substantially by $\$ 126 /$ ton for the 10 -acre average base case. Furthermore, this assumes the liner does not need to be replaced within the 30-year facility lifetime, beyond standard maintenance costs; if full liner replacement were required, this would add another $\$ 126 /$ ton. This reiterates the point that achieving low-cost algal biomass and biofuels depends strongly on siting the facility in a location with sufficiently high clay soil, and on any applicable regulatory policies that allow for the use of unlined ponds. The individual MBSP results for each discrete pond design based on fully lined ponds are shown in Figure 15.

Next, $\mathrm{CO}_{2}$ price also is shown to carry significant impact, with an MBSP increase of $\$ 111 /$ ton associated with a $\mathrm{CO}_{2}$ price of $\$ 100 /$ metric tonne representing an upper range of projected $\mathrm{CO}_{2}$ costs for carbon capture technologies [72,71]. Alternatively, MBSP would reduce substantially by $\$ 91 /$ ton if high-purity $\mathrm{CO}_{2}$ were available at no cost (aside from costs still included for on-site storage and distribution). A limited number of such opportunities may exist for example by colocation with ethanol, ammonia, or natural gas processing facilities. As an alternative to purified $\mathrm{CO}_{2}$, pipeline transport and delivery of bulk flue gas from a nearby power plant were also considered, which may be viewed as "free" for the $\mathrm{CO}_{2}$ itself but requires substantial costs for large-diameter pipelines for gas transportation both off site and on site. This scenario is discussed in more detail in the next section, given its importance on both costs and ramifications on the power plant. In summary, a co-located flue gas scenario appears to offer the potential to reduce MBSP by roughly $\$ 44 /$ ton relative to concentrated $\mathrm{CO}_{2}$, however the logistics for a flue gas scenario are very challenging and raise questions as to the practicality of this scenario for such a large facility size. 
Algal retention efficiencies across the dewatering steps were next investigated on a "net" efficiency basis. Here, the net retention represents the overall fraction of biomass produced from the cultivation ponds, which is ultimately recovered in the final dewatered product stream and available for downstream conversion. In the base case, this is very high at $99.9 \%$ with the only loss from the system occurring in the blowdown stream removed from the primary settler clarified water recycle. If this loss were increased to $10 \%$ ( $90 \%$ net retention), whether through increased blowdown or otherwise routing a fraction of the clarified water streams from dewatering away from the ponds (for example, to downstream anaerobic digestion in the conversion facility as was done in the 2012 harmonization model [23]), MBSP would increase by $\$ 107 /$ ton. Note that the "gross" dewatering efficiency is considerably lower, as the raw product of the three individual dewatering steps $(90 \times 99.5 \times 97 \%=87 \%)$. However, variances in individual retention efficiencies and therefore gross dewatering efficiency carry little economic impact assuming high recycle of clarified effluent streams and resultant net efficiency.

The final sensitivity parameter worth mentioning is the facility size based on wetted cultivation acreage. Beyond the economy of scale implications for individual pond size and configuration discussed previously, we also investigated how changing the assumed overall facility size impacts MBSP. For this parameter, the same 100-acre module layout for pond groupings was maintained, but total number of modules were either increased or decreased, which carries implications on circulation piping and pumping costs across the full facility, as well as total flow rates that the dewatering operations must accommodate. Figure 14 shows that if total facility cultivation footprint is doubled from 5,000 to 10,000 acres, there may be a fairly marginal savings in MBSP of roughly $\$ 16 /$ ton. However, if the size is reduced to 1,000 acres, MBSP costs increase more substantially by $\$ 102 /$ ton, driven by economy of scale losses for dewatering equipment (mainly central dewatering, as primary gravity settler dewatering scales linearly as individual module count is changed). The remaining sensitivity parameters are largely selfexplanatory. 
Average productivity, $\mathrm{g} / \mathrm{m} 2 /$ day $(40: 25: 15)$ Composition + productivity, g/m2/day (HPSD @ 35 : HCSD @ 25 : HLSD @ 15)

Leakage control (in-situ clay : fully lined) CO2 price $\$ /$ tonne $(\$ 0: \$ 45: \$ 100)$ Overall (combined) dewatering efficiency "net" (99.9\%: $90.0 \%)$ Cultivation area, acres $(10,000: 5,000: 1,000)$ Biomass composition (HCSD : HPSD) $\mathrm{TCl}(-25 \%: 0 \%:+25 \%)$

Flue gas vs. $\mathrm{CO} 2$ (flue gas : $\mathrm{CO} 2$ ) Pond CAPEX (\$124MM : \$159MM: \$197MM) Dewatering CAPEX $(-50 \%: 0 \%:+50 \%)$ On-stream factor, days/year $(365: 330: 300)$ $\mathrm{CO} 2$ recycle $(30 \%: 0 \%)$ Labor costs $(-50 \%: 0 \%:+50 \%)$ $\mathrm{N}$ recycle $(90 \%: 0 \%)$ Power Cost $(\$ 0.068 / \mathrm{kWh}: \$ 0.100 / \mathrm{kWh})$ Seasonal Variability $(1: 3: 5$ Inoculum system design basis, summer days between inoculation $(40: 20: 10)$ CO2 utilization efficiency ( $95 \%: 90 \%: 85 \%)$ Paddlewheel work, kWh/ha/day (48: $55: 75)$ Recirculation (gravity flow in one direction: pumping both directions)

$P$ recycle $(50 \%: 0 \%)$

Membrane power, $\mathrm{kWh} / \mathrm{m} 3(0.02: 0.04: 0.4)$ Annual average evaporation rate, $\mathrm{cm} /$ day $(0.06: 0.09: 0.12)$ Sulfur cost, $\$ / \mathrm{lb}(\$ 0: \$ 0.14)$ Centrifuge power, $\mathrm{kWh} / \mathrm{m} 3(0.7: 1.45: 2)$

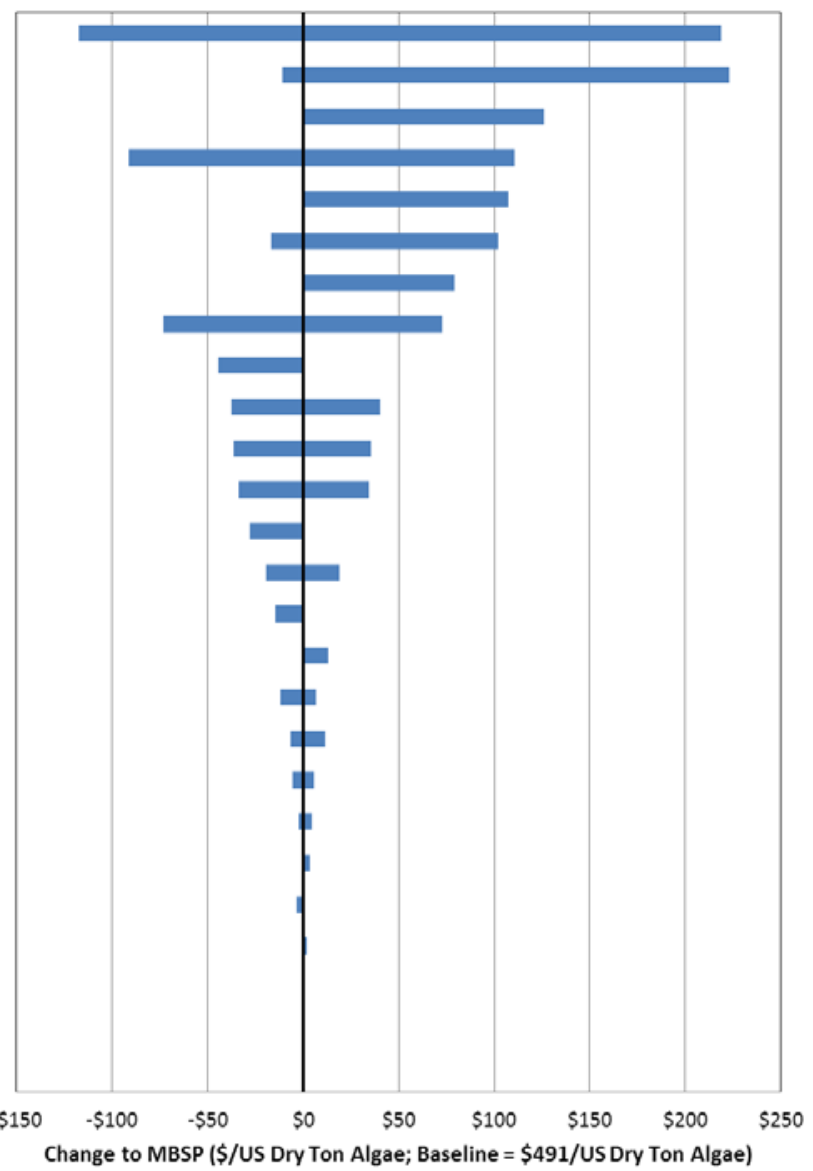

Figure 14. Tornado plot presenting results of the single-point sensitivity analysis on MBSP cost (\$491/ton reference case) 


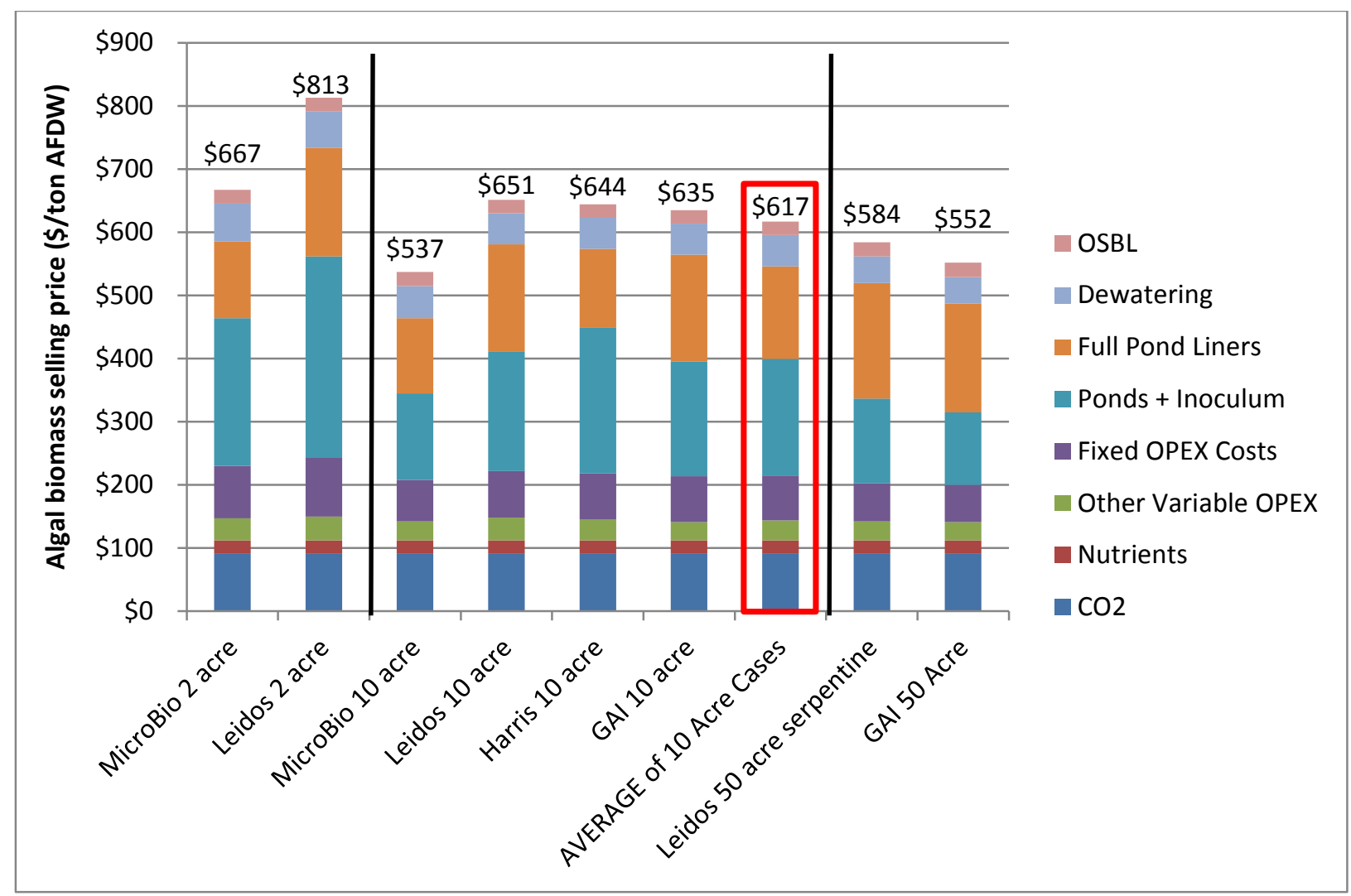

Figure 15. MBSP results for alternative scenario based on fully lined ponds.

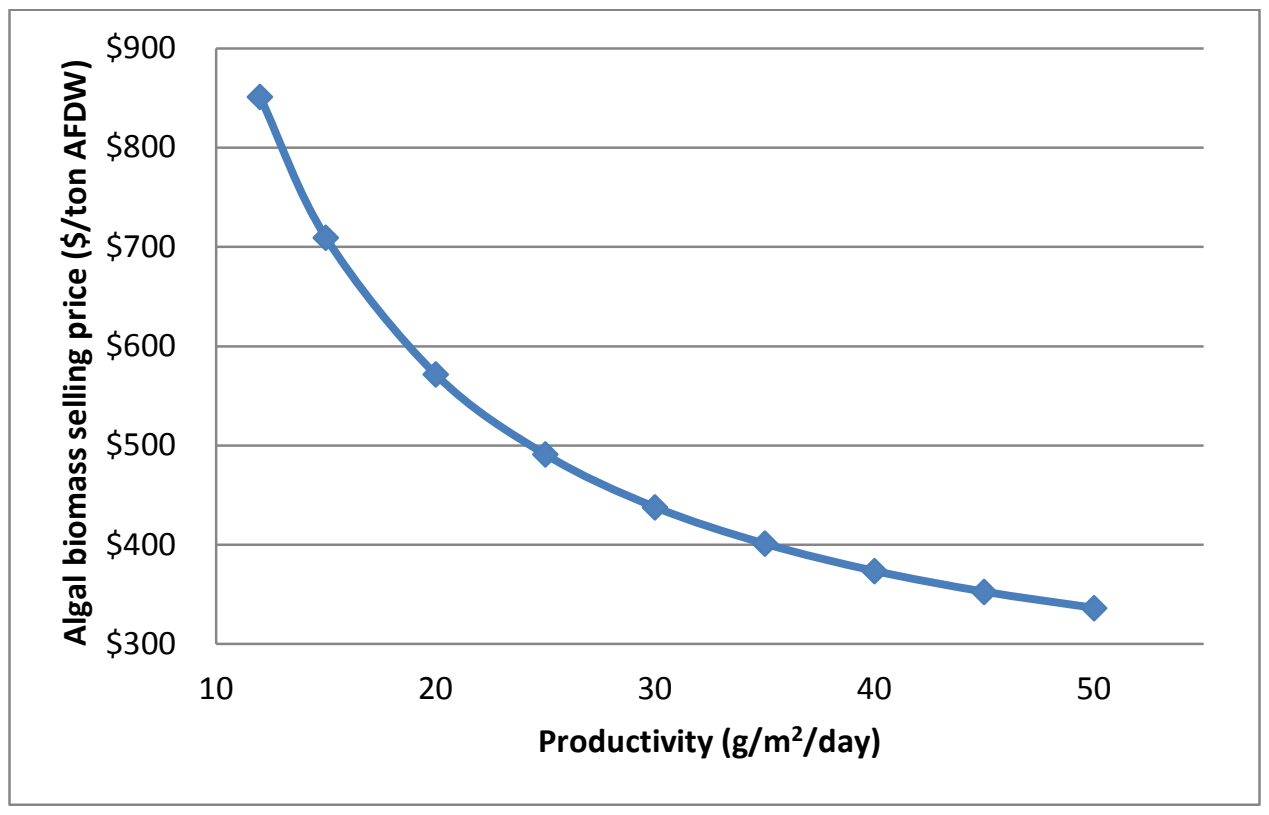

Figure 16. Scan of MBSP vs. Productivity for the Base Case (10-acre average pond costs) 


\section{Alternative Scenarios}

In addition to the single-point sensitivity analysis considered above, a number of additional alternative scenarios were also evaluated, which either do not fit with the tornado plot format or otherwise warrant further discussion and context. These additional scenarios are presented here, and include: (1) replacing purified $\mathrm{CO}_{2}$ with bulk flue gas (expanding on the single-point analysis discussed briefly above), (2) considering two alternative strains and biomass compositions for their impacts on MBSP, and (3) evaluating alternative dewatering options beyond the combination of the three operations utilized for the base case.

\section{Flue Gas $\mathrm{CO}_{2}$ Sourcing}

We first present a more detailed discussion related to the option to utilize bulk flue gas in the modeled pond facility. A key benefit of algae cultivation is its potential for capture and reuse of $\mathrm{CO}_{2}$ from point emitters including power plants. Indeed, the baseline $\mathrm{CO}_{2}$ cost of $\$ 45 / \mathrm{metric}$ tonne discussed in Section 4.3.3 is derived from cost estimates of flue gas $\mathrm{CO}_{2}$ separation, compression, and transportation at pulverized coal power plants. Likewise, the $\mathrm{CO}_{2}$ distribution system described previously assumes pure $\mathrm{CO}_{2}$ is delivered to the facility under pressure. Direct feeding of flue gas to algae ponds, on the other hand, is a commonly proposed design alternative. This section examines direct flue gas feed and its associated techno-economic challenges.

To first compute the volume of flue gas required, a stoichiometric carbon balance of the algal culture indicates that the steady-state, summer $\mathrm{CO}_{2}$ demand of the production ponds in this report is approximately 1,440 tonne/day. In the base case for pure $\mathrm{CO}_{2}$, uptake and utilization was assumed to be $90 \%$, with $\mathrm{CO}_{2}$ sparged into deep sumps in each individual pond. Due to the relatively low $\mathrm{CO}_{2}$ concentration in flue gas, outgassing losses are typically set to $15 \%-25 \%$ for sparging low-pressure bulk flue gas (with significant levels of nitrogen) directly into pond sumps $[69,70]$. If we therefore conservatively assume $75 \% \mathrm{CO}_{2}$ uptake from directly sparged flue gas, the summer $\mathrm{CO}_{2}$ requirement is 1,920 tonne/day or $43,630 \mathrm{kmol} /$ day. For a typical $500 \mathrm{MW}$ coal-fired power plant producing 0.95 tonne $\mathrm{CO}_{2} / \mathrm{MWh}$ [106], this is equivalent to $16 \%$ of the plant's total $\mathrm{CO}_{2}$ production. The flue gas composition was taken to be (vol\%): $13.47 \% \mathrm{CO}_{2}$, $2.38 \% \mathrm{O}_{2}, 15.5 \% \mathrm{H}_{2} \mathrm{O}, 0.8 \% \mathrm{Ar}$, and $67.85 \% \mathrm{~N}_{2}$. The water content of this mixture represents saturation at atmospheric pressure and $55^{\circ} \mathrm{C}\left(131^{\circ} \mathrm{F}\right)$, typical stack conditions of coal flue gas following desulfurization [72]. The total peak flue gas requirement for the algal culture is therefore $324,000 \mathrm{kmol} /$ day. While the majority of the facility, including harvest from ponds through dewatering, operates on a 24-hour-per-day basis, as the culture itself is only growing and utilizing $\mathrm{CO}_{2}$ during daylight hours, the flue gas delivery equipment must be designed to deliver the full daily amount in 12 hours, a rate of $27,000 \mathrm{kmol} / \mathrm{h}$. At stack conditions, this is a total gas volume of 815,000 actual $\mathrm{m}^{3} / \mathrm{h}(481,000 \mathrm{ACFM})$.

At such a large volume, pipeline delivery from a power plant to the facility over any significant distance is infeasible. Using Aspen HYSYS and Aspen Process Economic Analyzer, we obtained a rough CAPEX estimate of $\$ 135 \mathrm{MM}$ (installed) for a three-stage centrifugal compressor system to raise the flue gas to $200 \mathrm{psia}(13.6 \mathrm{~atm})$. At this pressure, the compressed flue gas can be delivered up to $15 \mathrm{~km}$ (roughly 9 miles) in a 36-inch pipe before choking; the pipeline adds another \$15MM CAPEX. The instantaneous power demand for this compressor is $80 \mathrm{MW}$. Although flue gas delivery only takes place for half of the day, electrically-connected equipment of this scale cannot be simply powered up and down on a daily basis. In practice, the compressor 
would continue to run overnight to maintain pressure in the pipeline; we estimated a daily average of $75 \mathrm{MW}$. It must be stressed that at 0.95 tonne $\mathrm{CO}_{2} / \mathrm{MWh}$, this is more power than is generated along with the 1,440 tonne/day of $\mathrm{CO}_{2}$ actually being utilized (63MW). Furthermore, assuming this power demand and a $13 \%$ annual capital charge (consistent with the standard DCFROR methods), the cost of $\mathrm{CO}_{2}$ delivered over the relatively short distance of $15 \mathrm{~km}$ is $\$ 49 /$ tonne, or $10 \%$ larger than the baseline $\$ 45 /$ tonne assumption for pure $\mathrm{CO}_{2}$. Economically and energetically, pressurized flue gas delivery is not a competitive alternative to $\mathrm{CO}_{2}$ separation over any significant distance.

If flue gas cannot be economically transported any significant distance by pipeline, then direct flue gas feed requires that the algae facility be co-located with the power plant. To that end, we considered a flue gas distribution system to replace the pure $\mathrm{CO}_{2}$ distribution system described earlier, using large-diameter HDPE pipes and induced-draft fans. The flue gas was assumed to be available at the saturated conditions described above, in the same location in the facility as the dewatering section. HDPE was chosen primarily for corrosion resistance. As noted above, the flue gas is saturated with water vapor at $55^{\circ} \mathrm{C}$. As all of the piping runs are several kilometers long, water will condense from the flue gas as it cools. Condensate from flue gas is acidic due to dissolved $\mathrm{CO}_{2}$ and will damage steel pipe and ducts over time if not mitigated.

Figure 17 shows the layout of flue gas piping and fans. Piping was sized at either 60 inches or 48 inches, depending on flow. It was impractical to combine the gas flow to the more distant branches in a single pipe (as was done for pure $\mathrm{CO}_{2}$ distribution), because the diameter required was prohibitive. Each fan was assumed to have an outlet pressure of 15 inches of water gauge (INWG). Fans were spaced along the runs to boost gas flow where the pressure approached zero, however again as noted previously the realistic constraints imposed by power distribution and availability at any given location in the facility could preclude placing fans in these specific locations along the runs. Centrifugal blowers connected to the headers serve each 100-acre module to ensure sufficient pressure to deliver flue gas to the spargers in each pond. Each blower's outlet pressure was 82 INWG (3 psig).

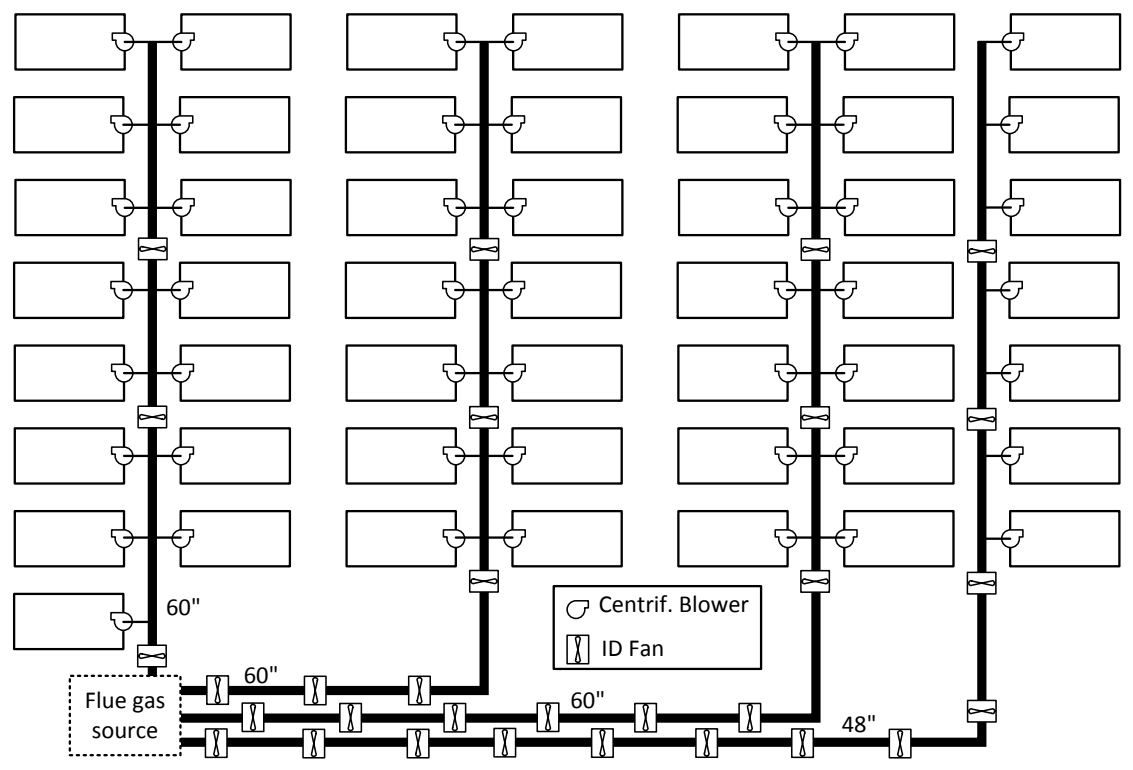

Figure 17. Layout of flue gas piping and fans for the 50 -module system 
Cost estimates for the HDPE piping runs, fans, and blowers were developed in ACCE. The installed capital cost for the system shown in Figure 16 is roughly $\$ 52 \mathrm{MM}$, more than 8 times the capital cost of the baseline pure $\mathrm{CO}_{2}$ distribution costs. The combined annual average power draw for the fans and blowers is $7,100 \mathrm{~kW}$. For TEA purposes, we assumed this instantaneous power demand would only be drawn for half of each day. After removing the costs for pure $\mathrm{CO}_{2}$ and its distribution capital from the base case, the resultant biomass cost was approximately $\$ 447 /$ ton (shown previously in Figure 14).

As a TEA exercise, direct feed of power plant flue gas to the algae culture appears to be a viable alternative to the baseline of pure $\mathrm{CO}_{2}$ feed, as it has the potential to reduce the most significant material operating cost essentially to zero (excluding consideration of power costs for either scenario). However, we have demonstrated that compression of whole flue gas at $13 \%-14 \% \mathrm{CO}_{2}$ into a reasonably sized pipeline, even for short distances, is infeasible as it can require more electricity to deliver a given amount of flue gas $\mathrm{CO}_{2}$ than was generated with that $\mathrm{CO}_{2}$ in the first place. We further demonstrated that a plant-adjacent co-located algae facility can work, but in reality the practicality of this scenario is more questionable given the requirement to find a suitable area with such a large available footprint for the combined facility (and particularly so for numerous such facilities as would be required to meet a national scale fuel production rate of 5 billion gallons per year, as was considered in prior harmonization efforts $[23,42])$. Flue gas delivery in a co-located facility is also significantly more capital-intensive than pure $\mathrm{CO}_{2}$ feed, which is a disadvantage from a capital utilization standpoint, as the delivery system is only used for half the day. Considering the robust field of flue gas $\mathrm{CO}_{2}$ capture research, and DOE's interest in the topic, pure $\mathrm{CO}_{2}$ feed is the more likely practical scenario for the foreseeable future at least for a large commercial facility near the size considered here. Other alternatives also exist, for example a system that GAI employs noted previously which is based on injecting flue gas $\mathrm{CO}_{2}$ into a closed carbonation system consisting of an absorption scrubber located on a circulation loop external to the pond; GAI indicated favorable operating performance for this system, including high $\mathrm{CO}_{2}$ retention efficiencies (with the inclusion of bicarbonate to regulate pond alkalinity) and lower/more favorable results for both $\mathrm{CO}_{2}$ costs and LCA profile attributed to this method for $\mathrm{CO}_{2}$ delivery than the pure $\mathrm{CO}_{2}$ results presented here [61]. Such a design is plausible here as well, but would be dependent on numerous factors including water chemistry/alkalinity, biomass growth rates versus circulation rates, and overall size/number of ponds a single carbonation station serves.

\section{Alternative Strains and Compositions}

As described in Section 2.3, the strain and compositional details selected for use in the base case model was based on Scenedesmus biomass harvested under mildly deplete nutrient conditions at ASU and subjected to thorough compositional analysis at NREL. This strain and compositional profile was selected to (1) remain as agnostic as possible to the downstream conversion pathway, with both component and elemental compositions available to a high degree of mass closure for use in downstream conversion models, (2) set a reasonable lipid content (27 wt\%) that is not overly-aggressive to justify the concomitant productivity targets projected in the model (25 $\mathrm{g} / \mathrm{m}^{2} /$ day AFDW annual average), and (3) make use of a strain with commercial relevance and application. Beyond the mid-harvest, high-carbohydrate/mid-lipid Scenedesmus (HCSD) biomass considered in the base case, two other strains also have been analyzed over a similar harvesting regime and varying states of nutrient depletion, including a freshwater Chlorella and a saline Nannochloropsis strain. These additional strain/composition scenarios were also 
considered in the model for their impact on MBSP, primarily through differences in nutrient costs dictated by biomass elemental composition (see Table 2), but also to enable consideration of a saline scenario for the Nannochloropsis case. For all strains and compositions considered here, seasonality effects were maintained with seasonal biomass productivities held constant as described in Section 4.1.2; downstream dewatering performance and cost assumptions were also left unchanged, but it is noted that in reality the efficacy of any given dewatering operation can be highly strain-dependent $[79,107,108]$. Thus, to better inform this scenario analysis, experimental data is needed for both biomass productivity tied to compositional analysis, as well as dewatering performance conducted in an integrated process for a range of strains.

A total of eight strain/composition scenarios were run through the biomass production model beyond the HCSD base case, with results shown in Figure 18. All strain details and identifying acronyms are shown in Table 2 (Section 2.3), but in summary, "HP," "HC," and "HL" denote high-protein (early harvest/high-nitrogen), high-carbohydrate (mid-harvest/nitrogen limited), and high-lipid (late-harvest/nitrogen deficient) harvesting regimes, respectively, according to the original protocols for growing and harvesting biomass employed at ASU, while "SD," "CZ," and "NC" denote Scenedesmus acutus (LRB-AP 0401), Chlorella vulgaris (LRB-AZ 1201), and Nannochloropsis granulata, respectively. Requirements for $\mathrm{CO}_{2}$, ammonia, and DAP were set following the same approach as discussed for the base case model, based on a $20 \%$ excess of the stoichiometric $\mathrm{N}$ and $\mathrm{P}$ demands for the given biomass composition at harvest, and stoichiometric $\mathrm{C}$ demands (plus additional $\mathrm{CO}_{2}$ to account for retention efficiency losses). Blowdown splits were left unchanged from the base case model for both the SD and CZ freshwater cases, in all cases maintaining circulation salt content below 4,000 $\mathrm{mg} / \mathrm{L}$ with an incoming salt content of $250 \mathrm{mg} / \mathrm{L}$ in the makeup freshwater. The blowdown for the $\mathrm{NC}$ case was adjusted given both higher incoming salt content of the makeup saline/brackish water (7,700 $\mathrm{mg} / \mathrm{L}$ ) and salt tolerance of the NC strain (up to 34,000 $\mathrm{mg} / \mathrm{L}$ ) based on typical values employed in PNNL's Resource Assessment model for Nannochloropsis grown in the general Gulf Coast region [109]. The high salt concentration of the blowdown streams for the saline Nannochloropsis case incurs an additional cost for salt/brine disposal. The brine disposal cost was set at $\$ 2.64 / \mathrm{m}^{3}$ associated with brine deep well injection [110]. This disposal cost translates to a $\$ 32 /$ ton increase in MBSP for the Nannochloropsis cases, which is a non-trivial cost penalty and further supports the choice of a freshwater base case (if the facility were nearby a coast such a disposal cost may not be required). The off-site makeup saline water delivery assumptions for the NC case were left unchanged relative to the freshwater cases (i.e. $108 \mathrm{~m}$ total head for bringing makeup water to the facility from a nearby resource).

As noted in the previous section for the single-point sensitivity analysis, the given SD biomass composition translates to a considerably higher MBSP for the early-harvest/high-protein case, given a nearly fivefold higher cost for $\mathrm{NH}_{3}$ and DAP nutrients relative to the mid-harvest HCSD basis (again noting the important caveat that this is before accounting for any potential nutrient recycles from downstream). On the other hand, late-harvest HLSD biomass results in a nearly identical MBSP (in fact marginally higher) as the amount of savings in N/P nutrients is much smaller, which is offset by a higher cost for $\mathrm{CO}_{2}$ given a $6 \%$ higher carbon content for HLSD relative to HCSD. Thus, purely based on considerations of nutrient loading tradeoffs associated with maintaining a culture in rapid growth phase (N-replete) versus lipid accumulation phases (N-limited or N-deficient), the HCSD basis appears to offer an optimum. This may or may not be the case when also considering the associated implications on the biomass productivity rate for 
these scenarios, as discussed in the single-point analysis above. The trends for the Chlorella biomass mirror those of the Scenedesmus strain across the various compositional profiles, but shifted up between $\$ 2-\$ 8 /$ ton for any given compositional basis. The Nannochloropsis results are somewhat different than either of the first two cases, with costs increasing in order of HL, $\mathrm{HC}$, and $\mathrm{HP}$ compositions, given a more dramatic decrease in $\mathrm{N}$ and $\mathrm{P}$ composition moving from the $\mathrm{HC}$ to HL scenarios, combined with a large reduction in ash content, which is much higher in general for the Nannochloropsis biomass (being a saline strain) than for either of the freshwater cases. The ash content is not assumed to detrimentally impact process performance for any of the facility operations, but it does increase total throughputs and thereby costs, particularly as biomass AFDW solids content begins to increase in the later dewatering steps. There was not a noticeable impact on MBSP attributed to dramatic differences in blowdown removal, as the blowdown fraction did not need to be substantially adjusted given the higher salinity tolerance of the strain. The HCNC basis result for the mid-harvest Nannochloropsis is estimated to increase MBSP by $\$ 67 /$ ton relative to the HCSD baseline for Scenedesmus. While these results are insightful, they would benefit further from experimental data for cultivation productivity attributed to any of the given compositional scenarios. Furthermore, again as noted previously, if downstream conversion processing operations allowed for a high degree of $\mathrm{N}$ and $\mathrm{P}$ recycle in a fully integrated facility, the nutrient cost penalties for HP vs HC compositions or for NC vs SD strains would be diminished (although the general comparative trends would still be applicable).

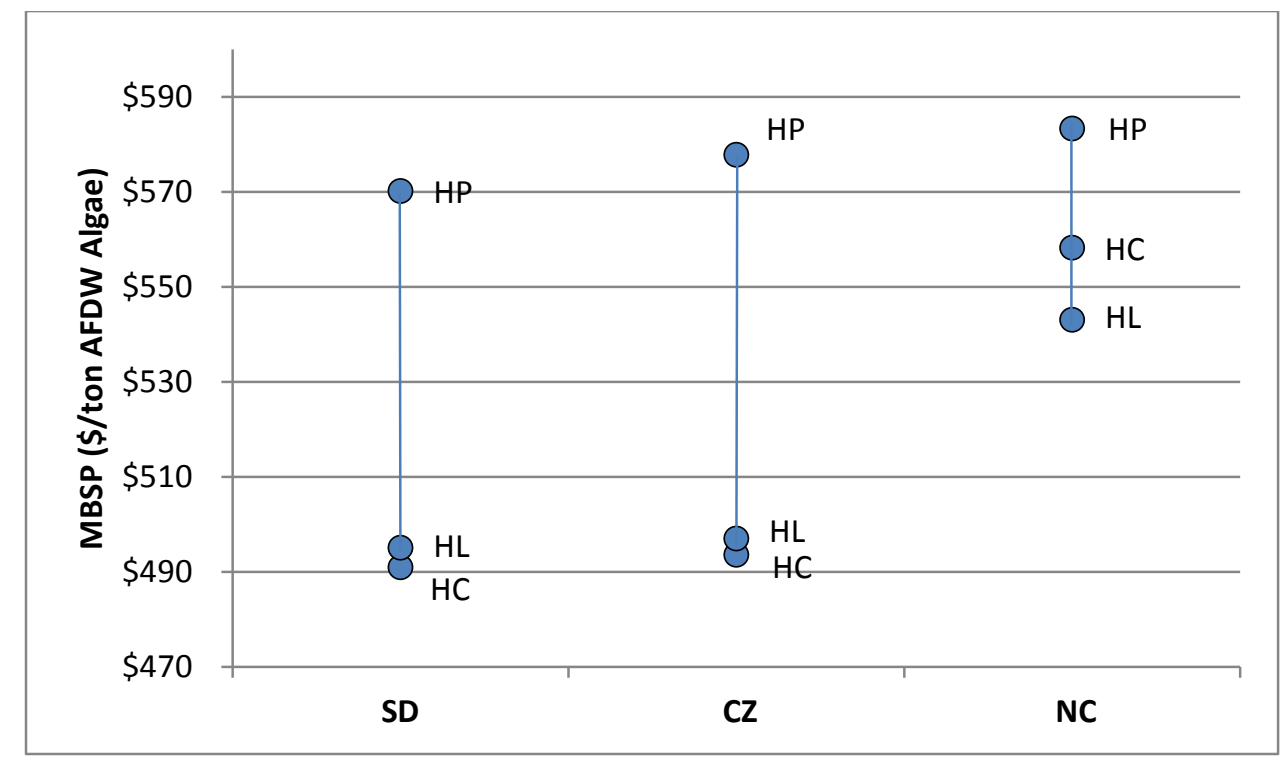

Figure 18. Modeled MBSP for three strains across three growth/harvesting regimes. $(S D=$ Scenedesmus (freshwater), CZ = Chlorella (freshwater), NC = Nannochloropsis (saline); HP, HC, and HL represent early-harvest/high-protein, mid-harvest/high-carbohydrate, and late-harvest/high-lipid biomass, respectively, based on original growth conditions used to generate biomass for analytical characterization. See Section 2.3, Table 2. Base case reference points are represented by HC cases; MBSP values are \$491/ton, \$494/ton, and \$558/ton for HCSD, HCCZ, and HCNC, respectively).

\section{Alternative Dewatering Scenarios}

Beyond the baseline dewatering configuration utilized for the base case, three alternative dewatering strategies were also evaluated for cost implications on MBSP. These alternative scenarios include: (1) replacing the secondary dewatering step utilizing membranes with a dissolved air flotation (DAF) system employing chitosan flocculant, (2) replacing the membranes 
with electrocoagulation technology, and (3) replacing the membranes and centrifuge (second and third dewatering steps, respectively) with a belt filter press. A more detailed explanation of each alternative scenario and its process design and cost assumptions is presented is Section 4.5. For both the base case dewatering system and the alternative scenarios, a number of single-point sensitivities were performed on key parameters to capture the range of variability for each parameter as presented in literature. The results are displayed in Figure 19.

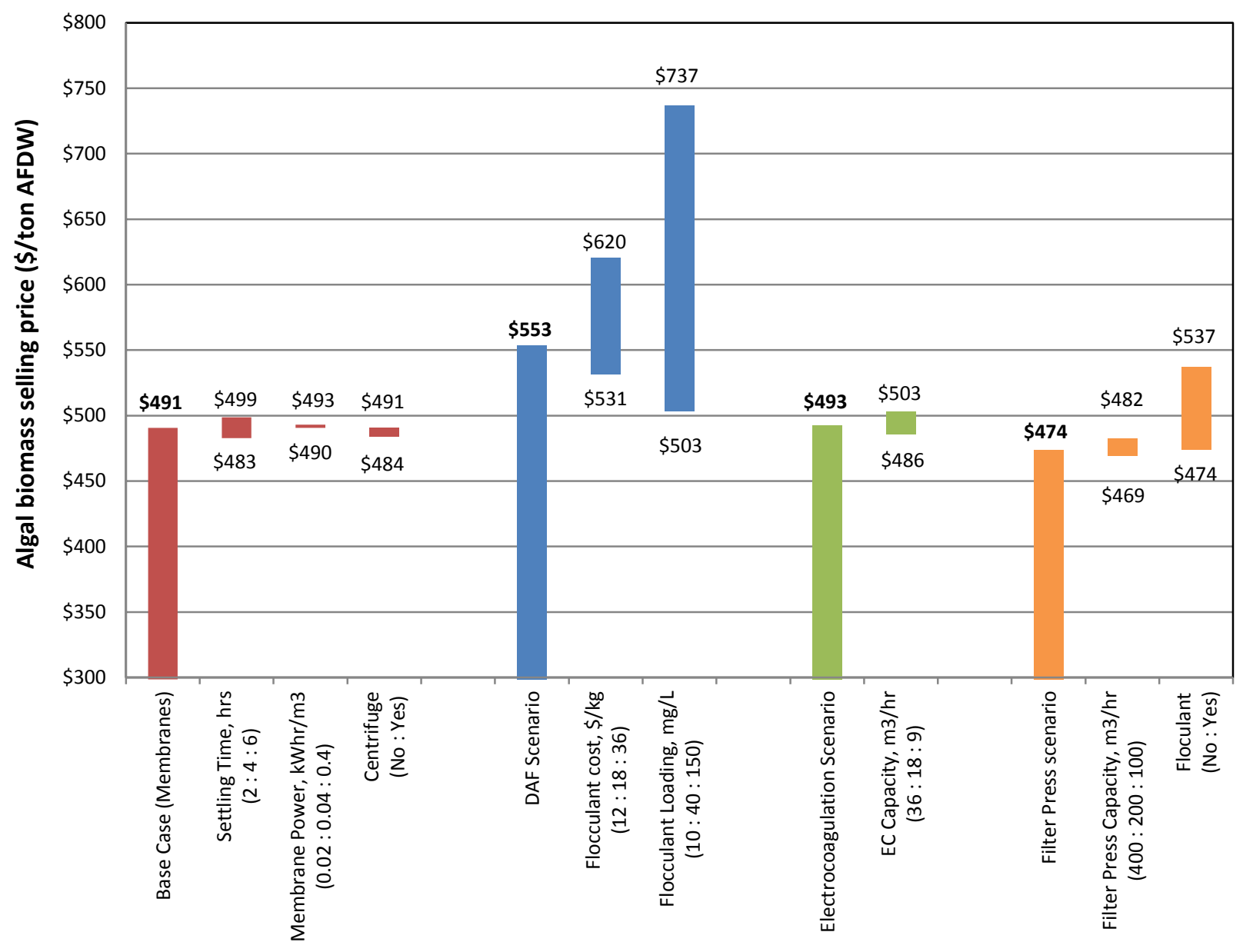

Figure 19. MBSP implications for alternative dewatering scenarios

First, the base case dewatering assumptions were examined with respect to settling time as required for the first-stage gravity settling step and for the power demand required for the second-stage membrane step. Settling time in primary settlers can vary significantly depending on factors such as algal species and settler design. The baseline value for settling time was assumed at 4 hours, based on feedback from MicroBio [25] who supported 4-6 hours as being reasonable for simplistic in-ground gravity settlers based on their operating experience with these units. Additionally, large-scale trials have demonstrated settling velocities of $1 \mathrm{~m} / \mathrm{hr}$ [43], which supports settling times of 4-6 hours for the 15-foot deep settler design. The high sensitivity value of 6 hours considered here represents a settling velocity of slightly less than $1 \mathrm{~m} / \mathrm{hr}$, while the low sensitivity value of 2 hours would represent an optimistic settling time that is likely achievable only using a shallower design. The results of the sensitivity study on settling time 
indicate a relatively small impact on MBSP, with the total MBSP range limited to $\$ 16 /$ ton between 2-6 hours. The power required to operate the base case membrane system also was examined. GAI has demonstrated an operational power demand for this unit of $0.04 \mathrm{kWh} / \mathrm{m}^{3}$ of feed to the membranes, and has subsequently improved on this result further with an expected "best case" power demand of $0.02 \mathrm{kWh} / \mathrm{m}^{3}$ [61] (set as the low sensitivity point here). However, such values are considerably lower than those reported elsewhere, as in Bilad et al. [77], which estimates the power consumption for this operation to be roughly an order of magnitude higher, therefore the high sensitivity value was set to $0.4 \mathrm{kWh} / \mathrm{m}^{3}$. While this may be expected to carry larger implications on overall facility power demand and associated sustainability metrics, the resulting impact to MBSP is marginal with only a $\$ 3 /$ ton difference between the high- and lowpower estimates. A final "aspirational" sensitivity assumed that the membranes are capable of achieving $20 \%$ solids, compared to the baseline case of $13 \%$, thereby eliminating the centrifuges altogether (supported by feedback from GAI who indicated further optimization allowing for outlet concentrations beyond 13\%). This scenario would result in a cost savings of $\$ 7 /$ ton.

Relative to the use of hollow fiber membranes for secondary dewatering, two of the three alternative dewatering options resulted in similar MBSP estimates while the third was noticeably higher. Namely, the DAF scenario is the most expensive of the options considered, primarily as a result of high operating costs due to flocculant requirements as assumed for the basis DAF design. This translates to an estimated MBSP roughly $\$ 60 /$ ton higher than the membrane base case. The electrocoagulation alternative to DAF or membranes as a secondary dewatering step translates to a similar MBSP at $\$ 3 /$ ton above the membrane basis. This is primarily due to high capital cost per unit volume processed for this operation. While this technology has recently gained in attention and research focus as a promising candidate for algal biomass dewatering (this was considered as a leading candidate by the National Alliance for Advanced Biofuels and Bioproducts (NAABB) consortium [51]), performance data for this unit is still lacking, particularly as may be required to support projecting targets for the technology out to 2022 for large commercial-scale operations. The filter press option results in a marginally lower MBSP estimate by $\$ 17 /$ ton relative to the membrane plus centrifuge base case, which is within the margin of uncertainty, and it also does not have a lengthy history (as supported by literature) specific to processing algae as much as other options, thus the reason it was restricted to consideration as an alternative scenario early on in the work. This operation would benefit from additional experimental validation to support its efficacy and cost potential for the use of algal biomass dewatering.

The DAF scenario was further evaluated for MBSP implications attributed to both cost and loading of flocculant, given considerable ranges for either parameter based on public information. The use of chitosan is maintained as the flocculant material (consistent with prior harmonization modeling efforts) as discussed previously in Section 4.5, primarily in an attempt to remain agnostic toward downstream processing operations or product/coproduct specification issues, which could become challenged with the use of an inorganic flocculant such as alum. Chitosan costs were set based on information from commercial vendors [86]. The value for low, baseline, and high chitosan costs are $\$ 12, \$ 18$, and $\$ 36$ per $\mathrm{kg}$, respectively. Over this price range (which is wide enough that it also may be viewed as representative for flocculant costs in general), MBSP costs are impacted significantly with a $\$ 89 /$ ton range in MBSP between the lowprice and high-price estimates. Required flocculant loading is also an operating parameter that can vary based on algal species and cell concentration [82]. Optimal chitosan dosage, 
specifically, was seen to vary widely between 2 to $200 \mathrm{mg} / \mathrm{L}$ in one study, dependent on the algal species [84]. Dosages of 2 and $200 \mathrm{mg} / \mathrm{L}$ are otherwise at the far fringes of the spectrum for what would be reasonable, therefore low and high values for chitosan dosage were adjusted to 10 and $150 \mathrm{mg} / \mathrm{L}$, respectively. The baseline value of $40 \mathrm{mg} / \mathrm{L}$ was reported in Heasman et al. [83]. As can be seen in Figure 19, flocculant loading has a significant impact on MBSP, more so than all other dewatering sensitivities. Increasing chitosan loading from 40 to $150 \mathrm{mg} / \mathrm{L}$ increases the MBSP by $\$ 184$, while reducing it to $10 \mathrm{mg} / \mathrm{L}$ decreases MBSP by $\$ 22$. This carries significance both for the use of DAF (which normally requires a flocculant to operate with good performance), but also for any other dewatering technique that may require flocculant usage, with the primary point being that flocculants are costly and their use should be minimized as much as possible, particularly for early operations with very low solids.

Neither electrocoagulation nor filter press technologies have been proven for dewatering algae at demonstration-scale for extended trials, and consequently the processing capacity of either option is relatively uncertain for a commercial scale model such as this. Estimating capacity improvements that may be plausible in the future is difficult, but conversations with equipment vendors provided information necessary to make initial estimates. Filter presses often employ a dewatering table as an inexpensive "pre-dewatering step" prior to the filter press. The dewatering table can concentrate the slurry by a factor of 3-5, although no research on dewatering tables used for algae was found in the literature. Nevertheless, a dewatering table followed by a filter press provides the potential to significantly increase capacity versus a filter press alone, while adding little in capital cost, therefore the high capacity case for the filter press sensitivity was set to $120 \mathrm{~m}^{3} / \mathrm{hr}, 200 \%$ of the baseline capacity of $40 \mathrm{~m}^{3} / \mathrm{hr}$. There are opportunities to reduce the cost of electrocoagulation technology, but a $200 \%$ increase in capacity for the same capital cost is likely overly optimistic for this case, therefore the high-capacity case for electrocoagulation was set at $36 \mathrm{~m}^{3} / \mathrm{hr}, 100 \%$ greater than the baseline capacity of $18 \mathrm{~m}^{3} / \mathrm{hr}$. The low-capacity case for both the filter press and electrocoagulation scenarios was set to $50 \%$ of baseline capacities. The resulting impact on MBSP tied to processing capacity is relatively minor, at $\$ 13 /$ ton for the filter press and $\$ 18 /$ ton for electrocoagulation. A final sensitivity considers the addition of flocculant for the filter press operation. Filter presses often employ flocculant to enhance separation, therefore the filter press scenario was also evaluated with the use of chitosan at the same cost and dosage levels assumed in the DAF scenario. Adding chitosan flocculant to the filter press operation increased MBSP by $\$ 64 /$ ton.

To summarize, the dewatering sensitivity analysis supports that membranes offer a cost-effective strategy for the important secondary dewatering step (moving between low-cost but still lowconcentration gravity settling and third-stage centrifugation, which is inexpensive if the initial concentration is around 10\%), and membrane dewatering efficacy has also been proven at large scale over sustained operations. Filter presses offer potential as well, but require further experimental investigation and validation to support their use specific to algal processing. Of all parameters considered, flocculant loading and cost exhibit much stronger drivers on MBSP than other variables, if their use is required (e.g., for DAF or otherwise). Assuming that flocculants are not used, dewatering operations do have room for improvement and certainly have more room for large-scale experimental validation across multiple strains, but do not appear to offer potential cost reductions of the same magnitude as the production pond area. 


\subsection{Sustainability Metrics for Base Model}

Following standard practice for recent design reports, here we provide an estimate of life-cycle resource consumption and environmental emissions. LCA provides a framework from which the environmental sustainability of a given process may be quantified and assessed. This section presents the sustainability metrics of the current conceptual process across the feedstock production and dewatering stages, with a focus on the greenhouse gas, fossil energy, and consumptive water use profiles for the modeled process. Although sustainability metrics are presented here in keeping with other recent design report practices for cellulosic feedstock pathways [44], it is imperative to note that the results presented here are strictly confined to the upstream cultivation and dewatering steps of the process, which is otherwise inherently integrated with downstream algal biomass conversion operations (e.g., ALU, HTL, or other processing configurations). Although it is reasonable to consider sustainability metrics for the feedstock and the conversion stages independently for terrestrial biomass pathways, algal processes are more inter-dependent between feedstock production and logistics operations (cultivation and dewatering) and downstream conversion steps, including numerous recycles and power integration across the process boundaries. As such, presentation of sustainability metrics attributed to only the cultivation and dewatering stage for algal processes do not carry as much meaning as for a fully integrated facility and pose a danger of being misinterpreted, particularly given the possibility for a high degree of $\mathrm{CO}_{2}$ and nutrient recycles from back-end conversion steps which must be accounted for in the associated conversion biorefinery LCA, if not reflected here. A complete LCA of the fully integrated process, incorporating the details from this model as well as pertinent downstream operations, is required to better understand and quantify the complete sustainability profile of this technology pathway; this is the subject of planned and ongoing investigation with partners at ANL, who coordinate "official" LCA models for algal processing pathways using GREET modeling tools under the BETO platform [111]. Therefore, the results presented here represent preliminary estimates of the sustainability metrics attributed to the modeled algal biomass facility, but may be superceded in the future with ANL GREET models.

Facility input and output streams, water consumption, and other process-related metrics were derived from the algal biomass production process model described above. SimaPro v.8.0.2 software [112] was used to develop and link units quantifying life-cycle impacts as previously documented by Hsu et al. [113]. Ecoinvent v.2.2 processes were used to fill the data gaps and modified to reflect U.S. conditions [114]. The material and energy flows of the cultivation and inoculation steps capture the impacts of input raw materials and outputs, such as air emissions and water loss predicted by the process model, as shown in Table 20 . This life-cycle inventory (LCI) table and subsequent discussion of sustainability metrics considers the base case (average of the four 10-acre pond designs) for the HCSD biomass basis, including use of the average pond circulation power demand across the four 10-acre designs ( $55 \mathrm{kWh} /$ ha per 24-hour day). Additionally, the LCI data presented in Table 20 are translated to an annual average daily basis; the daily values shown here (such as tonne/day) do not reflect actual daily rates for any season of the year, but rather are the average of the rates across all four seasons. 
Table 20. Input and Output Data for Modeled Production Facility (10-acre average base case). (Note: Daily rates shown below are based on annual averages over all modeled seasons.)

\begin{tabular}{|c|c|}
\hline Products & $\begin{array}{c}\text { Annual Average Rates, } \\
\text { tonne/day }\end{array}$ \\
\hline Algal biomass (AFDW) ${ }^{a}$ & 516 \\
\hline Algal biomass (total including ash) & 528 \\
\hline Water in biomass product stream & 2,082 \\
\hline \multicolumn{2}{|l|}{ Resource Consumption } \\
\hline $\mathrm{CO}_{2}$ (counted as biogenic in origin) & 1,148 \\
\hline Ammonia & 10 \\
\hline DAP & 5 \\
\hline Total process water input ${ }^{b}$ & 26,790 \\
\hline Electricity demand, $\mathrm{kWh} /$ day $^{\mathrm{c}}$ & 234,084 \\
\hline \multicolumn{2}{|l|}{ Output Streams } \\
\hline Water lost to blowdown & 6,272 \\
\hline Algae lost in blowdown & 0.33 \\
\hline \multicolumn{2}{|l|}{ Air Emissions } \\
\hline Water lost to evaporation & 18,060 \\
\hline $\mathrm{CO}_{2}$ outgassing from ponds (counted as biogenic) & 114 \\
\hline $\mathrm{O}_{2}$ from ponds & 890 \\
\hline \multicolumn{2}{|c|}{$\begin{array}{l}\text { a Final product rate after } 1 \% \text { loss assumed for biomass degradation in storage. } \\
\text { b Total water input, including the amount contained in the biomass product stream sent to conversion (in } \\
\text { many cases, a large fraction of this water is ultimately recycled back to ponds from downstream } \\
\text { conversion steps); water "loss" from the system is } 24,331 \text { tonne/day (evaporation plus blowdown). } \\
\text { " Based on average circulation power demand attributed to all four } 10 \text {-acre pond designs; facility power } \\
\text { demand for the individual } 10 \text {-acre pond scenarios is } 212,490 \mathrm{kWh} / \text { day for GAl, } 219,700 \mathrm{kWh} / \text { day for } \\
\text { MicroBio, } 240,100 \mathrm{kWh} / \text { day for Harris, and } 286,390 \mathrm{kWh} / \mathrm{day} \text { for Leidos. Power demand shown here is } \\
\text { for ISBL power only and does not include the power consumption implicit in the } \mathrm{CO}_{2} \text { delivered from off- } \\
\text { site flue gas carbon capture (this is accounted for separately in SimaPro under captured } \mathrm{CO}_{2} \text { ). }\end{array}$} \\
\hline
\end{tabular}

Details on contributions to greenhouse gas (GHG) emissions and fossil energy consumption for the modeled biomass facility are shown in Table 21, which correspond to the information in Table 20. Fossil GHG emissions associated with the base case model are estimated to be $0.73 \mathrm{~kg}$ $\mathrm{CO}_{2 \text {-eq }} / \mathrm{kg}$ biomass. Both the $\mathrm{CO}_{2}$ input and "emissions to the air" from the cultivation ponds (attributed to $\mathrm{CO}_{2}$ retention efficiency losses) shown in Table 20 are treated as biogenic in nature, following accepted methodologies for $\mathrm{CO}_{2}$ accounting in algal biofuels LCA which dictate that although the $\mathrm{CO}_{2}$ originates from fossil power plant flue gas, the power plant is operated to generate power and not to provide $\mathrm{CO}_{2}$, which otherwise would be emitted to the atmosphere and then later could be utilized in dilute form as biogenic $\mathrm{CO}_{2}$ for growing a different biomass resource [115] (this stipulation is specific to $\mathrm{CO}_{2}$ sourcing via power plant flue gas, and would not apply for other sources such as EOR pipeline operations sourcing fossil $\mathrm{CO}_{2}$ from underground reservoirs). Biogenic $\mathrm{CO}_{2}$ does not contribute to the increase of $\mathrm{GHG}$ in the atmosphere [116] and is not considered in the IPCC global warming methodology [117]. Hence, the contributions to GHG at the cultivation stage are predominantly driven by the methods used to capture, purify, and transport the $\mathrm{CO}_{2}$ feed in concentrated form.

In this case, the material and energy inventories representative of the carbon capture technology operation were based on averages from four literature sources that presented these details for current pulverized coal post-combustion capture processes integrated with the power plant 
[72,118-120]. The resulting averaged inputs for the carbon capture process were 1.78 MEA (monoethanolamine) and $582 \mathrm{MJ}$ energy demand per metric tonne of $\mathrm{CO}_{2}$ captured, as well as an output represented by ammonia emissions of $147 \mathrm{~g} \mathrm{NH}_{3} /$ metric tonne $\mathrm{CO}_{2}$ captured. The parasitic energy demand, which accounts for additional coal burned to generate the extra steam and electricity for the integrated carbon capture system, was specified in SimaPro as $100 \%$ coal generated energy. This approach represents today's current carbon capture technology whereas the proposed algal facility model assumes a second-generation carbon capture system implicit in the $\$ 45 /$ tonne $\mathrm{CO}_{2}$ cost target by 2022 , which could reduce the GHG penalty associated with this $\mathrm{CO}_{2}$ feed stream. The remaining balance represents the GHG profile associated with the underlying LCI processes (namely $\mathrm{NH}_{3}$ and DAP nutrient inputs), and the required ISBL process electricity. For the latter, the U.S. average electricity mix from the grid was applied consistently with the basis from Argonne National Laboratory's GREET model software [111]; this includes a GHG emission factor of $0.65 \mathrm{~kg} \mathrm{CO}_{2 \mathrm{e}} / \mathrm{kWh}$ and fossil energy consumption of $7.46 \mathrm{MJ} / \mathrm{kWh}$.

At $0.4 \mathrm{~kg} \mathrm{CO}$ 2-eq $/ \mathrm{kg}$ AFDW biomass, it is evident that indirect GHG emissions due to carbon capture from flue gas contributes the most to the overall GHG emissions, with the above caveat that this is for the use of today's energy-intensive MEA amine carbon capture technology used as the basis for this factor. The second major factor is ISBL process electricity with a total GHG profile of $0.3 \mathrm{~kg} \mathrm{CO}_{2 \text {-eq }} / \mathrm{kg}$ biomass. Fossil energy consumption associated with the production facility is estimated to be $8.8 \mathrm{MJ} / \mathrm{kg}$ AFDW biomass, again largely attributed to the carbon capture process and facility electricity demands. Allocations for facility power demand broken down by process area are shown graphically in Figure 20. As noted above, were the downstream conversion process integrated with the upstream biomass facility modeled here, a number of benefits would likely be observed including (1) recycle of a fraction of $\mathrm{CO}_{2}$ anywhere between $10 \%-40 \%$ (depending on downstream conversion steps and yields), which would reduce incoming makeup $\mathrm{CO}_{2}$ demands by a similar fraction, (2) recycle of a substantial fraction of nutrients on the order of $50 \% \mathrm{P}$ and $50 \%-90 \% \mathrm{~N}$ (dependent on similar factors as noted for $\mathrm{CO}_{2}$ ), and (3) in some cases, the generation of a net electricity coproduct in the downstream conversion facility which would partially offset the power demand shown here for the biomass production facility [1].

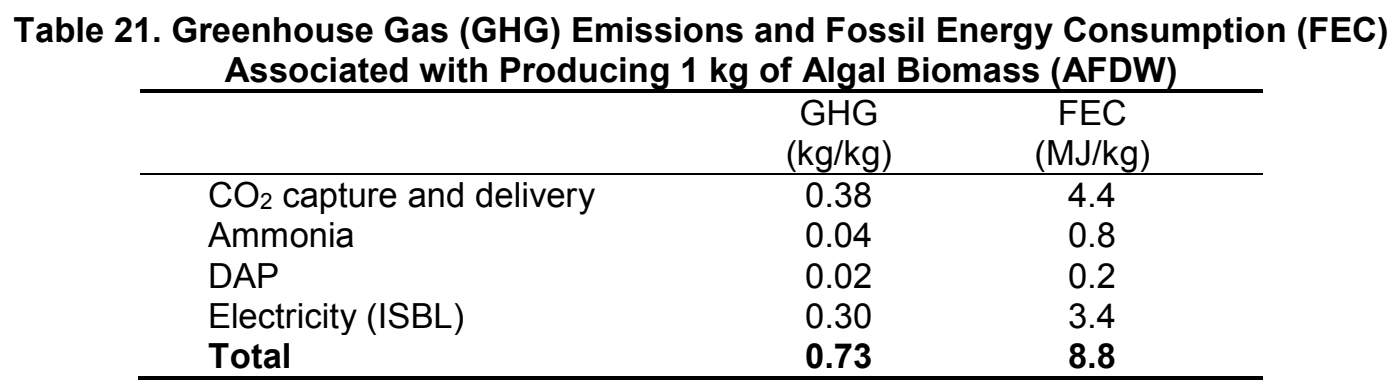

Table 22 summarizes the key sustainability metrics for the modeled biomass production facility base case (10-acre average scenario). On a mass basis, the GHG emissions for the cultivation stage are 0.73 ton $\mathrm{CO}_{2 \mathrm{e}}$ ton biomass product produced. The net fossil energy consumption is 7,962 MJ/ton biomass product (translated to a MJ/U.S. ton basis in this case given the focus on the biorefinery conversion stages typically presented in $\mathrm{MJ} / \mathrm{GGE}$ at a given GGE/ton fuel yield). In addition to GHG emissions and fossil energy consumption discussed above, water consumption (i.e., net water use during the production and dewatering operations) and total 
annual biomass yield are reported in Table 22. The net water consumption is estimated at 12,450 gal/ton biomass, which includes water maintained with the dewatered product at $80 \mathrm{wt} \%$ moisture, evaporation from production and inoculum ponds, and water lost to blowdown. Roughly $8 \%$ of this consumption ( $970 \mathrm{gal} /$ ton) is water contained in the biomass product stream, the majority of which may ultimately be made available for subsequent recovery and recycle back to the ponds from downstream conversion operations [1,2]. Either way, this is similar to water consumption estimated during prior harmonization efforts focused on the same U.S. Gulf Coast region (e.g., roughly 10,100 gal/ton projected in the 2012 harmonization study [23]). It is also substantially lower than published water demands for corn and soybean production, at 45,000 gal/ton and 63,000 gal/ton, respectively, based on average U.S. irrigation values [121]. The water footprint associated with algal biomass production is to be expected, given the use of thousands of acres of cultivation ponds open to atmospheric evaporation. While this may prove more challenging in the U.S. Southwest given water availability constraints in that region (and higher expected evaporation rates than those modeled here associated with the Gulf Coast), the original harmonization work assessed through PNNL's Resource Assessment model, which set the precedent for algal facility site screening and prioritization, was based on ensuring that no more than $5 \%$ of mean annual flows for the local watershed resources were consumed by the algal facilities, thus alleviating concerns for algal cultivation water demands becoming too taxing on local water resources in the region [23]. Additionally, water usage can also be mitigated through the use of saltwater or brackish water cultivation with more aggressive blowdown strategies. The breakouts for facility water consumption are shown graphically in Figure 20.

Table 22. Summary of Sustainability Metrics for the Process (average 10-acre pond base case)

\begin{tabular}{lr}
\hline Metric & Result \\
\hline GHG emissions (U.S. ton CO 2 /ton AFDW biomass product) & 0.73 \\
Process water consumption (m³/day) & 26,790 \\
Process water consumption (gal/ton AFDW biomass product) & 12,450 \\
Total biomass productivity (AFDW ton/acre/yr) & 38 \\
Net fossil energy consumption (MJ/ton AFDW biomass product) & 7,962 \\
\hline
\end{tabular}
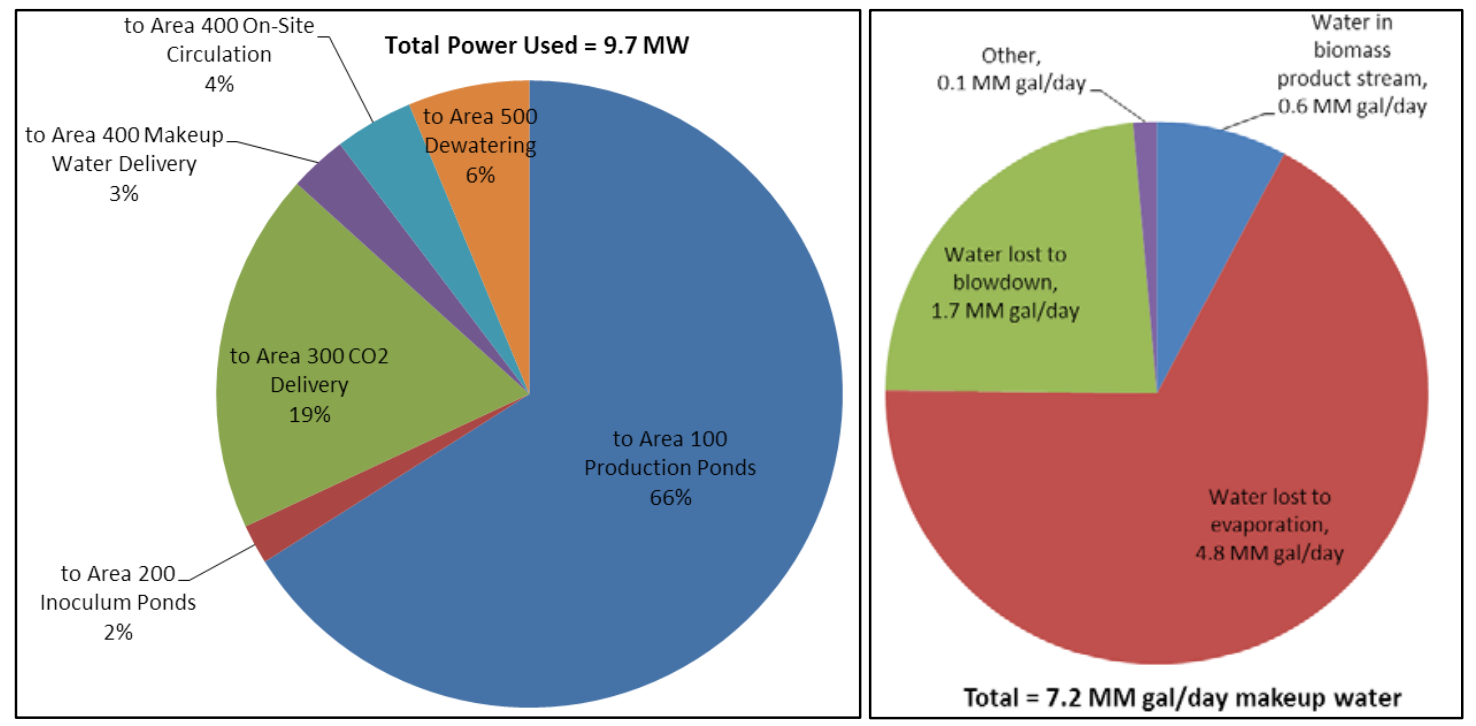

Figure 20. Allocations for ISBL facility power demand broken down by process area (left) and water consumption broken down by source of water loss (right) 


\section{Concluding Remarks}

\subsection{Summary}

The present report establishes a plausible case for achieving a modeled cost under $\$ 500 /$ ton AFDW for algal biomass production and processing, based on targets envisioned for demonstration by 2022 for improvements to both process performance and system design beyond the current state of the art. The integrated process pathway is based on a single set of sequential operations upstream and downstream of the cultivation step, including the use of high-purity $\mathrm{CO}_{2}$ delivered to the facility under pressure and sparged to individual ponds; utilization of nutrients based on demands set by biomass compositional analysis plus a small (20\%) excess; inoculum production based on sequential scale-up from a PBR to enclosed ponds to open fully lined ponds of increasingly larger cultivation volumes; a three-step dewatering process based on low-cost inground gravity settlers followed by hollow fiber membranes followed by centrifugation to concentrate the harvested biomass up to $20 \mathrm{wt} \%$ AFDW; and culture circulation throughout the 5,000-acre facility (based on wetted pond area) utilizing a series of pipelines and aqueduct channels. The key cultivation step is based on algal biomass production in open ponds and does not consider PBR cultivation (beyond that utilized for inoculum propagation) given the limited availability of cost and design details for commercial PBR systems, as well as to focus the scope of analysis from becoming too large for a single report; PBR cultivation will be a subject of future assessment. Given continuing wide disagreement in public literature around the "true" cost of algal biomass/biofuel production and a relatively large dataset of detailed pond designs made available for our use over the past two years, rather than considering a single pond design on which to base the modeled MBSP, the present analysis considers eight separate pond cost estimates furnished by four separate sources considered experts in the field across three discrete pond sizes.

The techno-economic analysis makes a number of important assumptions for future performance projections related to cultivation productivity and seasonal variability, which play a critical role in the resulting MBSP estimates. These include: (1) a target for cultivation biomass productivity at $25 \mathrm{~g} / \mathrm{m}^{2} /$ day (AFDW) based on annual average rates across individual seasons; (2) maximum seasonal variability in productivity of $3: 1$ between peak summer and minimum winter season performance (this value is particularly important for downstream conversion facility design); (3) an associated harvested biomass composition targeting a mid-level lipid content near $27 \%$ for a representative strain Scenedesmus; and (4) an $n^{\text {th }}$-plant target of 330 days/year for facility on-line time, e.g., 35 days/year downtime allowing for culture crashes, pond freezes, and planned maintenance. Based on these assumptions, the analysis conducted here presents a modeled MBSP ranging from $\$ 576-\$ 649 /$ ton AFDW (average $=\$ 612 /$ ton) of dewatered biomass for the two 2-acre pond designs considered in the integrated model, compared with an MBSP range between $\$ 452-\$ 545 /$ ton (average $=\$ 491 /$ ton) for the four 10 -acre designs, and $\$ 392-\$ 419 /$ ton (average $=\$ 406 /$ ton) for the two hypothetical 50-acre designs. These distinctive groupings highlight the important role that maximizing economy of scale plays in guiding optimum pond design for a large commercial algae farm; most importantly, increasing individual pond sizes from 1-3 acres (as currently exist today) up to 10 acres for commercial scale-up is estimated to reduce biomass cost on the order of $\$ 120$ /ton or more, which is critical to enable cost viability for biofuels through downstream conversion. While 10 -acre ponds represent a considerable increase in size beyond today's current standard, all four expert sources we consulted for 
establishment of the pond designs agree that such a size is plausible even if representing an upper limit of operability for "standard" paddlewheel raceway systems. Thus, the average of the four 10 -acre cases is selected as the "base case" for purposes of making use of a single MBSP target number, at \$491/ton AFDW in 2011 dollars. While this is a slightly higher cost result than the original BETO 2022 target of $\$ 430$ /ton projected in recent MYPP reports [45,46], it validates that a target of such a level is not unrealistic (e.g., less than $\$ 500 /$ ton), and, in fact, reaching a $\$ 430 /$ ton cost would still be within reach for example through slightly higher productivities than those projected here.

The modeled MBSP selling prices are strictly representative of $n^{\text {th }}$-plant assumptions regarding facility design, operation, and financing, and are not intended to reflect first-of-a-kind or earlyentry commercial facilities. The MBSP projections presented here are also most appropriately viewed as a "transfer price" for subsequent delivery to downstream biorefinery processing for conversion of the biomass into fuels and/or coproducts, as the high $80 \%$ moisture content of the biomass product is likely to limit economical transport of the material over any significant distance. Compared to terrestrial cellulosic biomass such as woody or herbaceous feedstocks (e.g., corn stover and switchgrass), which are typically projected at $\$ 80 /$ ton for future cost targets [46], the base case MBSP of \$491/ton projected here is significantly higher and highlights the primary challenge for algal biofuels attributed to costly biomass production and processing logistics for aquatic biomass. However, this premium for algal biomass is largely offset by the potential for significantly higher fuel yields from downstream conversion operations, on the order of 120-140 GGE/ton for either HTL or ALU algal conversion pathways, compared to roughly 50-80 GGE/ton projected for all terrestrial biomass conversion pathways considered in MYPP reports to date (including both thermochemical and biochemical conversion pathways from woody or herbaceous feedstocks) $[1,44,46]$.

Still, at a $\$ 430 /$ ton biomass price for either the ALU or HTL conversion pathway, the "best case" fuel cost for either pathway design case is currently projected at $\$ 4.35-\$ 4.49 /$ GGE if focused exclusively on fuel production. In order to further reduce fuel costs to an ultimate BETO target of $\$ 3 / \mathrm{GGE}$, either (1) biomass feedstock costs would need to reduce to a level of $\$ 300 /$ ton or less without sacrificing compositional quality or (2) the conversion pathways would need to consider opportunities for high-value coproducts. On the former point, we show in Sections 3 and 6.1 that reducing biomass cost to a level closer to $\$ 300 /$ ton would be challenging, although not impossible, requiring (for example) the pursuit of very large 50 -acre pond designs, further improving productivity beyond $25 \mathrm{~g} / \mathrm{m}^{2} /$ day annual average, and exploiting opportunities to utilize lower-cost $\mathrm{CO}_{2}$ sources. While some of these may be possible to a degree, a more readily achievable approach would likely be to consider opportunities for high-value coproducts produced alongside algal biofuels to reduce fuel costs. In the context of the ALU pathway, which is based on selective fractionation and isolation of biomass into its constituent lipid, carbohydrate, and protein fractions, there are many such opportunities for conversion of one or more of these constituents into an array of possible coproducts [122-124], which will be a subject of future research. For HTL conversion to fuels, costs may also be reduced by co-processing algal biomass with less expensive feedstocks (for example, terrestrial biomass or waste fats/greases), which may also reduce seasonal variability effects by increasing blended feeds during winter months [2]. 
Beyond the base case assumptions employed here, a number of alternative sensitivity scenarios were considered to quantify resulting impacts to MBSP. As expected, the strongest driver to overall economics was seen to be the achievable annual productivity, with substantial impacts to MBSP particularly if productivity were reduced below $25 \mathrm{~g} / \mathrm{m}^{2} /$ day (while maintaining the same compositional assumptions). Interestingly, if nutrient feeding strategies were adjusted to maintain the culture under a nutrient-replete, rapid-growth state (translating to a 4.8-fold increase in $\mathrm{N}$ and $\mathrm{P}$ nutrient costs based on the given compositional details), the resulting increase in productivity for pursuing this strategy would need to be more than $40 \%$ (e.g., more than 35 $\mathrm{g} / \mathrm{m}^{2} /$ day versus the $25 \mathrm{~g} / \mathrm{m}^{2} /$ day baseline) for this strategy to pay off compared to the lowernutrient base case at a higher state of lipid accumulation; however, this excludes any credits for nutrient recycle from downstream conversion operations, which could considerably reduce cost differences attributed to variations in composition and therefore fresh makeup nutrient costs. In any case, the resultant biomass product for such a strategy would likely be much less valuable for downstream conversion, as it would be high in protein and nitrogen but low in lipid content, carbohydrates, and overall carbon content.

The model exhibited a relatively low degree of cost sensitivity to most dewatering parameters for the low-cost dewatering strategies considered in the base case, but a higher degree of sensitivity for alternative dewatering options and particularly so for dissolved air flotation with the use of a flocculant. Finally, two critical sensitivities were considered with respect to the use of pond liners and the opportunity to utilize bulk flue gas in place of concentrated $\mathrm{CO}_{2}$. For the former parameter, the analysis reiterates that it is critical to make use of unlined ponds located on sites with high native clay content of the soil (or soil that otherwise supports physical or biological sealing), where adding full plastic pond liners would add over $\$ 120 /$ ton on average to the MBSP for the 10-acre pond designs, costing approximately as much as the pond systems themselves. If high-clay soil is not available, alternatives may exist for pond "self-sealing" by allowing a layer of algal or bacterial biomass to accumulate on the pond floor. Regarding $\mathrm{CO}_{2}$ delivery, the analysis found that in theory the use of bulk flue gas may provide the opportunity to reduce MBSP relative to the use of purified $\mathrm{CO}_{2}$ at $\$ 45 /$ tonne (sourced from flue gas carbon capture), however the logistics for flue gas pipeline transport at $10 \mathrm{vol} \%-15 \mathrm{vol} \% \mathrm{CO}_{2}$ are highly challenging and likely would require co-location of the algal facility with a flue gas point source (e.g., coal-fired power plant) for this scenario to even be plausible. Even then, it would still be limited in practicality for large flue gas pipelines feeding to individual ponds over such a large facility footprint.

In addition to providing an economic analysis, the present report also considers sustainability metrics for the base case scenario (i.e., the average of the 10-acre pond designs), by tracking and reporting on greenhouse gas emissions, fossil energy demand, and consumptive water use at the modeled production facility (production stage only, excluding downstream conversion). The sustainability analysis for the baseline scenario indicates a fossil GHG profile of 0.73 ton $\mathrm{CO}_{2 \mathrm{eq}} /$ ton AFDW biomass, fossil energy consumption of 7,962 MJ/ton, and water demand of $12,450 \mathrm{gal} /$ ton (driven primarily by seasonal pond evaporation losses). An important caveat for these results, however, is that both the GHG and fossil energy profiles are driven strongly by the assumed LCA inventory attributed to the $\mathrm{CO}_{2}$ carbon capture technology occurring off site, which is based on today's technology for MEA amine capture, whereas the $\$ 45 /$ tonne $\mathrm{CO}_{2}$ price represents a 2022 target that may be more appropriate as a second-generation carbon capture technology. Additionally, these sustainability metrics are only representative of a partial process 
focused on only the biomass production operations in an otherwise inherently integrated process with downstream conversion, thus the values carry somewhat limited meaning and a full TEA and LCA is required for the overall well-to-wheel integrated process including downstream conversion operations, in order to present a more complete understanding of such metrics. This will be a subject of continued modeling consideration moving forward between NREL and partner laboratories.

It is worthwhile to reiterate that algal production processes are still arguably in an early stage of development and understanding, relative to other terrestrial/cellulosic technology pathways. Thus, the absolute cost values established here, as well as the timeframe required to achieve these outcomes, inherently carries a somewhat higher degree of uncertainty given the nascent stage of research as presented in the public domain for operational data over sustained timeframes at large scales. This said, the economic potential for algal biomass production (i.e., at a cost target below $\$ 500 /$ ton) validates that a path forward exists to achieve a viable algal biofuels industry.

\subsection{Future Work}

Moving forward, to ultimately achieve cost goals and reduce uncertainty in key areas for the algal production and processing pathway in the context of a fully integrated process with downstream conversion, a number of important bottlenecks, uncertainties, and areas for further development are summarized below. Some of these points are repeated from NREL's recent technical memo for the algal lipid upgrading (ALU) process [125], with a common theme being the need for data, particularly for a fully integrated process at meaningful scale. More open data flow between modelers and commercial practitioners of these technologies would greatly improve our understanding of the current state of technology.

- Validate algae growth rates and biomass compositional analysis based on data from large-scale demonstrations: In order to validate realistic, achievable goals related to algal cultivation and corresponding biomass quality (i.e., composition), a sound understanding of the initial baseline is first required. While NREL and other partners have done substantial analysis on this subject $[23,42]$, these two key parameters still largely remain limited to modeled or semi-empirical data for today's current performance. Among a number of entities working to address this issue, the $\mathrm{ATP}^{3}$ and RAFT consortia programs are focused on this goal as a critical priority, working to provide publicly available data for cultivation test-bed sites located in regions across the United States. Data made available from these efforts will be leveraged in NREL's models to better quantify today's "state of technology" costs.

- Improve cultivation performance: To ultimately realize economic viability for algalderived biofuels regardless of the conversion technology, substantial improvements in both performance and cost will be required. For cultivation performance, this will depend to a large extent on both locality and strain specifics, with high-cost sensitivities on the downstream conversion process to seasonal variability factors. Minimizing seasonal variability to no more than 3:1 between peak and minimum productivities as modeled here will be important to demonstrate, whether by choice of strain(s) or location, or employing crop rotation strategies to utilize cold- and warm-temperature strains. Improving overall productivity remains a critical goal (albeit while controlling nutrient 
costs), and will likely require strain improvement efforts relative to current wild-type strain performance. Additionally, continued attention must be afforded to protection of crop yield against culture crashes (losses to grazers and pathogens) through improving strain robustness and systems design [126]; this is particularly critical in enabling the practical use of large size ponds called for in this report.

- Reduce cost for cultivation: In addition to improving cultivation performance, costs must be reduced at the same time. Primary means for reducing cultivation costs for open pond systems include avoiding pond liners (which will depend on local soil characteristics with suitable clay content, strain employed, and local regulatory policies) and constructing suitably large ponds, e.g., 10 acres or more for an individual pond configuration to maximize economy of scale benefits gained by reducing individual feed and harvest pipes, electrical runs, circulation equipment, and concrete, which are strong contributors to overall pond costs. Future work should consider production trials, soil studies, and resource modeling to identify areas with suitable soil characteristics to support the use of unlined ponds. Alternatively, further room for investigation exists to understand pond "self-sealing" mechanisms (e.g. by algal or bacterial biomass) in locations without high-clay soils. Biomass valorization to identify high-value coproduct opportunities also provides a way to offset cultivation costs.

- Reduce cost and increase efficiency of dewatering steps: While the performance for all three dewatering operations are supported to varying degrees by operational data based specifically on algae processing and concentration, they have not been demonstrated in an integrated way, nor for their specificity to a range of strains. The sequence of dewatering technologies employed in this design case are envisioned to aggressively reduce costs for this processing step, relative to more typical operations utilized today, such as centrifugation and/or the use of added flocculants.

- Identify opportunities for lower-cost carbon and nutrient sources: Costs for $\mathrm{CO}_{2}$ and nutrient inputs in the base case account for roughly $\$ 112 /$ ton out of the $\$ 491 /$ ton average 10 -acre MBSP results (over 22\% of total MBSP). One means of reducing these costs is to target conversion processes downstream that allow for a high degree of recycle back to the ponds (any such credit for recycle was not accounted for here, as instead it was accounted for in the ALU conversion design case by reducing final biofuel costs). Utilizing bulk flue gas in place of captured $\mathrm{CO}_{2}$ may provide an opportunity to reduce $\mathrm{CO}_{2}$ cost; however, this option may be limited to sites where co-locating an algal facility directly with the power plant is possible, and even then may be limited in overall facility size for flue gas delivery to ponds. Additional opportunities exist for integration with other process technologies, such as corn or cellulosic ethanol facilities, and warrant further investigation. Costs also may be reduced by considering the use of lower cost carbon/nutrient sources such as wastewater, which may at least reduce the need for dedicated $\mathrm{CO}_{2}$ or fertilizer nutrients and may also provide additional incentives for simultaneous wastewater treatment [17]. 


\section{References}

1. Davis, R., et al., Process Design and Economics for the Conversion of Algal Biomass to Biofuels: Algal Biomass Fractionation to Lipid-and Carbohydrate-Derived Fuel Products. NREL/TP-5100-62498. Golden, CO: National Renewable Energy Laboratory, 2014. http://www.nrel.gov/docs/fy15osti/62498.pdf.

2. Jones, S. B., et al., Process Design and Economics for the Conversion of Algal Biomass to Hydrocarbons: Whole Algae Hydrothermal Liquefaction and Upgrading. PNNL23227. Richland, WA: Pacific Northwest National Laboratory, 2014. http://www.pnnl.gov/main/publications/external/technical reports/PNNL-23227.pdf.

3. Davis, R., et al., Process Design and Economics for the Conversion of Lignocellulosic Biomass to Hydrocarbons: Dilute-Acid and Enzymatic Deconstruction of Biomass to Sugars and Catalytic Conversion of Sugars to Hydrocarbons. NREL/TP-5100-62498. Golden, CO: National Renewable Energy Laboratory, 2015.

http://www.nrel.gov/docs/fy15osti/62498.pdf.

4. Dutta, A., et al., Process Design and Economics for Conversion of Lignocellulosic Biomass to Ethanol: Thermochemical Pathway by Indirect Gasification and Mixed Alcohol Synthesis. NREL/TP-5100-51400. Golden, CO: National Renewable Energy Laboratory, 2011. http://www.nrel.gov/docs/fy11 osti/51400.pdf.

5. DOE, Biomass Multi-year Program Plan (MYPP)-May 2013. Washington, D.C.: Bioenergy Technologies Office, 2013. http://www1.eere.energy.gov/bioenergy/pdfs/mypp_may_2013.pdf.

6. Amer, L., et al. "Technoeconomic analysis of five microalgae-to-biofuels processes of varying complexity." Bioresource Technology, 102, 2011; 9350-9359.

7. Davis, R., et al. "Techno-economic analysis of autotrophic microalgae for fuel production." Applied Energy, 88, 2011; 3524-3531.

8. Delrue, F., et al. "An economic, sustainability, and energetic model of biodiesel production from microalgae." Bioresource Technology, 111, 2012; 191-200.

9. Harun, R., et al. "Technoeconomic analysis of an integrated microalgae photobioreactor, biodiesel and biogas production facility." Biomass and Bioenergy, 35, 2011; 741-747.

10. Beal, C. M., et al. "Algal biofuel production for fuels and feed in a 100-ha facility: A comprehensive techno-economic analysis and life cycle assessment." Algal Research, 2015.

11. Laurens, L. M. L., et al. "Acid-catalyzed algal biomass pretreatment for integrated lipid and carbohydrate-based biofuels production." Green Chemistry, 17(2), 2015; 1145-1158.

12. Rogers, J. "A critical analysis of paddlewheel-driven raceway ponds for algal biofuel production at commercial scales." Algal Research,(4), 2014; 76-88.

13. Richardson, J. W., et al. "A financial assessment of two alternative cultivation systems and their contributions to algae biofuel economic viability." Algal Research, 4, 2014; 96104.

14. Sun, A., et al. "Comparative cost analysis of algal oil production for biofuels." Energy, 36, 2011; 5169-5179.

15. Rosenberg, J. N., et al. "Microalgal biomass production and carbon dioxide sequestration from an integrated ethanol biorefinery in Iowa: A technical appraisal and economic feasibility evaluation." Biomass and Bioenergy, 35, 2011; 3865-3876. 
16. Williams, P. J. 1. B.; L. M. L. Laurens "Microalgae as biodiesel \& biomass feedstocks: Review \& analysis of the biochemistry, energetics \& economics." Energy \& Environmental Science, 3, 2010; 554-590.

17. Lundquist, T. J., et al., A Realistic Technology and Engineering Assessment of Algae Biofuel Production. 2010. http://www.energybiosciencesinstitute.org/media/AlgaeReportFINAL.pdf.

18. Pienkos, P. T.; A. Darzins "The promise and challenges of microalgal-derived biofuels." Biofuels, Bioproducts and Biorefining, 3, 2009; 431-440.

19. Chisti, Y. "Biodiesel from microalgae." Biotechnology Advances, 25, 2007; 294-306.

20. van Harmelen, T.; H. Oonk, Microalgae biofixation processes: Applications and potential contributions to greenhouse gas mitigation options. TNO Built environment and geosciences, 2006.

21. Huntley, M. E.; D. G. Redalje "CO2 Mitigation and Renewable Oil from Photosynthetic Microbes: A New Appraisal." Mitigation and Adaptation Strategies for Global Change, 12, 2006; 573-608.

22. Benemann, J. R.; W. J. Oswald, Systems and Economic Analysis of Microalgae Ponds for Conversion of Co2 to Biomass. Final Report. Berkeley, CA: California Univ. Dept. of Civil Engineering, 1996. http://www.osti.gov/scitech/servlets/purl/493389.

23. Davis, R., et al., Renewable Diesel from Algal Lipids: An Integrated Baseline for Cost, Emissions, and Resource Potential from a Harmonized Model. ANL/ESD/12-4; PNNL21437; NREL/TP-5100-55431. Golden, CO: National Renewable Energy Laboratory, 2012. http://www.nrel.gov/docs/fy12osti/55431.pdf.

24. AspenPlus2007 7.2. Cambridge MA.http://www.aspentech.com

25. Wortz I.; T. Lundquist; J. Benemann, MicroBio Engineering, Personal commumication, May 2015.

26. Christensen, P.; L. R. Dysert, Cost estimate classification system - as applied in engineering, procurement, and construction for the process industries. Recommended Practice No. 18R-97. AACE International, 2011.

27. Moreno-Garrido, I.; J. P. Cañavate "Assessing chemical compounds for controlling predator ciliates in outdoor mass cultures of the green algae Dunaliella salina." Aquacultural Engineering, 24, 2001; 107-114.

28. Wang, H., et al. "The contamination and control of biological pollutants in mass cultivation of microalgae." Bioresource Technology, 128, 2013; 745-750.

29. Jones, S., Pacific Northwest National Laboratory, Personal commumication, Nov. 2015.

30. Aden, A., et al., Lignocellulosic Biomass to Ethanol Process Design and Economics Utilizing Co-Current Dilute Acid Prehydrolysis and Enzymatic Hydrolysis for Corn Stover. Golden, CO: National Renewable Energy Laboratory (NREL), 2002. http://www.nrel.gov/docs/fy02osti/32438.pdf.

31. USDA. 2012 Census of Agriculture: United States Data-land in farms, harvested cropland, and irrigated land, by size of farm: 2012 and 2007 [cited Feb. 2016]. Available from http://www.agcensus.usda.gov/Publications/2012/Full Report/Volume 1, Chapter 1 U S/st99 1009 010.pdf.

32. Edwards, A. 2013. Australia's beautiful bright pink farms producing ALGAE that will end up in vitamin pills ... and your ice cream! Daily Mail, May 29. 
33. White, R. L.; R. A. Ryan "Long-Term Cultivation of Algae in Open-Raceway Ponds: Lessons from the Field." Industrial Biotechnology, 11(4), 2015; 213-220.

34. Laurens, L. M. L., et al. "Strain, biochemistry, and cultivation-dependent measurement variability of algal biomass composition." Analytical Biochemistry, 452(0), 2014; 86-95.

35. Rodolfi, L., et al. "Microalgae for oil: Strain selection, induction of lipid synthesis and outdoor mass cultivation in a low-cost photobioreactor." Biotechnology and Bioengineering, 102, 2009; 100-112.

36. Sheehan, J., et al., Look Back at the U.S. Department of Energy's Aquatic Species Program: Biodiesel from Algae; Close-Out Report. NREL/TP-580-24190. Golden, CO: National Renewable Energy Lab, 1998. http://www.nrel.gov/docs/legosti/fy98/24190.pdf.

37. Leow, S., et al. "Prediction of microalgae hydrothermal liquefaction products from feedstock biochemical composition." Green Chemistry, 17(6), 2015; 3584-3599.

38. Lourenço, S. O., et al. "Distribution of intracellular nitrogen in marine microalgae: Calculation of new nitrogen-to-protein conversion factors." European Journal of Phycology, 39(1), 2004; 17-32.

39. Wang, L., et al. "A flexible culture process for production of the green microalga Scenedesmus dimorphus rich in protein, carbohydrate or lipid." Bioresource Technology, 129(0), 2013; 289-295.

40. Zemke, P., et al. "Assessment of key biological and engineering design parameters for production of Chlorella zofingiensis (Chlorophyceae) in outdoor photobioreactors." Applied Microbiology and Biotechnology, 97(12), 2013; 5645-5655.

41. Laurens, L. L., et al. "Accurate and reliable quantification of total microalgal fuel potential as fatty acid methyl esters by in situ transesterification." Analytical and Bioanalytical Chemistry, 403(1), 2012; 167-178.

42. Davis, R. E., et al. "Integrated Evaluation of Cost, Emissions, and Resource Potential for Algal Biofuels at the National Scale." Environmental Science \& Technology, 48, 2014; 6035-6042.

43. Huntley, M. E., et al. "Demonstrated large-scale production of marine microalgae for fuels and feed." Algal Research, 2015.

44. Davis, R., et al., Process Design and Economics for the Conversion of Lignocellulosic Biomass to Hydrocarbons: Dilute-Acid and Enzymatic Deconstruction of Biomass to Sugars and Biological Conversion of Sugars to Hydrocarbons. Golden, CO: National Renewable Energy Laboratory, 2013. http://www.nrel.gov/docs/fy14osti/60223.pdf.

45. DOE, Bioenergy Technologies Office Multi Year Program Plan-July 2014. Washington, D.C.: Bioenergy Technologies Office, 2014. http://www.energy.gov/sites/prod/files/2014/07/f17/mypp july 2014.pdf.

46. DOE, Bioenergy Technologies Office Multi Year Program Plan-March 2015 Washington, D.C.: Bioenergy Technologies Office, 2015. http://www.energy.gov/sites/prod/files/2015/03/f20/mypp beto march2015.pdf.

47. Craggs, R., et al. "Hectare-scale demonstration of high rate algal ponds for enhanced wastewater treatment and biofuel production." Journal of Applied Phycology, 24, 2012; 329-337.

48. Lane, J. 2012. Change The World: Sapphire Energy's Green Crude Farm, Illustrated. Biofuels Digest 2012 [cited Feb. 8 2016]. Available from http://www.sapphireenergy.com/news-article/1212040-change-the-world-sapphireenergy-s-green 
49. Dirks, G. 2015. Paper read at 2015 BETO Algae Peer

Review.http://www.energy.gov/sites/prod/files/2015/04/f21/algae dirks 135100.pdf

50. Ogden, K. 2015. Paper read at 2015 BETO Algae Peer

Review.http://www.energy.gov/sites/prod/files/2015/04/f21/algae ogden_135111.pdf

51. NAABB, NAABB Full Final Report Section 2. DE-EE0003046 U.S. DOE, Bioenergy

Technologies Office, 2014.

http://www.energy.gov/sites/prod/files/2014/07/f18/naabb_full_final_report_section_II_0 .pdf.

52. NAABB, NAABB Full Final Report Section 3. DE-EE0003046 U.S. DOE, Bioenergy Technologies Office, 2014.

http://energy.gov/sites/prod/files/2014/07/f18/naabb_full_final_report_section_III.pdf.

53. Beal, C. M., et al. "Thermodynamic analysis of algal biocrude production." Energy, 44(1), 2012; 925-943.

54. Weyer, K., et al. "Theoretical Maximum Algal Oil Production." BioEnergy Research, 3(2), 2010; 204-213.

55. Huesemann, M. H., et al. "A screening model to predict microalgae biomass growth in photobioreactors and raceway ponds." Biotechnology and Bioengineering, 110(6), 2013; 1583-1594.

56. Wigmosta, M., Pacific Northwest National Laboratory, Personal commumication, April 2015.

57. ATP3. 2015. ATP3 Unified Field Studies 2015 [cited. Available from http://en.openei.org/wiki/ATP3.

58. Venteris, E. R., et al. "A GIS cost model to assess the availability of freshwater, seawater, and saline groundwater for algal biofuel production in the United States." Environ Sci Technol, 47(9), 2013; 4840-4849.

59. Resources, U. W. National Water Information System: Web Interface. USGS [cited Aug. 15 2015]. Available from http://waterdata.usgs.gov/nwis.

60. Hazlebeck, D. "Global Algal Innovations: Open-Raceway Algal Production Operations", 2014. http://www.algaebiomass.org/wp-content/gallery/2012-algae-biomasssummit/2010/06/T3 Tue 1500_DHazlebeck-11.pdf

61. Hazlebeck, D., Global Algal Innovations, Personal commumication, May 2015.

62. Acién, F. G., et al. "Production cost of a real microalgae production plant and strategies to reduce it." Biotechnology Advances, 30(6), 2012; 1344-1353.

63. Bosma, R., et al. "Design and construction of the microalgal pilot facility AlgaePARC." Algal Research, 6, Part B, 2014; 160-169.

64. Béchet, Q., et al. "Mechanistic Modeling of Broth Temperature in Outdoor Photobioreactors." Environmental Science \& Technology, 44(6), 2010; 2197-2203.

65. Warren D Seider, J. D. S., Daniel R. Lewin. Product and process design principles: Synthesis, Analysis, and Evaluation 2nd ed. New York: John Wiley and Sons, 2004.

66. Langley, N. M., et al. "A critical evaluation of CO2 supplementation to algal systems by direct injection." Biochemical Engineering Journal, 68, 2012; 70-75.

67. Mehrabadi, A., et al. "Wastewater treatment high rate algal ponds (WWT HRAP) for low-cost biofuel production." Bioresource Technology, 184, 2015; 202-214.

68. Weissman, J. C.; R. P. Goebel, Design and analysis of open pond systems for the purpose of producing fuels. SERI/STR-231-2840. 1987.

http://www.nrel.gov/docs/legosti/old/2840.pdf. 
69. Bao, Y., et al. "In situ carbon supplementation in large-scale cultivations of Spirulina platensis in open raceway pond." Biotechnology and Bioprocess Engineering, 17, 2012; 93-99.

70. de Godos, I., et al. "Evaluation of carbon dioxide mass transfer in raceway reactors for microalgae culture using flue gases." Bioresource Technology, 153, 2014; 307-314.

71. Gubler, R., et al., Chemical Economics Handbook, Carbon Dioxide. 743.2000. IHS Chemical, 2015.

72. Gerdes, K., Cost and performance of PC and IGCC plants for a range of carbon dioxide capture. DOE/NETL-2011/1498. National energy technology laboratory, 2011. http://www.netl.doe.gov/File\%20Library/Research/Energy\%20Analysis/Publications/Ger des-08022011.pdf.

73. Jilvero, H., et al. "Techno-economic evaluation of an ammonia-based post-combustion process integrated with a state-of-the-art coal-fired power plant." International Journal of Greenhouse Gas Control, 31, 2014; 87-95.

74. Stevens, R., Current and Future Technologies for Power Generation with PostCombustion Carbon Capture. DOE/NETL-2012/1557. National energy technology laboratory, 2012. http://netl.doe.gov/File\%20Library/Research/Energy\%20Analysis/Publications/NETLDOE-2012-1557.pdf.

75. DOE, Carbon Capture Technology Program Plan. Office of Fossil Energy, 2013. https://www.netl.doe.gov/File\%20Library/Research/Coal/carbon\%20capture/ProgramPlan-Carbon-Capture-2013.pdf.

76. Humbird, D., et al., Process Design and Economics for Biochemical Conversion of Lignocellulosic Biomass to Ethanol: Dilute-Acid Pretreatment and Enzymatic Hydrolysis of Corn Stover. NREL/TP-5100-47764. Golden, CO: National Renewable Energy Laboratory, 2011. http://www.nrel.gov/docs/fy11osti/47764.pdf.

77. Bilad, M. R., et al. "Membrane technology in microalgae cultivation and harvesting: a review." Biotechnol Adv, 32(7), 2014; 1283-1300.

78. Allnutt, F. C. T.; B. Kessler. 2015. Harvesting and Downstream Processing — and Their Economics In Biomass and Biofuels from Microalgae, edited by Navid R. Moheimani, Mark P. McHenry, Karne de Boer and Parisa A. Bahri: Springer International Publishing, 289-310.

79. Uduman, N., et al. "Dewatering of microalgal cultures: A major bottleneck to algae-based fuels." Journal of Renewable and Sustainable Energy, 2(1), 2010; 012701.

80. Bhave, R., et al. "Membrane-Based Energy Efficient Dewatering of Microalgae in Biofuels Production and Recovery of Value Added Co-Products." Environmental Science \& Technology, 46(10), 2012; 5599-5606.

81. Dassey, A. J.; C. S. Theegala "Harvesting economics and strategies using centrifugation for cost effective separation of microalgae cells for biodiesel applications." Bioresource Technology, 128(0), 2013; 241-245.

82. Schlesinger, A., et al. "Inexpensive non-toxic flocculation of microalgae contradicts theories; overcoming a major hurdle to bulk algal production." Biotechnology Advances, 30(5), 2012; 1023-1030.

83. Heasman, M., et al. "Development of extended shelf-life microalgae concentrate diets harvested by centrifugation for bivalve molluscs - a summary." Aquaculture Research, 31(8-9), 2000; 637-659. 
84. Chen, G., et al. "Chitosan and Its Derivatives Applied in Harvesting Microalgae for Biodiesel Production: An Outlook." Journal of Nanomaterials, 2014, 2014; 9.

85. Vandamme, D., et al. "Evaluation of electro-coagulation-flocculation for harvesting marine and freshwater microalgae." Biotechnology and Bioengineering, 108, 2011; 23202329.

86. Corporation, G. T. C. B. Industrial Chitosan prices [cited 2015]. Available from http://www.bestchitosan.com/e productshow/?19-Industrial-Grade-Chitosan-19.html.

87. OriginOil. "OriginOil technical description: Electro Water Separation Algae". Los Angeles, CA: OriginOil, 2014. www.originoil.com

88. "Chemical Engineering Plant Cost Index (CEPCI)." Chemical Engineering, April 2015; 80.

89. Bureau of Labor Statistics. Labor Indicies Series ID CEU3232500008 [cited 2015]. Available from http://data.bls.gov/cgi-bin/srgate.

90. U.S. Producer Price Indexes - Chemicals and Allied Products/Industrial Inorganic Chemicals Index. 2008. In Chemical Economics Handbook. Menlo Park, CA: SRI Consulting.

91. Bureau of Labor Statistics. Producer Price Index Series ID PCU325---325--- [cited 2015]. Available from http://data.bls.gov/cgi-bin/srgate.

92. Alabi, A. O., et al., Microalgae technologies and processes for biofuels/bioenergy productoin in british colombia. 2009.

http://www.fao.org/uploads/media/0901 Seed Science -

Microalgae technologies and processes for biofuelsbioenergy production in British Columbia.pdf.

93. Landwatch. August 2010. Statistical analysis of land prices August 2010 [cited. Available from http://www.landwatch.com.

94. USDA. National Agricultural Statistics Service: Quick Stats [cited 2015]. Available from http://quickstats.nass.usda.gov/.

95. EIA, U. S. Electricity Retail Price to Consumers [cited July 2013]. Available from http://www.eia.gov/electricity/data.cfm\#sales.

96. Statistics, U. S. B. o. L. Occupational Employment Statistics: 45-2091 Agricultural Equipment Operators [cited 2015]. Available from http://www.bls.gov/oes/current/oes452091.htm.

97. Statistics, U. S. B. o. L. Occupational Employment Statistics : 51-9012 Separating, Filtering, Clarifying, Precipitating, and Still Machine Setters, Operators, and Tenders [cited 2015]. Available from http://www.bls.gov/oes/current/oes519012.htm.

98. Statisics, U. S. B. o. L. Occupational Employment Statistics : 17-2051 Civil Engineers [cited 2015]. Available from http://www.bls.gov/oes/current/oes 172051.htm.

99. Statistics, U. S. B. o. L. Occupational Employment Statistics: 17-2081 Environmental Engineers [cited 2015]. Available from http://www.bls.gov/oes/current/oes 172081.htm.

100. W. Short, D. J. P., T. Holt, A manual for the Economic Evaluation and Energy Efficiency and Renewable Energy Technologies. Golden, CO: National Renewable Energy Laboratory, 1995. http://www.nrel.gov/docs/legosti/old/5173.pdf.

101. Department of the Treasury, I. R. S. 2009. How to Depreciate property 2009 [cited. Available from http://www.irs.gov/pub/irs-pdf/p946.pdf.

102. Robert H. Perry, D. W. G. Perry's Chemical Engineers' Handbook 7th ed. New York: McGraw-Hill, 1997. 
103. J.H. Gary, G. E. H. Petroleum refining: technology and economics 3rd ed. New York: M. Dekker, 1994.

104. Max S. Peters, K. T., Ronald E. West. Plant design and economics for chemical engineers ed. New York: McGraw-Hill, 2003.

105. Cran, J. "Improved factored method gives better preliminary cost estimates." Chem. Eng, 74, 1981; 65-79.

106. EIA, U. S. 2015. How much carbon dioxide is produced per kilowatthour when generating electricity with fossil fuels? 2015 [cited June 2015. Available from http://www.eia.gov/tools/faqs/faq.cfm?id=74\&t=11.

107. Brennan, L.; P. Owende "Biofuels from microalgae-A review of technologies for production, processing, and extractions of biofuels and co-products." Renewable and Sustainable Energy Reviews, 14, 2010; 557-577.

108. Molina Grima, E., et al. "Recovery of microalgal biomass and metabolites: process options and economics." Biotechnology Advances, 20(7-8), 2003; 491-515.

109. Wigmosta, M.; A. Coleman, Pacific Northwest National Laboratory, Personal commumication, May 2015.

110. "Renewable Energy Desalination: An Emerging Solution to Close the Water Gap in the Middle East and North Africa," edited by The World Bank. Washington D.C: The World Bank, 2012.

http://water.worldbank.org/sites/water.worldbank.org/files/publication/water-wpp-SunPowered-Desal-Gateway-Meeting-MENAs-Water-Needs 2.pdf

111. GREET Argonne National Laboratory.https://greet.es.anl.gov/publications

112. SimaPro Vers. 8.0.2. Product Ecology Consultants, Amersfoort, the Netherlands.http://simapro.com/

113. Hsu, D. D., et al. "Life Cycle Environmental Impacts of Selected U.S. Ethanol Production and Use Pathways in 2022." Environmental Science \& Technology, 44(13), 2010; 5289-5297.

114. Ecoinvent Vers. 2.2. Swiss Center for Life Cycle Inventories, Duebendorf, Switzerland. http://www.ecoinvent.ch/

115. E.D. Frank, J. H., I. Palou-Rivera, A. Elgowainy, M.Q. Wang, Life-Cycle Analysis of Algal Lipid Fuels with the GREET Model. ANL/ESD/11-5. Oak Ridge, TN: Energy Systems Division, Argonne National Laboratory, 2011. https://greet.es.anl.gov/publication-algal-lipid-fuels.

116. Biorecro, A. B., Global Status of BECCS Projects 2010. Canberra, Australia: Global CCs Institute, 2010.

117. Fisher, B. S., N. Nakicenovic, K. Alfsen, J. Corfee Morlot, F. de la Chesnaye, J.-Ch. Hourcade, K. Jiang, M. Kainuma, E. La Rovere, A. Matysek, A. Rana, K. Riahi, R. Richels, S. Rose, D. van Vuuren, R. Warren. 2007. Issues related to mitigation in the long term context In Climate Change 2007: Mitigation. Contribution of Working Group III to the Fourth Assessment Report of the Inter-governmental Panel on Climate Change. Cambridge, United Kingdom: Cambridge University Press.

118. Koornneef, J., et al. "Life cycle assessment of a pulverized coal power plant with postcombustion capture, transport and storage of CO2." International Journal of Greenhouse Gas Control, 2(4), 2008; 448-467. 
119. Modahl, I. S., et al. "Weighting of environmental trade-offs in CCS — an LCA case study of electricity from a fossil gas power plant with post-combustion $\mathrm{CO} 2$ capture, transport and storage." The International Journal of Life Cycle Assessment, 17(7), 2012; 932-943.

120. Pehnt, M.; J. Henkel "Life cycle assessment of carbon dioxide capture and storage from lignite power plants." International Journal of Greenhouse Gas Control, 3(1), 2009; 4966.

121. Chiu, Y.-W.; M. Wu "Assessing County-Level Water Footprints of Different CellulosicBiofuel Feedstock Pathways." Environmental Science \& Technology, 46(16), 2012; 9155-9162.

122. Davis, R. 2015. Algal Biofuels Techno-Economic Analysis. Paper read at 2015 BETO Algae Peer Review, March 24, 2015, at Alexandria, VA.http://www.energy.gov/sites/prod/files/2015/04/f21/algae davis 131200.pdf

123. Laurens, L. 2015. Algal Biomass Valorization. Paper read at 2015 BETO Algae Peer Review, March 24, 2015, at Alexandria, VA.http://www.energy.gov/sites/prod/files/2015/04/f21/algae laurens 134300.pdf

124. Pienkos, P. T. 2015. Algal Biomass Conversion. Paper read at 2015 BETO Algae Peer Review, March 24, 2015, at Alexandria, VA.http://www.energy.gov/sites/prod/files/2015/04/f21/algae_pienkos 134201.pdf

125. Ryan Davis, M. B., Algal Lipid Extraction and Upgrading to Hydrocarbons Technology Pathway. NREL/TP-5100-58049. Golden, CO: National Renewable Energy Laboratory, 2013. http://www.nrel.gov/docs/fy13osti/58049.pdf.

126. Smith, V. H.; T. Crews "Applying ecological principles of crop cultivation in large-scale algal biomass production." Algal Research, 4(0), 2014; 23-34. 


\section{Appendix A. Individual Equipment Cost Summary}

The following table shows abbreviated specifications, purchased cost, and installed cost for each piece of equipment in this process design, with all capital costs set based on the maximum throughput design case, i.e., summer season flows. Although each piece of equipment has its own line, many were quoted as part of a package. NREL would like to acknowledge the equipment vendors and external consultants who assisted us with the cost estimation effort for this design report. 


\begin{tabular}{|c|c|c|c|c|c|c|c|c|c|c|c|c|c|c|c|}
\hline \multicolumn{4}{|c|}{ Mechanical Equipment List } & \multicolumn{12}{|c|}{ Scaled Installed Costs } \\
\hline EQUIPMENT TITLE & DESCRIPTION & 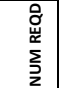 & $\$$ & 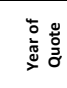 & $\begin{array}{l}\text { Purch Cost } \\
\text { in Base Yr }\end{array}$ & $\begin{array}{l}\text { Scaling } \\
\text { Variable }\end{array}$ & 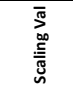 & $\frac{\mathscr{n}}{5}$ & 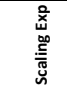 & 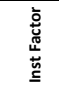 & 㳬 & 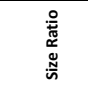 & $\begin{array}{c}\text { Scaled } \\
\text { Purch Cost }\end{array}$ & $\begin{array}{l}\text { Purch Cost } \\
\text { in Proj } \\
\text { Year }\end{array}$ & $\begin{array}{l}\text { Inst Cost in } \\
\text { Proj Year }\end{array}$ \\
\hline & A100: Leidos 10 -acre raceway ponds & & & & & & & & & & & & & & \\
\hline $\begin{array}{l}\text { Clear and grub } \\
\text { Strip (vorrburden) and stockpile }\end{array}$ & & & 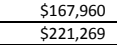 & $\frac{2014}{2014}$ & $\begin{array}{ll}\frac{\$ 516,960}{\$ 211,269} & \end{array}$ & SIZEEAC & $\frac{100}{100}$ & $\begin{array}{l}\frac{\text { wetete acres }}{\text { wetted acres }} \\
\end{array}$ & $\frac{1.00}{1.00}$ & $\frac{1.00}{1.00}$ & $\frac{5000}{5000}$ & $\frac{50}{50}$ & $\begin{array}{l}\$ 8,398,000 \\
\$ \$ 11,063,450\end{array}$ & 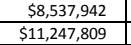 & 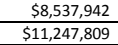 \\
\hline 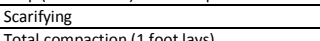 & & & 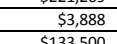 & 2014 & 53,888 & 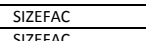 & 100 & 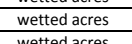 & $\begin{array}{l}1.00 \\
0.00\end{array}$ & 1.00 & 5000 & 50 & $\begin{aligned} \$ 194,400 \\
56500\end{aligned}$ & 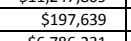 & $\frac{1}{\$ 19197,639}$ \\
\hline$\frac{\text { Total compaction (1 f foot lays) }}{\text { Totat cut and }}$ & & & 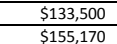 & $\frac{2014}{2014}$ & $\frac{5133,500}{S 155,100}$ & $\begin{array}{l}S I Z F A C \\
\text { SIZFFC }\end{array}$ & $\frac{100}{100}$ & $\begin{array}{ll}\text { wetted acres } \\
\text { wetede arces }\end{array}$ & $\frac{2.00}{1.00}$ & $\frac{1.00}{1.00}$ & 5000 & $\frac{50}{50}$ & $\begin{array}{l}\$ 6,675,000 \\
\$ 7,58,500 \\
\end{array}$ & $\begin{array}{l}\$ 6,786,231 \\
57887786 \\
\end{array}$ & $\begin{array}{ll}\$ 6,786,231 \\
57,8777766 \\
\end{array}$ \\
\hline $\begin{array}{l}\text { Fine grade } \\
\text { Find (snort }\end{array}$ & & & & & & & $\frac{100}{100}$ & & $\frac{1.00}{1.00}$ & $\frac{1.00}{1.00}$ & $\frac{5000}{5000}$ & $\frac{50}{50}$ & $\begin{array}{r}\$ 7,57,58,500 \\
\$ 20,449000 \\
\end{array}$ & $\begin{array}{r}\$, 788,786 \\
\$ 20,789,758 \\
\end{array}$ & $\begin{aligned} & \$ 1,877,766 \\
& \$ 20,789,758 \\
&\end{aligned}$ \\
\hline Berm pond liner & 40 mil geomembrane & & 543,687 & 2014 & $\$ 43,687$ & SIZEFAC & 100 & wetted acres & $\frac{1.00}{1.00}$ & 1.00 & 5000 & 50 & $\$ 2,184,350$ & 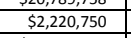 & $\$ 2,220,750$ \\
\hline $\begin{array}{l}\text { Paddlewheel } \\
\text { Padldewheel motor }\end{array}$ & & & $\begin{aligned} \$ 640,000 \\
\text { NCIUDED }\end{aligned}$ & 2014 & 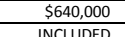 & SIZEFAC & 100 & wetted acres & 1.00 & 1.00 & 5000 & 50 & $\$ 32,000,000$ & $\$ 32,533,241$ & $\$ 32,533,241$ \\
\hline $\begin{array}{l}\text { Paddlewheel motor } \\
\text { Paddlewheel gearbox }\end{array}$ & & & $\begin{array}{l}\text { INCLUEDD } \\
\text { NCLUOEED }\end{array}$ & 2014 & $\begin{array}{l}\text { INCLCDEE } \\
\text { INCLUDED }\end{array}$ & & & & & & & & & & \\
\hline $\begin{array}{l}\text { Paddlewheee gearbox } \\
\text { Paddlewheel support }\end{array}$ & & & INCLUDED & 2014 & INCLUDEDD & & & & & & & & & & \\
\hline $\begin{array}{l}\text { Electrical to ponds, } 3 \text { conductor, } 10 \text { gavge } \\
\text { wire }\end{array}$ & & & $\$ 58,020$ & 2014 & $\$ 58,020$ & SIZEFAC & 100 & wetted acres & 1.00 & 1.00 & 5000 & 50 & $\$ 2901000$ & 52949342 & 52949,342 \\
\hline Instrumentation & & & $\$ 79,000$ & 2014 & $\$ 59,000$ & SIZEFAC & 100 & wetted acres & 1.00 & 1.00 & 5000 & 50 & $\$$ & $\$ 4,015,822$ & $\begin{array}{lll}54,015,822 \\
5\end{array}$ \\
\hline $\begin{array}{l}\text { Pond Concrete (sump and slide gate) (21) } \\
\text { cy/pond) }\end{array}$ & & & $\$ 156,959$ & 2014 & $\$ 156,959$ & SIZEFAC & 100 & wetted acres & 1.00 & 1.00 & 5000 & 50 & $\$$ & $\$ 7,97,726$ & \\
\hline Non formed concrete Work (piping " "tays") & & & $\frac{1171,829}{\$ 1929}$ & 2014 & $\$ 11,1,829$ & SIZEFAC & 100 & wetted acres & 1.00 & 1.00 & 5000 & 50 & $\$ 8,591,450$ & $\$ 8,734,616$ & 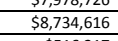 \\
\hline $\begin{array}{l}\text { Co2 Difuuers } \\
\text { Slide Gates }\end{array}$ & & & & 2003 & & $\begin{array}{l}\text { SIREACC } \\
\text { STEFAC }\end{array}$ & $\frac{100}{100}$ & $\begin{array}{l}\text { wetted acres } \\
\text { wetted }\end{array}$ & $\frac{1.00}{100}$ & $\frac{1.00}{1.00}$ & 5000 & $\frac{50}{50}$ & $\begin{array}{l}550,000 \\
55050 \\
50250\end{array}$ & 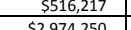 & $\begin{array}{l}\$ 516,217 \\
50921250\end{array}$ \\
\hline PVC pipe 18-inch diameter & $\begin{array}{l}\text { Pond fill main header } \\
\end{array}$ & & \$396,649 & 2014 & $\$ 396,649$ & SIZEFAC & 100 & $\begin{array}{lll}\text { wetted acres } & \\
\end{array}$ & 1.00 & 1.00 & 5000 & 50 & $\begin{array}{l}\$ \$, 252,32000 \\
\$ 19,832,450\end{array}$ & 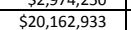 & 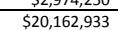 \\
\hline PVC pipe 18-inch diameter & Ponds drain header to harvest & & $\$ 47,778$ & 2014 & $\$ 44,778$ & SIZEFAC & 100 & wetted acres & 1.00 & 1.00 & 5000 & 50 & $\$ 2,388,900$ & $\$ 2,428,708$ & $52,428,708$ \\
\hline $\begin{array}{l}\text { PPC piep 8 8-inch diameter } \\
\text { Pumps from ACCE }\end{array}$ & Pond drain to drain header & 100 & 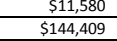 & $\frac{2014}{2012}$ & $\begin{aligned} \$ 111,50 \\
\$ 144,409 \\
\end{aligned}$ & $\begin{array}{lll}S I I F F A C \\
\text { Smix A A10.A100.13 }\end{array}$ & $\frac{100}{7182}$ & $\begin{array}{l}\text { wetted acres } \\
\text { gpm }\end{array}$ & $\frac{1.00}{0.80}$ & $\frac{1.00}{1.15}$ & $\frac{5000}{6180}$ & $\frac{50}{0.86}$ & $\begin{array}{r}\$ 559,000 \\
\$ 12,805,331 \\
\end{array}$ & $\begin{aligned} \$ 5582,68 \\
12,829,426 \\
\end{aligned}$ & $\begin{aligned} \$ 558,648 \\
\$ 14,792010 \\
\end{aligned}$ \\
\hline & A100: Harris 10-acre raceway ponds & & & & & & & & & & & & & & \\
\hline Site Excavation & Includes Labor and Materials & & $\$ 4,761$ & 2013 & 54,761 & SIREFAC & & ha wetted area & 1.00 & 1.00 & 2023 & 506 & $\$ 2,400,389$ & $\$ 2,486,504$ & $\$ 2,486,504$ \\
\hline $\begin{array}{l}\text { Backfill } \\
\text { spoil }\end{array}$ & 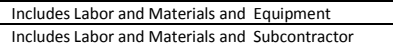 & & $\frac{\$ 14,284}{\$ \$ 120}$ & $\frac{2013}{2013}$ & $\frac{\$ 14,284}{\$ 120}$ & SIZEFAC & $\frac{4}{4}$ & $\begin{array}{l}\frac{h_{2}}{\text { ha wetted area }} \\
\text { ha wetede area }\end{array}$ & $\frac{1.00}{1.00}$ & $\frac{1.00}{1.00}$ & $\frac{2023}{2023}$ & 506 & $\frac{57,225,673}{560,703}$ & $\begin{array}{l}\$ 7,460,033 \\
\$ 522,62\end{array}$ & $\begin{aligned} 57,460,033 \\
526,672\end{aligned}$ \\
\hline Trench Excavation & 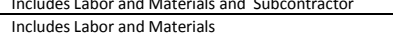 & & $\$ 564$ & 2013 & 5564 & SILFEAC & $\frac{4}{4}$ & & $\frac{1.00}{1.00}$ & $\frac{1.00}{1.00}$ & 2023 & & $\begin{array}{rll}550,103 \\
5285,304\end{array}$ & $\begin{array}{r}562,6 / 22 \\
529457 \\
\end{array}$ & $\begin{aligned} \$ 22,6 / 2 \\
\$ 294,557\end{aligned}$ \\
\hline Trench Backill and Tamp & Includes Labor and Materials & & & 2013 & & $\begin{array}{l}\text { SIZEFAC } \\
\end{array}$ & 4 & ha wetted area & 1.00 & 1.00 & 2023 & 506 & $\$ 317,173$ & $\$ 327$ & $\$ 327,460$ \\
\hline Excavation machinery & 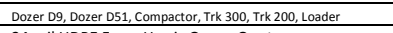 & & $\$ 56,325$ & 2013 & $\$ 56,325$ & SIZEFAC & 4 & ha wetted area & 1.00 & 1.00 & 2023 & 506 & $\$ 28,492,442$, & $\$ 29,416,576$ & $\$ 29,416,576$ \\
\hline $\begin{array}{l}\text { Berm Liner } \\
\text { Paddlewheel }\end{array}$ & 24 mil HDPE From Harris Group Quote & & $\frac{\$ 24,300}{\$ 52000}$ & 2013 20213 & 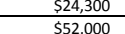 & $\begin{array}{l}\text { SIZEACA } \\
\text { SZZFAC }\end{array}$ & $\frac{4}{4}$ & 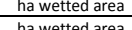 & 1.00 & 1.00 & 登2033 & 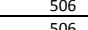 & & & \\
\hline $\begin{array}{l}\text { Padlewneel } \\
\text { Padlewheel Bearings }\end{array}$ & & & 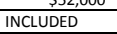 & 2013 & $\$ 52,000$ & & 4 & na wetted area & 1.00 & & 2023 & & $\$ 26,304,601$ & $\$ 22,153,180$ & \\
\hline & & & & 2013 & & & & & & & & & & & \\
\hline Paddlewheel Motor hookup, $\mathrm{C}$ & & & ELUDED & 2013 & & & & & & & & & & & \\
\hline 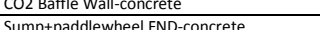 & & & & 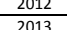 & 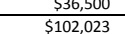 & 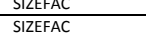 & 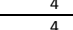 & $\begin{array}{l}\text { ha wattede area } \\
\text { ha wettted area }\end{array}$ & $\frac{1.00}{100}$ & 1.00 & 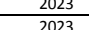 & $\frac{506}{506}$ & 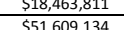 & 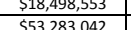 & \$18,498,553 \\
\hline Electrical to ponds, 3 conductor, 10 gauge wire & & & $\$ 58,020$ & 2014 & $\$ 55,020$ & 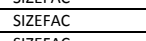 & 100 & wetted acres & $\frac{1.00}{1.00}$ & 1.00 & 5000 & $\frac{50}{50}$ & 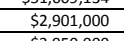 & 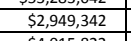 & $\begin{array}{lll}52,949,342 \\
532\end{array}$ \\
\hline $\begin{array}{l}\text { Instrumentation } \\
\text { Water Piping }\end{array}$ & & & $\begin{array}{l}\$ 9,000 \\
\$ 68,800\end{array}-1000$ & $\frac{2014}{2014}$ & $\frac{59,000}{568,800}$ & S & & $\begin{array}{l}\text { wetted acres } \\
\text { ha wetted area }\end{array}$ & $\frac{1.100}{1.00}$ & $\frac{1.00}{1.00}$ & & & & & $\begin{array}{r}\$ 4,0,35,822 \\
\$ 35,382,969 \\
\end{array}$ \\
\hline Pumps from ACCE & & $\frac{100}{100}$ & S1144,409 & 2012 & $\$ 144,409$ & smixA110.A100.13 & 7182 & gpm & 0.80 & 1.15 & 6180 & 1 & 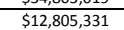 & $\frac{512,829,426}{\$ 5}$ & \$14,792, 1010 \\
\hline & & & & & & & & & & & & d total & & $\$ 206,855,774$ & 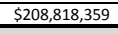 \\
\hline Civil Work & 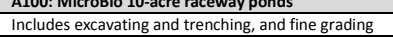 & & $\$ 4,892$ & 2009 & $\begin{array}{l}54,892 \\
\end{array}$ & SIZEFAC & & ha wetted area & 1.00 & 1.00 & 2023 & & $\$ 9,898,614$ & $\$ 11,108,676$ & $\$ 11,108,676$ \\
\hline & $\begin{array}{l}\text { Includes Paddlewheel Equipment and concrete } \\
\end{array}$ & & $\frac{\$ 15,778}{60302}$ & 2009 & $\begin{array}{lll}\$ 15,778 \\
1,072\end{array}$ & $\begin{array}{l}\text { SIZEFAC } \\
\text { SIIFAC }\end{array}$ & 1 & ha wetted area & 1.00 & 1.00 & 2023 & $\frac{2023}{2023}$ & $\begin{array}{ll}\$ 31,925,700 \\
\$ 1,20057\end{array}$ & & $\begin{array}{ll}535,828,477 \\
5,21521\end{array}$ \\
\hline Berm Liner & Partial Berm Liner & & $\frac{59,430}{55,182}$ & 2009 & & 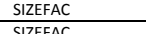 & $\frac{1}{4}$ & $\begin{array}{l}\text { ha wetted area } \\
\text { haw woted areaz }\end{array}$ & 1.00 & 1.00 & 2023 & $\frac{2023}{56}$ & & & 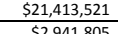 \\
\hline Water Piping ingerers & Pond piping (excludes yardpiping) & & $\begin{array}{llll}\$ 5,102 \\
\$ 10,176\end{array}$ & 2009 & & SILCEACAC & $\frac{4}{1}$ & 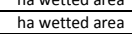 & $\frac{1.00}{1.00}$ & 1.00 & 2023 & 2023 & $\frac{2,20,50}{520,59}$ & $\frac{2,2,40}{\$ 23,10}$ & $\begin{array}{l}\$ 2,914,805 \\
\$ 23,107,528 \\
\end{array}$ \\
\hline Electrical for Ponds & $\$ 19 \mathrm{k} / \mathrm{ha}$ for full facility, ponds are $1 / 3$ of $\$ 1 \mathrm{k} / \mathrm{ha}$ & & 56,300 & 2009 & $\$ 6,300$ & & 1 & & 1.00 & 1.00 & 2023 & 2023 & & $\$ 14,305,958$ & $\$ 14,305,958$ \\
\hline Pumps from ACCE & & 100 & $\$ 144,409$ & 2012 & $\$ 144,409$ & smixA110.A100.13 & 7182 & $\mathrm{gpm}$ & 0.80 & 1.15 & 6180 & & $\begin{array}{ll}\$ 12,805,331 \\
\$ 100,67012\end{array}$ & $\begin{array}{ll}\frac{\$ 12,829,426}{\$ 1252520} \\
1\end{array}$ & $\begin{array}{l}\$ 14,792,010 \\
\$ 1229076\end{array}$ \\
\hline & A100: GA1 10-acre ponds & & & & & & & & & & & & & & \\
\hline & 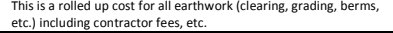 & & $\$ 9,000$ & 2014 & $\$ 9,000$ & SIZEFAC & 1 & acre & 1.00 & 1.00 & 5000 & 5000 & 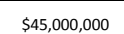 & $\$ 45,749,870$ & $\$ 45,799,870$ \\
\hline Partial liner & & & & 2011 & & SIZEFAC & & $\frac{\mathrm{ft}^{\prime}}{\mathrm{t}}$ & 1.00 & 1.00 & 3360500 & 3360500 & $52,184,325$ & $\$ 2,220,724$ & $\$ 52,220,724$ \\
\hline Pump Equipment Cost & 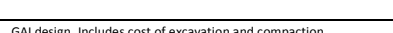 & & 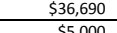 & 2014 & 536,690 & 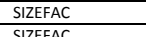 & 10 & $\begin{array}{l}\text { acre } \\
\text { acrea }\end{array}$ & 1.00 & $\begin{array}{ll}3.12 \\
100\end{array}$ & 5000 & 500 & $\begin{array}{ll}\$ 18,345,000 \\
\$ \$ 5000000\end{array}$ & & $\begin{array}{ll}\$ 58,190,174 \\
\$ 5416594 \\
\end{array}$ \\
\hline $\begin{array}{l}\text { Channel (aqueducts) } \\
\text { Pumps from ACCE }\end{array}$ & 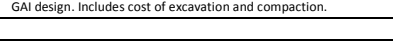 & 100 & $\begin{aligned} 55,000 \\
\$ 144,409\end{aligned}$ & $\frac{2014}{2012}$ & $\begin{aligned} 5,5000 \\
5144,409\end{aligned}$ & 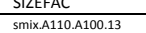 & $\frac{1}{7182}$ & $\frac{\text { acre }}{\text { gom }}$ & $\frac{1.00}{0.08}$ & $\frac{1.00}{1.15}$ & 5000 & $\frac{5000}{0.86}$ & $\begin{array}{l}\$ \$ 5,0,000,000 \\
12,805,331\end{array}$ & & $\begin{array}{l}\$ 25,416,594 \\
\$ 14,792,010\end{array}$ \\
\hline & A10. Drenturtion Ponda Base & $x^{\prime}$ & & & & & & & & & & & $\$ 103,334,656$ & $\$ 104,867,311$ & $\$ 146,369,373$ \\
\hline AVERAGE of 10-acre Costs & 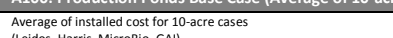 & & $\$ 158,506,910$ & 2011 & $\$ 158,506,910$ & SIZEFAC & 5000 & acre & 1.00 & 1.00 & 5000 & 1.00 & $\$ 158,506,910$ & $\$ 158,506,910$ & $\$ 158,506,910$ \\
\hline & & & & & & & & & & & & & 6,910 & & $\$ 158,506,910$ \\
\hline
\end{tabular}




\begin{tabular}{|c|c|c|c|c|c|c|c|c|c|c|c|c|c|c|c|}
\hline \multicolumn{4}{|c|}{ Mechanical Equipment List } & \multicolumn{12}{|c|}{ Scaled Installed Costs } \\
\hline EQUIPMENT TITLE & DESCRIPTION & 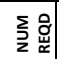 & $\$$ & 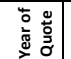 & $\begin{array}{l}\text { Purch Cost in } \\
\text { Base Yr }\end{array}$ & Scaling Variable & 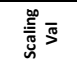 & $\frac{2}{5}$ & 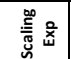 & 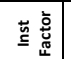 & 㶾 & 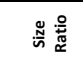 & $\begin{array}{l}\text { Scaled Purch } \\
\text { Cost }\end{array}$ & $\begin{array}{l}\text { Purch cost } \\
\text { in Proj Year }\end{array}$ & $\begin{array}{l}\text { Inst Cost in } \\
\text { Proj Year }\end{array}$ \\
\hline \multicolumn{16}{|c|}{ A200: Inoculation Pond Scheme (Does not include additional flue gas equipment and flue gas piping) } \\
\hline Tubular Photobioreactors & 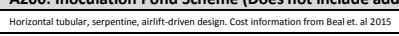 & & $\$ 18.22$ & 2014 & $\$ 18.22$ & APBR2 & 1 & $m^{\wedge 2}$ & 1.00 & 1.00 & 35242 & 35242 & $\$ 642,116$ & $\$ 652,816$ & $\$ 652,816$ \\
\hline Covered inoculum ponds & 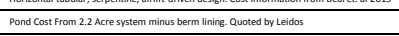 & & $\$ 5,427,316$ & 2014 & $\$ 5,427,316$ & ACOVPON & 100 & wetted acres & $\frac{1.00}{1.00}$ & $\frac{1.00}{1.00}$ & $\frac{3242}{23}$ & 0.23 & $\$ 1,260,377$ & $\$ 1,281,380$ & $\$ 1,281,380$ \\
\hline Open inoculum ponds & 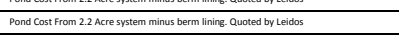 & & $\$ \frac{\$ 1,42,130}{\$ 5,427,316}$ & 2014 & $\begin{array}{lll}\$ 35,42,7,10 \\
\$ 5,416\end{array}$ & ALLNEPON & 100 & wetted acres & $\frac{1.00}{1.00}$ & $\frac{1.00}{1.00}$ & 116 & $\frac{.25}{1.16}$ & $\$ 1,20,317,885$ & $\frac{\$ 1,201,000}{\$ 6,406,898}$ & 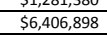 \\
\hline Lining for covered inoculum ponds & 40 mil geomembrane. Quoted by Leidos & & $\$ 3,097,827$ & 2014 & $\$ 3,097,827$ & ACOVPON & 4765888 & $\mathrm{ft}^{\wedge} 2 / 100$ acres & 1.00 & 1.00 & 1106775 & 0.23 & $\$ 719,404$ & $\$ 731,391$ & $\$ 731,391$ \\
\hline Air Supported Greenhouse & Covering for inoculum ponds. Quoted by MicroBio. & & $\$ 3.00$ & 2014 & $\$ 3.00$ & ACOVPON & 1 & $\mathrm{ft}^{\wedge} 2$ & 1.00 & 1.00 & 1112746 & 1112746 & $\$ 3,338,237$ & $\$ 3,393,865$ & $\$ 3,393,865$ \\
\hline Lining for open inoculum ponds & 40 mil geomembrane. Quoted by Leidos & & $\$ 3,097,827$ & 2014 & $\$ 3,097,827$ & ALINEPON & 4765888 & $\mathrm{ft}^{\mathrm{t}} 2 / 100$ acres & 1.00 & 1.00 & 5533873 & 1.16 & $\$ 3,597,018$ & $\$ 3,656,957$ & $\$ 3,656,957$ \\
\hline & & & & & & A200: Inoculation & nd Scheme & Does not include a & itional flue & gas equipr & ment and flue & gas piping) & $\$ 15,859,036$ & $\$ 16,123,308$ & $\$ 16,123,308$ \\
\hline
\end{tabular}

\begin{tabular}{|c|c|c|c|c|c|c|c|c|c|c|c|c|c|c|c|}
\hline \multicolumn{4}{|c|}{ Mechanical Equipment List } & \multicolumn{12}{|c|}{$\begin{array}{l}\text { Scaled Installed Costs } \\
\end{array}$} \\
\hline EQUIPMENT TITLE & DESCRIPTION & $\sum_{z}^{\Sigma}$ & $\$$ & 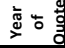 & $\begin{array}{l}\text { Purch Cost in } \\
\text { Base Yr }\end{array}$ & Scaling Variable & 点 & $\frac{9}{5}$ & 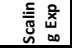 & 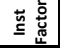 & $\frac{3}{2} \bar{z}$ & 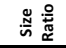 & $\begin{array}{c}\begin{array}{c}\text { Scaled Purch } \\
\text { cost }\end{array}\end{array}$ & $\begin{array}{l}\text { Purch Cost } \\
\text { in Proj Year }\end{array}$ & $\begin{array}{l}\text { Inst Cost in } \\
\text { Proj Year }\end{array}$ \\
\hline & A300: CO2 Piping & & & & & & & & & & & & & & \\
\hline Pipeline CO2 Storage Sphere & $45^{\prime}$ Diameter & 1.0 & $\$ 1,400,800$ & 2014 & $\$ 1,400,800$ & strm.A110.A100.57 & 68550 & $\mathrm{~kg} / \mathrm{h}$ & 0.60 & 1.25 & 65057 & 0.95 & $\$ 1,357,530$ & $\$ 1,380,151$ & $\$ 1,725,189$ \\
\hline Storage tank immersion vaporizers & $15^{\prime} \times 200 \mathrm{~W}$ & & $\$ 70,500$ & 2014 & $\$ 70,500$ & Strm.A110.A100.57 & 68550 & $\mathrm{~kg} / \mathrm{h}$ & 1.00 & 1.76 & 65057 & 0.95 & $\$ 66,908$ & $\$ 68,023$ & $\$ 119,720$ \\
\hline Trunk line & $27100^{\prime}$ length $\times 20^{\prime \prime}$ Diameter & & $\$ 1,661,900$ & 2014 & $\$ 1,661,900$ & strm.A110.A100.57 & 68550 & $\mathrm{~kg} / \mathrm{h}$ & 1.00 & 1.00 & 65057 & 0.95 & $\$ 1,577,225$ & $\$ 1,603,507$ & $\$ 1,603,507$ \\
\hline Branch line & $4 \mathrm{x}$ & & $\$ 912,300$ & 2014 & $\$ 912,300$ & strm.A110.A100.57 & 68550 & $\mathrm{~kg} / \mathrm{h}$ & 1.00 & 1.00 & 65057 & 0.95 & $\$ 865,818$ & $\$ 880,245$ & $\$ 880,245$ \\
\hline$\frac{\text { Within-plot piping }}{\text { Supply to Inoculum area }}$ & $\frac{6250^{\prime}}{1000^{\prime}}$ & 50 & $\frac{\$ 44,200}{\$ 59,300}$ & $\frac{2014}{2014}$ & $\begin{array}{ll}\$ 44,200 \\
\$ 59300\end{array}$ & $\begin{array}{l}\text { strm.A110.A10.0.57 } \\
\text { strm A110.0.0.57 }\end{array}$ & $\frac{68550}{68550}$ & $\mathrm{~kg} / \mathrm{h}$ & $\frac{1.00}{100}$ & 1.00 & 65057 & 0.95 & $\begin{aligned} \$ 2,097,399 \\
\$ 567290 \\
\end{aligned}$ & $\begin{aligned} \$ 2,132,349 \\
\$ 5726 \\
\end{aligned}$ & $\$ 2,132,349$ \\
\hline & & & & & & & & & & & A300: $\mathrm{CO}$ & ing total & $\begin{array}{r}\$ 56,2 / 9 \\
\$ 6,021,158\end{array}$ & $\begin{array}{r}\$ 5,216 \\
\$ 6,121,493\end{array}$ & $\$ 6,518,228$ \\
\hline
\end{tabular}

\begin{tabular}{|c|c|c|c|c|c|c|c|c|c|c|c|c|c|c|c|}
\hline \multicolumn{4}{|c|}{ Mechanical Equipment List } & \multicolumn{12}{|c|}{ Scaled Installed Costs } \\
\hline EQUIPMENT TITLE & DESCRIPTION & 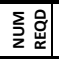 & $\$$ & 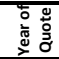 & $\begin{array}{l}\text { Purch Cost in } \\
\text { Base } Y r\end{array}$ & Scaling Variable & 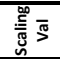 & $\frac{2}{5}$ & 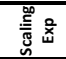 & 蒙意 & $\frac{3}{2} \frac{\pi}{7}$ & 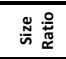 & $\begin{array}{l}\text { Scaled Purch } \\
\text { Cost }\end{array}$ & $\begin{array}{l}\text { Purch Cost } \\
\text { in Proj Year }\end{array}$ & $\begin{array}{l}\text { Inst Cost in } \\
\text { Proj Year }\end{array}$ \\
\hline \multicolumn{16}{|c|}{ A400: Makeup Water Delivery + On-Site Circulation } \\
\hline Channel (aqueducts) & GAl design. Includes cost of excavation and compaction. & & $\$ 100$ & 2014 & $\$ 100$ & SIZEFAC & 1 & acre & 1.00 & 1.00 & 5000 & 5000 & $\$ 500,000$ & $\$ 508,332$ & $\$ 508,332$ \\
\hline 34 in Diameter Pipe & Primary distribution pipe costed in ACCE & & $\$ 872,158$ & 2012 & $\$ 872,158$ & LPIPE36 & 5883 & $\mathrm{ft}$ & 1.00 & 1.51 & 5883 & 1.00 & $\$ 872,158$ & $\$ 873,799$ & $\$ 1,322,784$ \\
\hline & & & & & & DPIPE36 & 34 & Inches & 1.40 & & 34 & 1.00 & & & \\
\hline 26 in Diameter Pipe & Primary distribution pipe costed in ACCE & & $\$ 852,949$ & 2012 & $\$ 852,949$ & LPIPE28 & 9426 & $\mathrm{ft}$ & 1.00 & 1.48 & 9426 & 1.00 & $\$ 768,891$ & $\$ 770,337$ & $\$ 1,139,228$ \\
\hline & & & & & & DPIPE28 & 28 & Inches & 1.40 & & 26 & 0.93 & & & \\
\hline 20 in Diameter Pipe & Primary distribution pipe costed in ACCE & & $\$ 469,386$ & 2012 & $\$ 469,386$ & LPIPE20 & 9990 & $\mathrm{ft}$ & 1.00 & 1.72 & 9990 & 1.00 & $\$ 436,868$ & $\$ 437,690$ & $\$ 754,930$ \\
\hline 20 in Ulameler ripe & 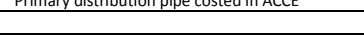 & & & & & DPIPE2O & $\frac{9900}{20}$ & Inches & $\frac{1.40}{1.40}$ & & $\frac{9900}{19}$ & 0.95 & & & \\
\hline 16 in Diameter Pipe & Module column distribution pipe costed in ACCE & & $\$ 416,554$ & 2012 & $\$ 416,554$ & LPIPE18 & 9360 & $\mathrm{ft}$ & 1.00 & 1.58 & 9360 & 1.00 & $\$ 416,554$ & $\$ 417,338$ & $\$ 661,342$ \\
\hline & & & & & & DPIPE18 & 16 & Inches & 1.40 & & 16 & 1.00 & & & \\
\hline 14 in Diameter Pipe & Module column distribution pipe costed in ACCE & & $\$ 321,593$ & 2012 & $\$ 321,593$ & LPIPE16 & 9360 & $\mathrm{ft}$ & 1.00 & 1.63 & 9360 & 1.00 & $\$ 321,593$ & $\$ 322,198$ & $\$ 525,487$ \\
\hline & & & & & & DPIPE16 & 14 & Inches & 1.40 & & 14 & 1.00 & & & \\
\hline 12 in Diameter Pipe & Module column distribution pipe costed in ACCE & & $\$ 267,709$ & 2012 & $\$ 267,709$ & LPIPE14 & 9360 & $\mathrm{ft}$ & 1.00 & 1.67 & 9360 & 1.00 & $\$ 267,709$ & $\$ 268,213$ & $\$ 448,542$ \\
\hline & & & & & & DPIPE14 & 12 & Inches & 2.00 & & 12 & 1.00 & & & \\
\hline Make-up water Pipeline & 1 mile pipeline to allowable water source & & \$2,638,100 & 2009 & $\$ 2,638,100$ & WPIPEID & 36 & $\begin{array}{llll}\text { Inches } & \\
\end{array}$ & 1.40 & 1.00 & 22 & $\begin{array}{ll}0.61 \\
\end{array}$ & $\$ 1,323,914$ & $\$ 1,485,757$ & $\$ 1,485,757$ \\
\hline Make-up Water Pump & centrifugal pump & & $\$ 705,500$ & 2009 & $\$ 705,500$ & smix.A600.Make-up & 10626 & $\mathrm{MM} \mathrm{gal} / \mathrm{yr}$ & 0.60 & 1.00 & 2575 & 0.24 & $\$ 301,423$ & $\$ 338,271$ & $\$ 338,271$ \\
\hline & & & & & & & & & eup Wate & Delivery & -Site Cir & ion total & $\$ 5,209,110$ & $\$ 5,421,935$ & $\$ 7,184,674$ \\
\hline
\end{tabular}

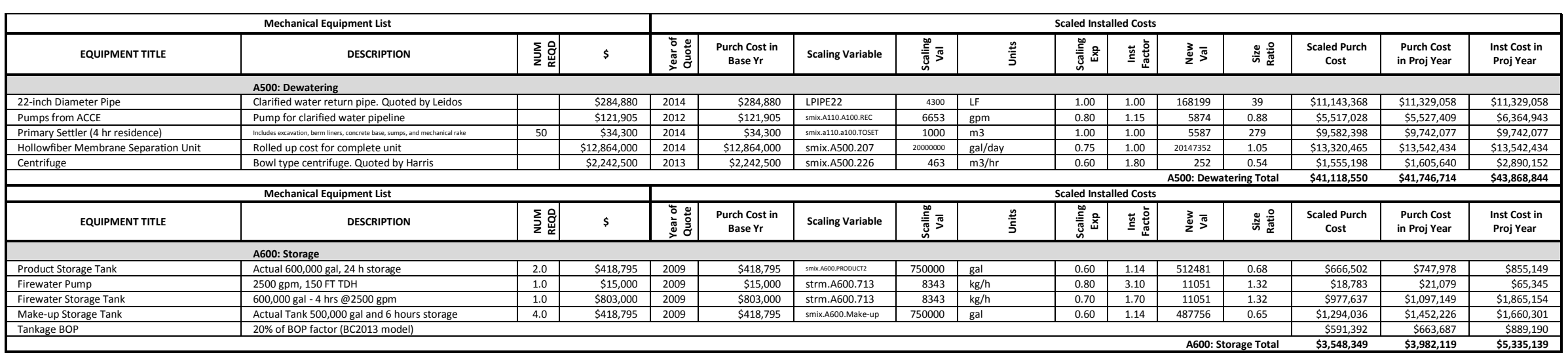




\section{Appendix B. Additional Design and Cost Details for Leidos Pond Scenarios}

\begin{tabular}{|c|c|c|c|c|c|c|c|c|c|c|c|}
\hline \multirow[b]{2}{*}{ DIRECT POND COSTS } & \multicolumn{4}{|c|}{$\begin{array}{l}\text { Raceways with Paddlewheels } \\
\text { In-situ Clay, with partial liner, } 10 \text { acre }\end{array}$} & \multicolumn{4}{|c|}{\begin{tabular}{|l|} 
Raceways with Paddlewheels \\
In-situ Clay, with partial liner, 2.2 acre
\end{tabular}} & \multicolumn{3}{|c|}{$\begin{array}{l}\text { Serpentine Pond } \\
\text { In-Situ Clay, with partial liner, } 48.6 \text { acre }\end{array}$} \\
\hline & Quantity & & Unit Cost Units & Total Cost & Quantity & & Unit Cost Units & Total Cost & Quantity & Unit Cost Units & Total Cost \\
\hline Civil Work & \multicolumn{4}{|c|}{ Feet of overburden to remove: 0.5 feet } & \multicolumn{4}{|c|}{ Feet of overburden to remove: 0.5 feet } & \multicolumn{3}{|c|}{ Feet of overburden to remove: 0.5 feet } \\
\hline Clear and grub & 130 & & $\$ 1,292$ acres & $\$ 167,960$ & 130 & & $\$ 1,292$ acres & $\$ 167,960$ & 130 & $\$ 1,292$ acres & $\$ 167,960$ \\
\hline Strip (overburden) and stockpile & 104867 & & $\$ 2.11 \mathrm{CY}$ & $\$ 221,269$ & 104867 & & $\$ 2.11 \mathrm{CY}$ & $\$ 221,269$ & 104867 & $\$ 2.11 \mathrm{CY}$ & $\$ 221,269$ \\
\hline Scarifying & 629200 & & $\$ 0.01 \mathrm{SY}$ & $\$ 3,888$ & 629200 & & $\$ 0.01 \mathrm{SY}$ & $\$ 3,888$ & 629200 & $\$ 0.01 \mathrm{sY}$ & $\$ 3,888$ \\
\hline Total Compaction (1 foot lays) & 267000 & & $\$ 0.50 \mathrm{CY}$ & $\$ 133,500$ & 286000 & & $\$ 0.50 \mathrm{CY}$ & $\$ 143,000$ & 363716 & $\$ 0.50 \mathrm{cY}$ & $\$ 181,858$ \\
\hline Total cut and fill (short runs) & 59000 & & $\$ 2.63 \mathrm{CY}$ & $\$ 155,170$ & 76500 & & $\$ 2.63 \mathrm{CY}$ & $\$ 201,195$ & 116361 & $\$ 2.63 \mathrm{CY}$ & $\$ 306,029$ \\
\hline Fine Grade & 629200 & & $\$ 0.65 \mathrm{SY}$ & $\$ 408,980$ & 629200 & & $\$ 0.65 \mathrm{SY}$ & $\$ 408,980$ & 629200 & $\$ 0.65 \mathrm{SY}$ & $\$ 408,980$ \\
\hline Civil Work Total & & & & $\$ 1,090,767$ & & & & $\$ 1,146,292$ & & & $\$ 1,289,985$ \\
\hline \multicolumn{12}{|l|}{ Leakage Barrier } \\
\hline Truck in Material, Clay & & & & $\mathrm{n} / \mathrm{a}$ & & & & $\mathrm{n} / \mathrm{a}$ & & & $n / a$ \\
\hline Blend clay with native soil & & & & $\mathrm{n} / \mathrm{a}$ & & & & $n / a$ & & & $n / a$ \\
\hline Mix-in Soil Amendment & & & & $\mathrm{n} / \mathrm{a}$ & & & & $\mathrm{n} / \mathrm{a}$ & & & $n / a$ \\
\hline Pond Liner, Liner, 40 mil geomembrane & 67210 & & $\$ 0.65$ SF & $\$ 43,687$ & 110350 & & $\$ 0.65 \mathrm{SF}$ & $\$ 71,728$ & 106530 & $\$ 0.65 \mathrm{SF}$ & $\$ 69,245$ \\
\hline Leakage Barrier Total & & & & $\$ 43,687$ & & & & $\$ 71,728$ & & & $\$ 69,245$ \\
\hline Paddlewheel / Motor / Gearbox / support & 10 & & $\$ 64,000$ ea & $\$ 640,000$ & 44 & & $\$ 38,800$ ea & $\$ 1,707,200$ & & & $\mathrm{n} / \mathrm{a}$ \\
\hline Paddlewheel Total & & & & $\$ 640,000$ & & & & $\$ 1,707,200$ & & & $\$ 0$ \\
\hline \multicolumn{12}{|l|}{ Electrical and Instrumentation } \\
\hline Electrical to ponds, 3 conductor, 2 gauge wire & 6850 & & $\$ 8.47 \mathrm{LF}$ & $\$ 58,020$ & 15600 & & $\$ 4.55 \mathrm{LF}$ & $\$ 70,980$ & & & $n / a$ \\
\hline Instrumentation (number of panels) & 10 & & $\$ 7,900.00$ ea & $\$ 79,000$ & 44 & & $\$ 7,900.00$ ea & $\$ 347,600$ & & & $n / a$ \\
\hline E\&I Work Total & & & & $\$ 137,020$ & & & & $\$ 418,580$ & & & $\$ 0$ \\
\hline \multicolumn{12}{|l|}{ Piping } \\
\hline PVC Piping & Pipe, LF & Fittings & & & Pipe, LF & Fittings & & & Pipe, LF Fittings & & \\
\hline 22-inch; Harvest to harvest return pond & 4300 & $\$ 13,980$ & $\$ 63.00 \mathrm{LF}$ & $\$ 284,880$ & 4900 & $\$ 13,980$ & $\$ 63.00 \mathrm{LF}$ & $\$ 322,680$ & & & $n / a$ \\
\hline 18-inch, Pond fill main header & 2335 & $\$ 305,584$ & $\$ 39.00 \mathrm{LF}$ & $\$ 396,649$ & 800 & $\$ 9,542$ & $\$ 39.00 \mathrm{LF}$ & $\$ 40,742$ & & & $n / a$ \\
\hline 16-inch; Pond fill sub-header & 0 & & $\$ 27.00 \mathrm{LF}$ & $\$ 0$ & 7120 & $\$ 437,832$ & $\$ 27.00 \mathrm{LF}$ & $\$ 630,072$ & & & $n / a$ \\
\hline 18-inch; Ponds drain header to harvest channel & 1150 & $\$ 16,728$ & $\$ 27.00 \mathrm{LF}$ & $\$ 47,778$ & 2200 & $\$ 63,856$ & $\$ 27.00 \mathrm{LF}$ & $\$ 123,256$ & & & $n / a$ \\
\hline 8-inch; Pond drain to drain header & 400 & $\$ 4,780$ & $\$ 17.00 \mathrm{LF}$ & $\$ 11,580$ & 1920 & $\$ 10,516$ & $\$ 17.00 \mathrm{LF}$ & $\$ 43,156$ & & & $\mathrm{n} / \mathrm{a}$ \\
\hline 12-inch, Harvest Return piping & & & & $\mathrm{n} / \mathrm{a}$ & & & & $\mathrm{n} / \mathrm{a}$ & $7800 \$ 15,400$ & $\$ 25.00 \mathrm{LF}$ & $\$ 210,400$ \\
\hline \multicolumn{12}{|l|}{ HDPE Piping } \\
\hline 2-inch; $\mathrm{CO} 2$ individual pond lines & 400 & $\$ 15,850$ & $\$ 8.49 \mathrm{LF}$ & $\$ 19,246$ & 1760 & $\$ 69,740$ & $\$ 8.49 \mathrm{LF}$ & $\$ 84,682$ & $5600 \$ 70,752$ & $\$ 8.49 \mathrm{LF}$ & $\$ 118,296$ \\
\hline 6-inch; $\mathrm{CO} 2$ feeder lines in pond columns & 0 & $\$ 0$ & $\$ 13.00 \mathrm{LF}$ & $\$ 0$ & 5000 & $\$ 8,644$ & $\$ 13.00 \mathrm{LF}$ & $\$ 73,644$ & $5000 \$ 19,244$ & $\$ 13.00 \mathrm{LF}$ & $\$ 84,244$ \\
\hline 8-inch; $\mathrm{CO} 2$ line & 3500 & $\$ 1,612$ & $\$ 17.70 \mathrm{LF}$ & $\$ 63,562$ & 1600 & $\$ 417$ & $\$ 17.70 \mathrm{LF}$ & $\$ 28,737$ & $1400 \$ 2,232$ & $\$ 17.70 \mathrm{LF}$ & $\$ 27,012$ \\
\hline \multicolumn{12}{|l|}{ Others } \\
\hline $\mathrm{CO} 2$ diffusers & 10 & & $\$ 1,000$ ea & $\$ 10,000$ & 44 & & $\$ 500$ ea & $\$ 22,000$ & 140 & $\$ 500.00$ ea & $\$ 70,000$ \\
\hline Slide Gates & 10 & & $\$ 5,851$ ea & $\$ 58,510$ & 44 & & $\$ 5,851$ ea & $\$ 257,444$ & $\mathrm{n} / \mathrm{a}$ & ea & $\$ 0$ \\
\hline Piping Work Total & & & & $\$ 892,205$ & & & & $\$ 1,626,413$ & & & $\$ 509,952$ \\
\hline \multicolumn{12}{|l|}{ Concrete } \\
\hline $\begin{array}{l}\text { Pond concrete - paddlewheel, motor, supports, } \\
\text { slide gate, inlet pipe }\end{array}$ & 209 & & $\$ 751.00 \mathrm{CY}$ & $\$ 156,959$ & 624 & & $\$ 751.00 \mathrm{CY}$ & $\$ 468,624$ & & & $n / a$ \\
\hline Non formed concrete work (piping "stays") & 0 & & $\$ 274.00 \mathrm{CY}$ & $\$ 171,829$ & 2621 & & $\$ 274.00 \mathrm{CY}$ & $\$ 269,270$ & 252 & $\$ 274.00 \mathrm{CY}$ & $\$ 69,170$ \\
\hline Concrete Work Total & & & & $\$ 328,788$ & & & & $\$ 737,894$ & & & $\$ 69,170$ \\
\hline TOTAL DIRECT POND COSTS & & & & $\$ 3,132,466$ & & & & $\$ 5,708,107$ & & & $\$ 1,938,351$ \\
\hline SUMMARY METRICS & & & $\$$ /acre & Total Cost & & & \$/acre & Total Cost & & \$lacre & Total Cost \\
\hline Total Direct Pond Cost (excluding land) & & & $\$ 32,360$ & $\$ 3,132,466$ & & & $\$ 58,968$ & $\$ 5,708,107$ & & $\$ 20,024$ & $\$ 1,938,351$ \\
\hline Civil Work & & & $\$ 11,268$ & $\$ 1,090,767$ & & & $\$ 11,842$ & $\$ 1,146,292$ & & $\$ 13,326$ & $\$ 1,289,985$ \\
\hline Leakage Control & & & $\$ 451$ & $\$ 43,687$ & & & $\$ 741$ & $\$ 71,728$ & & $\$ 715$ & $\$ 69,245$ \\
\hline Paddlewheel & & & $\$ 6,612$ & $\$ 640,000$ & & & $\$ 17,636$ & $\$ 1,707,200$ & & $\$ 0$ & $\$ 0$ \\
\hline E\&I & & & $\$ 1,415$ & $\$ 137,020$ & & & $\$ 4,324$ & $\$ 418,580$ & & $\$ 0$ & $\$ 0$ \\
\hline Piping & & & $\$ 9,217$ & $\$ 892,205$ & & & $\$ 16,802$ & $\$ 1,626,413$ & & $\$ 5,268$ & $\$ 509,952$ \\
\hline Concrete & & & $\$ 3,397$ & $\$ 328,788$ & & & $\$ 7,623$ & $\$ 737,894$ & & $\$ 715$ & $\$ 69,170$ \\
\hline
\end{tabular}




\section{Appendix C. Discounted Cash Flow Rate of Return Worksheet}

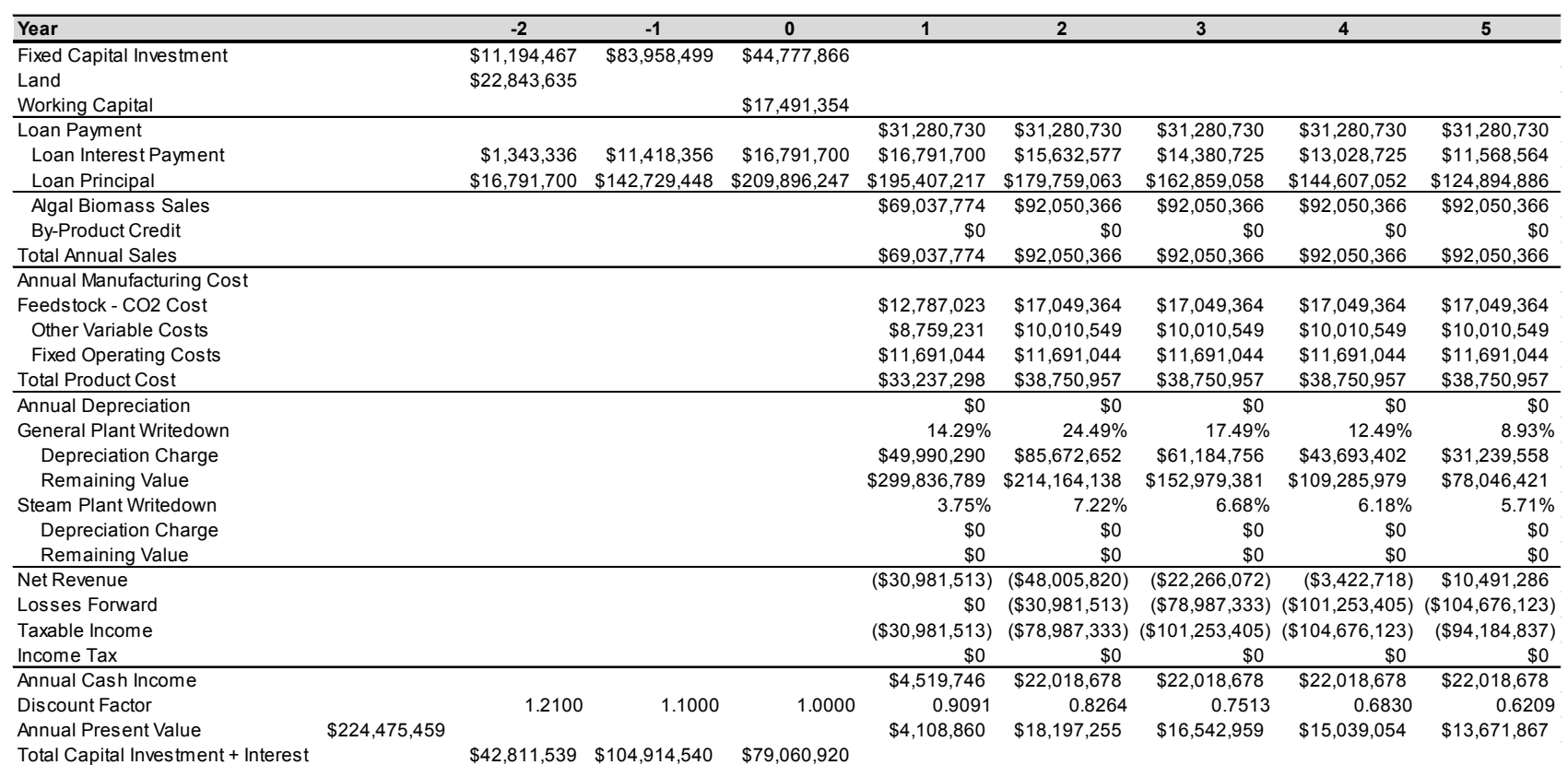

\begin{tabular}{lrr} 
Notal Capital Investment + Interest & $\$ 42,811,539$ & $\$ 104,914,540$ \\
Net Present Worth & $\$ 79,060,920$ \\
\hline 0
\end{tabular}

\begin{tabular}{|c|c|c|c|c|c|c|c|c|c|}
\hline Year & 6 & 7 & 8 & 9 & 10 & 11 & 12 & 13 & 14 \\
\hline \multicolumn{10}{|l|}{$\begin{array}{l}\text { Fixed Capital Investment } \\
\text { Land } \\
\text { Working Capital }\end{array}$} \\
\hline Loan Payment & $\$ 31,280,730$ & $\$ 31,280,730$ & $\$ 31,280,730$ & $\$ 31,280,730$ & $\$ 31,280,730$ & $\$ 0$ & $\$ 0$ & $\$ 0$ & $\$ 0$ \\
\hline Loan Interest Payment & $\$ 9,991,591$ & $\$ 8,288,460$ & $\$ 6,449,078$ & $\$ 4,462,546$ & $\$ 2,317,091$ & $\$ 0$ & $\$ 0$ & $\$ 0$ & $\$ 0$ \\
\hline Loan Principal & $\$ 103,605,747$ & $\$ 80,613,476$ & $\$ 55,781,824$ & $\$ 28,963,639$ & $\$ 0$ & $\$ 0$ & $\$ 0$ & $\$ 0$ & $\$ 0$ \\
\hline Algal Biomass Sales & $\$ 92,050,366$ & $\$ 92,050,366$ & $\$ 92,050,366$ & $\$ 92,050,366$ & $\$ 92,050,366$ & $\$ 92,050,366$ & $\$ 92,050,366$ & $\$ 92,050,366$ & $\$ 92,050,366$ \\
\hline By-Product Credit & $\$ 0$ & $\$ 0$ & $\$ 0$ & $\$ 0$ & $\$ 0$ & $\$ 0$ & $\$ 0$ & $\$ 0$ & $\$ 0$ \\
\hline Total Annual Sales & $\$ 92,050,366$ & $\$ 92,050,366$ & $\$ 92,050,366$ & $\$ 92,050,366$ & $\$ 92,050,366$ & $\$ 92,050,366$ & $\$ 92,050,366$ & $\$ 92,050,366$ & $\$ 92,050,366$ \\
\hline Annual Manufacturing Cost & $\$ 0$ & $\$ 0$ & $\$ 0$ & $\$ 0$ & $\$ 0$ & $\$ 0$ & $\$ 0$ & $\$ 0$ & $\$ 0$ \\
\hline Feedstock - CO2 Cost & $\$ 17,049,364$ & $\$ 17,049,364$ & $\$ 17,049,364$ & $\$ 17,049,364$ & $\$ 17,049,364$ & $\$ 17,049,364$ & $\$ 17,049,364$ & $\$ 17,049,364$ & $\$ 17,049,364$ \\
\hline Other Variable Costs & $\$ 10,010,549$ & $\$ 10,010,549$ & $\$ 10,010,549$ & $\$ 10,010,549$ & $\$ 10,010,549$ & $\$ 10,010,549$ & $\$ 10,010,549$ & $\$ 10,010,549$ & $\$ 10,010,549$ \\
\hline Fixed Operating Costs & $\$ 11,691,044$ & $\$ 11,691,044$ & $\$ 11,691,044$ & $\$ 11,691,044$ & $\$ 11,691,044$ & $\$ 11,691,044$ & $\$ 11,691,044$ & $\$ 11,691,044$ & $\$ 11,691,044$ \\
\hline Total Product Cost & $\$ 38,750,957$ & $\$ 38,750,957$ & $\$ 38,750,957$ & $\$ 38,750,957$ & $\$ 38,750,957$ & $\$ 38,750,957$ & $\$ 38,750,957$ & $\$ 38,750,957$ & $\$ 38,750,957$ \\
\hline \multicolumn{10}{|l|}{ Annual Depreciation } \\
\hline General Plant Writedown & $8.92 \%$ & $8.93 \%$ & $4.46 \%$ & & & & & & \\
\hline Depreciation Charge & $\$ 31,204,575$ & $\$ 31,239,558$ & $\$ 15,602,288$ & & & & & & \\
\hline Remaining Value & $\$ 46,841,846$ & $\$ 15,602,288$ & $(\$ 0)$ & & & & & & \\
\hline Steam Plant Writedown & $5.29 \%$ & $4.89 \%$ & $4.52 \%$ & $4.46 \%$ & $4.46 \%$ & $4.46 \%$ & $4.46 \%$ & $4.46 \%$ & $4.46 \%$ \\
\hline Depreciation Charge & $\$ 0$ & $\$ 0$ & $\$ 0$ & $\$ 0$ & $\$ 0$ & $\$ 0$ & $\$ 0$ & $\$ 0$ & $\$ 0$ \\
\hline Remaining Value & $\$ 0$ & $\$ 0$ & $\$ 0$ & $\$ 0$ & $\$ 0$ & $\$ 0$ & $\$ 0$ & $\$ 0$ & $\$ 0$ \\
\hline Net Revenue & $\$ 12,103,242$ & $\$ 13,771,391$ & $\$ 31,248,043$ & $\$ 48,836,863$ & $\$ 50,982,318$ & $\$ 53,299,409$ & $\$ 53,299,409$ & $\$ 53,299,409$ & $\$ 53,299,409$ \\
\hline Losses Forward & $(\$ 94,184,837)$ & $(\$ 82,081,594)$ & $(\$ 68,310,204)$ & $(\$ 37,062,161)$ & $\$ 0$ & $\$ 0$ & $\$ 0$ & $\$ 0$ & $\$ 0$ \\
\hline Taxable Income & $(\$ 82,081,594)$ & $(\$ 68,310,204)$ & $(\$ 37,062,161)$ & $\$ 11,774,702$ & $\$ 50,982,318$ & $\$ 53,299,409$ & $\$ 53,299,409$ & $\$ 53,299,409$ & $\$ 53,299,409$ \\
\hline Income Tax & $\$ 0$ & $\$ 0$ & $\$ 0$ & $\$ 4,121,146$ & $\$ 17,843,811$ & $\$ 18,654,793$ & $\$ 18,654,793$ & $\$ 18,654,793$ & $\$ 18,654,793$ \\
\hline Annual Cash Income & $\$ 22,018,678$ & $\$ 22,018,678$ & $\$ 22,018,678$ & $\$ 17,897,533$ & $\$ 4,174,867$ & $\$ 34,644,616$ & $\$ 34,644,616$ & $\$ 34,644,616$ & $\$ 34,644,616$ \\
\hline Discount Factor & 0.5645 & 0.5132 & 0.4665 & 0.4241 & 0.3855 & 0.3505 & 0.3186 & 0.2897 & 0.2633 \\
\hline Annual Present Value & $\$ 12,428,970$ & $\$ 11,299,064$ & $\$ 10,271,876$ & $\$ 7,590,301$ & $\$ 1,609,592$ & $\$ 12,142,726$ & $\$ 11,038,842$ & $\$ 10,035,311$ & $\$ 9,123,010$ \\
\hline
\end{tabular}




\begin{tabular}{|c|c|c|c|c|c|c|c|c|}
\hline Year & 15 & 16 & 17 & 18 & 19 & 20 & 21 & 22 \\
\hline $\begin{array}{l}\text { Fixed Capital Investment } \\
\text { Land } \\
\text { Working Capital }\end{array}$ & & & & & & & & \\
\hline Loan Payment & $\$ 0$ & $\$ 0$ & $\$ 0$ & $\$ 0$ & $\$ 0$ & $\$ 0$ & $\$ 0$ & $\$ 0$ \\
\hline Loan Interest Payment & $\$ 0$ & $\$ 0$ & $\$ 0$ & $\$ 0$ & $\$ 0$ & $\$ 0$ & $\$ 0$ & $\$ 0$ \\
\hline Loan Principal & $\$ 0$ & $\$ 0$ & $\$ 0$ & $\$ 0$ & $\$ 0$ & $\$ 0$ & $\$ 0$ & $\$ 0$ \\
\hline Algal Biomass Sales & $\$ 92,050,366$ & $\$ 92,050,366$ & $\$ 92,050,366$ & $\$ 92,050,366$ & $\$ 92,050,366$ & $\$ 92,050,366$ & $\$ 92,050,366$ & $\$ 92,050,366$ \\
\hline By-Product Credit & $\$ 0$ & $\$ 0$ & $\$ 0$ & $\$ 0$ & $\$ 0$ & $\$ 0$ & $\$ 0$ & $\$ 0$ \\
\hline Total Annual Sales & $\$ 92,050,366$ & $\$ 92,050,366$ & $\$ 92,050,366$ & $\$ 92,050,366$ & $\$ 92,050,366$ & $\$ 92,050,366$ & $\$ 92,050,366$ & $\$ 92,050,366$ \\
\hline \multicolumn{9}{|l|}{ Annual Manufacturing Cost } \\
\hline Feedstock - CO2 Cost & $\$ 17,049,364$ & $\$ 17,049,364$ & $\$ 17,049,364$ & $\$ 17,049,364$ & $\$ 17,049,364$ & $\$ 17,049,364$ & $\$ 17,049,364$ & $\$ 17,049,364$ \\
\hline Other Variable Costs & $\$ 10,010,549$ & $\$ 10,010,549$ & $\$ 10,010,549$ & $\$ 10,010,549$ & $\$ 10,010,549$ & $\$ 10,010,549$ & $\$ 10,010,549$ & $\$ 10,010,549$ \\
\hline Fixed Operating Costs & $\$ 11,691,044$ & $\$ 11,691,044$ & $\$ 11,691,044$ & $\$ 11,691,044$ & $\$ 11,691,044$ & $\$ 11,691,044$ & $\$ 11,691,044$ & $\$ 11,691,044$ \\
\hline Total Product Cost & $\$ 38,750,957$ & $\$ 38,750,957$ & $\$ 38,750,957$ & $\$ 38,750,957$ & $\$ 38,750,957$ & $\$ 38,750,957$ & $\$ 38,750,957$ & $\$ 38,750,957$ \\
\hline \multicolumn{9}{|l|}{ Annual Depreciation } \\
\hline $\begin{array}{l}\text { General Plant Writedown } \\
\text { Depreciation Charge } \\
\text { Remaining Value }\end{array}$ & & & & & & & & \\
\hline Steam Plant Writedown & $4.46 \%$ & $4.46 \%$ & $4.46 \%$ & $4.46 \%$ & $4.46 \%$ & $4.46 \%$ & $2.23 \%$ & \\
\hline Depreciation Charge & $\$ 0$ & $\$ 0$ & $\$ 0$ & $\$ 0$ & $\$ 0$ & $\$ 0$ & $\$ 0$ & \\
\hline Remaining Value & $\$ 0$ & $\$ 0$ & $\$ 0$ & $\$ 0$ & $\$ 0$ & $\$ 0$ & $\$ 0$ & \\
\hline Net Revenue & $\$ 53,299,409$ & $\$ 53,299,409$ & $\$ 53,299,409$ & $\$ 53,299,409$ & $\$ 53,299,409$ & $\$ 53,299,409$ & $\$ 53,299,409$ & $\$ 53,299,409$ \\
\hline Losses Forward & $\$ 0$ & $\$ 0$ & $\$ 0$ & $\$ 0$ & $\$ 0$ & $\$ 0$ & $\$ 0$ & $\$ 0$ \\
\hline Taxable Income & $\$ 53,299,409$ & $\$ 53,299,409$ & $\$ 53,299,409$ & $\$ 53,299,409$ & $\$ 53,299,409$ & $\$ 53,299,409$ & $\$ 53,299,409$ & $\$ 53,299,409$ \\
\hline Income Tax & $\$ 18,654,793$ & $\$ 18,654,793$ & $\$ 18,654,793$ & $\$ 18,654,793$ & $\$ 18,654,793$ & $\$ 18,654,793$ & $\$ 18,654,793$ & $\$ 18,654,793$ \\
\hline Annual Cash Income & $\$ 34,644,616$ & $\$ 34,644,616$ & $\$ 34,644,616$ & $\$ 34,644,616$ & $\$ 34,644,616$ & $\$ 34,644,616$ & $\$ 34,644,616$ & $\$ 34,644,616$ \\
\hline Discount Factor & 0.2394 & 0.2176 & 0.1978 & 0.1799 & 0.1635 & 0.1486 & 0.1351 & 0.1228 \\
\hline Annual Present Value & $\$ 8,293,646$ & $\$ 7,539,678$ & $\$ 6,854,253$ & $\$ 6,231,139$ & $\$ 5,664,671$ & $\$ 5,149,701$ & $\$ 4,681,547$ & $\$ 4,255,952$ \\
\hline
\end{tabular}

\begin{tabular}{|c|c|c|c|c|c|c|c|c|}
\hline Year & 23 & 24 & 25 & 26 & 27 & 28 & 29 & 30 \\
\hline \multicolumn{9}{|l|}{$\begin{array}{l}\text { Fixed Capital Investment } \\
\text { Land } \\
\text { Working Capital }\end{array}$} \\
\hline Loan Payment & $\$ 0$ & $\$ 0$ & $\$ 0$ & $\$ 0$ & $\$ 0$ & $\$ 0$ & $\$ 0$ & $\$ 0$ \\
\hline Loan Interest Payment & $\$ 0$ & $\$ 0$ & $\$ 0$ & $\$ 0$ & $\$ 0$ & $\$ 0$ & $\$ 0$ & $\$ 0$ \\
\hline Loan Principal & $\$ 0$ & $\$ 0$ & $\$ 0$ & $\$ 0$ & $\$ 0$ & $\$ 0$ & $\$ 0$ & $\$ 0$ \\
\hline Algal Biomass Sales & $\$ 92,050,366$ & $\$ 92,050,366$ & $\$ 92,050,366$ & $\$ 92,050,366$ & $\$ 92,050,366$ & $\$ 92,050,366$ & $\$ 92,050,366$ & $\$ 92,050,366$ \\
\hline By-Product Credit & $\$ 0$ & $\$ 0$ & $\$ 0$ & $\$ 0$ & $\$ 0$ & $\$ 0$ & $\$ 0$ & $\$ 0$ \\
\hline Total Annual Sales & $\$ 92,050,366$ & $\$ 92,050,366$ & $\$ 92,050,366$ & $\$ 92,050,366$ & $\$ 92,050,366$ & $\$ 92,050,366$ & $\$ 92,050,366$ & $\$ 92,050,366$ \\
\hline \multicolumn{9}{|l|}{ Annual Manufacturing Cost } \\
\hline Feedstock - CO2 Cost & $\$ 17,049,364$ & $\$ 17,049,364$ & $\$ 17,049,364$ & $\$ 17,049,364$ & $\$ 17,049,364$ & $\$ 17,049,364$ & $\$ 17,049,364$ & $\$ 17,049,364$ \\
\hline Other Variable Costs & $\$ 10,010,549$ & $\$ 10,010,549$ & $\$ 10,010,549$ & $\$ 10,010,549$ & $\$ 10,010,549$ & $\$ 10,010,549$ & $\$ 10,010,549$ & $\$ 10,010,549$ \\
\hline Fixed Operating Costs & $\$ 11,691,044$ & $\$ 11,691,044$ & $\$ 11,691,044$ & $\$ 11,691,044$ & $\$ 11,691,044$ & $\$ 11,691,044$ & $\$ 11,691,044$ & $\$ 11,691,044$ \\
\hline Total Product Cost & $\$ 38,750,957$ & $\$ 38,750,957$ & $\$ 38,750,957$ & $\$ 38,750,957$ & $\$ 38,750,957$ & $\$ 38,750,957$ & $\$ 38,750,957$ & $\$ 38,750,957$ \\
\hline \multicolumn{9}{|l|}{ Annual Depreciation } \\
\hline \multicolumn{9}{|l|}{$\begin{array}{l}\text { General Plant Writedown } \\
\text { Depreciation Charge } \\
\text { Remaining Value }\end{array}$} \\
\hline \multicolumn{8}{|l|}{ Depreciation Charge } & \\
\hline Net Revenue & $\$ 53,299,409$ & $\$ 53,299,409$ & $\$ 53,299,409$ & $\$ 53,299,409$ & $\$ 53,299,409$ & $\$ 53,299,409$ & $\$ 53,299,409$ & $\$ 53,299,409$ \\
\hline Losses Forward & $\$ 0$ & $\$ 0$ & $\$ 0$ & $\$ 0$ & $\$ 0$ & $\$ 0$ & $\$ 0$ & $\$ 0$ \\
\hline Taxable Income & $\$ 53,299,409$ & $\$ 53,299,409$ & $\$ 53,299,409$ & $\$ 53,299,409$ & $\$ 53,299,409$ & $\$ 53,299,409$ & $\$ 53,299,409$ & $\$ 53,299,409$ \\
\hline Income Tax & $\$ 18,654,793$ & $\$ 18,654,793$ & $\$ 18,654,793$ & $\$ 18,654,793$ & $\$ 18,654,793$ & $\$ 18,654,793$ & $\$ 18,654,793$ & $\$ 18,654,793$ \\
\hline Annual Cash Income & $\$ 34,644,616$ & $\$ 34,644,616$ & $\$ 34,644,616$ & $\$ 34,644,616$ & $\$ 34,644,616$ & $\$ 34,644,616$ & $\$ 34,644,616$ & $\$ 34,644,616$ \\
\hline Discount Factor & 0.1117 & 0.1015 & 0.0923 & 0.0839 & 0.0763 & 0.0693 & 0.0630 & 0.0573 \\
\hline $\begin{array}{l}\text { Annual Present Value } \\
\text { Total Capital Investment + Interest }\end{array}$ & $\$ 3,869,047$ & $\$ 3,517,315$ & $\$ 3,197,559$ & $\$ 2,906,872$ & $\$ 2,642,611$ & $\$ 2,402,374$ & $\$ 2,183,976$ & $\begin{array}{r}\$ 1,985,433 \\
(\$ 2,311,540)\end{array}$ \\
\hline
\end{tabular}




\section{Appendix D. Process Flow Diagrams}

High-level stream table information from Aspen Plus modeling output follows, for key streams associated with each process operation area. The stream table values are associated with the HCSD biomass base case scenario, for the summer season which is used to set the basis for the facility design capacity. This is followed by high-level PFDs for the associated process areas. As the stream table information focuses primarily on the high-level overall process and does not include every individual modeled stream within each process area, mass balance closure around a given unit area may not be $100 \%$. 


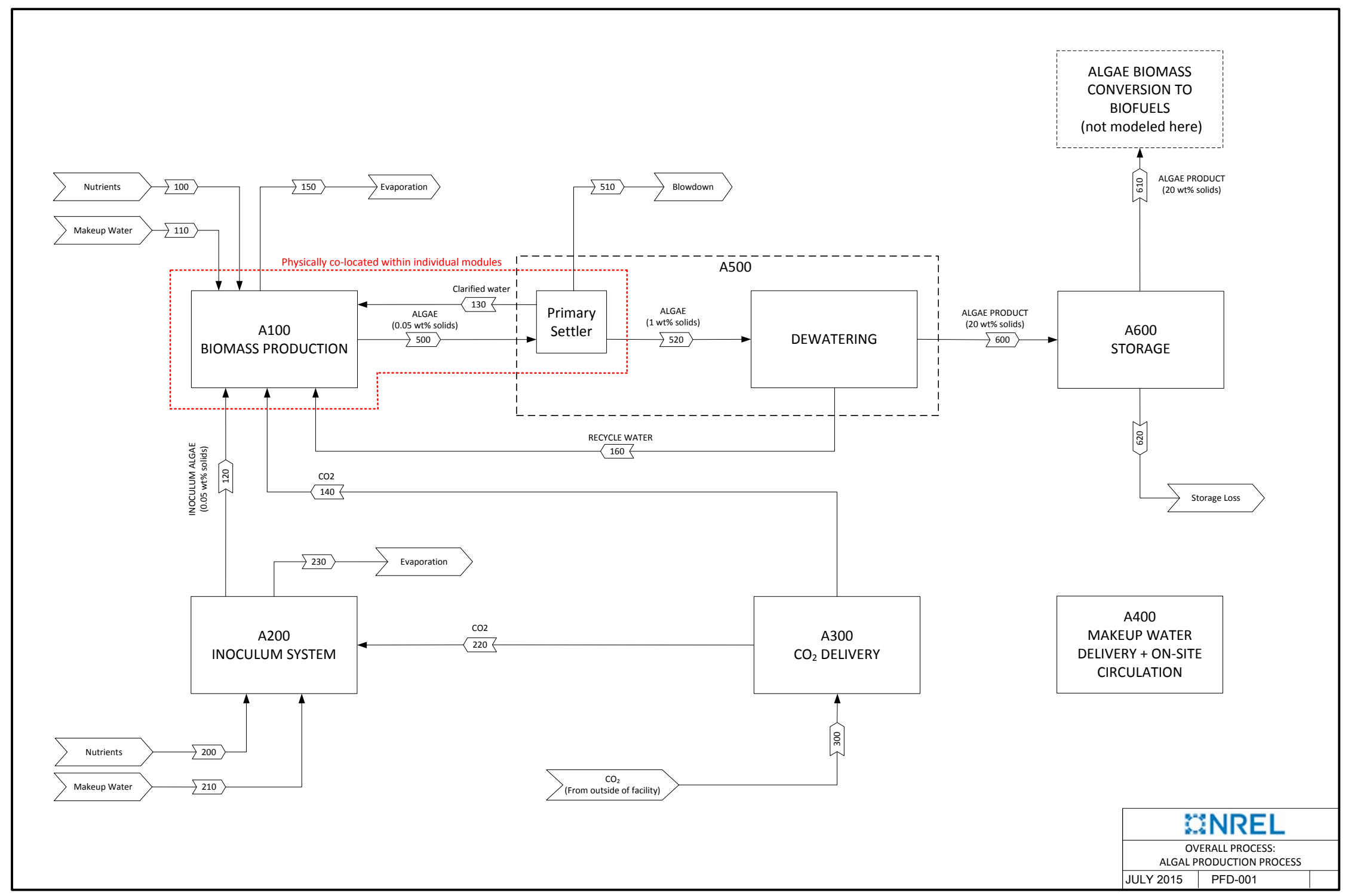

Figure 21. Overall process schematic for Aspen stream tables 
Aspen Plus mass balance information for key stream tables:

\begin{tabular}{|c|c|c|c|c|c|c|c|c|c|c|}
\hline COMPONENT & UNITS & 100 & 110 & 120 & 130 & 140 & 150 & 160 & 200 & 210 \\
\hline Total Flow & $\mathrm{kg} / \mathrm{hr}$ & 863 & $1,202,718$ & 2,909 & $66,420,622$ & 65,057 & 815,493 & $3,000,092$ & 31 & 20,258 \\
\hline Percent Solids & Wt \% & 0 & 0 & 29.4 & 0.0054 & 0 & 0 & 0.037 & 0 & 0 \\
\hline Temperature & ${ }^{\circ} \mathrm{C}$ & 25 & 25 & 25 & 25 & 32 & 25 & 25 & 25 & 25 \\
\hline Pressure & atm & 1 & 1 & 1 & 1 & 4 & 1 & 1 & 1 & 1 \\
\hline Ammonia & $\mathrm{kg} / \mathrm{hr}$ & 581 & 0 & 4 & 139 & 0 & 0 & 6 & 21 & 0 \\
\hline DAP & $\mathrm{kg} / \mathrm{hr}$ & 282 & 0 & 2 & 67 & 0 & 0 & 3 & 10 & 0 \\
\hline $\mathrm{O}_{2}$ & $\mathrm{~kg} / \mathrm{hr}$ & 0 & 0 & 0 & 0 & 0 & 50,400 & 0 & 0 & 0 \\
\hline $\mathrm{CO}_{2}$ & $\mathrm{~kg} / \mathrm{hr}$ & 0 & 0 & 0 & 0 & 65,057 & 6,506 & 0 & 0 & 0 \\
\hline Salt (NaCl) & $\mathrm{kg} / \mathrm{hr}$ & 0 & 301 & 225 & 80,892 & 0 & 0 & 3,653 & 0 & 225 \\
\hline Water & $\mathrm{kg} / \mathrm{hr}$ & 0 & $1,202,417$ & 1,821 & $66,335,960$ & 0 & 758,588 & $2,995,308$ & 0 & 20,032 \\
\hline Algae (AFDW) & $\mathrm{kg} / \mathrm{hr}$ & 0 & 0 & 857 & 3,478 & 0 & 0 & 1,096 & 0 & 0 \\
\hline Ash & $\mathrm{kg} / \mathrm{hr}$ & 0 & 0 & 0 & 86 & 0 & 0 & 27 & 0 & 0 \\
\hline
\end{tabular}

\begin{tabular}{|c|c|c|c|c|c|c|c|c|c|c|}
\hline COMPONENT & UNITS & 220 & 230 & 300 & 500 & 510 & 520 & 600 & 610 & 620 \\
\hline Total Flow & $\mathrm{kg} / \mathrm{hr}$ & 1,851 & 19,231 & 66,908 & $69,877,491$ & 304,135 & $3,152,731$ & 152,640 & 152,336 & 303 \\
\hline Percent Solids & Wt \% & 0 & 0 & 0 & 0.051 & 0.005 & 1.0 & 20.4 & 20.2 & 100 \\
\hline Temperature & ${ }^{\circ} \mathrm{C}$ & 25 & 25 & 40 & 25 & 25 & 25 & 25 & 25 & 25 \\
\hline Pressure & atm & 1 & 1 & 128 & 1 & 1 & 1 & 2 & 2 & 2 \\
\hline Ammonia & $\mathrm{kg} / \mathrm{hr}$ & 0 & 0 & 0 & 146 & 0.6 & 7 & 0.3 & 0.3 & 0 \\
\hline DAP & $\mathrm{kg} / \mathrm{hr}$ & 0 & 0 & 0 & 71 & 0.3 & 3 & 0.1 & 0.1 & 0 \\
\hline $\mathrm{O}_{2}$ & $\mathrm{~kg} / \mathrm{hr}$ & 0 & 1,463 & 0 & 0 & 0 & 0 & 0 & 0 & 0 \\
\hline $\mathrm{CO}_{2}$ & $\mathrm{~kg} / \mathrm{hr}$ & 1,851 & 151 & 65,057 & 0 & 0 & 0 & 0 & 0 & 0 \\
\hline Salt (NaCl) & $\mathrm{kg} / \mathrm{hr}$ & 0 & 0 & 0 & 85,063 & 370 & 3,801 & 148 & 148 & 0 \\
\hline Water & $\mathrm{kg} / \mathrm{hr}$ & 0 & 17,617 & 0 & $69,756,413$ & 303,747 & $3,116,702$ & 121,396 & 121,396 & 0 \\
\hline Algae (AFDW) & $\mathrm{kg} / \mathrm{hr}$ & 0 & 0 & 0 & 34,939 & 16 & 31,445 & 30,349 & 30,046 & 303 \\
\hline Ash & $\mathrm{kg} / \mathrm{hr}$ & 0 & 0 & 0 & 859 & 0.4 & 773 & 746 & 746 & 0 \\
\hline
\end{tabular}




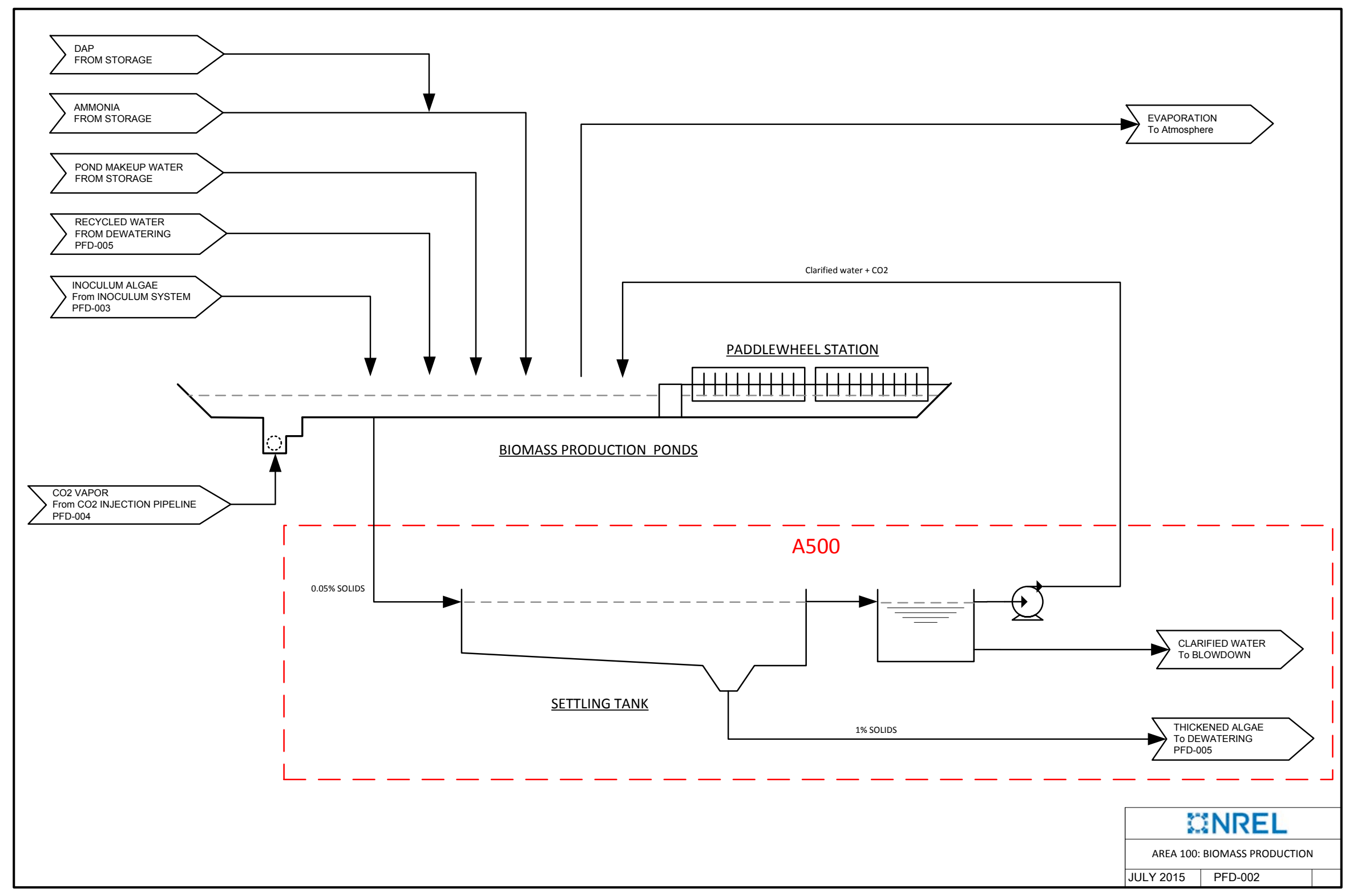




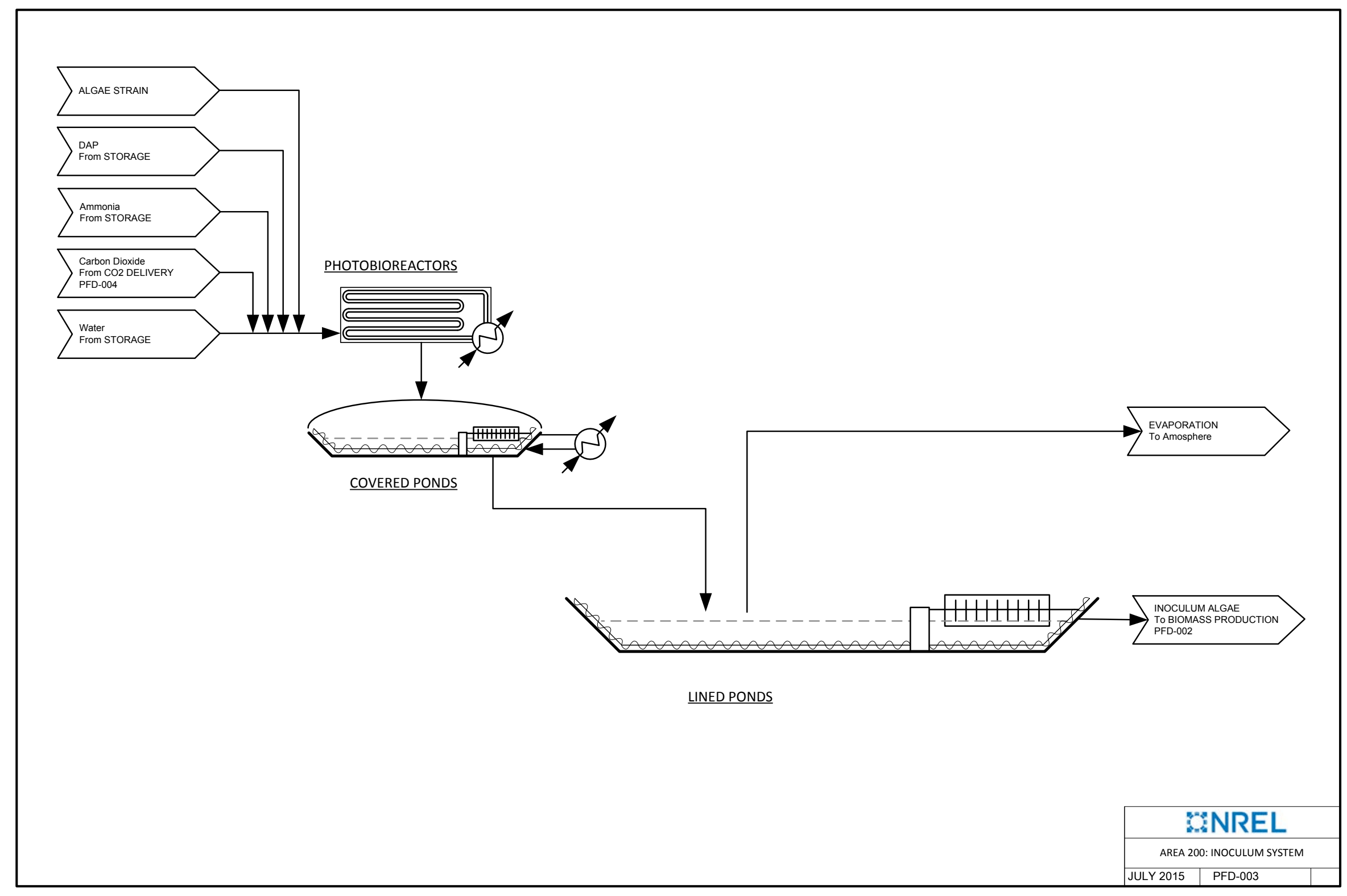




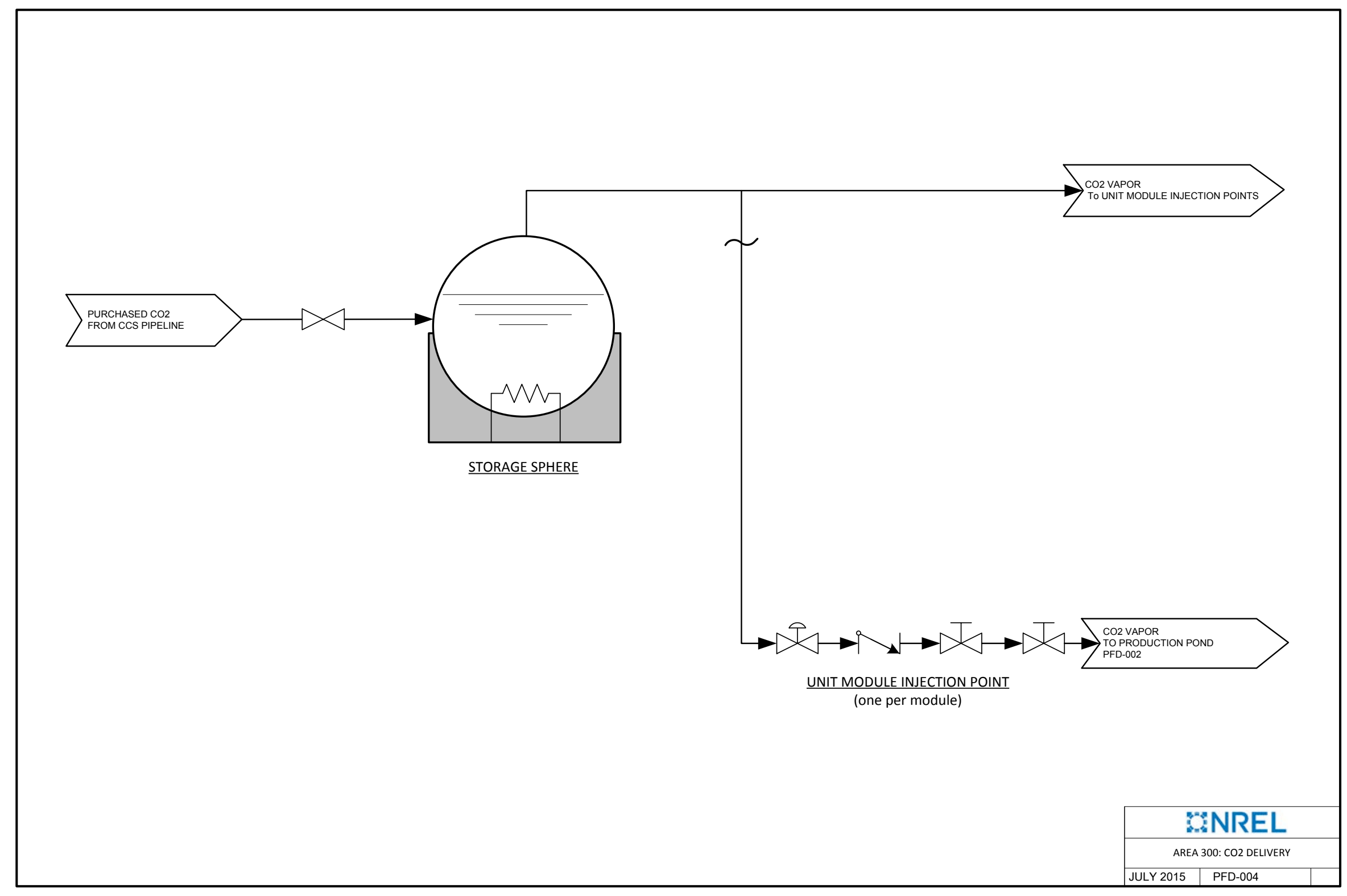




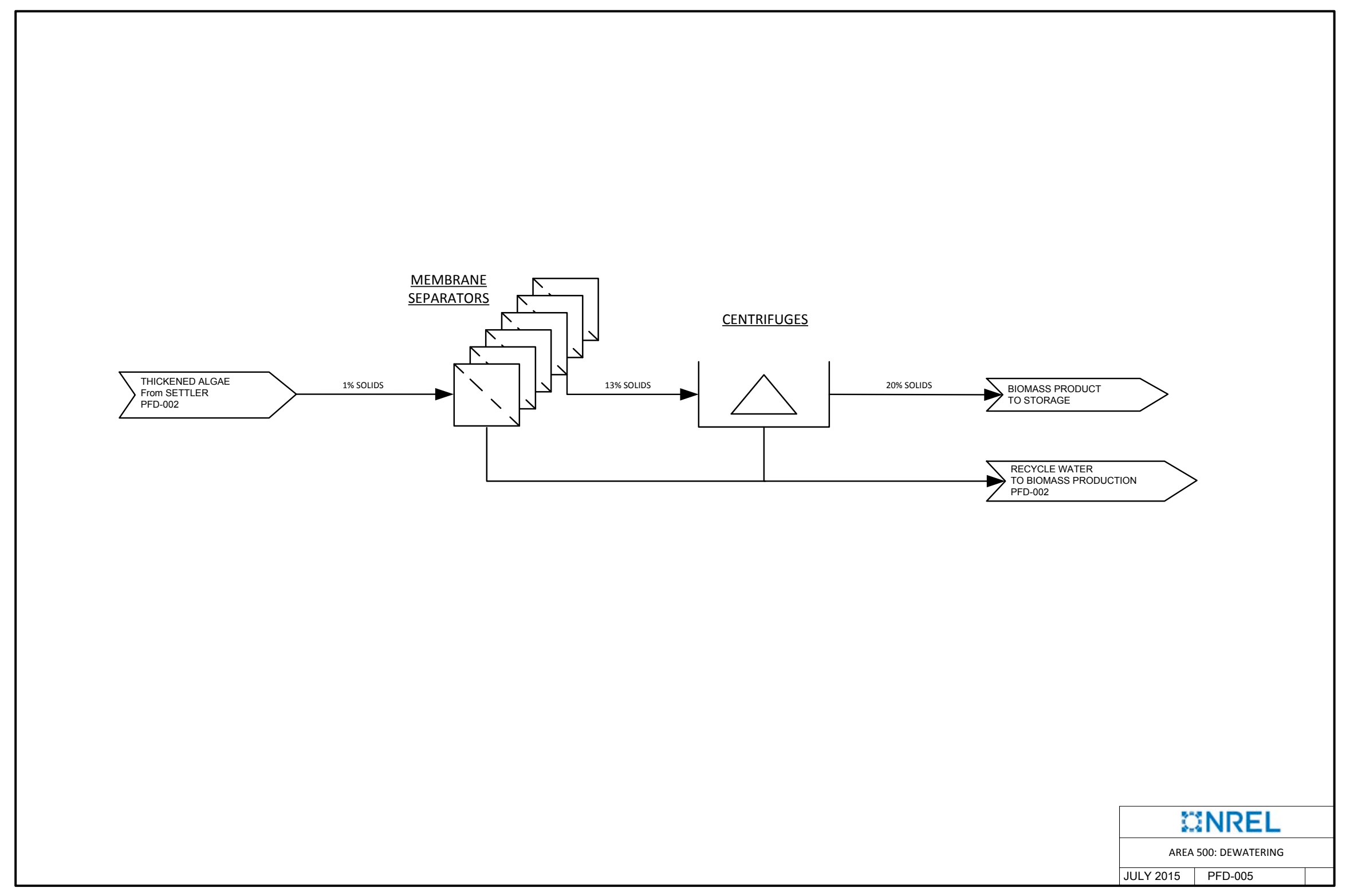




\section{Appendix E. TEA Summary Worksheets for Individual Pond Scenarios}

The following worksheets present additional cost and process details for each of the eight individual pond design cases evaluated in the TEA models.

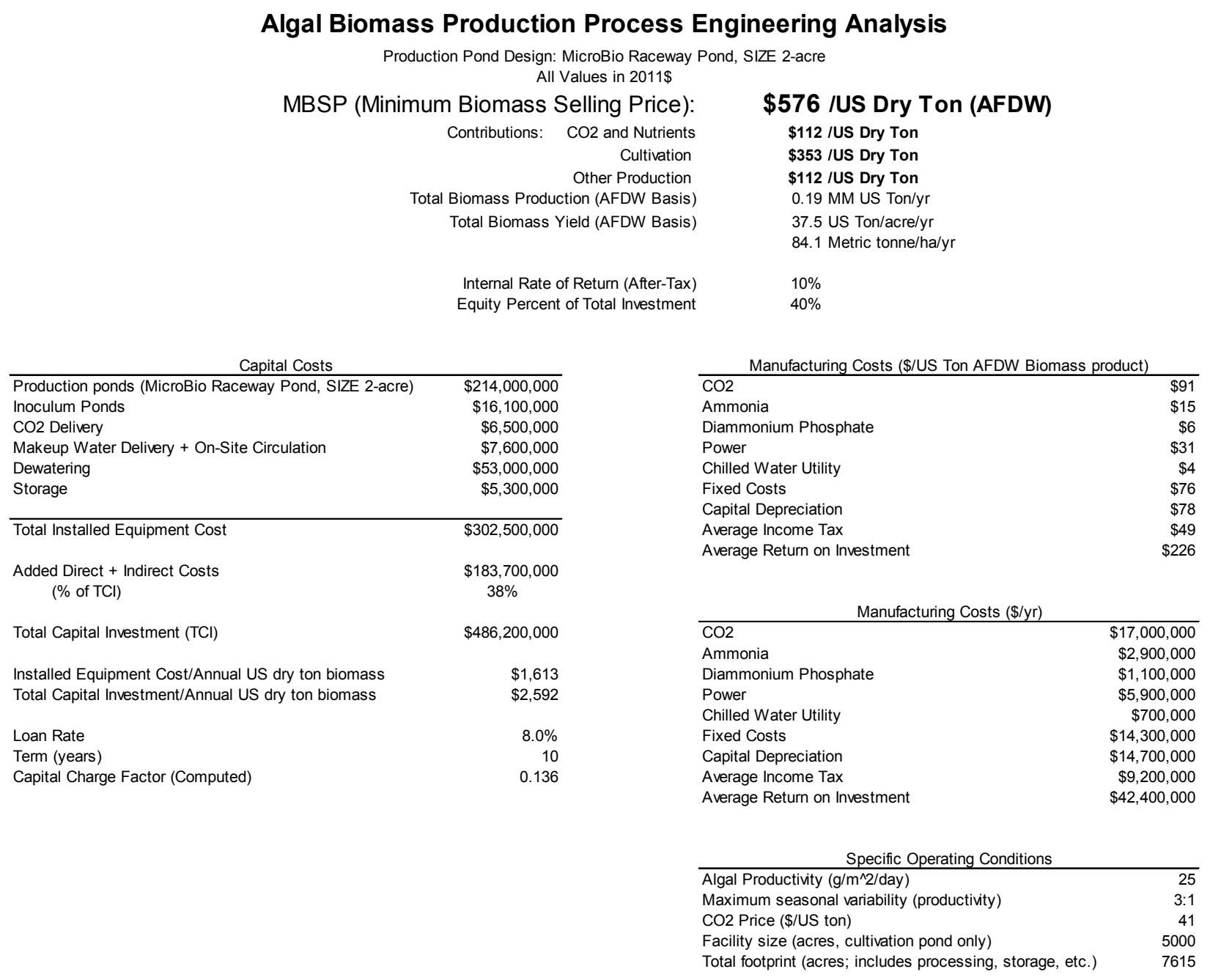




\title{
Algal Biomass Production Process Engineering Analysis
}

Production Pond Design: Leidos Raceway Pond, SIZE 2-acre All Values in $2011 \$$

MBSP (Minimum Biomass Selling Price):

Contributions: $\mathrm{CO} 2$ and Nutrients

Cultivation

Other Production

Total Biomass Production (AFDW Basis)

Total Biomass Yield (AFDW Basis)

\author{
\$649 /US Dry Ton (AFDW) \\ $\$ 112$ /US Dry Ton \\ $\$ 430$ /US Dry Ton \\ \$107 IUS Dry Ton \\ $0.19 \mathrm{MM}$ US Ton/yr \\ 37.5 US Ton/acre/yr \\ 84.1 Metric tonne/ha/yr \\ $10 \%$ \\ $40 \%$
}

Internal Rate of Return (After-Tax)

Equity Percent of Total Investment

\begin{tabular}{l} 
Capital Costs \\
\hline Production ponds (Leidos Raceway Pond, SIZE 2-acre) \\
Inoculum Ponds \\
CO2 Delivery \\
Makeup Water Delivery + On-Site Circulation \\
Dewatering \\
Storage \\
\hline Total Installed Equipment Cost \\
Added Direct + Indirect Costs \\
$\quad$ (\% of TCI) \\
Total Capital Investment (TCI) \\
Installed Equipment Cost/Annual US dry ton biomass \\
Total Capital Investment/Annual US dry ton biomass \\
Loan Rate \\
Term (years) \\
Capital Charge Factor (Computed)
\end{tabular}

$\$ 279,100,000$

$\$ 16,100,000$

$\$ 6,500,000$

$\$ 7,600,000$

$\$ 53,000,000$

$\$ 5,300,000$

$\$ 367,600,000$

$\$ 209,500,000$

$36 \%$

$\$ 577,100,000$

$\$ 1,960$

$\$ 3,077$

$8.0 \%$

10
0.136

\begin{tabular}{lr}
\multicolumn{2}{c}{ Manufacturing Costs (\$/US Ton AFDW Biomass product) } \\
\hline CO2 & $\$ 91$ \\
Ammonia & $\$ 15$ \\
Diammonium Phosphate & $\$ 6$ \\
Power & $\$ 34$ \\
Chilled Water Utility & $\$ 4$ \\
Fixed Costs & $\$ 81$ \\
Capital Depreciation & $\$ 94$ \\
Average Income Tax & $\$ 58$ \\
Average Return on Investment & $\$ 266$
\end{tabular}

\begin{tabular}{lr}
\multicolumn{2}{c}{ Manufacturing Costs $(\$ / y r)$} \\
\hline CO2 & $\$ 17,000,000$ \\
Ammonia & $\$ 2,900,000$ \\
Diammonium Phosphate & $\$ 1,100,000$ \\
Power & $\$ 6,400,000$ \\
Chilled Water Utility & $\$ 700,000$ \\
Fixed Costs & $\$ 15,200,000$ \\
Capital Depreciation & $\$ 17,600,000$ \\
Average Income Tax & $\$ 10,900,000$ \\
Average Return on Investment & $\$ 49,900,000$
\end{tabular}

Specific Operating Conditions

\begin{tabular}{lr}
\hline Algal Productivity (g/m^2/day) & 25 \\
Maximum seasonal variability (productivity) & $3: 1$ \\
CO2 Price (\$/US ton) & 41 \\
Facility size (acres, cultivation pond only) & 5000 \\
Total footprint (acres; includes processing, storage, etc.) & 7615
\end{tabular}

\$649 /US Ton Biomass MBSP 


\title{
Algal Biomass Production Process Engineering Analysis
}

Production Pond Design: MicroBio Raceway Pond, SIZE 10-acre

$$
\text { All Values in } 2011 \$
$$

MBSP (Minimum Biomass Selling Price):

Contributions: $\mathrm{CO} 2$ and Nutrients

Cultivation

Other Production

Total Biomass Production (AFDW Basis)

Total Biomass Yield (AFDW Basis)

\author{
\$452 IUS Dry Ton (AFDW) \\ $\$ 112$ /US Dry Ton \\ $\$ 235$ /US Dry Ton \\ $\$ 105$ /US Dry Ton \\ $0.19 \mathrm{MM}$ US Ton/yr \\ 37.5 US Ton/acre/yr \\ 84.1 Metric tonne/ha/yr \\ $10 \%$ \\ $40 \%$
}

Internal Rate of Return (After-Tax)

Equity Percent of Total Investment

\begin{tabular}{lr}
\multicolumn{2}{c}{ Capital Costs } \\
\hline Production ponds (MicroBio Raceway Pond, SIZE 10-acre) & $\$ 123,500,000$ \\
Inoculum Ponds & $\$ 16,100,000$ \\
CO2 Delivery & $\$ 6,500,000$ \\
Makeup Water Delivery + On-Site Circulation & $\$ 7,200,000$ \\
Dewatering & $\$ 43,900,000$ \\
Storage & $\$ 5,300,000$ \\
& \\
\hline Total Installed Equipment Cost & $\$ 202,500,000$ \\
Added Direct + Indirect Costs & \\
$\quad$ (\% of TCl) & $\$ 138,800,000$ \\
Total Capital Investment (TCl) & $41 \%$ \\
& $\$ 341,300,000$ \\
Installed Equipment Cost/Annual US dry ton biomass & \\
Total Capital Investment/Annual US dry ton biomass & $\$ 1,080$ \\
& $\$ 1,820$ \\
Loan Rate & $8.0 \%$ \\
Term (years) & 10 \\
Capital Charge Factor (Computed) & 0.137
\end{tabular}

\begin{tabular}{lr}
\multicolumn{2}{c}{ Manufacturing Costs (\$/US Ton AFDW Biomass product) } \\
\hline CO2 & $\$ 91$ \\
Ammonia & $\$ 15$ \\
Diammonium Phosphate & $\$ 6$ \\
Power & $\$ 26$ \\
Chilled Water Utility & $\$ 4$ \\
Fixed Costs & $\$ 60$ \\
Capital Depreciation & $\$ 54$ \\
Average Income Tax & $\$ 36$ \\
Average Return on Investment & $\$ 160$ \\
& \\
& \\
& \\
\hline CO2 & \\
Ammonia & \\
Diammonium Phosphate & $\$ 17,000,000$ \\
Power & $\$ 2,900,000$ \\
Chilled Water Utility & $\$ 1,100,000$ \\
Fixed Costs & $\$ 4,900,000$ \\
Capital Depreciation & $\$ 700,000$ \\
Average Income Tax & $\$ 11,200,000$ \\
Average Return on Investment & $\$ 10,100,000$ \\
& $\$ 6,800,000$ \\
& $\$ 30,000,000$
\end{tabular}

\begin{tabular}{lr}
\multicolumn{2}{c}{ Specific Operating Conditions } \\
\hline Algal Productivity (g/m^2/day) & 25 \\
Maximum seasonal variability (productivity) & $3: 1$ \\
CO2 Price (\$/US ton) & 41 \\
Facility size (acres, cultivation pond only) & 5000 \\
Total footprint (acres; includes processing, storage, etc.) & 7615
\end{tabular}

\$452 /US Ton Biomass MBSP 


\section{Algal Biomass Production Process Engineering Analysis}

Production Pond Design: Leidos Raceway Pond, SIZE 10-acre

$$
\text { All Values in 2011\$ }
$$

MBSP (Minimum Biomass Selling Price):

Contributions:

$$
\begin{array}{r}
\mathrm{CO} 2 \text { and Nutrients } \\
\text { Cultivation } \\
\text { Other Production }
\end{array}
$$

Total Biomass Production (AFDW Basis)

Total Biomass Yield (AFDW Basis)

Internal Rate of Return (After-Tax)

Equity Percent of Total Investment

\author{
\$491 /US Dry Ton (AFDW) \\ $\$ 112$ /US Dry Ton \\ $\$ 278$ /US Dry Ton \\ $\$ 101$ /US Dry Ton \\ $0.19 \mathrm{MM}$ US Ton/yr \\ 37.5 US Ton/acre/yr \\ 84.1 Metric tonne/ha/yr \\ $10 \%$ \\ $40 \%$
}

\begin{tabular}{lr}
\multicolumn{2}{c}{ Capital Costs } \\
\hline Production ponds (Leidos Raceway Pond, SIZE 10-acre) & $\$ 155,300,000$ \\
Inoculum Ponds & $\$ 16,100,000$ \\
CO2 Delivery & $\$ 6,500,000$ \\
Makeup Water Delivery + On-Site Circulation & $\$ 7,200,000$ \\
Dewatering & $\$ 43,900,000$ \\
Storage & $\$ 5,300,000$ \\
\hline Total Installed Equipment Cost & $\$ 234,300,000$ \\
& \\
Added Direct + Indirect Costs & $\$ 151,400,000$ \\
$\quad$ (\% of TCI) & $39 \%$ \\
Total Capital Investment (TCI) & $\$ 385,700,000$ \\
Installed Equipment Cost/Annual US dry ton biomass & $\$ 1,249$ \\
Total Capital Investment/Annual US dry ton biomass & $\$ 2,056$ \\
& \\
Loan Rate & $8.0 \%$ \\
Term (years) & 10 \\
Capital Charge Factor (Computed) & 0.137
\end{tabular}

\begin{tabular}{lr}
\multicolumn{2}{c}{ Manufacturing Costs (\$/US Ton AFDW Biomass product) } \\
\hline CO2 & $\$ 91$ \\
Ammonia & $\$ 15$ \\
Diammonium Phosphate & $\$ 6$ \\
Power & $\$ 32$ \\
Chilled Water Utility & $\$ 4$ \\
Fixed Costs & $\$ 62$ \\
Capital Depreciation & $\$ 61$ \\
Average Income Tax & $\$ 40$ \\
Average Return on Investment & $\$ 180$
\end{tabular}

\begin{tabular}{lr}
\multicolumn{2}{c}{ Manufacturing Costs $(\$ / \mathrm{yr})$} \\
\hline CO2 & $\$ 17,000,000$ \\
Ammonia & $\$ 2,900,000$ \\
Diammonium Phosphate & $\$ 1,100,000$ \\
Power & $\$ 5,900,000$ \\
Chilled Water Utility & $\$ 700,000$ \\
Fixed Costs & $\$ 11,600,000$ \\
Capital Depreciation & $\$ 11,500,000$ \\
Average Income Tax & $\$ 7,500,000$ \\
Average Return on Investment & $\$ 33,800,000$
\end{tabular}

\begin{tabular}{lr}
\multicolumn{2}{c}{ Specific Operating Conditions } \\
\hline Algal Productivity (g/m^2/day) & 25 \\
Maximum seasonal variability (productivity) & $3: 1$ \\
CO2 Price (\$/US ton) & 41 \\
Facility size (acres, cultivation pond only) & 5000 \\
Total footprint (acres; includes processing, storage, etc.) & 7615
\end{tabular}

\$491 /US Ton Biomass MBSP 


\section{Algal Biomass Production Process Engineering Analysis}

Production Pond Design: Harris Raceway Pond, SIZE 10-acre

All Values in $2011 \$$

MBSP (Minimum Biomass Selling Price):

Contributions: $\mathrm{CO} 2$ and Nutrients

Cultivation

Other Production

Total Biomass Production (AFDW Basis)

Total Biomass Yield (AFDW Basis)

Internal Rate of Return (After-Tax)

Equity Percent of Total Investment

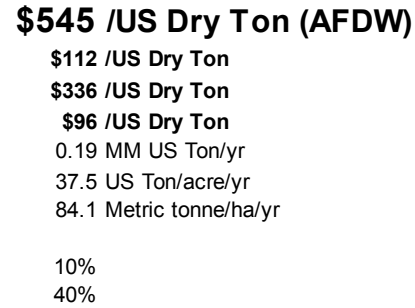

$40 \%$

\begin{tabular}{l} 
Capital Costs \\
\hline Production ponds (Harris Raceway Pond, SIZE 10-acre) \\
Inoculum Ponds \\
CO2 Delivery \\
Makeup Water Delivery + On-Site Circulation \\
Dewatering \\
Storage \\
\hline Total Installed Equipment Cost \\
Added Direct + Indirect Costs \\
(\% of TCI) \\
Total Capital Investment (TCI) \\
Installed Equipment Cost/Annual US dry ton biomass \\
Total Capital Investment/Annual US dry ton biomass \\
Loan Rate \\
Term (years) \\
Capital Charge Factor (Computed)
\end{tabular}

$\$ 208,800,000$

$\$ 16,100,000$

$\$ 6,500,000$

$\$ 7,200,000$

$\$ 43,900,000$

$\$ 5,300,000$

$\$ 287,800,000$

$\$ 172,600,000$

$37 \%$

$\$ 460,400,000$

$\$ 1,534$

$\$ 2,455$

$8.0 \%$

10
0.136 \begin{tabular}{ll}
\multicolumn{3}{l}{ Manufacturing Costs (\$/US Ton AFDW Biomass product) } \\
\hline CO2 & $\$ 91$
\end{tabular}

Ammonia

Diammonium Phosphate

Power

Chilled Water Utility

Fixed Costs

Capital Depreciation

Average Income Tax

Average Return on Investment $\$ 213$

\begin{tabular}{lr}
\multicolumn{2}{c}{ Manufacturing Costs $(\$ / y r)$} \\
\hline CO2 & $\$ 17,000,000$ \\
Ammonia & $\$ 2,900,000$ \\
Diammonium Phosphate & $\$ 1,100,000$ \\
Power & $\$ 5,400,000$ \\
Chilled Water Utility & $\$ 700,000$ \\
Fixed Costs & $\$ 12,400,000$ \\
Capital Depreciation & $\$ 13,900,000$ \\
Average Income Tax & $\$ 8,800,000$ \\
Average Return on Investment & $\$ 40,000,000$
\end{tabular}

Specific Operating Conditions

Algal Productivity $\left(\mathrm{g} / \mathrm{m}^{\wedge} 2 /\right.$ day $)$

Maximum seasonal variability (productivity)

CO2 Price (\$/US ton)

Facility size (acres, cultivation pond only)

Total footprint (acres; includes processing, storage, etc.) 


\section{Algal Biomass Production Process Engineering Analysis}

Production Pond Design: GAI Pond, SIZE 10-acre

All Values in $2011 \$$

MBSP (Minimum Biomass Selling Price):

Contributions: $\mathrm{CO} 2$ and Nutrients

Cultivation

Other Production

Total Biomass Production (AFDW Basis)

Total Biomass Yield (AFDW Basis)

Internal Rate of Return (After-Tax)

Equity Percent of Total Investment

\begin{tabular}{l} 
Capital Costs \\
\hline Production ponds (GAI Pond, SIZE 10-acre) \\
Inoculum Ponds \\
CO2 Delivery \\
Makeup Water Delivery + On-Site Circulation \\
Dewatering \\
Storage \\
\hline Total Installed Equipment Cost \\
Added Direct + Indirect Costs \\
$\quad$ (\% of TCI) \\
Total Capital Investment (TCI) \\
Installed Equipment Cost/Annual US dry ton biomass \\
Total Capital Investment/Annual US dry ton biomass \\
Loan Rate \\
Term (years) \\
Capital Charge Factor (Computed)
\end{tabular}

$\$ 146,400,000$

$\$ 16,100,000$

$\$ 6,500,000$

$\$ 7,200,000$

$\$ 43,900,000$

$\$ 5,300,000$

$\$ 225,400,000$

$\$ 147,800,000$

$40 \%$

$\$ 373,200,000$

$\$ 1,202$

$\$ 1,990$

$8.0 \%$

10
0.137

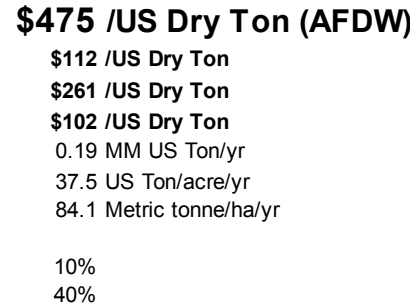

$40 \%$

\begin{tabular}{|c|c|}
\hline $\mathrm{CO} 2$ & $\$ 91$ \\
\hline Ammonia & $\$ 15$ \\
\hline Diammonium Phosphate & $\$ 6$ \\
\hline Power & $\$ 25$ \\
\hline Chilled Water Utility & $\$ 4$ \\
\hline Fixed Costs & $\$ 61$ \\
\hline Capital Depreciation & $\$ 59$ \\
\hline Average Income Tax & $\$ 39$ \\
\hline Average Return on Investment & $\$ 175$ \\
\hline \multicolumn{2}{|l|}{ Manufacturing Costs $(\$ / y r)$} \\
\hline $\mathrm{CO} 2$ & $\$ 17,000,000$ \\
\hline Ammonia & $\$ 2,900,000$ \\
\hline Diammonium Phosphate & $\$ 1,100,000$ \\
\hline Power & $\$ 4,800,000$ \\
\hline Chilled Water Utility & $\$ 700,000$ \\
\hline Fixed Costs & $\$ 11,500,000$ \\
\hline Capital Depreciation & $\$ 11,100,000$ \\
\hline Average Income Tax & $\$ 7,300,000$ \\
\hline Average Return on Investment & $\$ 32,800,000$ \\
\hline \multicolumn{2}{|l|}{ Specific Operating Conditions } \\
\hline Algal Productivity $\left(\mathrm{g} / \mathrm{m}^{\wedge} 2 /\right.$ day $)$ & 25 \\
\hline Maximum seasonal variability (productivity) & $3: 1$ \\
\hline CO2 Price (\$/US ton) & 41 \\
\hline Facility size (acres, cultivation pond only) & 5000 \\
\hline Total footprint (acres; includes processing, storage, etc.) & 7615 \\
\hline
\end{tabular}




\section{Algal Biomass Production Process Engineering Analysis}

Production Pond Design: Leidos Serpentine Pond, SIZE 50-acre

$$
\text { All Values in } 2011 \$
$$

MBSP (Minimum Biomass Selling Price):

Contributions: $\mathrm{CO} 2$ and Nutrients

Cultivation

Other Production

Total Biomass Production (AFDW Basis)

Total Biomass Yield (AFDW Basis)

Internal Rate of Return (After-Tax)

Equity Percent of Total Investment

\begin{tabular}{lr}
\multicolumn{2}{c}{ Capital Costs } \\
\hline Production ponds (Leidos Serpentine Pond, SIZE 50-acre) & $\$ 111,300,000$ \\
Inoculum Ponds & $\$ 16,100,000$ \\
CO2 Delivery & $\$ 6,500,000$ \\
Makeup Water Delivery + On-Site Circulation & $\$ 8,200,000$ \\
Dewatering & $\$ 37,100,000$ \\
Storage & $\$ 5,300,000$ \\
\hline Total Installed Equipment Cost & $\$ 184,500,000$ \\
& \\
Added Direct + Indirect Costs & $\$ 127,500,000$ \\
$\quad$ (\% of TCI) & $41 \%$ \\
Total Capital Investment (TCl) & $\$ 312,000,000$ \\
Installed Equipment Cost/Annual US dry ton biomass & $\$ 984$ \\
Total Capital Investment/Annual US dry ton biomass & $\$ 1,663$ \\
& \\
Loan Rate & $8.0 \%$ \\
Term (years) & 10 \\
Capital Charge Factor (Computed) & 0.137
\end{tabular}

\begin{tabular}{lr}
\multicolumn{2}{c}{ Manufacturing Costs (\$/US Ton AFDW Biomass product) } \\
\hline CO2 & $\$ 91$ \\
Ammonia & $\$ 15$ \\
Diammonium Phosphate & $\$ 6$ \\
Power & $\$ 26$ \\
Chilled Water Utility & $\$ 4$ \\
Fixed Costs & $\$ 49$ \\
Capital Depreciation & $\$ 49$ \\
Average Income Tax & $\$ 33$ \\
Average Return on Investment & $\$ 146$ \\
& \\
& \\
\hline CO2 Manufacturing Costs (\$/yr) & \\
Ammonia & \\
Diammonium Phosphate & $\$ 17,000,000$ \\
Power & $\$ 2,900,000$ \\
Chilled Water Utility & $\$ 1,100,000$ \\
Fixed Costs & $\$ 4,800,000$ \\
Capital Depreciation & $\$ 700,000$ \\
Average Income Tax & $\$ 9,200,000$ \\
Average Return on Investment & $\$ 9,200,000$ \\
\end{tabular}

\begin{tabular}{lr}
\multicolumn{2}{c}{ Specific Operating Conditions } \\
\hline Algal Productivity (g/m^2/day) & 25 \\
Maximum seasonal variability (productivity) & $3: 1$ \\
CO2 Price (\$/US ton) & 41 \\
Facility size (acres, cultivation pond only) & 5000 \\
Total footprint (acres; includes processing, storage, etc.) & 7615
\end{tabular}

\$419 /US Ton Biomass MBSP 


\section{Algal Biomass Production Process Engineering Analysis}

Production Pond Design: GAI Pond, SIZE 50-acre

All Values in $2011 \$$

MBSP (Minimum Biomass Selling Price):

Contributions: $\mathrm{CO} 2$ and Nutrients

Cultivation

Other Production

Total Biomass Production (AFDW Basis)

Total Biomass Yield (AFDW Basis)

Internal Rate of Return (After-Tax)

Equity Percent of Total Investment

\begin{tabular}{l} 
Capital Costs \\
\hline Production ponds (GAI Pond, SIZE 50-acre) \\
Inoculum Ponds \\
CO2 Delivery \\
Makeup Water Delivery + On-Site Circulation \\
Dewatering \\
Storage \\
\hline Total Installed Equipment Cost \\
Added Direct + Indirect Costs \\
$\quad$ (\% of TCI) \\
Total Capital Investment (TCI) \\
Installed Equipment Cost/Annual US dry ton biomass \\
Total Capital Investment/Annual US dry ton biomass \\
Loan Rate \\
Term (years) \\
Capital Charge Factor (Computed)
\end{tabular}

$\$ 86,000,000$

$\$ 16,100,000$

$\$ 6,500,000$

$\$ 8,200,000$

$\$ 37,100,000$

$\$ 5,300,000$

$\$ 159,200,000$

$\$ 117,500,000$

$42 \%$

$\$ 276,700,000$

$\$ 849$

$\$ 1,475$

$8.0 \%$

10
0.138

\section{\$392 /US Dry Ton (AFDW)}

$\$ 112$ /US Dry Ton

$\$ 180$ /US Dry Ton

$\$ 100$ /US Dry Ton

$0.19 \mathrm{MM}$ US Ton/yr

37.5 US Ton/acre/yr

84.1 Metric tonne/ha/yr

$10 \%$

$40 \%$

\begin{tabular}{|c|c|}
\hline $\mathrm{CO} 2$ & $\$ 91$ \\
\hline Ammonia & $\$ 15$ \\
\hline Diammonium Phosphate & $\$ 6$ \\
\hline Power & $\$ 25$ \\
\hline Chilled Water Utility & $\$ 4$ \\
\hline Fixed Costs & $\$ 47$ \\
\hline Capital Depreciation & $\$ 43$ \\
\hline Average Income Tax & $\$ 30$ \\
\hline Average Return on Investment & $\$ 131$ \\
\hline \multicolumn{2}{|l|}{ Manufacturing Costs $(\$ / y r)$} \\
\hline $\mathrm{CO} 2$ & $\$ 17,000,000$ \\
\hline Ammonia & $\$ 2,900,000$ \\
\hline Diammonium Phosphate & $\$ 1,100,000$ \\
\hline Power & $\$ 4,700,000$ \\
\hline Chilled Water Utility & $\$ 700,000$ \\
\hline Fixed Costs & $\$ 8,800,000$ \\
\hline Capital Depreciation & $\$ 8,100,000$ \\
\hline Average Income Tax & $\$ 5,600,000$ \\
\hline Average Return on Investment & $\$ 24,600,000$ \\
\hline \multicolumn{2}{|l|}{$\begin{array}{r}\text { Specific Operating Conditions } \\
\end{array}$} \\
\hline Algal Productivity $\left(\mathrm{g} / \mathrm{m}^{\wedge} 2 /\right.$ day $)$ & 25 \\
\hline Maximum seasonal variability (productivity) & $3: 1$ \\
\hline CO2 Price (\$/US ton) & 41 \\
\hline Facility size (acres, cultivation pond only) & 5000 \\
\hline Total footprint (acres; includes processing, storage, etc.) & 7615 \\
\hline
\end{tabular}

